Mathematical and Geological Approaches to Minimizing the Data Requirements for Statistical Analysis of Hydraulic Conductivity

\title{
Technical Completion Report
}

\section{By}

Fred M. Phillips

John L. Wilson

Allan L. Gutjahr

David W. Love

J. Matthew Davis

Ruth C. Lohmann

Susan J. Colarullo

Madeline B. Gotkowitz

\author{
New Mexico Institute of Mining and Technology \\ Department of Geoscience \\ Socorro, New Mexico, 87801
}

December 1992

Work Performed Under Contract No. DE-FG04-89ER60843

\author{
Prepared for \\ U.S. Department of Energy \\ Office of Health and Environmental Research
}

\section{DISCLAIMER}

\begin{abstract}
This report was prepared as an account of work sponsored by an agency of the United States Government. Neither the United States Government nor any agency thereof, nor any of their employees, makes any warranty, express or implied, or assumes any legal liability or responsibility for the accuracy, completeness, or usefulness of any information, apparatus, product, or process disclosed, or represents that its use would not infringe privately owned rights. Reference herein to any specific commercial product, process, or service by trade name, trademark, manufacturer, or otherwise does not necessarily constitute or imply its endorsement, recommendation, or favoring by the United States Government or any agency thereof. The views and opinions of authors expressed herein do not necessarily state or reflect those of the United States Government or any agency thereof.
\end{abstract}




\section{DISCLAMMER}

Portions of this document may be illegible in electronic image products. Images are produced from the best available original document. 


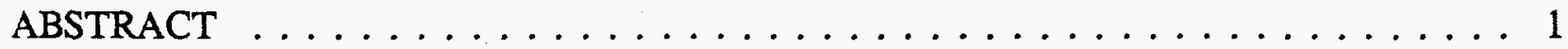

CHAPTER I: INTRODUCTION $\ldots \ldots \ldots \ldots \ldots \ldots \ldots \ldots \ldots$

CHAPTER II: AIR MINI-PERMEAMETER $\ldots \ldots \ldots \ldots \ldots \ldots \ldots \ldots$

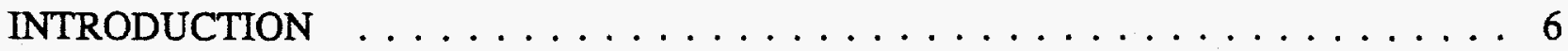

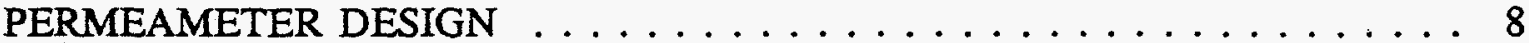

CALIBRATION AND ANALYSIS $\ldots \ldots \ldots \ldots \ldots \ldots \ldots \ldots \ldots \ldots$

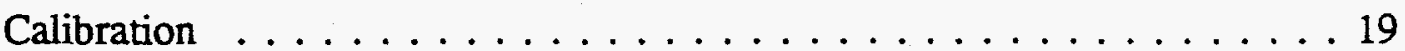

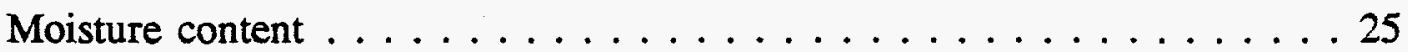

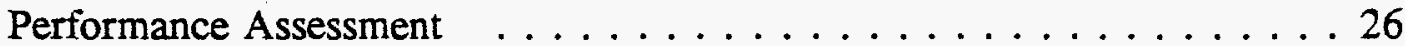

CONCLUSIONS . . . . . . . . . . . . . . . . . . . 29

CHAPTER III: ARCHITECTURAL ELEMENT MAPPING AND ASSOCIATED CORRELATION STRUCTURE $\ldots \ldots \ldots \ldots \ldots \ldots \ldots \ldots \ldots \ldots$

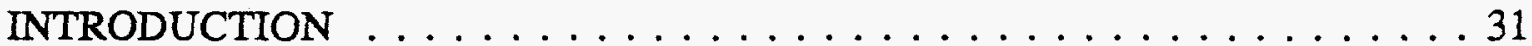

METHODS ......................... 33

Architectural Element Analysis . . . . . . . . . . . . 34

Air-Permeametry . . . . . . . . . . . . . . . . . 34

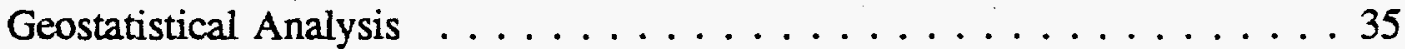

STUDY AREA . . . . . . . . . . . . . . . . . 36



Field Site . . . . . . . . . . . . . . . . . . . . . . 39

ARCHITECTURAL ELEMENT ANALYSIS $\ldots \ldots \ldots \ldots \ldots \ldots \ldots \ldots 42$

Architectural Element Type Descriptions . . . . . . . . . . . . 42

High-Energy Channel Element (CH-1): . . . . . . . . . . 45

Low-Energy Channel Element $(\mathrm{CH}-2): \ldots \ldots \ldots \ldots . \ldots . \ldots 46$

Overbank Fine Element: OF . . . . . . . . . . . . . 47

Paleosol Elements: Ps, Pc, and Pgs . . . . . . . . 47

Architectural Element Map . . . . . . . . . . . . . . 49

GEOSTATISTICAL ANALYSIS . . . . . . . . . . . . . 54



CHAPTER IV: SMALL-SCALE PERMEABILITY DISTRIBUTION STUDIES $\ldots \ldots$. 64

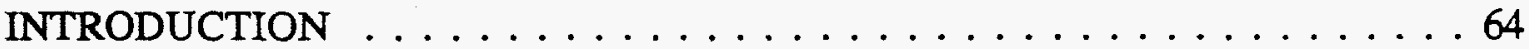

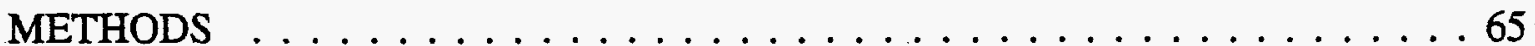



Sampling Scheme . . . . . . . . . . . . . . 66

Sampling of Air-Permeability . . . . . . . . . . . 67

Statistical Analysis . . . . . . . . . . . . . . . 67

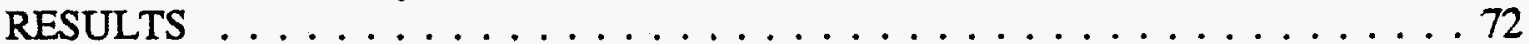

Small-Scale Study 1 (SS1) . . . . . . . . . . . . 72

Small-Scale Study 2 (SS2) $\ldots \ldots \ldots \ldots \ldots \ldots \ldots$ 
Small-Scale Study $3(\mathrm{SS} 3) \ldots \ldots \ldots \ldots \ldots \ldots$

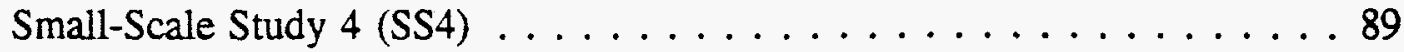

DISCUSSION . . . . . . . . . . . . . . . . . . . 94

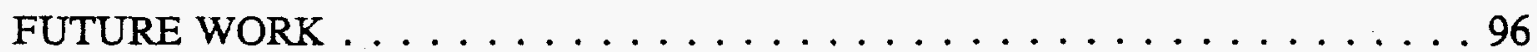

CHAPTER V: MARKOV RANDOM FIELDS . . . . . . . . . . . . . . 97

INTRODUCTION . . . . . . . . . . . . . . . . . . 97

DISCRETE, NATURAL SCALES OF GEOLOGIC HETEROGENEITY . . . 98

CONTINUOUS VS. DISCRETE STOCHASTIC PROCESSES . . . . . . . . . 99

LITHOLOGIC FACIES SEQUENCES AS ONE-DIMENSIONAL MARKOV

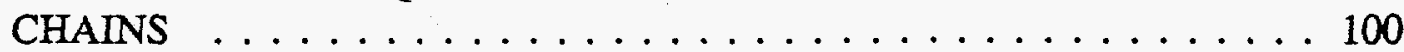

THE JOINT DISTRIBUTION AS THE GIBBS DISTRIBUTION $\ldots \ldots \ldots 102$

CONDITIONAL PDF AS THE JOINT PDF WITH Z RESTRICTED TO THE

NEIGHBORHOOD . . . . . . . . . . . . . . . . . . . . 104

INTERACTION ENERGY $\ldots \ldots \ldots \ldots \ldots \ldots \ldots \ldots \ldots \ldots$

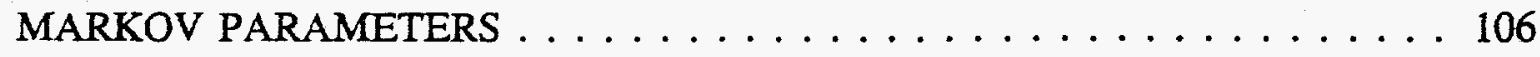

EVOLUTION OF 128-By-128 MRF REALIZATION . . . . . . . . . . . 108

128-by-128 BINARY HYDRAULIC CONDUCTIVITY REALIZATIONS $\ldots . .108$

128-by-128 MRF and FFT Realizations . . . . . . . . . . . 112

Concentration Breakthrough Curves . . . . . . . . . . . 112

GENERATION OF MULTIPLE SCALE STRUCTURE . . . . . . . . . 115

TWO-SCALE MRF vs. SINGLE-SCALE CONTINUOUS REALIZATIONS $\ldots 117$

TWO-SCALE HYBRID MRF/CONTINUOUS VS. SINGLE -SCALE

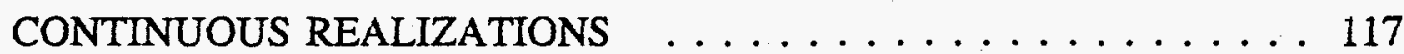

DESIGN OF OPTIMAL SAMPLING NETWORKS . . . . . . . . . . . . 129

CONCLUSIONS . . . . . . . . . . . . . . . . . . . . 129

FUTURE RESEARCH $\ldots \ldots \ldots \ldots \ldots \ldots \ldots \ldots \ldots \ldots$

CHAPTER VI: DISCUSSION AND CONCLUSIONS . . . . . . . . . . . . 134

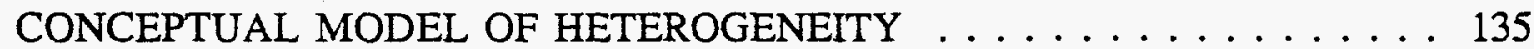

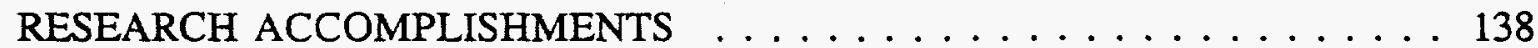

FUTURE WORK . . . . . . . . . . . . . . . . . . . 138

ACKNOWLEDGEMENTS . . . . . . . . . . . . . . . . . . . . . . . . . . . . . 139

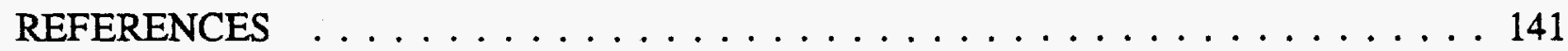

APPENDIX I

Graduate Students Trained and Degrees Granted $\ldots \ldots \ldots \ldots$. . . . . 147

APPENDIX II

Small-scale Permeability Study Data . . . . . . . . . . . . . . 148

APPENDIX III . . . . . . . . . . . . . . . . . . . . . . . . . . . . . . . 149

Publications Emanating from Project $\ldots \ldots \ldots \ldots \ldots \ldots \ldots \ldots$ 


\section{LIST OF FIGURES}

Figure 2.1. Schematic diagram of air-minipermeameter. . . . . . . . . . . 9

Figure 2.2. Circuit diagram for timing device. . . . . . . . . . . . . 11

Figure 2.3. Illustration of pressure loss due to mechanical friction and flow through the instrument. . . . . . . . . . . . . . . . . . . . 14

Figure 2.4. Experimental plot of frictional force vs. velocity for estimation of $\beta \ldots \ldots 16$

Figure 2.5. Experimental plot of $\Delta \mathrm{P}$ vs. flow rate for the estimation of $\alpha \ldots \ldots \ldots 17$

Figure 2.6. Plot of net pressure and permeability vs. measured time for the prototype

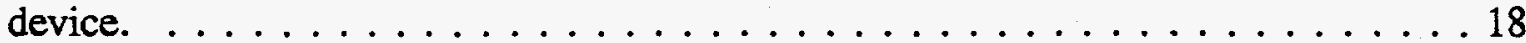

Figure 2.7. Schematic diagram of device used to measure one-dimensional air

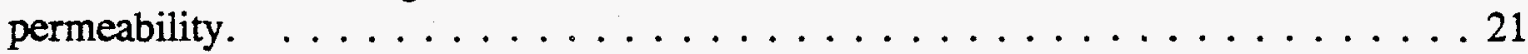

Figure 2.8. Calibration plot of air-permeabilities measured with 1-D device and LSAMP. . . . . . . . . . . . . . . . . . 22

Figure 2.9. Calibration plot of air-permeabilities measured with CFD and LSAMP. . . 24

Figure 2.10 . Permeability measurement error $\left(k_{d r y}-k_{\text {wet }} / k_{d y y}\right)$ vs. volumetric water

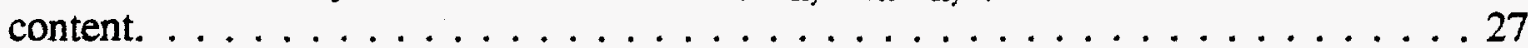

Figure 3.1. General location map. . . . . . . . . . . . . . . . . . 38

Figure 3.2. Paleogeographic setting of the Albuquerque Basin $\ldots \ldots \ldots \ldots \ldots \ldots 4$

Figure 3.3. Architectural Element Map. . . . . . . . . . . . . . . . 50

Figure 3.4. Cross-sectional views of Architectural Element Map . . . . . . . . . . 52

Figure 3.5. Comparison of empirical cumulative probability $(+)$ with theoretical

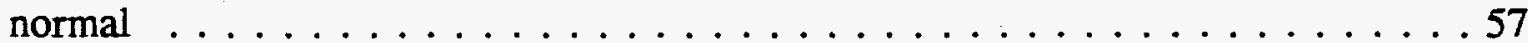

Figure 3.6. Directional variograms of $\log$-permeability . . . . . . . . . . . . . 59

Figure 3.7. Multi-directional horizontal variogram . . . . . . . . . . . 60

Figure 3.8. Schematic block diagram of the relationship between depositional environment and observed architectural element orientations . . . . . . . 61

Figure 4.1. Schematic illustration of variogram search window . . . . . . . . . 68



Figure 4.3. Small scale study-1. Photo and map. . . . . . . . . . . . . 74

Figure 4.4. Sample locations (SS-I). . . . . . . . . . . . . . . . . . . 75



Figure 4.6. Directional variograms for SS1. . . . . . . . . . . . . . . 77

Figure 4.7. Small-scale-study-2 (SS2). Photo and map. . . . . . . . . . . . . . 79

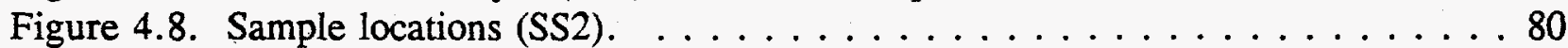

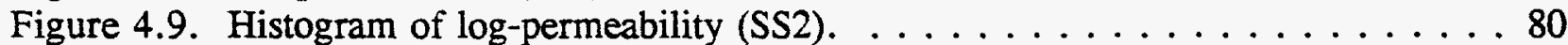

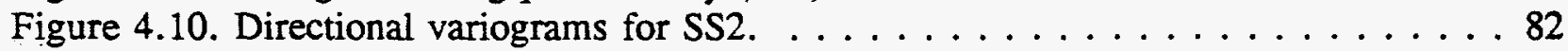

Figure 4.11. Small-scale-study-3. Photograph and map. . . . . . . . . . . 84

Figure 4.12 . Sample locations $(\mathrm{SS} 3) . \ldots \ldots \ldots \ldots \ldots \ldots \ldots \ldots$

Figure 4.13 . Histogram of $\log$-permeability $(\mathrm{SS} 3) . \ldots \ldots \ldots \ldots \ldots$. . . . . . 86

Figure 4.14. Directional variograms $(\mathrm{SS} 3) . \ldots \ldots \ldots \ldots \ldots \ldots$

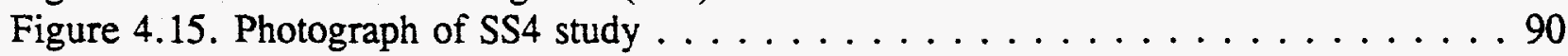

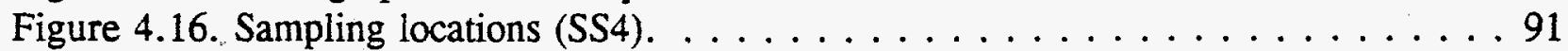

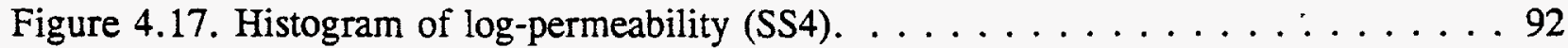

Figure 4.18. Directional variograms (SS4). . . . . . . . . . . . . . . 93

Figure 5.1. Vertical geologic sequence as a one-dimensional Markov chain. . . . . . . 101 
Figure 5.2. Simulated realization of Sierra Ladrones Cross-Section C-C'. . . . . . . . 109

Figure 5.3. Evolution of a 128 -by-128 MRF realization. . . . . . . . . . . . . . . 110

Figure 5.4. Discrete binary Markov conductivity field realization with pathlines. . . . . 111

Figure 5.5. Comparison of discrete and continuous realizations. . . . . . . . . . . 113

Figure 5.6. Comparison of breakthrough curves for discrete and continuous

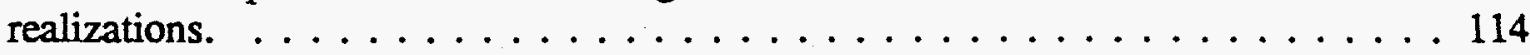

Figure 5.7. Embedding of multiple scales of heterogeneity. . . . . . . . . . 116

Figure 5.8. Embedding of two discrete scales (8-by-8 and 128-by-128). . . . . . . 118

Figure 5.9. Embedding of two discrete scales (4-by-4 and 64-by-64). . . . . . . . . 119

Figure 5.10. Comparison of two-scale discrete and single-scale continuous fields (128by-128).

Figure 5.11. Comparison of two-scale discrete and single-scale continuous fields (64-by$64)$.

Figure 5.12 . Breakthrough curves for realizations in Figure $5.10 \ldots \ldots \ldots \ldots \ldots 122$

Figure 5.13. Breakthrough curves for realizations in Figure $5.11 \ldots \ldots \ldots \ldots . \ldots . . \ldots 123$

Figure 5.14. Comparison of unconditional hybrid and continuous realizations. . . . . . 124

Figure 5.15. Breakthrough curves for realizations of Figure 5.14 . . . . . . . . 126

Figure 5.16. Comparison of conditioned hybrid and continuous realizations. . . . . . . 127

Figure 5.17. Breakthrough curves for realizations of Figure 5.16. . . . . . . . . 128

Figure 5.18. Schematic illustration of possible sampling strategy . . . . . . . . 130

Figure 6.1. Conceptual Geostatistical-sedimentological model of heterogeneity. . . . . 138 


\section{LIST OF TABLES}

Table 2.1. Summary of one-way ANOVA on triplicate measurements . . . . . . . . 28

Table 2.2. Statistical summary of repeated measurements on sandstone cores under laboratory and field conditions . . . . . . . . . . . . . . . . 29

Table 3.1. Facies Classification Scheme . . . . . . . . . . . . . . . . . . . 44

Table 3.2. Facies Groupings for Definition of Architectural Elements . . . . . . . 45

Table 3.3. Summary of Log-permeability Statistics . . . . . . . . . . . . . . . . 55

Table 4.1. Statistics of SS1 and SS1 Hydrofacies . . . . . . . . . . . . . 76

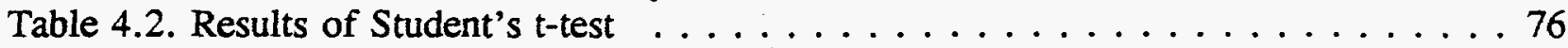

Table 4.3. Statistics of SS2 and SS2 Hydrofacies . . . . . . . . . . . . 81

Table 4.4. Results of Student's t-test for SS-2 hydrofacies. . . . . . . . . . . . . 81

Table 4.5. Statistics of SS3 and SS3 facies . . . . . . . . . . . . . . . . 87

Table 4.6. Results of Student's t-test of SS3 facies. . . . . . . . . . . . . . . 87

Table 4.7. Statistics of SS4 . . . . . . . . . . . . . . . . . . . . 89

Table 4.8. Statistics of the five study areas . . . . . . . . . . . . . . 95

Table 4.9. Results of Student's t-test of the four study areas . . . . . . . . . . 95 


\section{ABSTRACT}

Field-scale heterogeneity has been recognized as a dominant control on solute dispersion in groundwater. Numerous random field models exist (e.g. Gaussian, indicator, fractal, multi-scale non-fractal) for quantifying heterogeneity and its influence on solute transport. Minimizing data requirements in model selection and subsequent parameterization will be necessary for efficient application of quantitative models in contaminated subsurface environments. In this study, a detailed quantitative sedimentological study is performed to address the issue of incorporating geologic information into the geostatistical characterization process.

A field air-minipermeameter is developed for rapid in-situ measurements. The permeameter weighs 2 kilograms and is calibrated to measurements obtained with well documented methods. The field study is conducted on an outcrop of fluvial/interfluvial deposits of the Pliocene-Pleistocene Sierra Ladrones Formation in the Albuquerque Basin of central New Mexico. Architectural element analysis is adopted for mapping and analysis of depositional environment. Geostatistical analysis is performed at two scales. At the architectural element scale, geostatistical analysis of assigned mean log-permeabilities of a $0.16 \mathrm{~km}^{2}$ peninsular region indicates that the directions of maximum and minimum correlation correspond to the directions of the large-scale depositional processes. At the facies scale, permeability is found to be adequately represented as a log-normal process. Log-permeability within individual lithofacies appears uncorrelated. The overall correlation structure at the facies scale is found to be a function of the mean log-permeability and spatial distribution of the individual lithofacies. Based on field observations of abrupt spatial 
changes in lithology and hydrologic properties, an algorithm for simulating multi-dimensional discrete Markov random fields.

Finally, a conceptual model is constructed relating the information inferred from depositional environment analysis to the various random field models of heterogeneity. The occurrence and spatial assemblage of geologic units (lithofacies and architectural elements) can be used as indications of the modality, and the number and directions of the dominant scales of correlation. Future work is needed in refining the conceptual model for deposits of other depositional processes and developing methods of estimating random field model parameters for the various models. 


\section{CHAPTER I: INTRODUCTION}

One of the major challenges facing hydrogeology today is that of groundwater contamination. The migration of a contaminant plume centroid is controlled by the mean groundwater seepage velocity. About the plume centroid, spatial variations in local groundwater velocities are associated with spatial variations in hydraulic conductivity. This differential advection results in a pseudo-mixing process known as macrodispersion. In general, the dispersion of a contaminant plume about its centroid is directly related to the geological heterogeneities encountered by the migrating plume.

Over the past ten years it has become generally accepted that the factor determining field dispersivity is field-scale heterogeneity of the hydraulic conductivity (Schwartz, 1977; Delhomme, 1979; Pickens and Grisak, 1981; Gelhar, 1986). Some investigators have taken the approach of attempting to deterministically describe the spatial distribution of heterogeneities (e.g., Pickens and Grisak, 1981; Guven et al., 1984; Guven and Molz, 1986). An alternative, perhaps more general, approach is to quantify the distribution of heterogeneities in terms of its statistical properties (e.g., Dagan, 1984; Gelhar and Axness, 1983; Neuman et al., 1987). This has been accomplished by assuming that the log of the hydraulic conductivity distribution may be approximated by a second order intrinsic Gaussian random field, quantified in terms of its mean, variance, and three spatial correlation lengths (Gutjahr and Gelhar, 1981; Mizell et al., 1982; Gelhar and Axness, 1988). These are . incorporated in some functional relationship describing the spatial covariance. 
Because of the generalized nature of this approach, it appears to potentially be a very powerful way of describing contaminant transport under a wide variety of field conditions. The theoretical developments based on this approach have reached a high level of sophistication. Unfortunately, this sophistication has far outstripped the corresponding level of expertise concerning the actual distribution of hydraulic conductivity in geological materials. In fact, there is very little evidence to indicate to what extent hydraulic conductivity distributions in actual geological materials even approximate those of a multivariate Gaussian random field, much less what covariance functions and correlation scales are appropriate under specific geological circumstances.

The lack of evidence supporting the multi-variate Gaussian random field representation of heterogeneity has resulted in the development of numerous alternative random field models exhibiting different spatial attributes. Some of the models have been motivated by field observations, others are purely hypothetical. The goal of each model is to provide a more realistic representations of the spatial distribution of hydraulic conductivity. Journel and Alabert (1988), for example, present an indicator simulation algorithm which better preserves the connectivity of extreme values (high and low conductivity) and is not restricted to normal probability distributions. Similarly, to represent multiple scales of correlation, many researchers have proposed fractal models of heterogeneity (Wheatcraft and Tyler, 1988; Neuman, 1990). Burrough (1983) argues for a nested non-fractal model to describe the spatial variation of soil properties in a one-dimensional transect. Based on our own field observations, Colarullo and Gutjahr (1991) have developed an algorithm for simulating multi-dimensional discrete Markov random fields. So in addition to a lack of 
evidence supporting the multi-variate Gaussian random field, practitioners are now faced with choosing between a number of different of random field models each of which emphasizes a different style of heterogeneity.

Such models are expected to be major tools in dealing with contamination problems at DOE sites. Unfortunately, to date there is no quantitative criteria for discriminating between random field models even with abundant data. Once a model is chosen the statistical parameters needed can generally be obtained only through geostatistical analysis of large numbers of hydraulic conductivity measurements. Both the costs and the risks associated with obtaining a sufficient number of measurements in highly contaminated environments are very large. We address the question: "How can the data requirements for geostatistical characterization of hydraulic parameters be reduced by incorporation of geologic information and macroscopic proxy information?". Here, geostatistical characterization includes both model selection and the parameterization of the chosen model. We address this question by performing a detailed quantitative sedimentological study of outcrop heterogeneity.

The main objective of this hydrogeological study is to establish a conceptual framework within which descriptive geological categorizations, together with simple macroscopic measurements and mapping, can be related to the statistics of the permeability distribution through an understanding of the physical processes responsible for creating the permeability distribution. With the aid of such a conceptual framework, work at any particular site could rapidly be focused on the types and locations of the critical measurements necessary to adequately characterize the statistics of permeability spatial distribution. 


\section{CHAPTER II: AIR MINI-PERMEAMETER}

\section{INTRODUCTION}

Aquifer heterogeneity is generally accepted as the dominant control on subsurface contaminant migration. However, statistical models to quantify the spatial variation of hydraulic conductivity (e.g. Gelhar, 1986; Wheatcraft and Tyler, 1988) have outstripped the availability of data to validate and parameterize the models. Many more studies of geologic spatial variability will be necessary to test the underlying assumptions of the proposed statistical models. One very economical method for collecting large numbers of permeability measurements is by means of air mini-permeameters. In situ measurements of permeability in dry material can be performed rapidly and economically when air is the fluid. The method is particularly suited to the study of hydraulic conductivity distributions on outcrops. When measuring the hydraulic properties of a medium three conditions must be satisfied. First, the solution to the flow equation (Darcy's law) must be known for the particular flow geometry. The second condition is an accurate knowledge of the applied pressure or potential; and the third condition is obtaining an accurate measure of the flowrate through the porous medium.

Eijpe and Weber (1971) developed one of the first air mini-permeameters capable of quick and non-destructive permeability measurements on consolidated and unconsolidated sands. Goggin et al. (1988a), performed an experimental and theoretical analysis of flow associated with a mini-permeameter in which air is injected into an outcrop or core plugs via a hole drilled through the center of a rubber stopper. The rubber stopper applicator is referred to as the tip seal and allows for non-destructive measurements of permeability at a 
small scale. As in the case of Eijpe and Weber (1971), Goggin et al. (1988a) utilized a compressed air tank as a source and measured the pressure and flow rate with diaphragm gauges and rotameters, respectively.

In an effort to quantify the spatial distribution of permeability in outcrops analogous to petroleum reservoirs, several outcrop studies have been conducted using the minipermeameter of Goggin et al. (1988a) or a similar instrument. Goggin et al. (1988b) obtained several thousand measurements of air-permeability on an outcrop of the eolian Page Sandstone (Jurassic) in Northeastern Arizona. Using the same device as Goggin et al. (1988a,b), Kittridge et al. (1989) performed a comparison of outcrop and subsurface permeability in the carbonate San Andres Formation (Permian) of southeastern New Mexico. Dreyer et al. (1990) used a similar air mini-permeameter to assess the relationship between depositional facies and permeability in the delta-plain distributary channels of the Ravenscar Group (Jurassic) in Yorkshire, England. By collecting large numbers of permeability measurements in outcrop, these studies have yielded insight into the relationship between observed geologic features and geostatistical characteristics of permeability heterogeneity in cemented sedimentary rocks.

Recent geologic deposits with minimal diagenetic lithification are of particular interest in groundwater hydrology. An alternative design is required to measure the air permeability of these weakly lithified highly permeable materials. First, the air pressure used in the measurements must be small to avoid grain movement. Second, outcrops of weakly lithified sediments are often unstable requiring a lightweight and highly portable instrument.

To honor the pressure constraint and increase portability, a mechanical pressure source was developed to replace the compressed air source. The piston of a ground glass syringe falls steadily through the syringe casing with negligible leakage between the syringe piston and casing. The falling piston applies a small constant pressure and the flow rate is calculated by timing the rate the piston falls. The combination of the low-pressure glass 
syringe air source and a tip seal can be combined with the model of Goggin et al. (1988b) to calculate permeability.

\section{PERMEAMETER DESIGN}

The lightweight, syringe-based, air-minipermeameter (LSAMP) described in this paper is presented schematically in Figure 2.1. The device consists of three main

components: 1) a glass syringe which applies the pressure to the outcrop, 2) a timing device which measures the rate at which the syringe piston displaces a known volume, and 3) a tip seal which injects air into the outcrop.

The syringe component of our prototype device consists of a Becton-Dickenson ${ }^{*}$ $100 \mathrm{cc}$ ground glass syringe which is ground further with 800 grit corundum. When the syringe is oriented vertically, the syringe piston falls relatively freely through the casing. Friction between the piston and casing is present and must be accounted for.

The piston must fall steadily in the presence of the abundant dust and loose sand typically encountered in the field. To achieve this, an air-filter is placed in-line to filter the air drawn into the piston between measurements. At the upper end of the syringe, a plastic bag is taped around the syringe casing with sufficient room for the piston to be drawn up to its full extent. The plastic bag serves as a "boot" to keep particulate matter from falling into the top of the syringe while ensuring that the top of the piston is exposed to atmospheric pressure.

The second component of the LSAMP is the timing circuit. The volumetric flow rate is measured by timing the rate at which the piston passes two known locations on the syringe. Knowledge of the volume displaced and the time required allows calculation of the flow-rate. Two sets of miniature photo-sensors (Microswitch ${ }^{\circledR}$ ) are employed. Each set of 


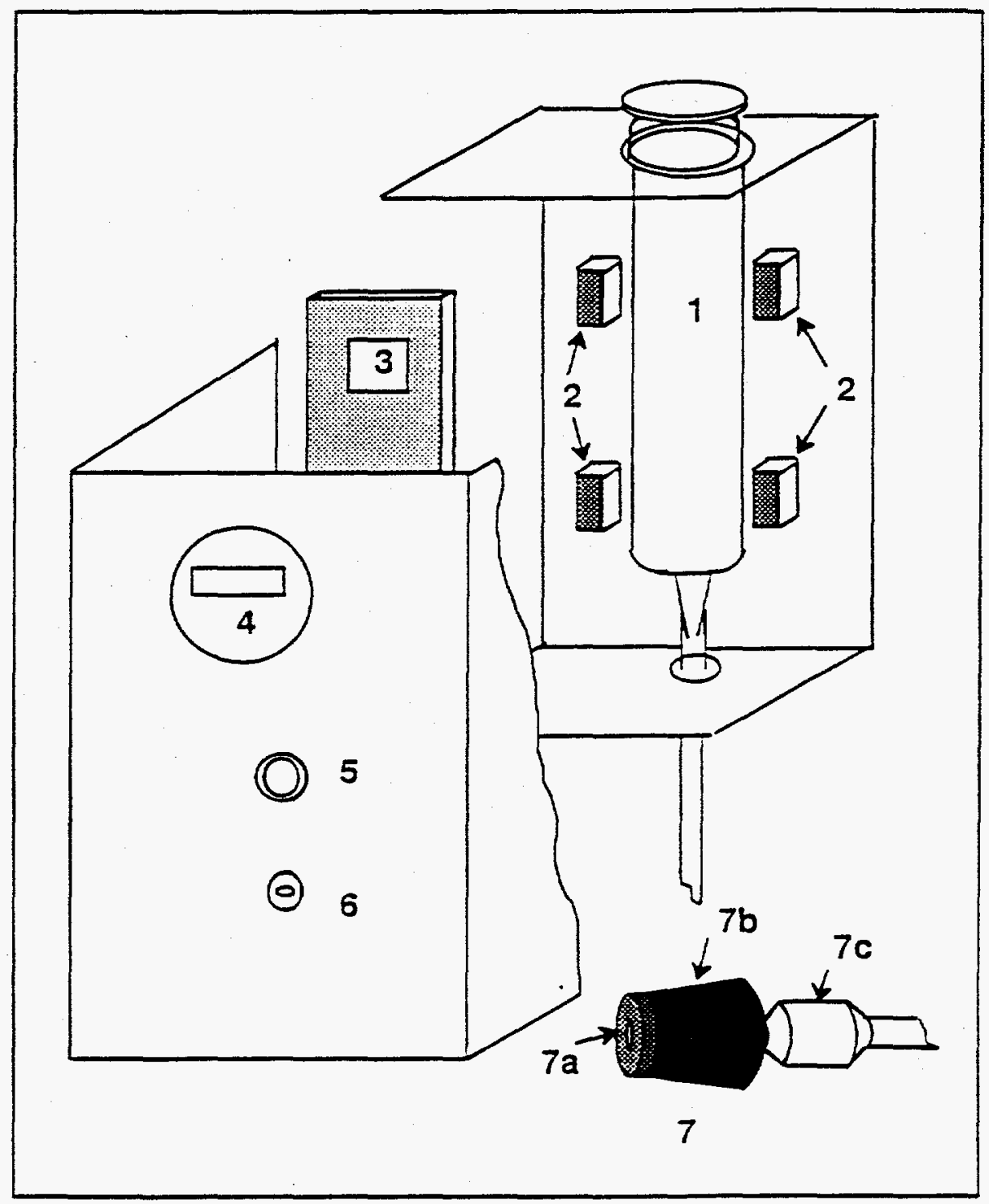

Figure 2.1. Schematic diagram of air-minipermeameter. 1. $100 \mathrm{cc}$ ground glass syringe; 2 . photo-sensors; 3. circuit board; 4. stopwatch; 5 . reset button; 6 . on/off switch; 7 . tip seal assembly; 7a. foam rubber with $0.03 \mathrm{~cm} \mathrm{ID} \mathrm{grommet;} \mathrm{7b.} \mathrm{\# 6} \mathrm{rubber} \mathrm{stopper;} \mathrm{7c.} \mathrm{quick}$ disconnect. 
sensors consists of an infrared light emitter and receiver. The sensors are insensitive to ambient light and operate on a 9 volt direct current (VDC) source. The photo-sensor pairs act as switches and are connected to a stop-watch via the circuitry shown in Figure 2.2. The photo-sensor "switch" (Figure 2.2) is open (9VDC) when the sensors are in contact and closed (ground) when the piston passes. This hi-lo signal is sent to a bounceless switch circuit (Figure 2.2). When the piston passes either pair of sensors, the photo-sensor switch closes, and the bounceless switch sends a square-wave pulse of duration 0.1 second to the OR-GATE. When the OR-GATE receives a square-wave pulse from either set of sensors, a 1.5 VDC pulse of duration 0.1 second is sent to the start-stop switch of the stopwatch. While the duration of the pulse is controlled by the circuitry, the shortest measurement time is approximately one-half second. Thus, the first pulse of 0.1 second ceases prior to the piston passing the second set of sensors.

The third main component of the LSAMP is the tip seal. The tip seal (Figure 2.1; part \#7) is the means of applying the air to the sample surface. The tip seal of our prototype device is designed specifically for weakly cemented sands. First, in order to obtain a no-flow boundary along the annulus of the seal, a soft foam-rubber pad approximately $5 \mathrm{~mm}$ thick is adhered to the base to the rubber stopper. The foam rubber pad readily conforms to the sandy surface. A 0.66 centimeter diameter brass grommet is placed in the center of the foam rubber pad to ensure a circular orifice of fixed radius while sampling. Second, a larger diameter (\#6) rubber stopper is used; the increased diameter distributes the application force over a larger surface preventing penetration of the tip seal annulus into the sample material. A quick-disconnect connects the tip seal to the permeameter via $1 / 4$ " flexible tubing.

The glass syringe and circuitry are encased in a 5" $\times 6^{\prime \prime} \times 9^{\prime \prime}$ box with a total weight of approximately 2 kilograms. The length of the tubing to the tip seal is one meter. The LSAMP differs from other field permeameters in that it is an entirely self contained 


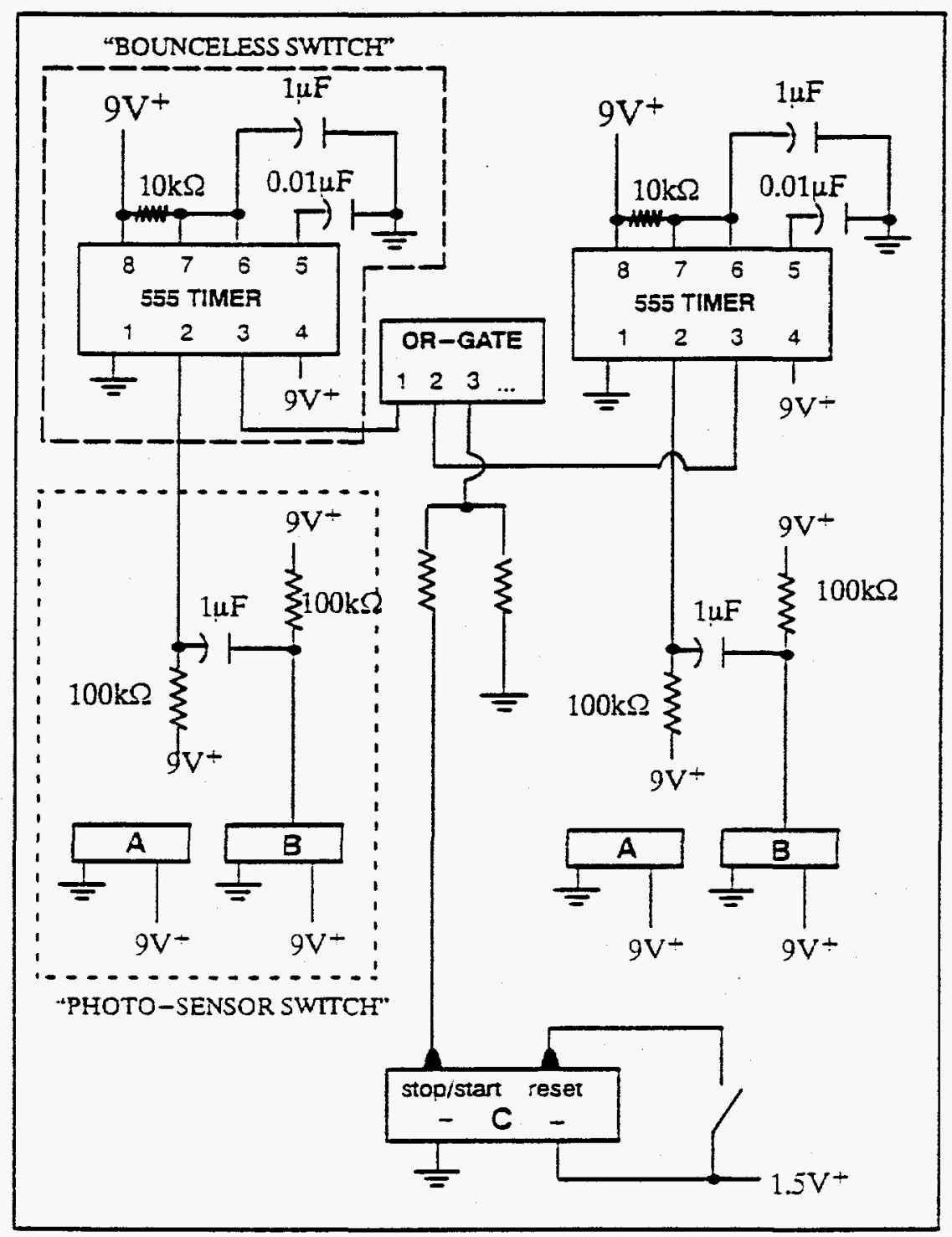

Figure 2.2. Circuit diagram for timing device. $A=$ modulated light emitter; $B=$ modulated light receiver; $\mathrm{C}=$ stopwatch. 
apparatus designed for a single user. The LSAMP can either be placed on a four-legged stand or suspended from a neck-strap. Measurements of permeability are obtained by orienting the device (i.e. the syringe) vertically with a bubble level, extending the syringe piston, placing the tip seal to the outcrop, releasing the piston, and recording the time measured to displace the fixed volume. The measured time is used to calculate the volumetric flow-rate and the applied pressure. With our prototype device, the measured times of 60.0 and 0.68 seconds correspond to permeabilities of 0.5 and 200 darcy, respectively.

\section{CALIBRATION AND ANALYSIS}

According to Goggin et al. (1988a), the permeability for the tip seal flow geometry is obtained from:

$$
k=\frac{2 \mu q P_{1}}{a G_{0}\left(P_{1}^{2}-P_{0}^{2}\right)}
$$

$$
\text { Where: } \quad \begin{aligned}
& k=\text { Permeability }\left[\mathrm{m}^{2}\right] \\
& \mu=\text { Viscosity of air }[\mathrm{Pa} \cdot \mathrm{s}] \\
& q=\text { Volumetric flow rate }\left[\mathrm{m}^{3} / \mathrm{s}\right] \\
& P_{1}=\text { Pressure applied at tip seal/outcrop interface }[\mathrm{Pa}] \\
& P_{0}=\text { Atmospheric pressure }[\mathrm{Pa}] \\
& a=\text { Radius of tip seal orifice }[\mathrm{m}] \\
& \left.\mathrm{G}_{0}=\text { Geometric factor [dimensionless }\right]
\end{aligned}
$$

To calculate permeability, both the applied pressure and flow-rate must be known. The tip-seal injection pressure, $P_{1}$, is governed by static forces acting on the piston, atmospheric pressure, and pressure losses resulting from flow through the instrument. The mechanical force acting on the piston is the gravitational force $(\mathrm{F}=\mathrm{mg})$ minus the frictional 
resistance force exerted on the piston by the syringe casing. The pressure losses resulting from flow through the instrument are due primarily to the in-line air-filter and the tip-seal assemblage. Since Equation (1.1) contains a difference of squared pressures it is necessary to use absolute pressure. As such, atmospheric pressure makes a direct additive contribution to the tip-seal injection pressure. All of these effects must be accounted for in the calculation of applied tip-seal injection pressure.

The pressure, in pascals, resulting from the gravitational force is calculated simply as:

$$
\begin{array}{ll}
\qquad P_{g}=\frac{m g}{A} \\
\text { Where: } \quad \begin{array}{l}
m=\text { mass of piston }[\mathrm{kg}] \\
g=\text { gravitational acceleration }\left[\mathrm{m} / \mathrm{s}^{2}\right] \\
A=\text { area of piston }\left[\mathrm{m}^{2}\right]
\end{array}
\end{array}
$$

The mechanical friction and pressure loss across the in-line air-filter and tip-seal assemblage require experimental analysis. The laboratory experimental setup for the analysis of the instrument effects consists of (1) the air-minipermeameter, (2) a set of standards, (3) a 0-9 $\mathrm{kPa}$ pressure transducer, and (4) a microcomputer equipped with an analog-to-digital data acquisition board. As shown in Figure 2.3, the pressure transducer is placed first in between the nipple of the syringe and the air-filter. The pressure measured at this location is used to calculate the frictional force acting on the syringe piston. That is, the resultant pressure $(\mathrm{F} / \mathrm{A})$ is the difference between the gravitational force and the frictional force, divided by the area of the syringe. The mechanical friction in the syringe can be modeled as lubricated friction, which is proportional to some fixed power of the velocity (Symon, 1971):

$$
F_{f}=\beta v^{ \pm n}
$$

Where $F_{f}$ is the frictional force $[\mathrm{N}], v$ is the velocity $[\mathrm{m} / \mathrm{s}]$, and $\beta$ and $n$ are empirical 


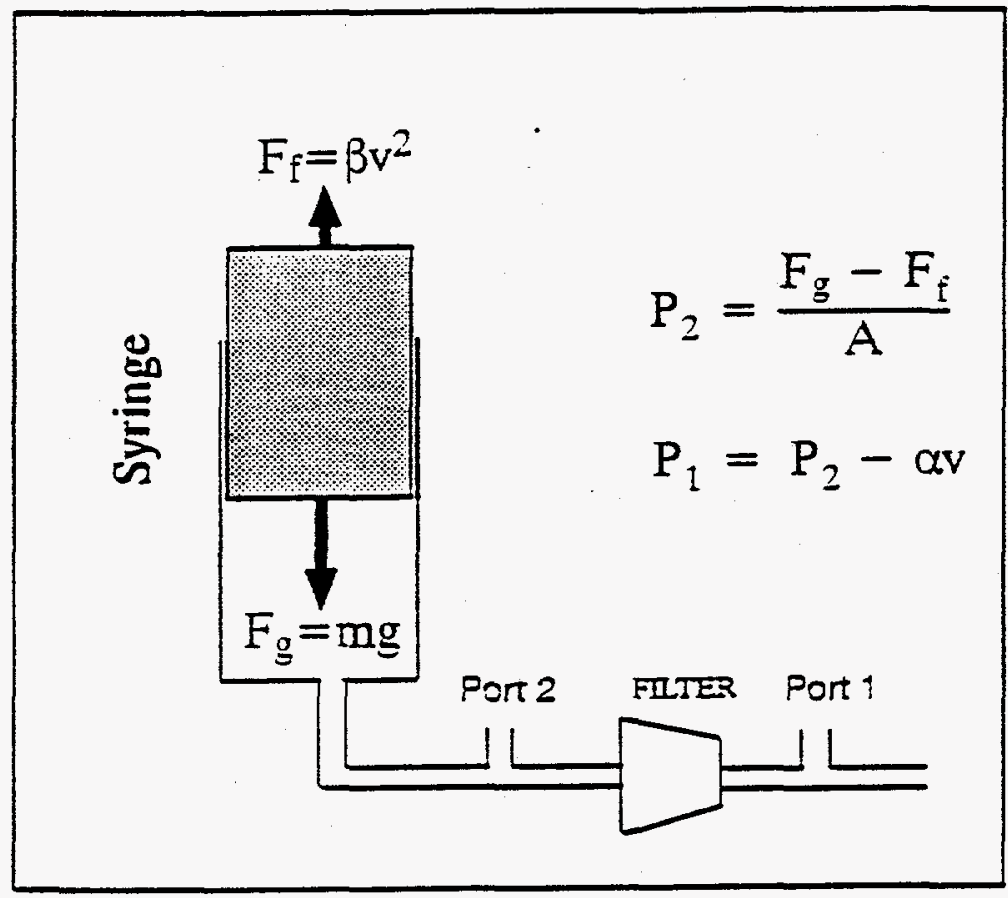

Figure 2.3. Illustration of pressure loss due to mechanical friction and flow through the instrument. Ports (1) and (2) correspond to pressure measurement locations in the estimation of $\alpha$ and $\beta$. 
coefficients. For each measurement, the frictional force is plotted against the velocity of the instrument. Ports (1) and (2) correspond to pressure measurement locations in the estimation of $\alpha$ and $\beta$.

piston (Figure 2.4). The coefficient of friction, $\beta$, for the quadratic model $(n=2)$ was determined to be $140\left[\mathrm{~N} \cdot \mathrm{s}^{2} / \mathrm{m}^{2}\right]$ by performing a least squares fit to the experimental data. Incidentally, pressure losses through the orifice at the bottom of the syringe are implicitly accounted for in the friction model.

Similarly, the pressure loss resulting from flow through the in-line air-filter and tipseal assemblage is a function of the rate at which the piston falls. Figure 2.5 presents the pressure drop across the air filter as a function of flow-rate. A linear model is used to account for this pressure loss:

$$
\Delta P=\alpha q-b
$$

The coefficient of resistance, $\alpha$, was estimated via a least squares analysis to be $8.3 \times 10^{6}$ $\left[\mathrm{Pa} \cdot \mathrm{s} / \mathrm{m}^{3}\right]$. The coefficient $b$ is a threshold pressure required to induce flow through the system and is estimated to be $50[\mathrm{~Pa}]$.

For both sources of resistance, the applied pressure is a function of the rate at which the piston the falls. The flow-rate is measured directly via the timing circuitry enabling the calculation of applied pressure for each measurement. For the prototype device, the applied pressure in (1) is modeled by:

$$
P_{1}=P_{0}+P_{n}
$$

Where $P_{0}$ is atmospheric pressure and $P_{n}$ is the net pressure due to mechanical forces and pressure losses.

$$
P_{n}=\frac{F_{g}}{A}-\frac{F_{f}}{A}-\Delta P=\frac{m g}{A}-\frac{\beta v^{2}}{A}-\alpha q+b
$$

Both the net pressure and the permeability are dependent on the rate at which the piston passes a known volume. For the prototype device, the net pressure and permeability [from 


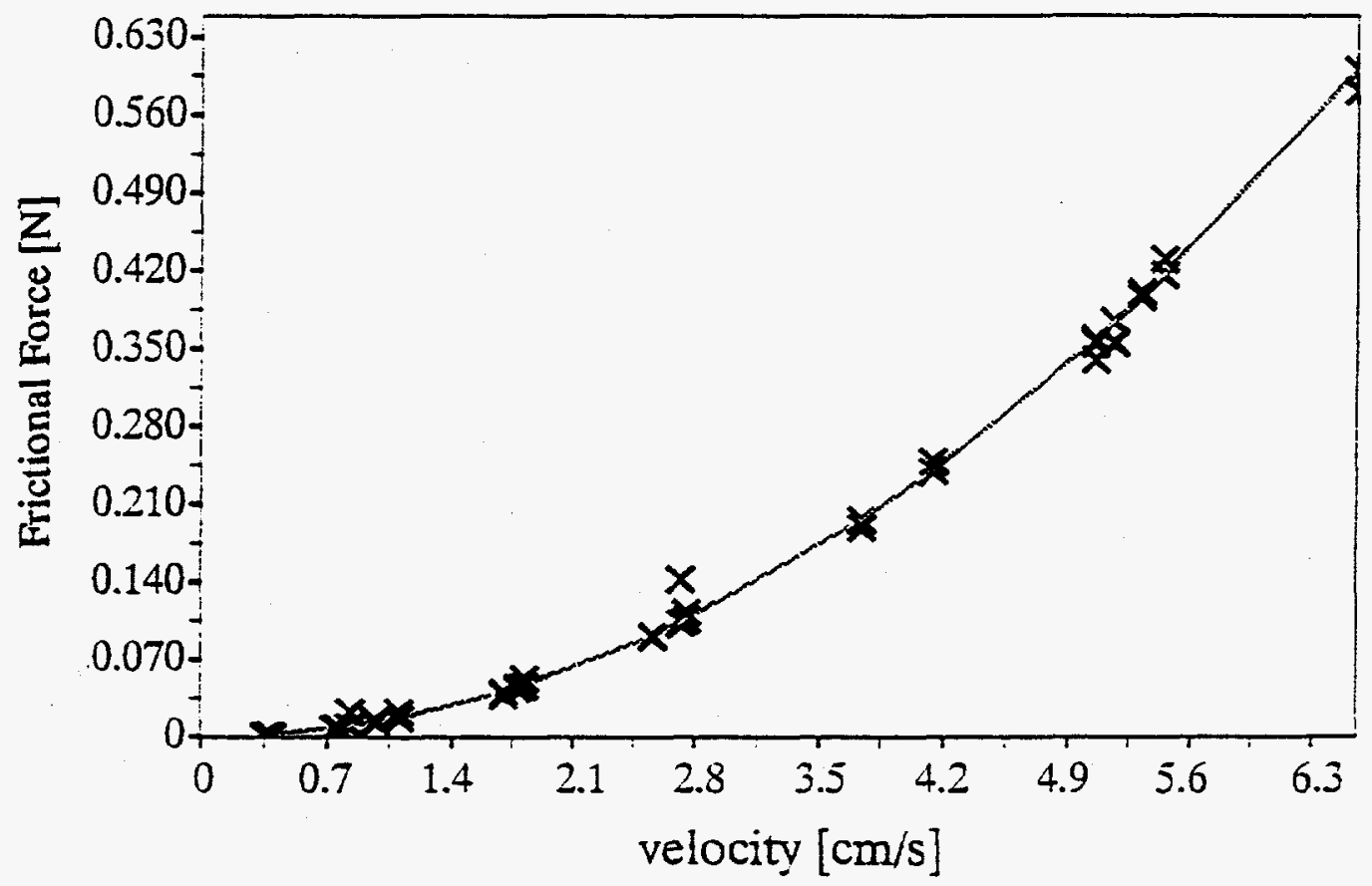

Figure 2.4. Experimental plot of frictional force vs. velocity for estimation of $\beta$. 


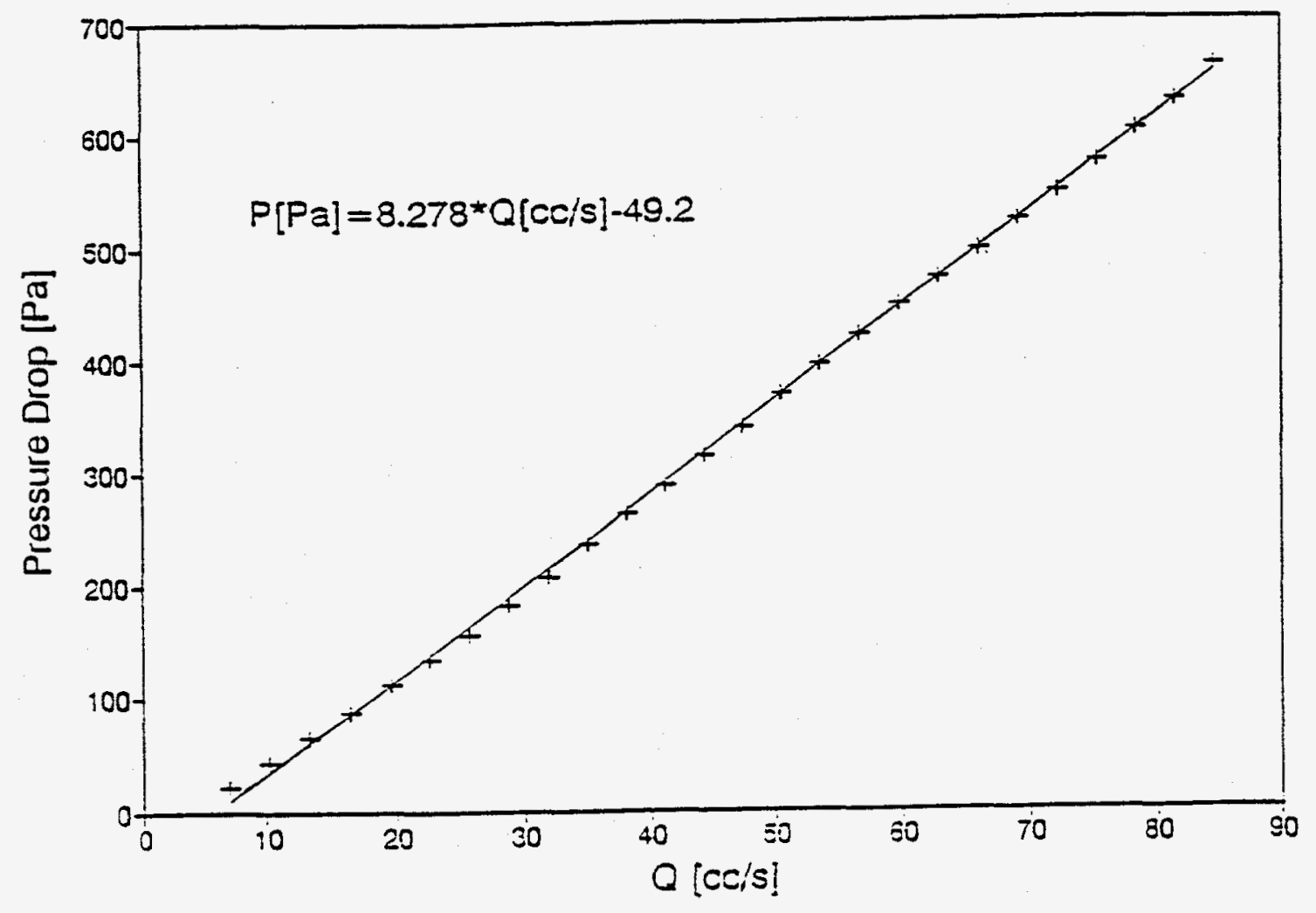

Figure 2.5. Experimental plot of $\Delta \mathrm{P}$ vs. flow rate for the estimation of $\alpha$. 


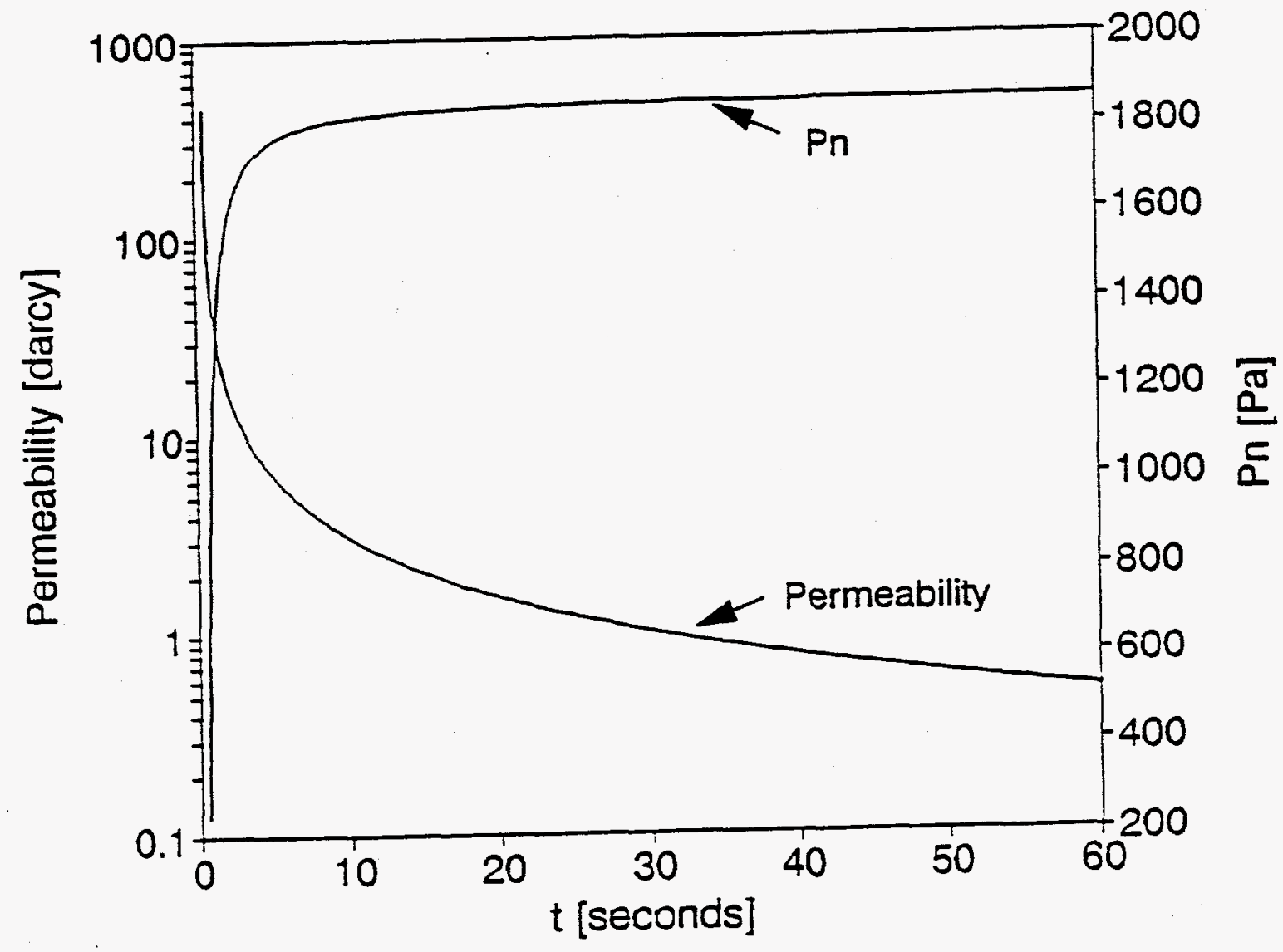

Figure 2.6. Plot of net pressure and permeability vs. measured time for the prototype device. Permeability is the solid line and net pressure is the dashed line. 
equation (2.1)] are plotted against time (Figure 2.6). The high degree of sensitivity at small times is largely a function of inverse relationship between flow-rate and measured time. The smallest time plotted is 0.62 seconds corresponding to the measured time with no outlet resistance (free-fall). For times greater than one minute, the sensitivity of the device is very low. That is, relatively large differences in measured times result in very small differences in calculated permeability. The approximate range of times which offer optimal sensitivity are those greater than 0.75 and less than 60 seconds. This range translates into a permeability range of 127 and 0.51 darcys, respectively.

The observed range of permeability measurements is, to a certain degree, a function of the prototype device dimensions and piston mass. From equations (2.1) and (2.3), different permeability ranges can be explored by changing the various dimensions of the device.

\section{Calibration}

The calibration of the LSAMP consists of comparing permeability values obtained with the LSAMP to measurements obtained with a conventional method. In order to maintain consistency in a variety of experiments, a set of laboratory fabricated sandstones were used as standards. The sandstones were fabricated by mixing sands of different grain size with a cementing agent and packing the mixture in $100 \mathrm{~cm}^{3}$ stainless steel cylindrical rings ( 5 centimeters diameter and 5 centimeters long). One set of 16 standards was fabricated using a low viscosity epoxy as a cementing agent. For each standard, sand and epoxy were mixed together thoroughly so that just enough epoxy was present to coat the grains. The sand-epoxy mixture was then packed into a ring in four to five lifts, tamping the mixture after each lift. The minimum permeability of standards fabricated by the epoxy method was five darcys. In order to fabricate standards with a lower permeability, "plaster 
of Paris" (powdered anhydride) was used as the cementing agent for a set of four additional standards. The "plaster of Paris" was mixed with the sand and tamped into the rings dry. Screened caps were then placed on the bottom of the rings, and the rings placed in approximately one centimeter of standing water. Capillary forces were allowed to draw interstitial water into the samples. The moistened sediment filled rings were then oven-dried. A total of 20 standards were fabricated and were used throughout the calibration process.

One-dimensional air-permeability of the fabricated standards was measured with a laboratory device following the ASTM D4525 method. The experimental set-up is shown in Figure 2.7 and consists of a drying tube, a low-pressure regulator, rotameters to measure air-flow-rate, and a pressure transducer. A plexiglass cap was constructed to fit over one end of the 5 centimeter diameter standards. Depending on the permeability of the standard, five to twenty different air-flow- rates were used on each standard. For each air-flow-rate the applied pressure was measured with the pressure transducer, and the one-dimensional permeability was calculated in the standard way. In general, for higher permeability standards, fewer flow rates were measured, since the maximum flow rate $(65 \mathrm{cc} / \mathrm{s})$ of the rotameters was exceeded.

Air-permeability was also measured at each end of the standards with the lightweightsyringe-air-minipermeameter (LSAMP). The results of this calibration are shown in Figure 2.8. The permeability measure at each end of the standards generally brackets the onedimensional average permeability. The lack of a well defined correlation results primarily from the heterogeneity of the packed standards. The bulk sampling volume of the LSAMP is approximately 1 cubic centimeter. The one-dimensional measurements, on the other hand, represent the permeability of the $100 \mathrm{~cm}^{3}$ soil ring standards. The scale effect due to the different volumes is believed to greatly affect the correlation between the two methods of measuring permeability.

A second calibration experiment was conducted to compare permeability measured 


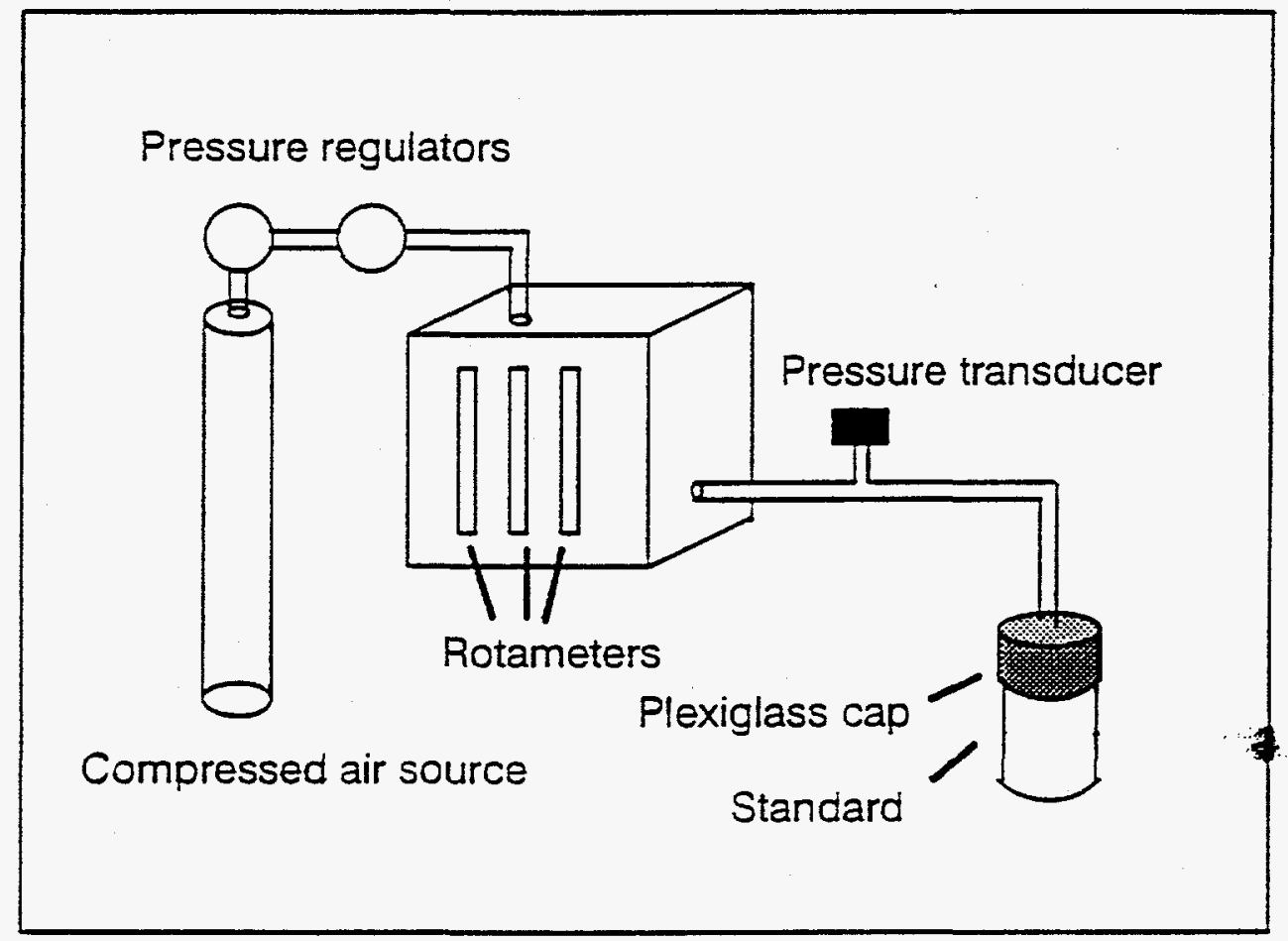

Figure 2.7. Schematic diagram of device used to measure one-dimensional air permeability. 


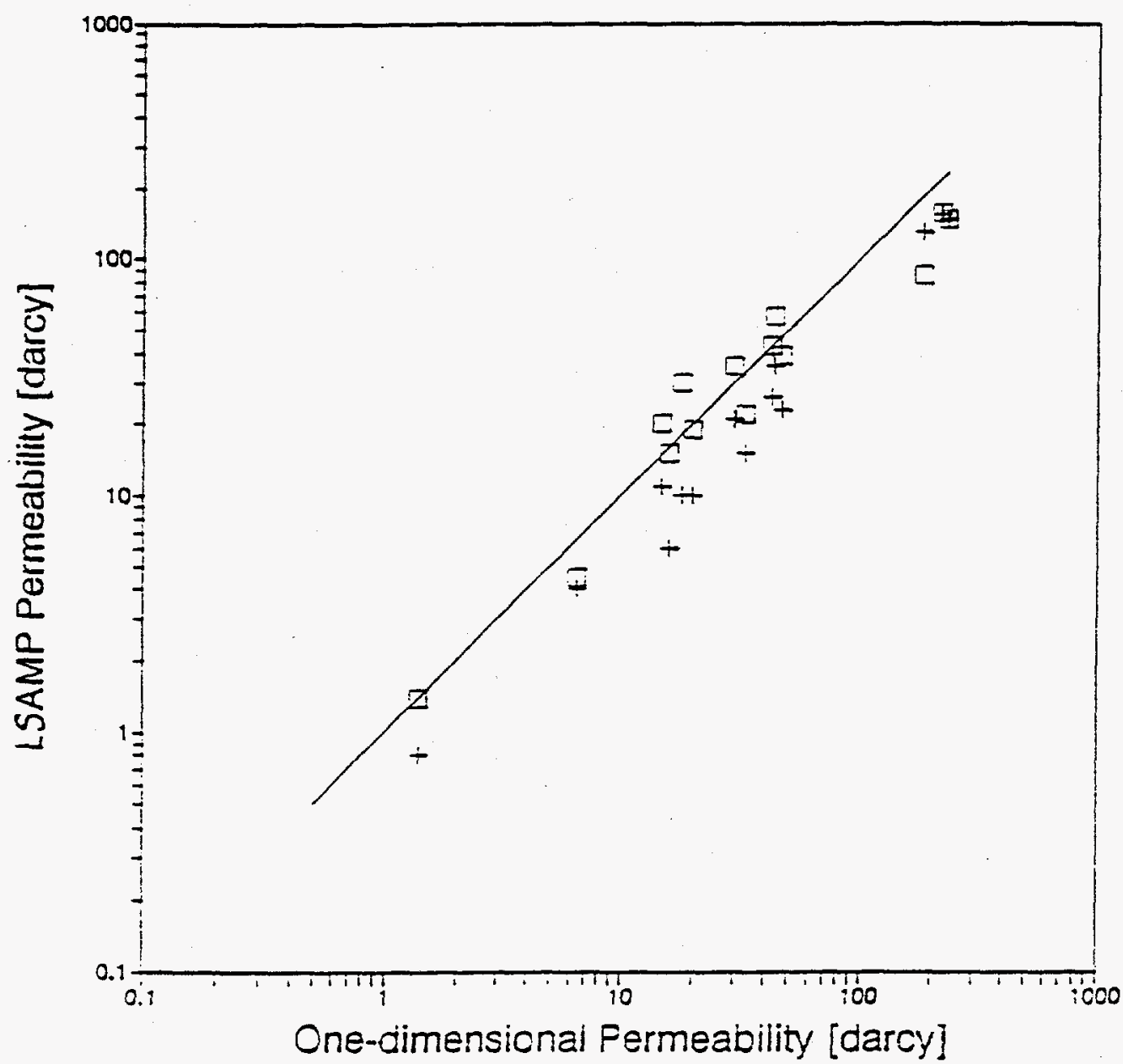

Figure 2.8. Calibration plot of air-permeabilities measured with 1-D device and LSAMP. Solid line is a one-to-one reference line. 
with the LSAMP to measurements obtained with a continuous flow device using the same tip seal (CFD). While permeability measured with the CFD is not a well established standard, the accuracy of a similar device has been documented in the works of Goggin et al. (1988a), Kittridge et al. (1989), and Dreyer et al. (1990). This approach ensures that both methods (LSAMP and CFD) are measuring the same volume of porous media. Results of the second calibration experiment are shown in Figure 2.9. While this calibration approach results in a much stronger correlation, a slight bias of under-estimation is present. The cause of this minor bias is unknown. One possibility is non-Darcy flow phenomenon.

Two types of non-Darcy flow phenomenon have been documented. First, gas slippage must be considered when the mean free path of the gas is comparable to the pore size (Katz and Lee; 1990). The second non-Darcy flow phenomenon results in additional pressure losses associated with high flow rates.

Gas slippage in tight formations results in an over-estimation of permeability. This phenomenon is considered negligible on two counts. First, permeabilities are not overestimated and the mean free path of air at atmospheric pressure is on the order of $10^{-8}$ meters (Adamson; 1979) while the pore size of the materials sampled is on the order of $10^{-4}$ meters.

High velocity flow effects, on the other hand, result in additional pressure losses and an under-estimation of permeability. Traditionally, the Reynoid's number is used to assess the importance of high velocity flow effects. Based on experimental observations in onedimensional cores, Darcy's Law is valid for Reynold's numbers not exceeding a value between 1 and 10 (Bear; 1972). Since the flow geometry in the porous media resuiting from the tip seal is three-dimensional (approximately spherical), the applicability of the one-to-ten rule is questionable. In fact, since the seepage velocity decreases proportional to the radius squared, it is possible that for diverging flow conditions Darcy's Law may be applicable for apparent Reynold's numbers greater than ten. 


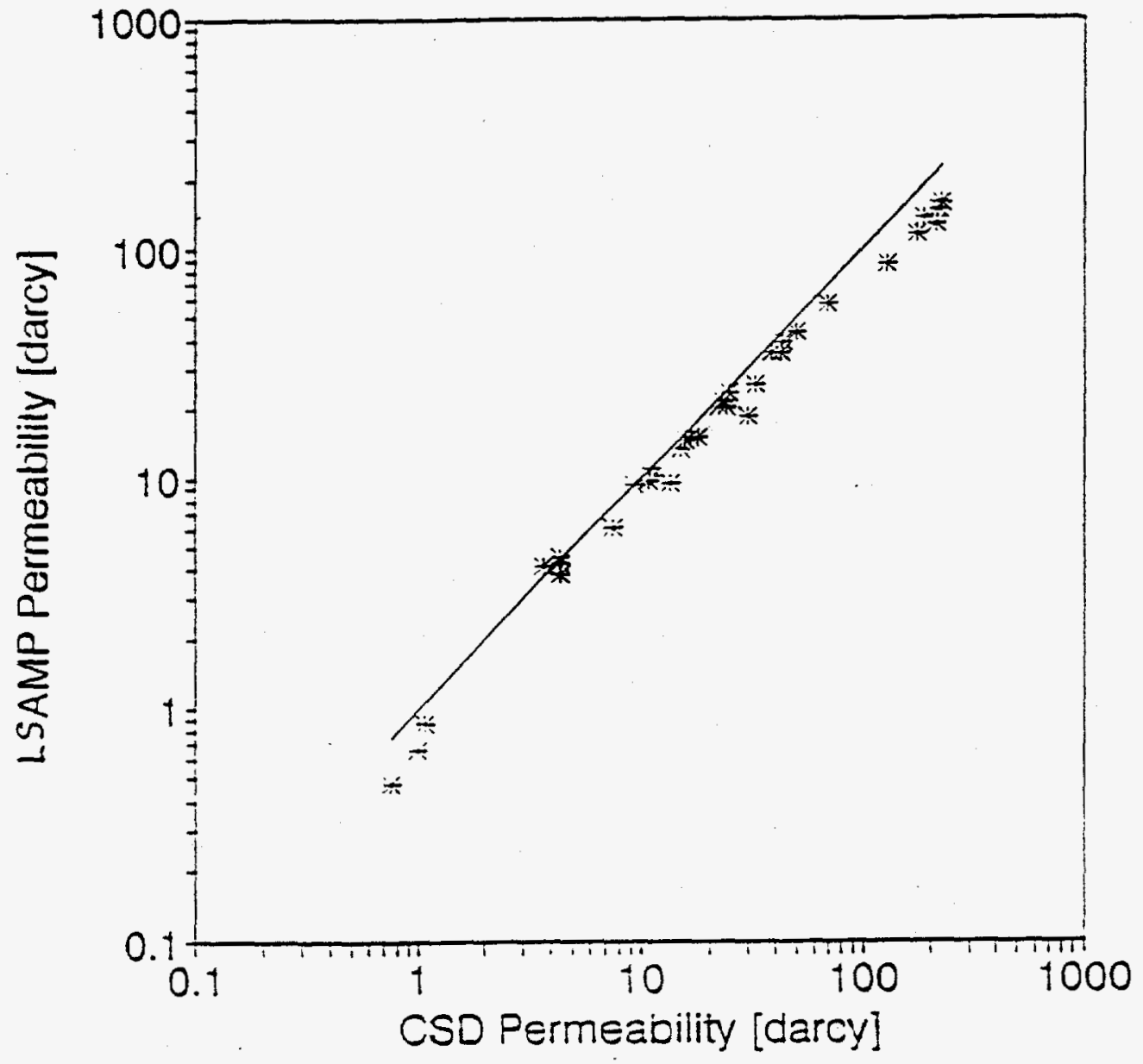

Figure 2.9. Calibration plot of air-permeabilities measured with CFD and LSAMP. Solid line is a one-to-one reference line. 
For the data presented in Figure 2.8, the Reynold's numbers for the one-dimensional measurements are consistently less than one. The Reynold's numbers for the corresponding LSAMP measurements range between 0.5 and 200 , with the highest Reynold's numbers corresponding with the highest permeabilities. For permeabilities above 100 darcys, the LSAMP measurements appear to consistently under-estimate the one-dimensional permeabilities. Since this is near the upper end of the LSAMP measuring range, the relative significance of high velocity flow effects is unclear.

In general, permeability measurements obtained with the LSAMP agree well with traditional one-dimensional permeability measurements and permeability measured with a less conventional continuous flow device. Effects of gas slippage are not observed and are not expected to be significant. Minor high velocity flow effects may be present for the highest permeabilities but further research is required on the validity of Darcy's law under the prescribed flow geometry.

\section{Moisture content}

The presence of interstitial fluids will cause a lower air permeability. An experiment was conducted to assess the measurement error associated with the water saturation. Four epoxy-sandstone blocks (approximately $15 \times 10 \times 4$ centimeters) were fabricated in the same manner as the columns described above. On each block permeability measurements were made at locations approximately 2.5 centimeters apart. The blocks were then wetted by partially submersing them in approximately 2 centimeters of standing water. The wetted blocks were then set on a rack and allowed to gravity drain. The blocks were then dried in steps. Drying was achieved by placing the blocks in a $90 \mathrm{C}$ oven for 20-30 minutes. After each heating period, the blocks were allowed to cool to room temperature. Permeability measurements were taken at one of the previousiy measured locations after each drying step. The use of multiple locations per block ensured against preferential drying from the 
measurement process. The mass of the blocks was also measured at each drying step to calculate the gravimetric moisture content, w. Volumetric water content for each drying step is estimated by:

$$
\theta=\frac{\rho_{d}^{b}}{\rho_{l}} w
$$

Where: $\quad \rho_{d}^{b}=$ dry bulk density of the block

$\rho_{l}=$ density of water

$w=$ gravimetric moisture content

The percent error in permeability $\left(k_{d r y}-k_{\text {wer }} / k_{d r y}\right)$ is plotted against the moisture content in Figure 2.10. The results indicate that when the volumetric water content is less than $5 \%$, the measurement error is also less than $5 \%$.

\section{Performance Assessment}

Performance of the LSAMP is assessed by statistically analyzing the repeatability of the instrument under laboratory conditions and the reproducibility of measurements made under both field and laboratory conditions. First, triplicate measurements under laboratory conditions were made on each end of 19 standard cores. The results of a one-way analysis of variance (ANOVA) of the measurements is presented in Table 2.1. For both the original data and the logarithm transformed data the large $\mathrm{F}$ value is a clear indication that the variability associated with measurement error is much less than the variability of the core permeabilities. 


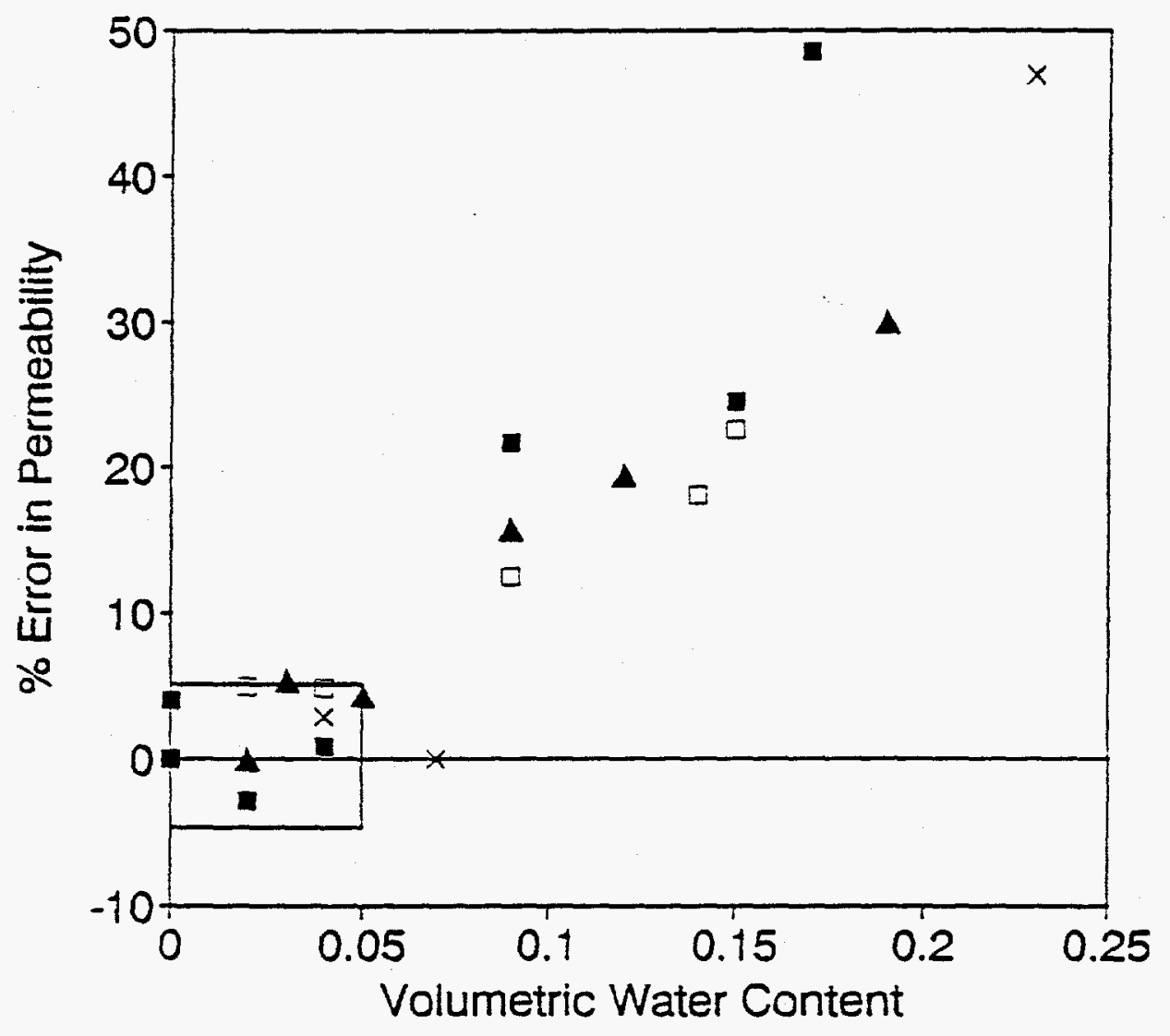

Figure 2.10. Permeability measurement error $\left(k_{d r y}-k_{\text {ved }} / k_{d r y}\right)$ vs. volumetric water content. 
Table 2.1. Summary of one-way ANOVA on triplicate measurements at each end of 19 standard cores performed under laboratory conditions.

\begin{tabular}{|c|c|c|c|c|c|}
\hline Data & Source of Variation & $\begin{array}{l}\text { Sum of } \\
\text { Squares }\end{array}$ & $\begin{array}{l}\text { Degrees of } \\
\text { Freedom }\end{array}$ & $\begin{array}{l}\text { Mean } \\
\text { Square }\end{array}$ & $\begin{array}{c}F \\
\text { value }\end{array}$ \\
\hline \multirow{3}{*}{$\begin{array}{c}\text { Original } \\
\text { Data }\end{array}$} & Among Samples & 94478 & 37 & 2553 & \multirow{3}{*}{1792} \\
\hline & Within Replicates & 108 & 76 & 1.42 & \\
\hline & Total Variation & 94586 & 113 & 837 & \\
\hline \multirow{3}{*}{$\begin{array}{c}\text { Logarithmic } \\
\text { Data }\end{array}$} & Among Samples & 18.3 & 37 & 0.50 & \multirow{3}{*}{2655} \\
\hline & Within Replicates & 0.01 & 76 & $1.87 \times 10^{-4}$ & \\
\hline & Total Variation & 18.3 & 113 & 0.16 & \\
\hline
\end{tabular}

Since the AMP is primarily designed for use in the field, it is also desirable to assess if the calibration results are portable to the field. Two of the standard cores used in calibration were measured repeatedly under field and laboratory conditions. At an outcrop study site, twenty-two field LSAMP measurements of two standard cores were obtained. Temperatures in the field ranged from 80 to $100+^{\circ} \mathrm{F}$, winds varied from $0-20 \mathrm{mph}$, and the standards were measured at various times of the day. Twenty-two measurements of permeability were also obtained for the two standard cores under laboratory conditions.

The means and standard deviations of the permeability measurements under field and laboratory conditions for each standard are presented in Table 2.2. The standard deviations of the measurements under field conditions is higher than those obtained under laboratory conditions. This is interpreted as resulting from more variable sampling conditions in the field. To test the hypothesis that the sample populations have different means, the $t$-test is employed. Since each the sample populations appear to have different standard deviations, the results of the t-test can only be considered approximate. The results of the t-test are also presented in Table 2.2. For Standard 1, the hypothesis that the populations have different 
means can be rejected at the $10 \%$ significance level. The field and laboratory mean permeability measurements of Standard 2 are 95.3 and 103 darcys, respectively. The hypothesis that populations have different means cannot be rejected Standard 2. As in the calibration analysis, we appear to be near the upper LSAMP measuring range at 100 darcys. The coefficient of variation however remains small (.11) under field conditions indicating that the LSAMP is relatively repeatable.

Table 2.2. Statistical summary of repeated measurements on sandstone cores under laboratory and field conditions. Values are in darcys.

\begin{tabular}{|c|c|c|c|c|c|c||}
\hline Conditions & \multicolumn{3}{|c|}{ STD 1 } & \multicolumn{3}{c|}{ STD 2 } \\
\hline \hline & $\mu$ & $\sigma$ & CV & $\mu$ & $\sigma$ & CV \\
\hline Field & 14.29 & 1.06 & 0.07 & 95.28 & 10.07 & 0.11 \\
\hline Laboratory & 14.31 & 0.31 & 0.02 & 103.3 & 5.05 & 0.05 \\
\hline t- values & \multicolumn{3}{|c|}{0.09} & \multicolumn{3}{c|}{3.33} \\
\hline
\end{tabular}

\section{CONCLUSIONS}

Outcrop studies of geologic heterogeneity provide a means of correlating observed geologic structures with the spatial variability of permeability. The lightweight syringe-based air-minipermeameter (LSAMP) developed for the rapid, non-destructive, in situ measurement of permeability is particularly useful for weakly lithified materials exhibiting permeabilities in the range .5 to 100 darcy. For studies conducted in rugged terrain, the increased portability of the LSAMP is of particular importance.

Permeability measurements obtained with the LSAMP compare well with both onedimensional permeability measurements and the continuous source device permeability measurements. Under-estimation of permeability at the upper end of the measurement range 
may result from high velocity flow effects. Further work is needed to quantify the Reynold's number threshold at which flow deviates from Darcy's law under the prescribed flow geometry. If high velocity flow effects are significant, a numerical solution of Forcheimer's equation is a means to estimate permeability. Moisture content is found to play a significant role. However, for volumetric moisture contents less than $5 \%$, the associated permeability measurement error is less than 5 percent. Analysis of measurement error under laboratory conditions indicates that the variability associated with instrument error is much less than the variability over the range of permeabilities measured. A slight increased measurement is observed and expected under field conditions. This increase in error is more pronounced for the upper end of the measurable range but remains at an acceptable level. Further refinement and modifications on the LSAMP design should greatly enhance the tools for collecting large numbers of quantitative measurements in the study of geologic heterogeneity. 


\section{CHAPTER III: ARCHITECTURAL ELEMENT MAPPING AND ASSOCIATED CORRELATION STRUCTURE}

\section{INTRODUCTION}

This chapter proposes that a combination of sedimentological and geostatistical analyses provide an effective means of characterizing subsurface heterogeneity. Prediction of contaminant migration and dispersion requires an understanding of subsurface heterogeneity at the scale of the contaminant plume. This heterogeneity is by nature deterministic. That is, at every location there is one value of hydraulic conductivity. However, since obtaining these values is not possible, a statistical representation of heterogeneity is often employed, and the contaminant migration is studied as a statistical process. This provides a means for assessing groundwater contamination statistically. In essence, our lack of knowledge regarding the hydrogeologic properties in the subsurface translates into uncertainty in the behavior of a contaminant plume. Improving subsurface characterization enhances our ability to understand and predict contaminant plume behavior.

A wide variety of statistical models of aquifer heterogeneity have been proposed in the literature (e.g. Gelhar and Axness, 1983; Wheatcraft and Tyler, 1990; Burrough, 1983; Colarullo and Gutjahr, 1991; Journel and Alabert, 1988). Each model is based on different spatially-correlated random variables, and each exhibit different spatial properties. Haldorsen and Damsleth (1990) provide a comprehensive review of these models, as developed for both groundwater hydrology and petroleum engineering. One reason for the proliferation of models is that a single statistical model is not applicable to all types of geologic deposits. However, the development of statistical models has greatly exceeded the understanding of heterogeneity in actual geologic deposits. It is then difficult to justify 
which statistical models best represent heterogeneity in different geologic deposits.

Using only subsurface measurements of hydraulic conductivity to theoretically discriminate between candidate statistical models is arduous. Estimation of the necessary model parameters, such as the probability distribution and correlation lengths, requires hundreds to thousands of measurements. The costs and risks associated with sampling contaminated aquifers at this intensity is prohibitive.

Alternative approaches for discriminating between different statistical models of heterogeneity and parameterizing them would greatly enhance our ability to characterize and effectively remediate contaminated aquifers. One such alternative approach is to incorporate geologic information. Sedimentological models of depositional environments are based on the occurrence and spatial assemblage of lithologic units. Lithologic descriptions often contain information about hydrogeologic properties. The use of geologic information in discriminating between statistical models of heterogeneity, and in their parameterization, should begin with a conceptual understanding relating models to the spatial assemblage of lithologic units (depositional environment). Ideally, primary effects such as depositional environment should be treated separately from the secondary effects of diagenesis.

Outcrop studies of geology and permeability provide the most comprehensive source of two-and-three-dimensional information on geologic heterogeneity. Several such outcrop studies have been conducted. In clastic deposits a good correlation between permeability and lithologic facies has been found in eolian (Goggin et al. 1988a, Chandler et al. 1989) and delta-plain distributary (Dreyer et al. 1990) environments. A similar study of carbonate sediments (Kittridge et al. 1989) revealed a weaker correlation between lithologic facies and permeability. While each of these studies have greatly contributed to understanding heterogeneity in different depositional environments, a comprehensive analysis relating the spatial assemblage of lithologic units to the overall statistical properties has not been performed. In addition, diagenetic effects are present in each of the studies and were not 
accounted for explicitly.

The objective of this study was to develop a better understanding of how the sedimentological relationship between depositional processes and depositional products can be used to statistically characterize hydrogeologic properties. An outcrop of the PliocenePleistocene Sierra Ladrones Formation in the Albuquerque Basin of central New Mexico provides the site for this study. Located west of Belen, New Mexico, the Cejita Blanca escarpment exposes the deposits of the ancestral Rio Grande system. Erosion of the largely uncemented deposits has resulted in badlands topography offering good three-dimensional exposures.

Three main steps of analysis were employed. First, it was necessary to understand as well as possible the depositional environment. This information was obtained from paleogeographic reconstruction and previous studies in the area. The second step was to obtain an accurate spatial representation of the architectural elements through geologic mapping. Architectural elements defined according to facies analysis were mapped over a $0.16 \mathrm{~km}^{2}$ peninsular section of the outcrop and air-permeability measurements provide quantitative information on hydrologic properties within the elements. Then by combining the spatial representation of lithologic units with the measured hydrogeologic characteristics, the statistical properties were related to the deposition processes.

\section{METHODS}

The empirical characterization of outcrop heterogeneity involved detailed mapping of lithologic units, quantitative measurements of hydraulic conductivity, and geostatistical analysis of the combined data. Mapping of lithologic units followed Miall's (1985) architectural element scheme. The architectural elements were defined based on an initial facies mapping of a 50 meter wide by 20 meter high outcrop (Davis et al. 1991). The majority of permeability measurements were obtained with an air-minipermeameter in the 
sandy deposits. Some preliminary measurements of the conductivity in the clay and silt deposits were obtained with a triaxial cell and a falling-head apparatus. Based on the measurements of permeability and hydraulic conductivity in the different architectural elements, the three-dimensional architectural element map was analyzed by means of traditional geostatistical techniques.

Architectural Element Analysis

The alluvial architecture scheme is used as a basis for defining the mappable units of the field site. Miall (1985) proposed that alluvial deposits consist of eight basic architectural elements which can be identified by their "grain size, bedform, position, internal sequence and, most critically, by external geometry". In a later work, Miall (1988) refined the definition of an architectural element as a "a lithosome characterized by its geometry, facies composition and scale [that] represents a particular process or suite of processes occurring within a depositional system." A lithosome is defined as a body of sediment deposited under uniform physiochemical conditions (Bates and Jackson, 1984).

\section{Air-Permeametry}

In addition to the mapping of lithofacies and architectural elements, air permeability measurements provide quantitative hydrologic information. An minipermeameter developed for this study enables the rapid, in-situ, and non-destructive sampling of air permeability. The minipermeameter design follows the general approach of Goggin et al. (1988b) in which a constant pressure is applied to a prepared surface via flexible tubing attached to a tip seal. However, our device uses lower pressure, different design principles and is more portable (Davis et al, 1992a). The annulus of the tip seal provides a no-flow boundary. The permeability is calculated from Darcy's law and the applied pressure, measured flow rate, and geometry of the tip seal. 
Calibration of the AMP was conducted on laboratory fabricated standards. The standards consist of stainless steel columns five centimeters in diameter and 5 centimeters long packed with a sand-epoxy mixture. Permeability measurements obtained with the minipermeameter were compared with measurements obtained using the same tip-seal (i.e. flow geometry) but utilizing a continuous air source and directly measuring the applied pressure and flow rate. The calibration was conducted on both laboratory fabricated standards and sands obtained from the field. Thirty-three measurements of the different materials ranging from 0.5 darcy to 250 darcy were made with the two devices. The correlation $\left(r^{2}=0.99\right)$ between the two measurement techniques was excellent.

Geostatistical Analysis

Geostatistics is the branch of statistics which studies and describes random variables correlated in space and/or time. Spatial correlation of a random variable means that values of the variable are more similar at two points located near one another than two points located further apart (Isaaks and Srivastava, 1990). Statistical models of subsurface heterogeneity are based on an assumption that hydraulic conductivity at each location in space is a realization of a random process which follows some probability distribution. In addition, the value of a realization at a given location is statistically dependent on neighboring values. The distance over which the values are statistically related is called the correlation length.

The correlation structure of a random variable is summarized by the experimental variogram. The variogram graphically expresses the dissimilarity between data values as a function of separation distances in space. The variogram is estimated by calculating the variance of the differences of values which are separated by a certain lag distance. For example, all the differences of values separated by 1 meter are calculated and the variance of the differences is the variogram estimate for lag 1 meter. This procedure is repeated for 
increasing lags. The result is plotted as a function of lag. Variograms are often approximated by exponential functions. The variogram at lag zero corresponds to the fact that, provided there is no measurement error, the differences of values with themselves are zero, resulting in zero variance. At small lags the differences become non-zero but remain relatively small. As the separation distance increases, the differences between values and the variance of those differences also increase. The range of a variogram refers to the separation distance (lag) at and above which values of the variogram no longer increase. The sill of a variogram refers to the maximum value of the variogram and corresponds to the variance of the population.

\section{STUDY AREA}

The Albuquerque Basin, located within the south-central portion of New Mexico (inset of Figure 3.1), is approximately $1000 \mathrm{~km}$ long and $30-50 \mathrm{~km}$ wide. The basin is structurally bounded to the west by the Lucero and Ladron uplifts, to the north by the San Felipe fault belt, to the east by the Manzano-Los Pinos uplift, and to the south by the Joyita uplift. The Albuquerque Basin is one of several en echelon basins resulting from extension of the Rio Grande Rift.

Two episodes of rifting appear to have opened the basin to its current structural configuration (Chapin \& Seager, 1975; Seager et al, 1984). The first episode occurred between the late Oligocene ( $30 \mathrm{Ma})$ and the early Miocene (18 Ma), and the second in the late Miocene (10-5 Ma). Seismic reflection data indicates that the basin is composed of a series of half grabens dipping eastward in the northern half of the basin and westward in the southern half (Lozinsky, 1988). During the early stages of rifting, the Albuquerque Basin was a part of a series of closed internally drained bolsons. Sedimentation within these bolsons resulted in playas deposits in the central portions of the basins and alluvial fans adjacent to the tectonically active surrounding mountains. 
Between 10 and $5 \mathrm{Ma}$, an increase in tectonic activity resulted in an increase in the rate of sedimentation (Lozinsky, 1988). As a result, the separate closed basins filled and coalesced into a single basin. Approximately $5 \mathrm{Ma}$, the ancestral Rio Grande integrated its drainage with the Gulf of Mexico (Lozinsky et al., 1991), causing the closed basins to coalesce into a series

of externally drained basins. This shift in drainage patterns caused fluvial deposition to replace playa deposition in the central part of the Albuquerque Basin. The rate of sedimentation declined after approximately $5 \mathrm{Ma}$ as the Rio Grande and its tributaries agraded.

Basin filling ceased approximately 0.5 Ma (Lozinsky et al., 1991) and the Rio Grande and its tributaries began to entrench. This entrenchment left a large portion of the basin fill isolated from deposition or erosion, thereby creating a broad flat geomorphic surface known as the Llano de Albuquerque. Between $0.5 \mathrm{Ma}$ and the present time, incision of these rivers has dissected the Llano de Albuquerque, revealing extensive outcrops of the upper basin fill. The most notable of these escarpments flank the wedge-shaped remains of the Llano just north of the modern confluence of the Rio Grande and Rio Puerco (see Figure 3.1). The west-facing escarpment is formed by downcutting of the Rio Puerco into the basin fill deposits, and is called the Ceja del Rio Puerco. The east-facing escarpment is a result of incision of the Rio Grande and is called the Cejita Blanca.

\section{Previous Work}

The basin fill deposits of the Albuquerque Basin have been studied since the early 1930's (e.g. Bryan and McCann, 1937; 1938; Denny, 1940; and Stearns, 1953). The Albuquerque Basin fill was collectively known as the Santa Fe Formation (Bryan, 1938) until 1963 when Baldwin (in Spiegel and Baldwin, 1963; p. 38-39) formally proposed the Santa Fe be raised to the group status. 


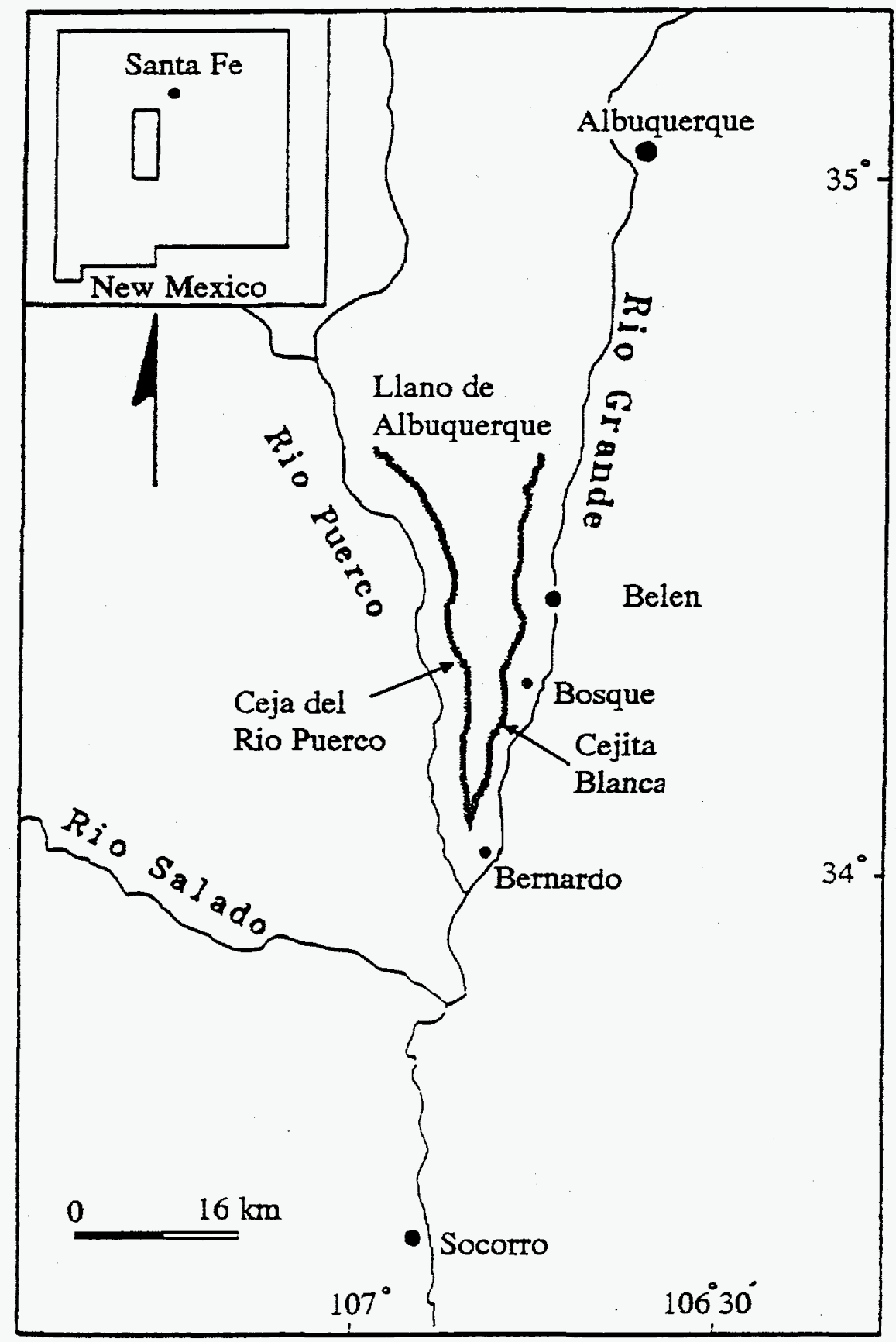

Figure 3.1. General location map. The field site is located on the Cejita Blanca escarpment west of Bosque. 
Machette (1978) subdivided the Santa Fe Group within the Central Albuquerque Basin into the lower Popotosa Formation and the upper Sierra Ladrones Formation. The Popotosa records deposition between the early Miocene and the late Oligocene, and consists of the playa deposits interfingered with alluvial fan and eolian sediments. The Sierra Ladrones records the infilling of the Albuquerque Basin with alluvial fan and fluvial sediments between the uppermost Oligocene and the middle Pleistocene (5 to $0.5 \mathrm{Ma}$ ).

Several studies have been carried out which describe the lithologies present within the Sierra Ladrones Formation exposed in the Ceja del Rio Puerco and the Cejita Blanca. Young (1982) studied the stratigraphy and sedimentology of the Sierra Ladrones Formation exposed in the Ceja del Rio Puerco. Young (1982) recognized the presence of both alluvial fan and fluvial lithofacies. The presence of obsidian derived from the Grants Ridge area coupled with Young's paleocurrent measurements led him to conclude that the fluvial facies were derived from the northwest, outside of the Albuquerque basin. The ancestral Rio Puerco drained the Grants Ridge area, as does the modern Rio Puerco and Rio San Jose.

Lozinsky (1988) measured three vertical sections of exposed Sierra Ladrones Formation in the south-central Albuquerque Basin, one of which was located on the westfacing Cejita Blanca escarpment near Belen, New Mexico. Lozinsky (1988) noted the presence of paleosols within this section, as well as the presence of a Grants obsidian cobble in the upper $20 \mathrm{~m}$ of the section. Based on the observed lithologies and petrographic analysis of thin sections of samples from these sections, Lozinsky (1988) concluded that the Belen section sediments were deposited by a large and complex fluvial system, this system most likely being the Rio Puerco/San Jose fluvial system.

Field Site

The field site for this study is located along the east-facing Cejita Blanca, just west of Bosque, New Mexico. Figure 3.1 illustrates the location of the study area within the 
Albuquerque Basin. The portion of the escarpment chosen for study extends eastward as a peninsula from the north-south trending Cejita Blanca. The outcrop studied is approximately 100 meters high covering $0.16 \mathrm{~km}^{2}$. The outcrop slopes are angle of repose or steeper. The overbank clays and paleosols as well as some cemented lenses of gravels and sands provide the structural stability of the outcrop. The majority of the sediments however are uncemented. Colluvium is present in some locations as a thin veneer generally less than 10 centimeters and can be removed easily with a trowel or small shovel.

Results of previous studies of the upper Sierra Ladrones Formation exposed within the Ceja del Rio Puerco and the Cejita Blanca suggest that during the late Pliocene to eariyPleistocene, the positions of the Rio Grande and its tributaries were relatively similar to their current configuration. Figure 3.2 summarizes the hypothesized drainage system which Lozinsky et al. (1991) propose deposited the Upper Sierra Ladrones Formation. As shown, both the ancestral Rio Puerco and Rio San Jose joined the Rio Grande in the Albuquerque Basin, converging to form a single trunk stream near Socorro. The field site is located just west of the Rio Grande Channel zone in the region of input from both the Rio Puerco and the Rio San Jose. Preliminary petrographic data collected by Harris (1991) at the Bosque Site supports the Pliocene-Pleistocene drainage configuration shown in Figure 3.2. Point count data suggests that the field site sediments received influx from the Rio Grande, Rio Puerco and the Rio San Jose.

The depositional environment of the upper Sierra Ladrones Formation is fairly well understood due to their geologically recent origin as well as previous outcrop and petrographic analysis. The exposures along the Cejita Blanca escarpment offer an excellent opportunity to study the relationship between depositional environment, fluvial architecture, and aquifer geologic heterogeneity. 


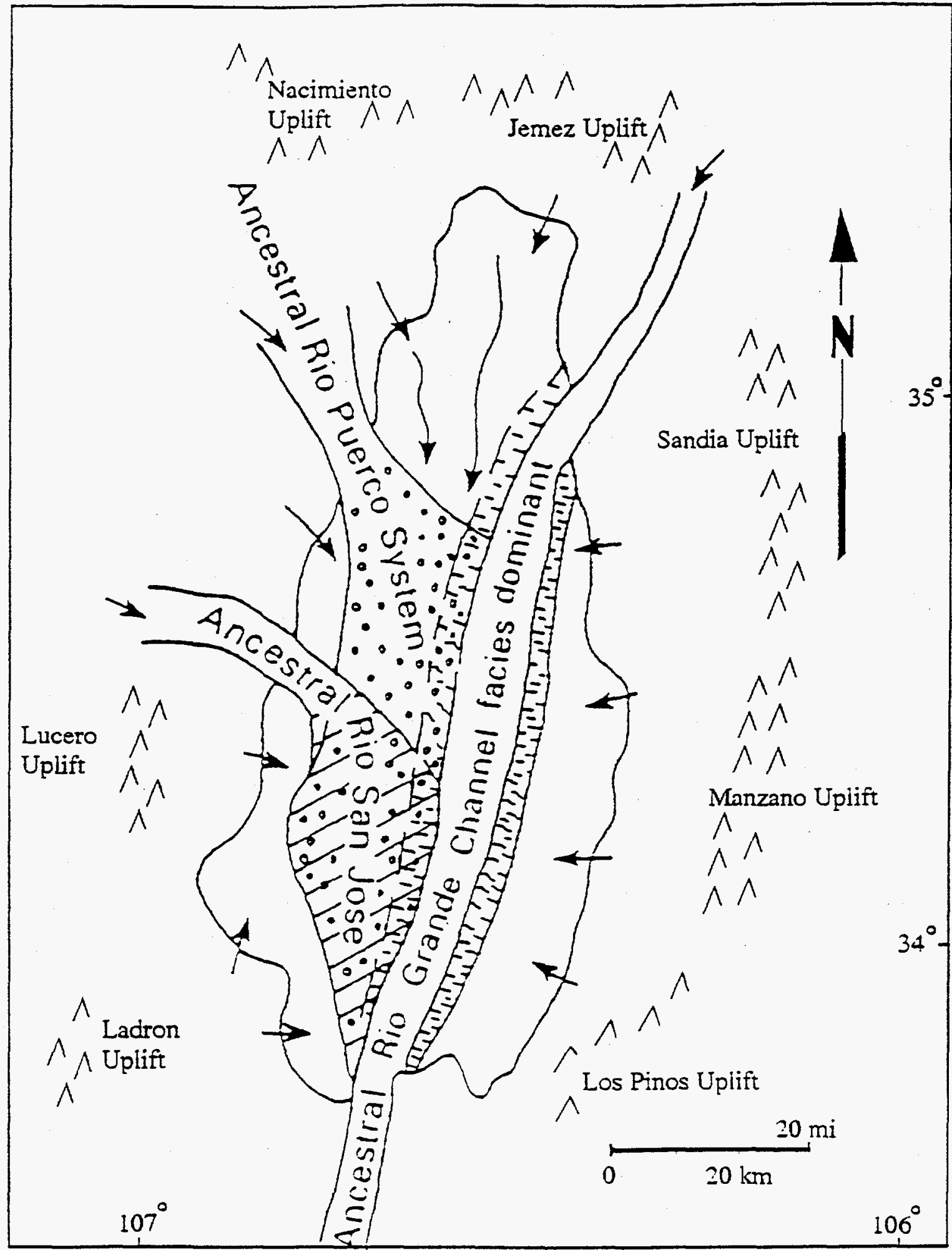

Figure 3.2. Paleogeographic setting of the Albuquerque Basin during Pliocene-Pleistocene time. Arrows indicate direction of sediment input. (Adapted from Lozinsky et al., 1991) 


\section{ARCHITECTURAL ELEMENT ANALYSIS}

The alluvial architecture scheme is used as a basis for defining the mappable units of the field site. Miall (1985) proposed that alluvial deposits consist of eight basic architectural elements which can be identified by their "grain size, bedform, position, internal sequence and, most critically, by external geometry". In a later work, Miall (1988) refined the definition of an architectural element as a "a lithosome characterized by its geometry, facies composition and scale [that] represents a particular process or suite of processes occurring within a depositional system." A lithosome is defined as a body of sediment deposited under uniform physiochemical conditions (Bates and Jackson, 1984). The architectural elements at the field site are defined based on an initial facies mapping of a 50 meter wide by 20 meter high outcrop (Davis et al. 1991).

The bulk of the field work for this study involved mapping of architectural elements around the perimeter of the outcrop. The architectural elements are defined according to facies analysis closely following Miall (1985). The elements are on the order generally on the order of one meter thick while the area mapped covers approximately $0.16 \mathrm{~km}^{2}$. In order to maintain adequate spatial control on the architectural element map and permeability measurement locations, traditional surveying techniques are employed.

\section{Architectural Element Type Descriptions}

A facies-scale mapping exercise was conducted on an initial outcrop trending N35E with an average slope of approximately 45 degrees (Davis et al., 1991). The initial outcrop is approximately 25 meters high and 60 meters wide. The facies map constructed serves as a basis for defining the architectural elements. Miall's (1978) classification scheme was used as a basis for the classification of observed lithofacies. Table 3.1 summarizes the lithofacies observed during the preliminary outcrop study. Lithofacies Smb, Sfl, and Sm, were added 
to Miall's (1978) classification. Facies Smb consists of crudely crossbedded sand, sand-size clay clasts and armored mud balls. The basal contact of the Smb facies is commonly erosional. The facies $\mathrm{Sfl}$ is finely laminated sands with abundant climbing ripples. The third addition to Miall's (1978) classification is the facies Sm. The Sm facies is a massive sand in which most or all sedimentary structures have been destroyed. This facies is strongly associated with the paleosol facies and is interpreted as an immature soil.

The facies mapped during the initial outcrop study serve as a basis for defining architectural elements. Four main types of elements are defined. The elements are summarized in Table 3.2. Two types of channel elements, an overbank fine element, and a paleosol element. The definitions follow closely those described in Miall (1985) with the exception of the overbank fine element. Miall (1985) includes the paleosol facies in the overbank fine element. This study treats paleosols as a distinct architectural element. Allen (1974) demonstrated the utility of paleosols in terms of studying the depositional environment of an alluvial sequence. In an arid to semi-arid climate, the amount of time required for the formation of a mature soil is on the order of 10,000 to 100,000 years (Birkeland, 1984). In addition, the permeability of the sandy paleosols is much greater than the overbank clays and silt. Since the objective of this study is to assess how the three-dimensional assemblage of lithologic units relates to hydrologic heterogeneity, it is preferable to treat them separately. 
Table 3.1. Facies Classification Scheme

\begin{tabular}{|c|c|c|}
\hline Facies Code & Facies Description & Sedimentary structures \\
\hline Gms & $\begin{array}{l}\text { massive, matrix supported } \\
\text { gravel }\end{array}$ & none \\
\hline $\mathrm{Gm}$ & $\begin{array}{c}\text { massive or crudely } \\
\text { bedded gravel }\end{array}$ & $\begin{array}{c}\text { horizontal bedding, } \\
\text { imbrication }\end{array}$ \\
\hline $\mathrm{Gt}$ & stratified gravel & trough crossbeds \\
\hline St & $\begin{array}{l}\text { sand, medium to } \mathrm{v} \text {. coarse, } \\
\text { may be pebbly }\end{array}$ & $\begin{array}{l}\text { solitary or grouped trough } \\
\text { crossbeds }\end{array}$ \\
\hline Sr & sand, v. fine to coarse & ripple marks of all types \\
\hline Sh & $\begin{array}{l}\text { sand, v. fine to v. coarse, } \\
\text { may be pebbly }\end{array}$ & $\begin{array}{l}\text { horiz lamination, parting or } \\
\text { streaming lineation }\end{array}$ \\
\hline Sp & $\begin{array}{l}\text { sand, medium to } \mathrm{v} \text {. coarse, } \\
\text { may be pebbly }\end{array}$ & $\begin{array}{l}\text { solitary or grouped planar } \\
\text { crossbeds }\end{array}$ \\
\hline S1 & sand, fine & low angle $(<10)$ crossbeds \\
\hline Smb & $\begin{array}{l}\text { fine to medium sand with } \\
\text { mudballs }\end{array}$ & crude crossbedding \\
\hline Sfl & sand, v. fine to coarse & fining upward sequence \\
\hline Sm & $\begin{array}{l}\text { sand, v. fine to v. coarse, } \\
\text { may be pebbly }\end{array}$ & none \\
\hline Sgm & $\begin{array}{l}\text { sand, fine to v. coarse, } \\
\text { pebbly }\end{array}$ & none \\
\hline $\mathrm{Fl}$ & sand, silt, mud & $\begin{array}{c}\text { fine lamination, very small } \\
\text { ripples }\end{array}$ \\
\hline Fsc & silt, mud & laminated to massive \\
\hline $\mathrm{Fm}$ & mud, silt & massive, desiccation cracks \\
\hline Fr & silt, mud & rootlets \\
\hline $\mathbf{P}$ & carbonate & pedogenic features \\
\hline
\end{tabular}


Table 3.2. Facies Groupings for Definition of Architectural Elements

\begin{tabular}{|c|l|l|}
\hline Element Code & \multicolumn{1}{|c|}{ Facies Present } & \multicolumn{1}{|c|}{ Description/Comments } \\
\hline CH-I & Gm, Gt, Sp, St, Sl, Sgm & $\begin{array}{l}\text { Channel element consists dominantly } \\
\text { gravelly and coarse sand facies. }\end{array}$ \\
\hline $\mathrm{CH}-2$ & $\begin{array}{c}\text { Gms, St, Sp, Sfl, Sh, Sl, } \\
\text { Smb, Fl, Fm, Fsc }\end{array}$ & $\begin{array}{l}\text { Sand and sand size clay clasts dominate } \\
\text { with local lag gravel deposits. }\end{array}$ \\
\hline P & P, Sm, Fsc & Soils and stacked soils \\
\hline OF & Fr, Fm, Fsc, P & Overbank fines \\
\hline
\end{tabular}

High-Energy Channel Element (CH-1):

The high-energy channel element is dominated by light to dark grey poorly sorted coarse sand to gravel. Coarse gravel lag deposits and trough-crossbedding structures are common at the base of this element type. The deposits often fine upward into horizontally laminated clean sands. Clay interbeds and clay rip-up clasts are rare in the gravel elements. Elements of this type are generally between 1 and 3 meters thick.

An intact obsidian cobble was found in one of gravel elements located higher in the section. This cobble is believed to be derived from Mt. Taylor, which was last active $3 \mathrm{Ma}$ (Lipman \& Mehnert, 1980), and lies within the drainage basin of the Rio San Jose. The gravel elements $(\mathrm{CH}-1)$ mapped at the field site appear to be deposits of a fast-moving competent river.

As discussed previously, a study of the provenance of these gravel elements was carried out by Harris (1991). Preliminary results from this analysis suggest that the gravels at the field site received input from all three rivers, the Rio Grande, the Rio Puerco and its tributary the Rio San Jose. Further work is necessary to further constrain the provenance of the deposits studied. 
Low-Energy Channel Element (CH-2):

The low-energy channel element is characterized by tan to light gray, very fine to medium sand $(3.5-1.0 \phi)$ with locally abundant $0.5 \mathrm{~cm}$ to $1.5 \mathrm{~cm}$ thick clay drapes. The sand deposits consist of moderately to well sorted, subangular to subrounded sand grains. Sand-sized clay clasts are common particularly near the base of these deposits. The base of the elements are horizontal to concave upwards, with little or no observable gravel lag. Armored mud balls are locally common at the base ranging from 2 to $60 \mathrm{~cm}$ in diameter. CH-2 elements are largely unconsolidated and range in thickness from $0.5 \mathrm{~m}$ to $9.0 \mathrm{~m}$.

Common sedimentary structures include continuous and discontinuous horizontal laminated medium sands, foresets of inclined-planar cross bedding within fine to medium sands, ripple-cross-laminated fine to medium sands, and climbing-ripple stratification in veryfine to fine sands. Clay drapes interbedded with very-fine sand and laminated clay and silt are common towards the top of these elements.

The CH-2 elements are believed to have been deposited by either the ancestral northwestern tributaries to the Rio Grande (Rio Puerco and Rio San Jose) and/or Rio Grande floodplain sands. A third possibility is a shared floodplain receiving sediment from both the ancestral Rio Grande and the ancestral tributary system. The occurrence of sand-size clay clasts and armored mud balls indicates ephemeral flow conditions. In addition the occurrence of climbing ripples indicate an environment where an abundance of sediment was being deposited from suspension in slowly moving waters (McKee, 1966). Such flow conditions occur during the waning phases of a large flood (McKee, 1967), and in natural levee environments adjacent to the axial channel. 
Overbank Fine Element: OF

This element is composed of dark brown clay locally interbedded with tan silt and thin immature sand and clay paleosols. The most common sedimentary structure is parallel stratification between clay and silt. Interbeds of immature paleosols are especially common higher in the section. Lower in the section, this element is often a massive dark brown clay with red-brown sand-filled polygonal cracks. Elements of this type are very common and range from 1 to 7 meters thick.

The OF elements are interpreted as representing the portions of the floodplain where the primary mode of sedimentation is from the slow settling of clay and silt-sized materials from suspension. This may be either the distal portion of the floodplain during the large flood events or relatively proximal portions of the floodplain during small flood events. The relative abundance, thickness, and lateral continuity of these clay-silt elements suggests that the alluvial plain on which the river(s) flowed may have been relatively wide and flat (Mack and Seager, 1990). A wide flat alluvial plain would cause individual flood events to easily overtop its banks, and spread a sheet of fine sand near the channel (McKee, 1967) and laterally continuous layers of clay and silt at more proximal distance from the channel.

Paleosol Elements: Ps, Pc, and Pgs

The paleosol element is further divided into three sub-element classes based primarily on parent material. These include the most common sand paleosol (Ps), a clay/silt paleosol (Pc), and a paleosol which has parent material consisting of a sand and gravel mixture.

The Ps element exhibits an orange-red soil color of 5 YR 6/5 to 5YR 6/6 (Munsell 
Soil Color Chart) and is composed of moderately to well-sorted, very-fine to fine sand. The sand grains are subangular to rounded, depending on the sampling location. Few if any sedimentary structures remain in the upper two-thirds of these elements, although weak horizontal stratification is visible in the lower third in some of these paleosols. Many of these sand paleosols exhibit a marked zone of white $\mathrm{CaCO}_{3}$ accumulation. The most mature of the sand paleosols in the section studied coincide with Stage-II of McGrath and Hawley (1987).

This element is interpreted as a combination of fluvial and eolian sands which were left exposed on the floodplain, free of sedimentation for thousands of years. Elements of this type exhibit both tabular and lens-shaped geometries. The tabular elements are commonly composed of well-sorted, well-rounded quartz grains, indicating a possible eolian origin. The lens-shaped Ps elements may represent fluvial sands abandoned by the channel which received an eolian sand influx at the surface as pedogenesis progressed.

Again due to the distinct hydrologic properties of the clays and silts, paleosols with overbank-fine parent material are mapped separately as element Pc. The clay paleosol element is a red-brown (2.5 YR, 4/6) paleosol consisting of clay and sandy clay. This element was differentiated from the clay-silt (OF) element on the basis of its red-brown color, its lack of original sedimentary structures, and its blocky texture. Only one notable element of this type was mapped at the Bosque site (purple on the Architectural Element Map and cross sections). The thickness of this element is variable, ranging from 0.3 meters to 1.5 meters. It grades into a clay-silt element in the southwestern portion of the field site (see Cross section C-C'). Thin clay paleosol layers $(1-3 \mathrm{~cm})$ exist within some of the clay-silt 
elements, but they are lumped into the OF element for the sake of simplicity.

This clay paleosol is interpreted as a floodplain mud which was deprived of fluvial influx for an extended period of time, probably due to the rapid movement of the fluvial channel away from the floodplain.

The third paleosol element delineated in this study is the gravel-sand paleosol. Only one element of this type was mapped at the Bosque Site. It is red/pink in color $(2.5 \mathrm{YR}$, $6 / 6)$, and is composed of pebble and cobble-sized fragments in a matrix of sandy material. Preliminary analysis of this element in thin section shows that the grains in the matrix are very-fine to fine sand and angular. The thin sections show that many of the grains are coated with clay, which is evidence of eluviation in the soil profile. No original sedimentary structures remain in this largely calcite-cemented deposit.

\section{Architectural Element Map}

The Architectural Element Map (Figure 3.3) illustrates the extent of the mapping at the field site. The map was prepared by a combination of extensive surveying and traditional geologic mapping. A topographic base map of the area was first prepared by surveying approximately 1000 points on the outcrop from twenty-two survey stations encompassing the peninsular escarpment. About three-fourths of the survey locations correspond to architectural element contacts while the remaining fourth correspond to topographically important features. The survey data was hand-contoured with the aid of field notes, photographs of the outcrop, stereographic areal photographs and videotape recorded during the survey. The base map was then field checked for accuracy. 
Architectural Element Map

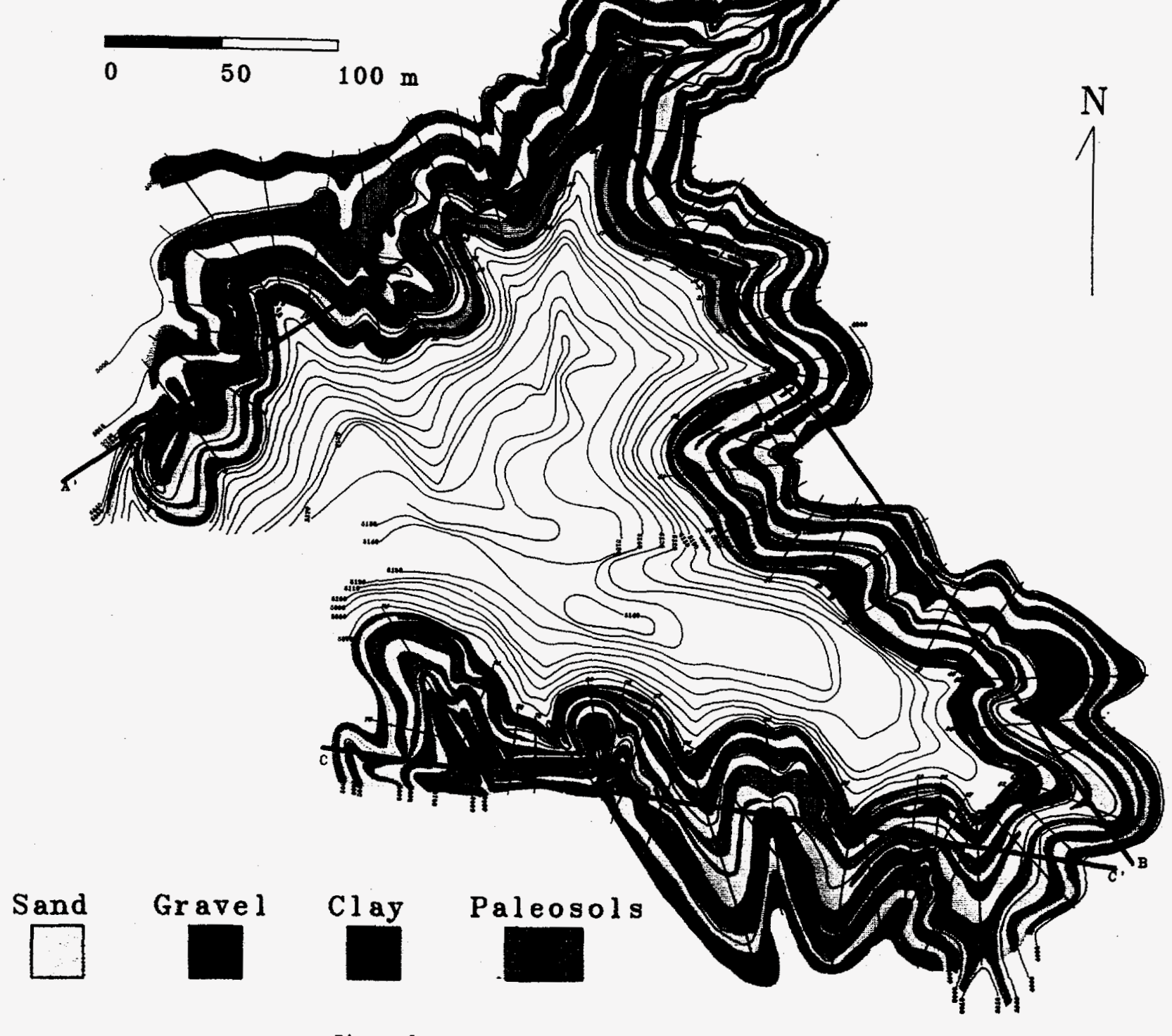


The architectural element contacts recorded by the survey data were superimposed on the base topographic map. The "gaps" in geologic information were then filled by measuring numerous vertical sections up the outcrop with a five-foot Jacob staff and tracing units laterally between the vertical sections. The locations of these sections on the base map were determined by careful comparison of the surrounding topographic and geologic features on the base map with those visible in the field. Photographs and videotapes of the outcrop taken while surveying provided additional information during the mapping phase.

Details of the geologic geometries are not readily apparent on the architectural element map due to the map scale and the relatively steep topography. An analysis of the three dimensional character of the deposits was aided by construction of cross sections (Figure 3.4) along the principal faces. The cross sections represent a projection of mapped elements onto the planes shown on the architectural element map. Since the scale of the elements greatly exceeds the projection distances, this method provides an accurate mean of studying the geometry of the elements in a series of two-dimensional maps.

Analysis of the geologic cross-sections (Figure 3.4) shows that the architectural elements at the field site exhibit a large degree of lateral continuity with occasional scours by the sand and gravel elements into the underlying units. The orientation of the scours estimated by correlating the sand scours across the field site on the Architectural Element Map (Figure 3.3) ranges from N10E to N70W, with an average flow direction of N30W. Analysis of the Architectural Element Map also shows that, on average, the sand elements pinch out in a westerly direction. This would suggest that the axis of the channel which deposited these sands lay to the east of the study site. In general, the abundance of 


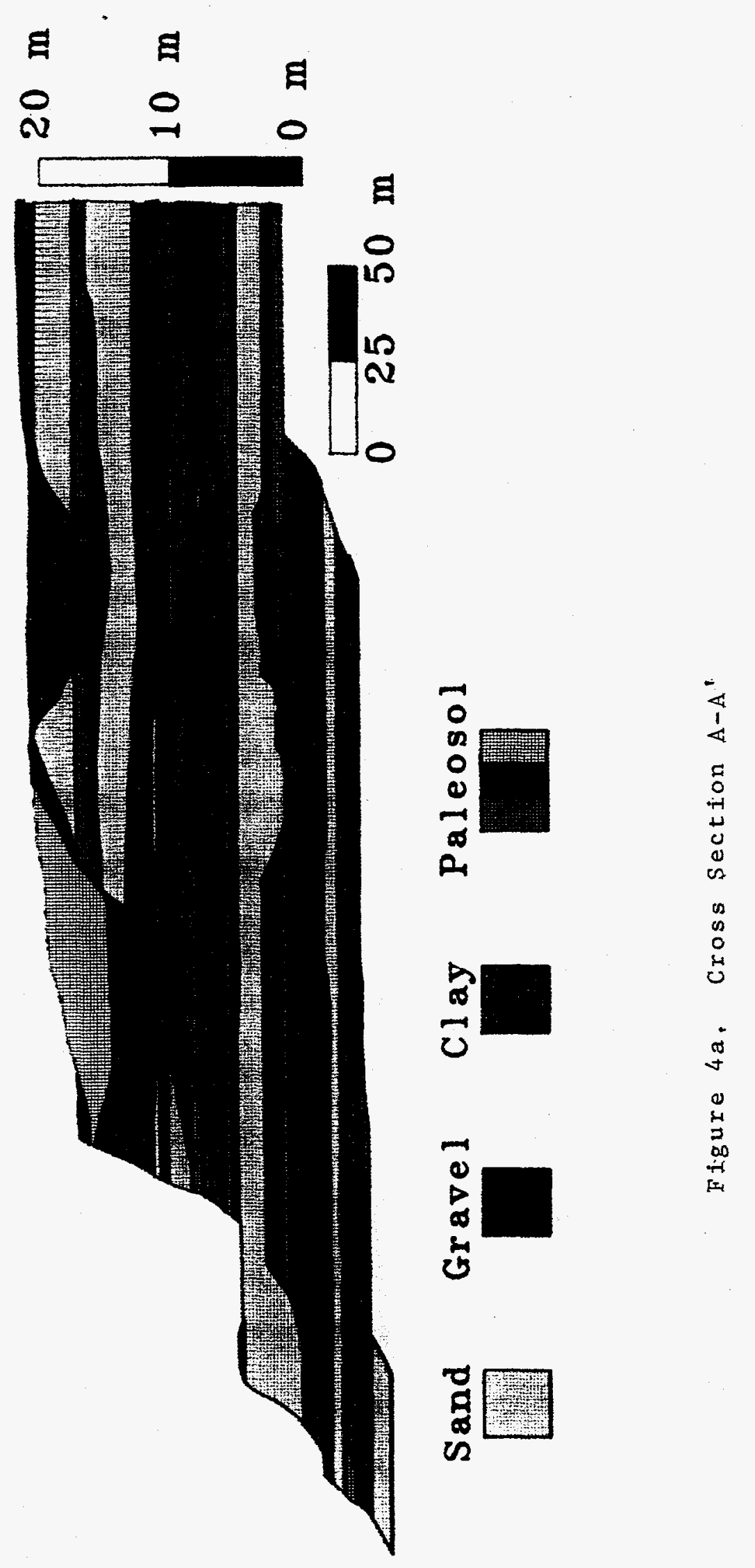




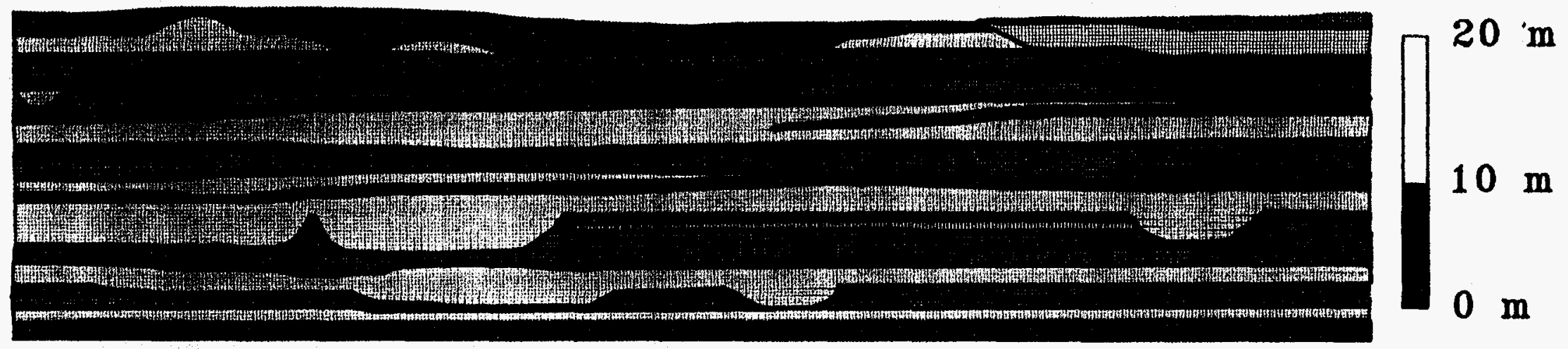

Sand Gravel Clay Paleosol

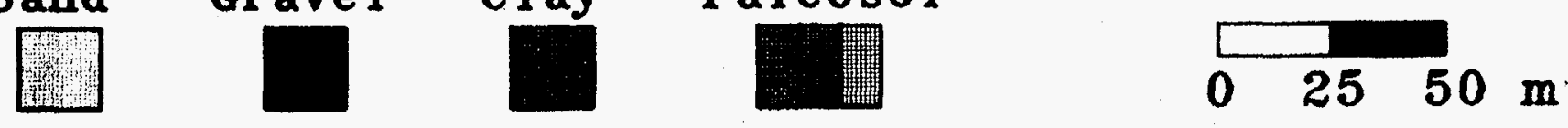

Figure 4b. Cross Section $B_{-B^{\prime}}$ 


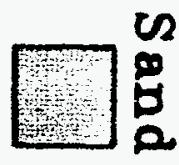

10
00
0
0
0
0
0
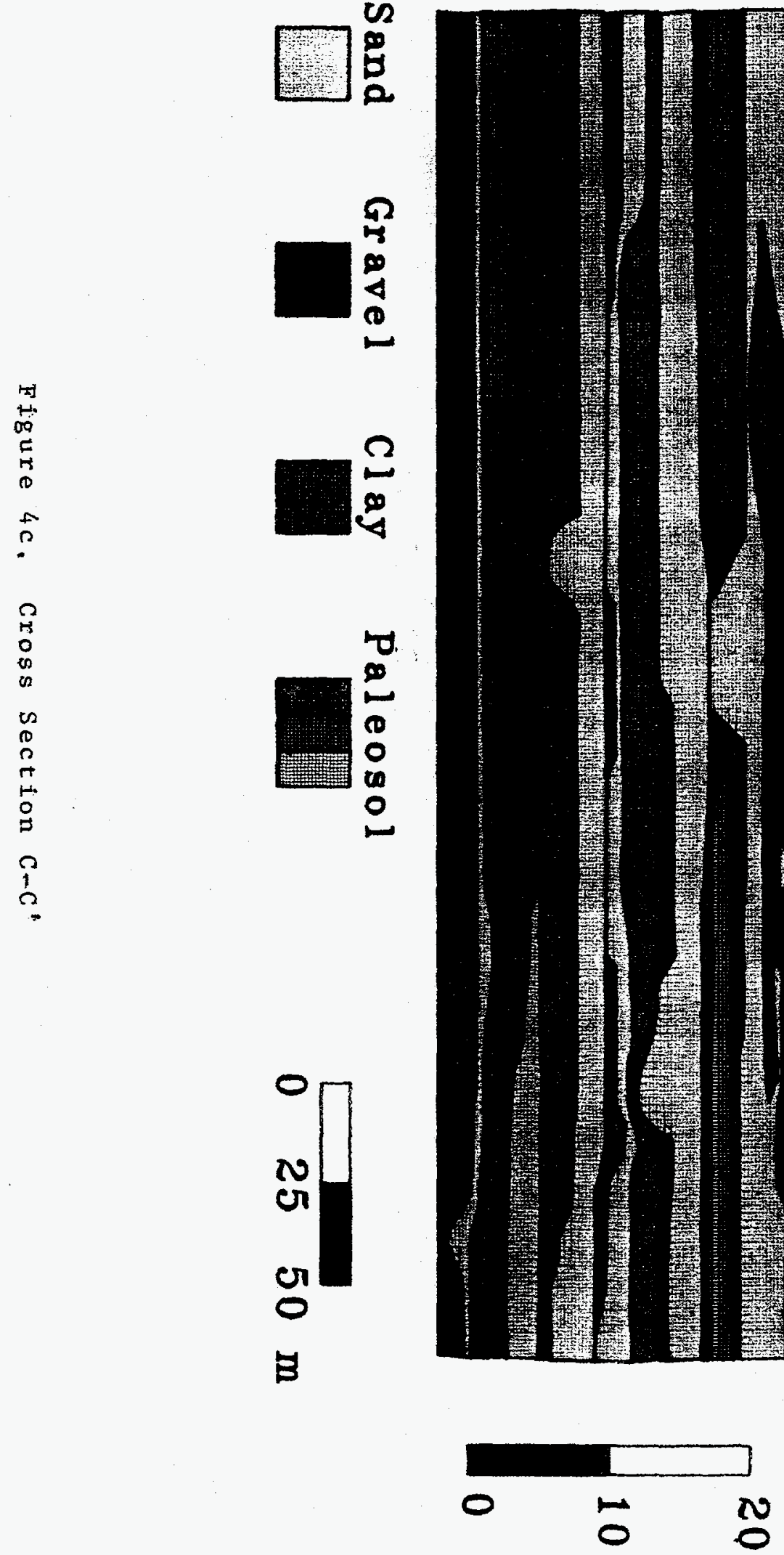
laterally continuous sands with occasional scours suggests that during large flood events, the flood waters overtopped the banks, and moved across the floodplain in sheetlike flow in some areas, and in channelized flow in others. As discussed above, not all of the sand elements at the site are floodplain deposits, as some of the deeper scours may represent deposits of the channel system.

Recognition of several sedimentary cycles on the geologic cross sections (Figure 3.4) yields additional information about the alluvial architecture at the field site. A sedimentary cycle in this case is considered to be a vertical sequence of sediments deposited by a river as it moves away from and returns to its original position. The sand elements $(\mathrm{CH}-2)$ are assumed to mark the nearby presence of a the channel system. Clay and silt elements (OF) signify that the river has moved some distance away, leaving fine-grained flood plain deposits in its wake. The paleosols (Ps, Pc and Pgs) are indicative of a region deprived of sediment influx, and therefore suggest that the river channel is at a large distance from the area.

Common sedimentary cycles seen on the three cross-sections exhibit preferred sequences of $\mathrm{CH}-\mathrm{OF}-\mathrm{P}-\mathrm{OF}-\mathrm{CH}, \mathrm{CH}-\mathrm{OF}-\mathrm{CH}$, and $\mathrm{CH}-\mathrm{P}-\mathrm{OF}-\mathrm{CH}$. These cycles suggest the river(s) migrated across a broad alluvial plain in both small (CH-OF-P-OF-CH) and large (CH-P-OF-CH) avulsive steps.

The abundance of overbank clays, silts and paleosols suggests that the field site was located a considerable distance from axial fluvial channels for a large portion of the time recorded by these deposits. Moreover, the sands themselves $(\mathrm{CH}-2)$ are characterized by predominantly lower flow regime sedimentary structures and fine grain-size, both of which indicate deposition in shallow, slow-moving waters such as would be found on a floodplain. 


\section{GEOSTATISTICAL ANALYSIS}

The purpose of the geostatistical analysis is to estimate the statistical correlation structure of permeability. For this study, the individual architectural elements are assumed to be homogeneous so the heterogeneity of the system results from the spatial assemblage of architectural elements exhibiting different mean permeability. This method is adopted to capitalize on the abundance of spatial geologic information and the limited measures of permeability. Permeability within architectural elements does vary spatially, analysis of the within-element variability is a subject of continuing investigation. However, due to the large discrepancy in mean permeability of the sandy elements and the overbank fine elements, the heterogeneity resulting from spatial changes in lithology alone is a significant contribution to the overall heterogeneity.

The method employed of consists of estimating the mean log-permeability of each of . the four principal architectural elements. This is followed by constructing a data set containing location and permeability for analysis of correlation statistics. The empirical cumulative probability distribution of the log-permeability measured in the elements $\mathrm{CH}-1$, $\mathrm{CH}-2$, and $\mathrm{P}$ are compared with theoretical normal probability distributions (Figure 3.5). Permeability in these three elements appear to follow a log-normal distributions with different mean values. Table 3.3 summarizes the population statistics for log-permeability measured in the sandy architectural elements. Sufficient samples were not collected for analysis of full population statistics of the low-permeability OF element. However, measurements of two independent samples of the OF material were conducted in the lab using a triaxial cell apparatus and a falling head apparatus. Both methods on both samples yielded permeability 
values on the order of $10^{-6}$ darcys. These data are used to estimate the variogram of the deposits by assigning the mean log-permeability value to horizontally gridded locations on the mapped region.

A dense grid of test points (one point every meter in the $\mathrm{x}$ and the $\mathrm{y}$ direction) was overlain on the Architectural Element Map (Figure 3.3). The $(x, y)$ coordinates of the test points as well as the coordinates of the digitized polygons defining the areal distribution of architectural elements were then introduced into a FORTRAN77 computer program to determine within which element (represented as a polygon) each test point lay. The computer program specified 54,402 data points, each characterized by an $\mathrm{x}$ and $\mathrm{y}$ location as well as an associated element code. The element code was transformed into $\log (\mathrm{k})$ according to Table 3.3. For the estimation of elevation (z) of each horizontal data point, the ANSI C programs TRIMAKE and TRIMAT (Macedonio and Pareshci, 1991) were used. TRIMAKE constructs triangles from the irregularly spaced digitized topographic contour data.

Table 3.3. Summary of Log-permeability Statistics

\begin{tabular}{|c|c|c|c|}
\hline \hline Element & $\mu$ [darcy] & $\sigma^{2}$ & $\mathrm{n}$ \\
\hline $\mathrm{CH}-1$ & 1.32 & 0.06 & 17 \\
\hline $\mathrm{CH}-2$ & 0.84 & 0.10 & 245 \\
\hline $\mathrm{P}$ & 0.44 & 0.10 & 110 \\
\hline $\mathrm{OF}$ & -6 & $\mathrm{n} / \mathrm{a}$ & 2 \\
\hline
\end{tabular}

This triangulation data is then used in TRIMAT to estimate elevation on a rectangular grid of the same characteristics as the previous test point grid. The resulting data set consists of 54,402 records of three-dimensional location and assigned mean $\log (\mathrm{k})$. 
A modified version of GAMV3 (Deutsch and Journel, 1991) was used to estimate the variogram of the assigned permeability data. GAMV3 allows the user to specify not only the direction for sampling, but also the horizontal and vertical angle tolerances. The code was also modified to allow the user to specify a maximum vertical search range. The purpose of this maximum vertical search range is to maintain a specified horizontal search window over large horizontal distance. Variogram analysis of the data set was performed in the horizontal and vertical directions. The data set is largely bimodal due to the assigned mean $\log (k)$ of -6 darcys for the OF element while the other elements have assigned mean $\log (\mathrm{k})$ values of approximately 1 darcy. The variogram estimates are then largely controlled by the occurrence of the OF element.

A 50 degree vertical angle tolerance used for the vertical variogram estimate (Figure 3-6a) was necessary, as the average slope of the outcrop is about 30 degrees. The periodic behavior observed at a lag separation of 7 meters coincides with the vertical repeatability of the OF elements. Measurements of the vertical distance separating OF elements were made at 100 locations on the three cross-sections. The vertical repetition of the OF element occurs in two modes. One is a higher frequency of approximately 2 meters and the other a lower frequency of approximately 4 meters. The dip in the vertical variogram at 7 meters is interpreted as representing the lower frequency cyclicity of the OF element, but having the magnitude of the separation distorted by the large vertical angle tolerance.

The horizontal variograms were estimated in six directions separated by 30 degrees. An abundance of data in the horizontal direction allows for a much tighter horizontal search window. The horizontal angle tolerance is 15 degrees and the vertical angle tolerance is 10 degrees. Also to minimize search window effects, the maximum vertical displacement between pairs is 0.10 meters. The horizontal variograms for the directions $\mathrm{N} 30 \mathrm{~W}$ and $\mathrm{N} 60 \mathrm{E}$ 


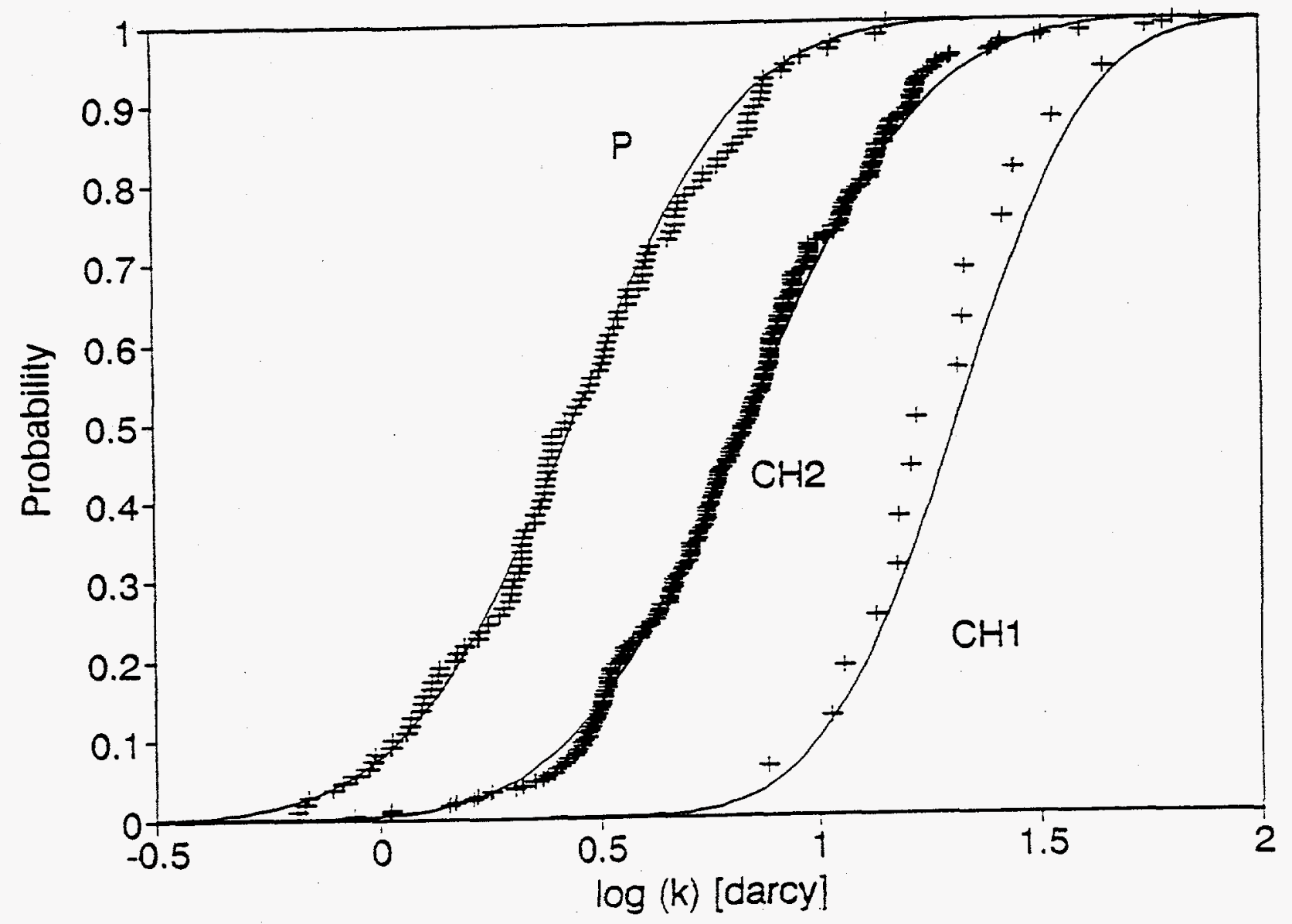

Figure 3.5. Comparison of empirical cumulative probability $(+)$ with theoretical normal for the log-permeability data. 
are presented in traditional form (Figures 3-6b and 3-6c). The horizontal variogram estimates exhibit a similar exponential behavior for lags up to 40 meters. In the N30W direction, the variogram for lags greater than 40 meters appears to reach a sill of 6 for lags up to 140 meters. The N30W variogram then increases for lags greater than 140 meters to reach a sill of 8 at 160 meters. In the N60E direction, the variogram continues to increase for lags greater than 40 meters, reaching a sill of 8 at lag 120 meters. Similarly, in the N90E direction the variogram reaches a sill of 8 at approximately 100 meters. This systematic difference in lag associated with a sill of 8 represents statistical anisotropy in the horizontal direction.

The multi-directional horizontal variogram (Figure 3.7) reveals aspects of the correlation structure not readily apparent in the two traditional variograms. First, the correlation structure exhibits non-perpendicular anisotropy. The principal directions of the variogram are $\mathrm{N} 30 \mathrm{~W}$ and $\mathrm{N} 90 \mathrm{E}$. The correlation in the $\mathrm{N} 30 \mathrm{~W}$ direction corresponds to the average direction of the CH-2 scours. Significantly less correlation exists in the N9OE direction. This is believed to be controlled by the lateral relationship between the $\mathrm{CH}-2$ and OF elements. The CH-2 grades laterally into the OF element as the interbedded sands and clays become dominated by clays to the west. This lateral gradation was probably controlled by the transition from the proximal sandy floodplain to the distal mud dominated floodplain, as illustrated in the block diagram shown in Figure 3.8. In addition, there appears to be some low frequency oscillatory behavior for lags of approximately 100 meters (Figure 3.7). While random oscillations are common in variogram estimates, the oscillations observed in this case are parallel to paleoflow and appear to correspond to the average separation of channel scours in the NE-SW direction (see Cross-Section C-C' - Figure 3.4).

The directional variogram of the spatial lithologic data clearly coincides with the 

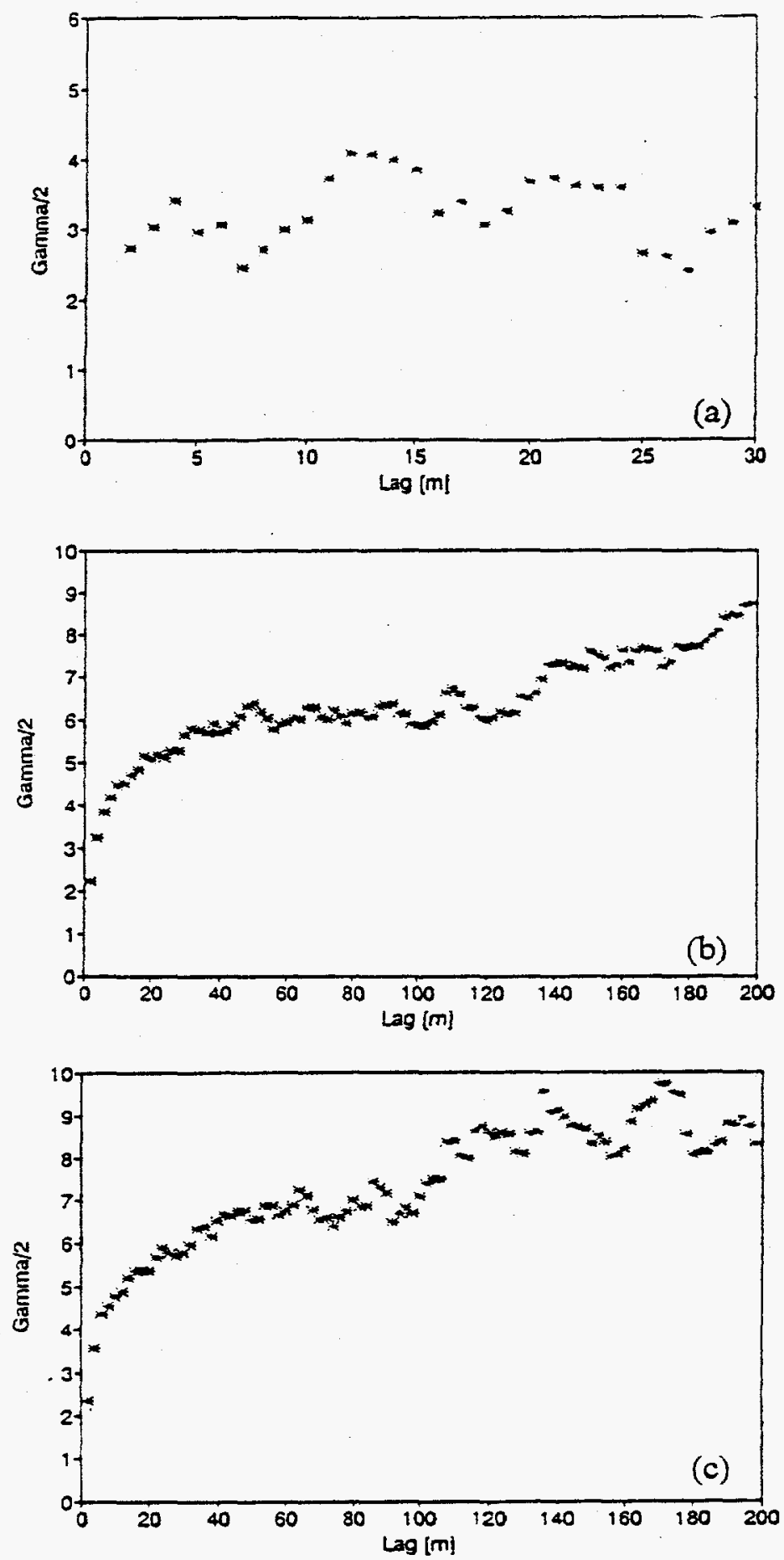

Figure 3.6. Directional variograms of log-permeability: (a) vertical variogram with vertical angle tolerance 50 degrees; (b) N30W horizontal variogram; (c) N60E horizontal variogram. Angle tolerances in the horizontal variogram searches were 15 degrees (horizontai) and 10 degrees (vertical). The maximum vertical displacement between pairs is 0.10 for the horizontal variograms. 




Figure 3.7. Multi-directional horizontal variogram const-seted by combining horizontal variogram estimates in the directions NOE. N3OE. N60E. $100 \mathrm{E}$. N30W, and N60W. Angle tolerances for variogram search are same as in Figure 7 . Racius of variogram is 180 meters. 


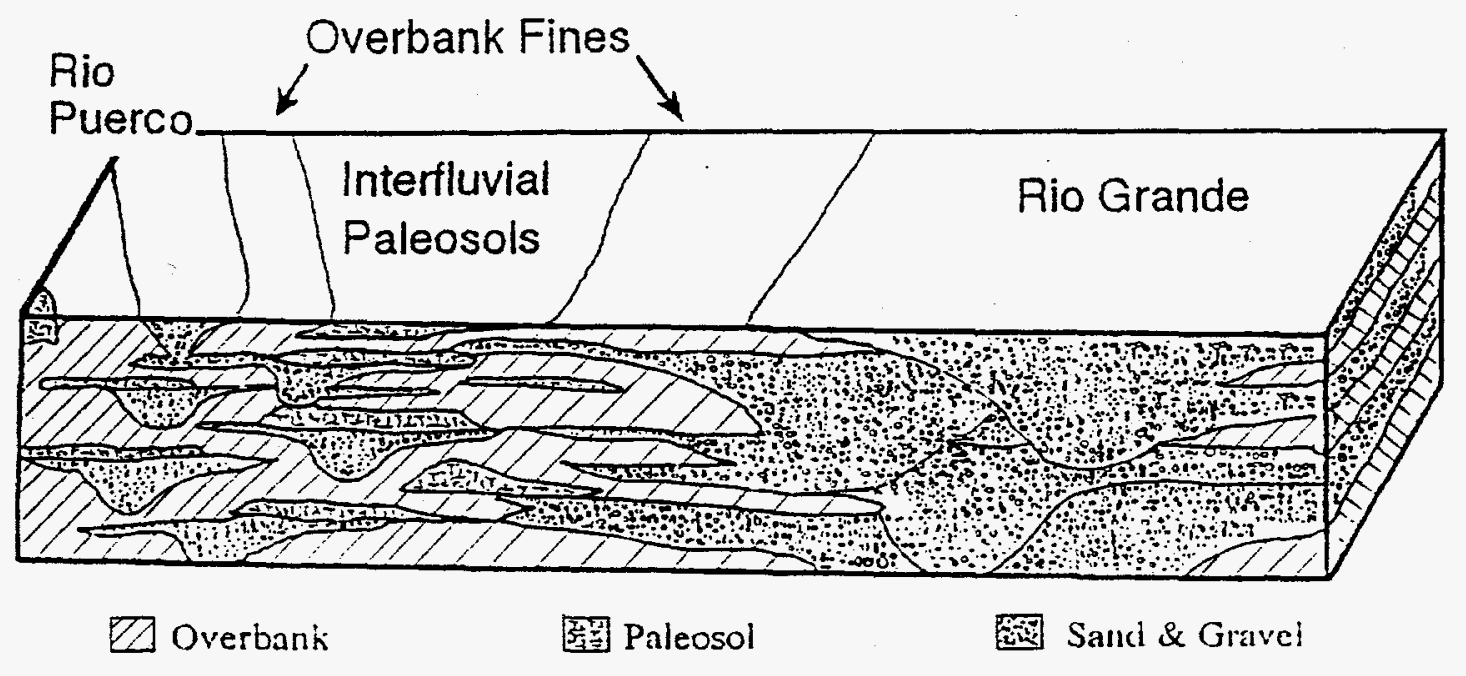

Figure 3.8. Schematic block diagram of the relationship between depositional environment and observed architectural element orientations. 
observed architecture of the deposits. While the specific architecture and correlation structure are unique to the site studied, the factors controlling the correlation structure appear to be related to the depositional environment. In fact, the correlation structure exhibits features which could be inferred directly from our prior knowledge of depositional environment; namely, the deposits resuited from a complex fluvial/interfluvial system with influences from the north-south flowing ancestral Rio Grande and its northwestern tributaries.

While the correlation structure follows exponential behavior (Figure 3.6), it is important to note that the this system was treated as a discrete process. Most statistical models of heterogeneity treat the spatial variation of hydraulic conductivity as a continuous process with exponential variograms (e.g. Garabedian et al., 1991). The architectural relationships observed in the fluvial/interfluvial deposits studied indicate that discrete models will also be necessary for some depositional environments.

By relating the spatial statistics of permeability with alluvial architecture, we enhance our ability to quantitatively analyze hydrologic flow and transport by combining paleogeographic and basin evolution information with limited hydrologic data.

\section{CONCLUSIONS}

Architectural elements deposited by the ancestral Rio Grande system are on the order of one meter thick and are laterally extensive over 100's of meters. There is a good correlation between architectural element type and mean log-permeability. The spatial dimensions of the elements as well as their spatial assemblage appear to be a dominant control on the geostatistical properties of the deposit. The variogram estimate obtained from the mean log-permeability data exhibits non-perpendicular anisotropy. The vertical variogram is periodic and appears to be controlled by the vertical repeatability of the overbank fine element. The horizontal correlation structure is aiso largely controlled by the external geometry of the overbank fine element. Channel scours in the overbank fine 
element trending N30W result in preferred correlation in that direction. Similarly, the direction of poorest correlation corresponds to the lateral transition of the sand channel element to overbank fine elements. While cursory analysis of the cross-sections implies a greater degree of heterogeneity in the direction transverse to paleoflow, the behavior of the variograms cannot be predicted based solely on the cross-sections.

The detailed hydrogeologic study of the Sierra Ladrones outcrop demonstrates that architectural element analysis is a useful tool in assessing geologic heterogeneity at scales commonly found in groundwater contamination problems. Continued multi-dimensional analyses of the spatial assemblage of lithologic units in deposits of different depositional environments are needed in developing alternative methods for estimating the spatial statistics of permeability in heterogeneous formations. Developing a conceptual understanding of how the spatial assemblage of architectural elements dictates the appropriate statistical models of heterogeneity will greatly enhance the ability of hydrogeologists to characterize subsurface geologic heterogeneity. 


\section{CHAPTER IV: SMALL-SCALE PERMEABILITY DISTRIBUTION STUDIES}

\section{INTRODUCTION}

Empirical studies of permeability patterns must be conducted in order to better understand and predict heterogeneity of natural geologic material. Four small-scale studies (referred to as SS1 through SS4) of permeability distributions have been conducted at the Sierra Ladrones Formation field site in order to investigate permeability patterns within a particular architectural element. These studies represent facies-scale heterogeneity resulting from changes in the flow regime or flow direction within a depositional unit. Throughout these studies an attempt has been made to map measured permeabilities within a recognizable geologic unit at a scale at which the permeability distribution is uncorrelated or correlated over very short distances. At this point, heterogeneities which do exist are at a scale smaller than the sample spacing. We can then proceed to use statistical analysis to describe the spatial variability of permeability at the scale of observation.

If it is found that architectural elements of the same type exhibit similar permeability patterns then, once those patterns have been identified, the task of characterizing aquifer heterogeneity simplifies to finding a representation of the spatial distribution of the elements. These small-scale studies have been carried out to investigate three topics related to this: what is the nature of geologic and hydrogeologic variation within elements?; is there a connection between observable geologic features and the correlation structure of the associated permeability distribution?; and finally, to compare and contrast the styles of heterogeneity found within and between architectural elements at the Sierra Ladrones Bosque field site. 


\section{METHODS}

Mapping Technique

As the purpose of this study is to investigate the spatial variation of geology and permeability, a mapping technique is required to identify the relative locations of data sampling points. A rough form of photogrammetry was used to plan and implement the sampling strategy. Photographs of the outcrop areas were taken at a scale which allowed the identification of significant features on the outcrop. These photographs were taken with sufficient overlap so that photo-mosaics of each study area could be made.

Permeability distribution mapping was carried out by sampling with the LSAMP as described in Chapter 2. The geology at each small-scale study site was also mapped. Six architectural elements have been defined in Chapter 1, and the same classification scheme is

used here. As the purpose of this small-scale project is to describe and compare the styles of heterogeneity found within a particular element, each of the sites was selected to fall within a single architectural element. Two of the architectural elements have been studied here, the Ch-II and $\mathbf{P}$ elements, for reasons discussed below.

Within the architectural elements, the deposits studied were delineated on the basis of first and higher order surfaces (Allen, 1983). In general, first and second order surfaces occur within lithofacies, and third and higher order surfaces bound lithofacies. The first order surfaces provide the smallest mappable criteria, and are based on local changes in the orientation of the laminae. Typically, these contacts are erosional. Each first order unit is designated as a "facies". As a consequence of this, areas here identified as separate facies may indeed belong to the same lithofacies as identified in Chapter 1 .

The mapping was used to classify the smallest sedimentary unit which could be identified in the field. The mapped units were then lumped into larger packages of sediments identified as "hydrofacies"; each hydrofacies consists of facies with similar grain size and lithology. These hydrofacies are analogous to Allen's (1983) second-order contacts, which 
consist of units related by facies and/or paleocurrent direction. Therefore, a hydrofacies may or may not have a permeability distribution different from those of other hydrofacies in the same study area.

The facies and hydrofacies delineated at each small-scale study site were numbered for identification. Grain size was recorded according to the American/Canadian Stratigraphic scale, and a description of bedding and structures was recorded.

\section{Sampling Scheme}

In order to optimize the process of variogram estimation, sampling locations were located on a grid. For computational purposes, the grid dimensions should be less than the correlation length of the property being sampled for. As the correlation length of each study area was unknown at the outset of each study, a random approach was developed to assure sampling throughout a range of spacings. This method was adapted from that developed by Davis (1991). The LSAMP measures approximately one cubic centimeter of material. With this in mind, sampling locations were held to a minimum of two centimeters spacing. This then determined the smallest scale of heterogeneity which could be detected in this study. Spatial correlation occurring at a scale smaller than this becomes lost within the nugget value in the experimental variograms.

Control points were drawn on the photomosaic in an orthogonal grid at dimensions which provided for the desired number of control points to be distributed throughout the study area. A pair of random numbers was generated for each control point; one of these random values was multiplied by the grid length in the $\mathrm{x}$ direction, the other was multiplied by the grid length in the y direction. These numbers then served as the sampling dimensions for that particular control point. The endpoints of the dimension lengths measured from that control point determined four sampling locations associated with that control point. In each of the five studies described here, a third random number was generated for each control 
point to designate the point as a "four" or a "nine". A "four" would be sampled at the four corners of the sample grid, while sampling on a "nine" would be a point grid of the specified dimensions. This sampling scheme provided an adequate distribution of pairs of data points for variogram estimation and was not biased to a particular scale of heterogeneity.

The photomosaic was used in the field to identify the locations of control points on the outcrop. The sampling dimensions were measured from each control point, and each sampling location was recorded as an $\mathrm{x}, \mathrm{y}$ distance from the first control point.

\section{Sampling of Air-Permeability}

The lightweight syringe air mini-permeameter (LSAMP), described in Chapter 2, was used to measure air flow rates at each sampling location. Free-fall, or the time recorded when the syringe is allowed to fall with the tip seal open to the air, was sampled regularly to ensure against air-permeameter malfunction.

Each small-scale study site was prepared by digging away the colluvial cover to reach a vertical face of undisturbed deposit. Ideal locations were those with weakly lithified material. The prepared outcrop was allowed to dry for a few days before sampling took place to ensure that soil moisture would not affect the LSAMP.

The range of the LSAMP is suited for the measurement of weakly lithified sands and soils. In each of the study areas materials and features of the outcrop are present which have associated permeabilities that are beyond the range of the LSAMP, such as clay balls and clay drapes, calcite nodules, lenses of coarse or loose material, fractures, and holes. The sampling points which fall on these areas were recorded as a "non-measurement".

\section{Statistical Analysis}

The purpose of the statistical analysis carried out here is to characterize the spatial distribution of permeability with a random field model. Histograms are used to estimate the 
probability distribution of the random variable, and variograms are used to estimate its correlation structure.

Analysis of distribution statistics are carried out for each of the five data sets and for each of the hydrofacies subsets identified within them. Structural statistics were carried out on each of the four complete data sets, and experimental variograms calculated in the vertical and horizontal direction are presented for each. Omnidirectional variograms were also calculated for each of the hydrofacies subsets with sufficient sample sizes, but are not presented here. All variogram estimation was completed with Geostatistical Environmental Assessment Software (GEO-EAS), version 1.2.1 (Englund, 1991).

In order to estimate a variogram, the user must define a "search window" in order to group data points into lag classes based on separation distances. The search window is defined by distance and angle tolerances, and a maximum bandwith. The distance tolerance specifies the length of the window, the angle tolerance and the bandwidth specify the arclength of the window, as illustrated in Figure 4.1. To assess directional correlation it is desirable to use as small a search window as possible while still including a sufficient number of pairs of data

\section{An illustration of the function of the Lag Cullort, Directions Tolerance, and Maximum Bandwidlo parameters}

The pair P1, P7 will be included in the compu. cetion for Lag1. The pairs P1, P2 and P1, P6 will be included in the computalion for Lage



Figure 4-1. Illustration of the "search window" for variogram estimation (From Englund, 1991) 
including a sufficient number of pairs of data within each lag. Therefore, a variogram calculated in the horizontal direction may contain pairs of points off from the horizontal by an amount up to the angle tolerance at a distance of the maximum bandwidth. Figure $\mathbf{4 . 2}$ illustrates the effects of the search window on the experimental variogram and a fitted variogram model. Figure $4.2 \mathrm{a}$ shows a calculated variogram with no bandwidth specified. It reaches a sill of about 0.37 at a distance of about 70 centimeters, and is fitted with a gaussian model with a nugget of 0.07 :

$$
\gamma(\xi)=.07+.3\left[1-\exp \left(-|\xi|^{2} / 40^{2}\right)\right]
$$

Figures $4.2 \mathrm{~b}$ and $4.2 \mathrm{c}$ show the variogram of the same data calculated with the same distance and angle tolerances but with a 10 centimeter bandwidth. The variogram reaches a sill of about 0.19 at a range of about 50 centimeters. Figure $4.2 \mathrm{~b}$ is fitted with the gaussian model as above, and Figure $4.2 \mathrm{c}$ is fitted with an exponential model with a nugget of 0.04 :

The effect of the shortened bandwidth is to keep the calculated variogram more truly horizontal. The data is from study SS3, which displays a very discrete style of heterogeneity

$$
\gamma(\xi)=.04+.15[1-\exp (-\mid \xi / 16.67)]
$$

at the facies scale. Facies delineated within SS3 have significantly different mean permeabilities. The wider bandwidth allows pairs of points to be drawn from across these facies boundaries, while the bandwidth of 10 centimeters decreases the pairing of points from across the boundaries. This is a rather extreme example, but it serves to illustrate the importance of the search window in variogram estimation. 

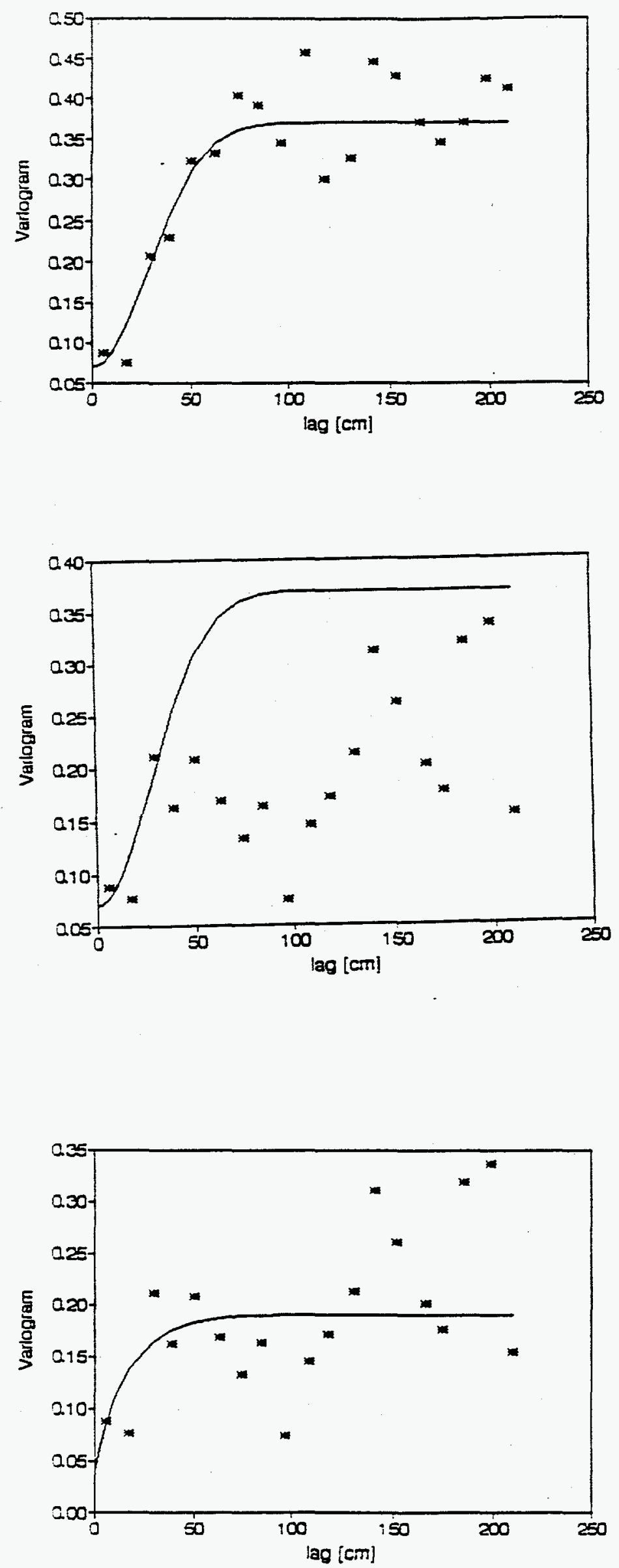

Figure 4-2a. Effect of search windon on experimental variogram. No banc width specified. Gaussian model fitted with sill=.37, range $=70$, nugget $=.07$.
Figure 4-2b. Bandwidth on variogra search window set at $10 \mathrm{~cm}$. Experimental variogram reaches a sill $=.19$, range $=50$. Gaussian model fitted with same parameter as shown in Figure 4-2a.
Figure 4-2c. Bandwidth set at $10 \mathrm{c}$ as in Figure 4-2b. Exponential model fitted with sili=.19, range $=50$, nugget $=.04$. 
In this study the search window is kept as small as possible while maintaining a sufficient number of pairs. Generally, 60 pairs is the minimum number of pairs contributing to each lag class.

Journel and Huijbregts (1978) suggest that reliable variogram estimations can be made based on lags of up to approximately half of the sample space dimension. Beyond this lag, estimated values of the sample variogram tend to become unreliable because the variogram becomes more a function of correlation between data observed along the edges of the study area. Variograms presented here include the entire sampling domain unless the number of pairs in the lag classes fall below 30 . Variogram models were fit to the sample variograms based on lags of approximately half of the sampie space dimension.

Another issue in the calculation of experimental variograms is the treatment of extreme values. Sampling locations which fell on materials with extreme values of permeability, such as clay or gravel, could not be measured with the LSAMP. These "nonmeasurements" were originally treated in the variogram estimation by assigning values of mean permeability for that material found in the literature. The inclusion of values of permeability ranging over many orders of magnitude led to very erratic estimations of the variogram. Reasonable estimates of the variogram can often be attained by eliminating outliers (Armstrong, 1984), and this was the approach taken in the variograms presented here. The elimination of extreme values is justified in this case because of they lack spatial continuity within each study area, and there is no apparent correlation of their spatial distribution. For example, a scattering of clay balls with an average diameter of five centimeters might not significantly alter the effective permeability of a sand layer two meters wide, but their inclusion in the estimation of the variogram will completely mask the correlation structure of the sand layer.

Variogram calculation is also affected by the presence of geographically distinct populations (Armstrong, 1984). In our case, the appearance in the variogram of 
heterogeneous populations is of particular interest. Specifically, we would like to know if the dimensions of the units which exhibit different mean permeabilities will be reflected in the form of the experimental variogram. With this in mind, a Student's $t$-test was used to determine if the observed permeability distribution from a particular hydrofacies was the same as that of other hydrofacies delineated within the study area. All $t$-tests are evaluated with a two-tailed distribution of probability less than 0.05 . If the $t$ value obtained is less than the critical $t$-value, the null hypothesis that the means are equal cannot be rejected.

The Student's t-test assumes independence of measurements, however this may be violated by spatially correlated data (Gotway, 1990). Results of the t-test are presented here with the understanding that the assumption of independent observations requires further attention.

Also of general interest in the variogram estimation is the nugget. The nugget is the variogram estimate at zero lag and is generally attributed to experimental measurement and/or lack of correlation below the smallest sampling interval. Here, we believe that both factors contribute to the modeled nugget.

\section{RESULTS}

Small-Scale Study 1 (SS1)

The location referred to here as SS1 is located at the Bosque field site. The prepared outcrop is approximately 2.1 meters wide and 1.6 meters high, as shown in Figures 4.3a and 4.3b. It appears to be a channel bar sand deposit and is a part of the CH-II architectural element.

Six facies, F1 through F6, were identified within the study outcrop. Facies F1 is approximately 0.7 meters high and consists of even and wavy parallel, thickly laminated upper-fine and lower-medium sands. There is soft-sediment deformation present near a large ( 0.1 meter in diameter) clay ball in the lower right-hand corner of the facies. 
F2 is approximately 0.2 meters in height, and consists of coarse sand with scattered pebbles. There are small (from 2 to 5 centimeters in diameter) clay balls present, and scattered, discontinuous clay drapes. F2 cuts into $\mathrm{F} 1$ at approximately a $16^{\circ}$ angle.

F3 is approximately 0.2 meters high, and consists of even, parallel, thickly laminated sand, ranging from lower-coarse to very coarse sands. F4 is approximately 0.3 meters high; bedding is even, parallel, horizontal laminae of upper-fine to lower-medium sands. F5 is approximately 0.2 meters high and consists of climbing ripples, in upper-fine to lowermedium sand. F6 is approximately 0.15 meters high and consists of even, parallel laminae dipping east.

The six facies delineated within the study area were further divided into hydrofacies as follows: hydro-facies 1 (HD1) consists of $\mathrm{F} 1 ; \mathrm{HD} 2$ is equivalent to $\mathrm{F} 2 ; \mathrm{HD} 3$ consists of F3, F4, and F5; HD4 is equivalent to F6.

One hundred and fifty one sample locations were identified on this outcrop, as shown in Figure 4.4. Of these, 142 air-permeameter measurements were obtained. All nonmeasurements were due to the presence of clay balls.

A histogram of the SS1 data indicated a skewed right distribution. After performing a natural logarithm transform of the original data, the logarithmic data appear to be normally distributed (Figure 4.5). Statistics of the transformed data are presented in Tabie 4.1.

The hypothesis that the hydrogeologic facies divisions represent different populations with different means is evaluated with the Student's t-test. The t-values of possible combinations are shown in Table 4.2, indicating that there is no statistically significant difference between $\mathrm{HD} 2$ and HD3, but the hypothesis that HD1 has the same mean permeability as HD2 and HD3 is rejected. HD4, with a sample size of 4, is not large enough to compare to the other hydro-facies, and was not considered in the analyses which follow. 


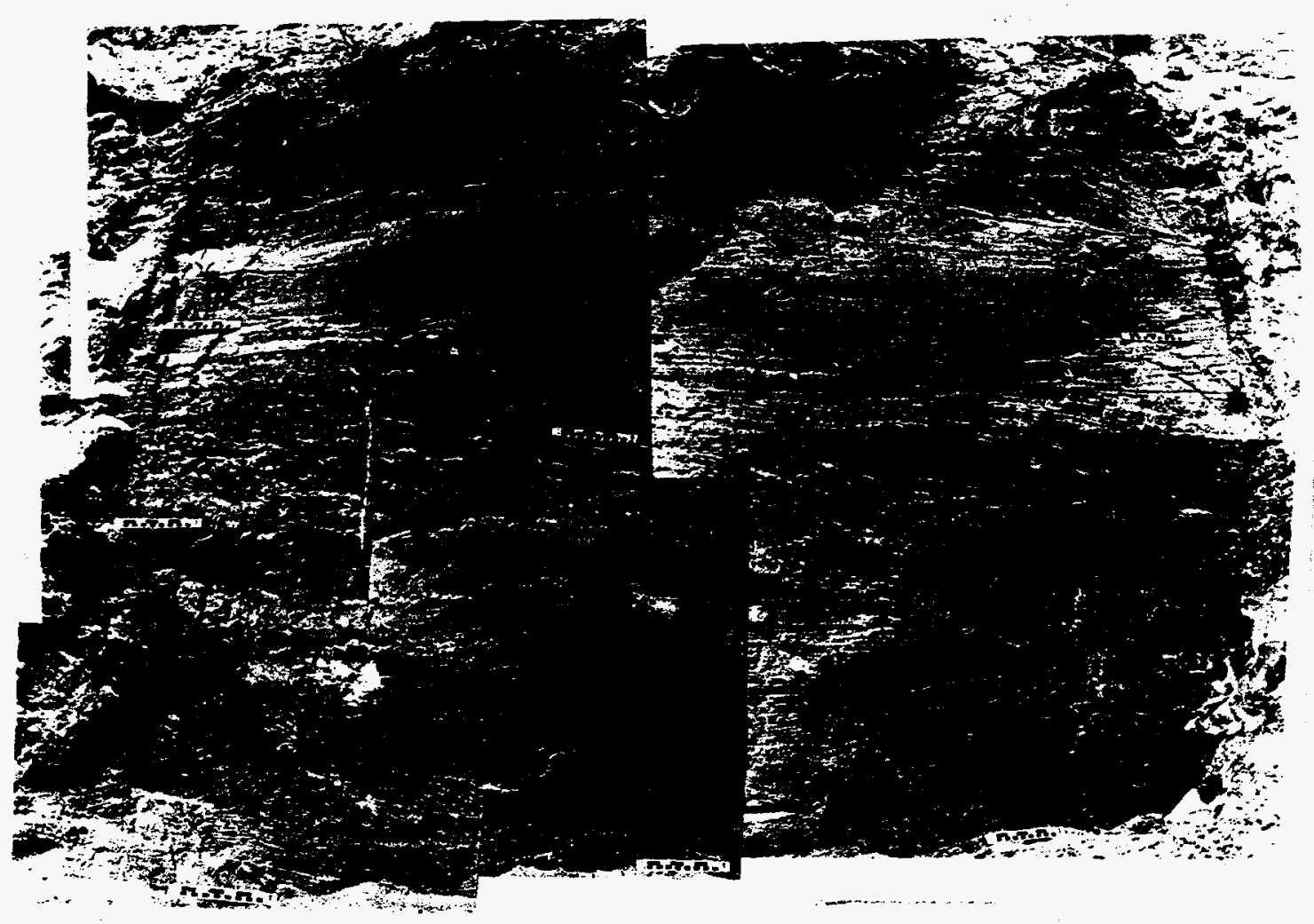

Pigure 4-3a. Photograph of SS-1 study area.

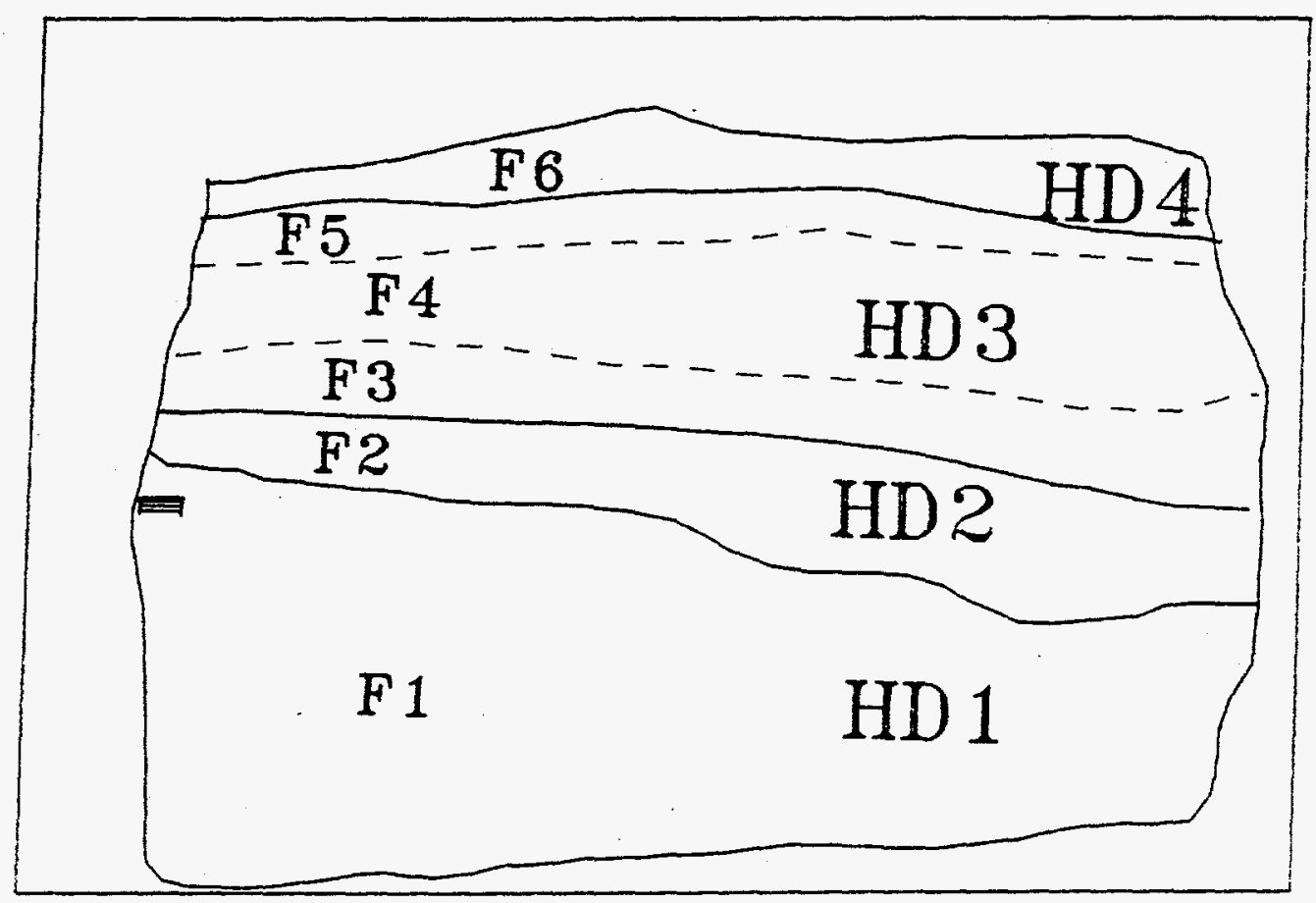

Figure 4-3b. Map of SS-1 study area. Dashed lines show divisions of facies located within each hydrofacies.scale bar equals $15 \mathrm{~cm}$. 
Table 4.1. Statistics of SS1 and SS1 Hydrofacies

\begin{tabular}{ccccc}
\hline & SS1 & HD1 & HD2 & HD3 \\
\hline $\mathbf{N}$ & 142 & 61 & 19 & 59 \\
\hline mean & 3.0 & 2.7 & 3.3 & 3.1 \\
\hline variance & 0.2 & 0.2 & 0.12 & 0.1 \\
\hline
\end{tabular}

Table 4.2. Results of Student's t-test

\begin{tabular}{ccc}
\hline \hline $\mathrm{df} / \mathrm{t}_{\text {criticas }} / \mathrm{t}_{\text {obsained }}$ & HD2 & HD3 \\
\hline HD1 & $78 / 1.99 / 5.02$ & $118 / 1.98 / 5.90$ \\
\hline HD2 & -- & $76 / 2.00 / 1.84$ \\
\hline
\end{tabular}

Structural analysis via directional variogram estimation was also performed on the logarithmic data set. The sample size of $\mathrm{HD} 2$ was not large enough for variogram estimation. Experimental horizontal variograms of $\mathrm{HD} 1$ and $\mathrm{HD} 3$ were calculated, and each displayed a range of approximately 70 centimeters. The horizontal variogram estimate of the entire SS1 data set is presented in Figure 4.6a, and is fit with an exponential model with a nugget of 0.04 , sill of 0.18 and a range of 90 centimeters:

$$
\gamma_{h}(\xi)=.04+.14[1-\exp (-|\xi| / 30)]
$$

The vertical variogram estimate of SS1 is shown in Figure 4.6b, fitted with an exponential model:

$$
\gamma_{v}(\xi)=.08+.11[1-\exp (-\mid \xi V / 18.33)]
$$

The range in the vertical direction, 55 centimeters, is close to the average vertical thickness of the observable hydrogeologic facies, 53 centimeters.

Small-Scale Study 2 (SS2)

The location referred to here as SS2 is about twenty meters above and to the east of the location of SS1. The prepared outcrop is approximately 1.5 meters high and 1.5 meters 


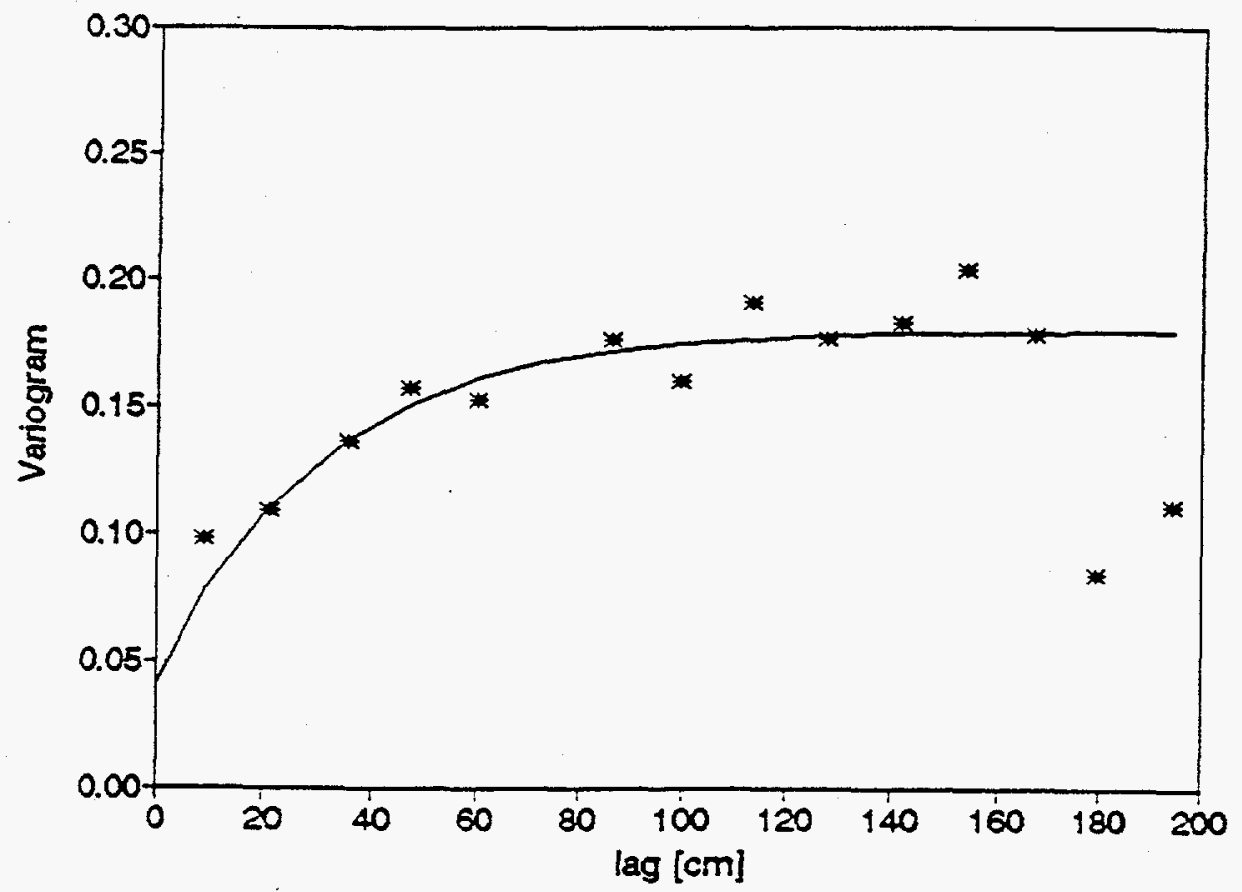

Figure 4-6a. Fitted horizontal variogram of logarithmic SS-I air-permeability data. Model sill=.18, range=90, nugget $=.04$.

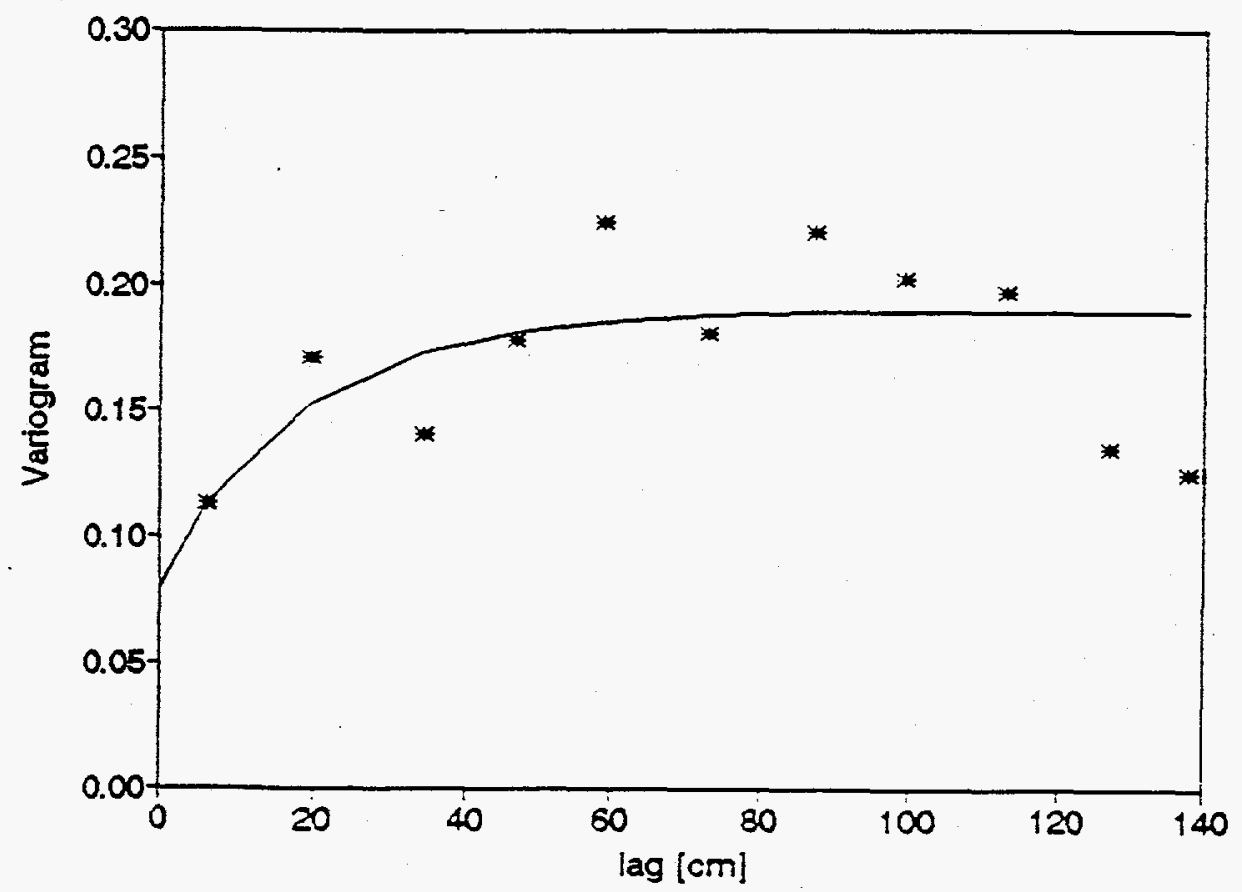

Figure 4-6b. Fitted vertical variogram of logarithmic $s s-1$ air-permeability data. Model sill=.19, range=55, nugget $=.08$. 


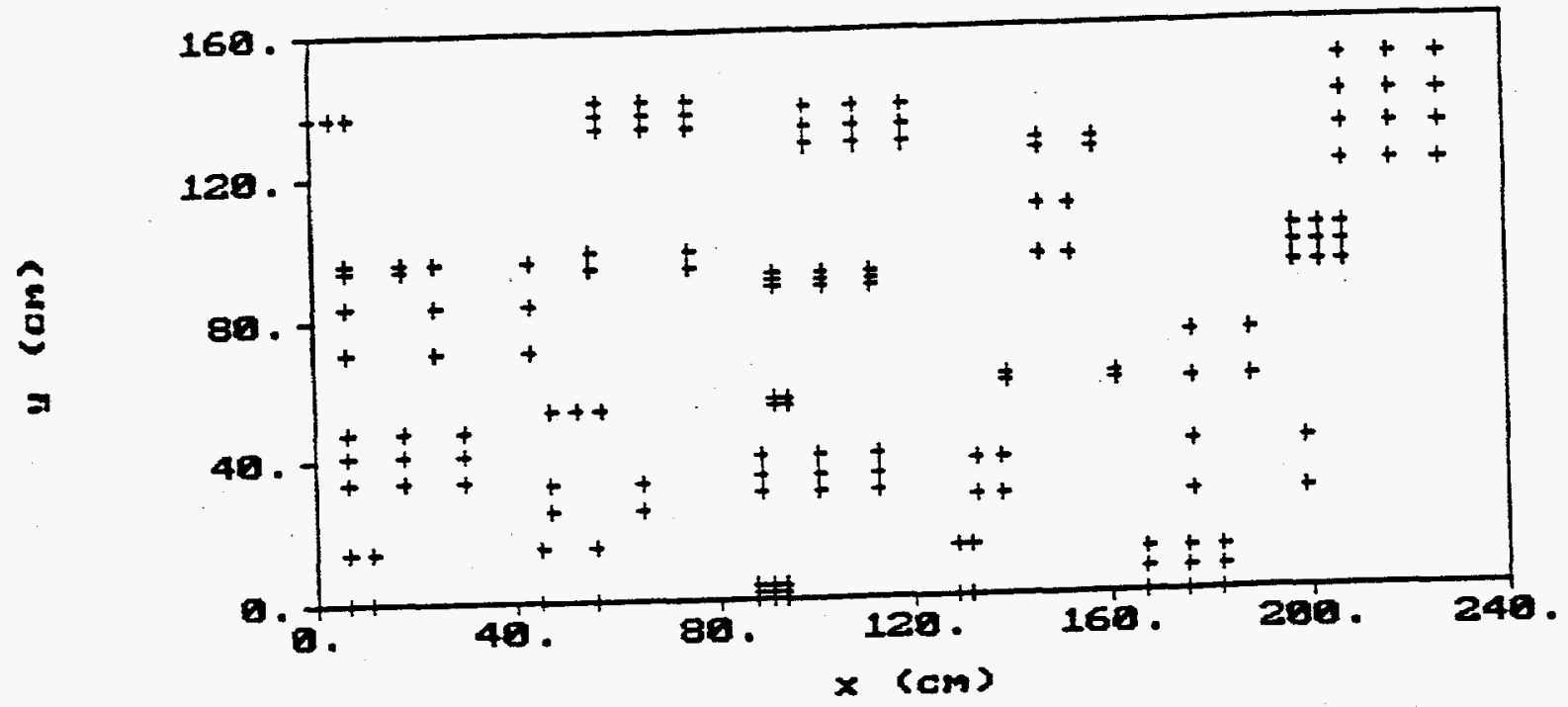

Figure 4-4. Distribution of 151 air-permeability sample locations in SS-1 study area.

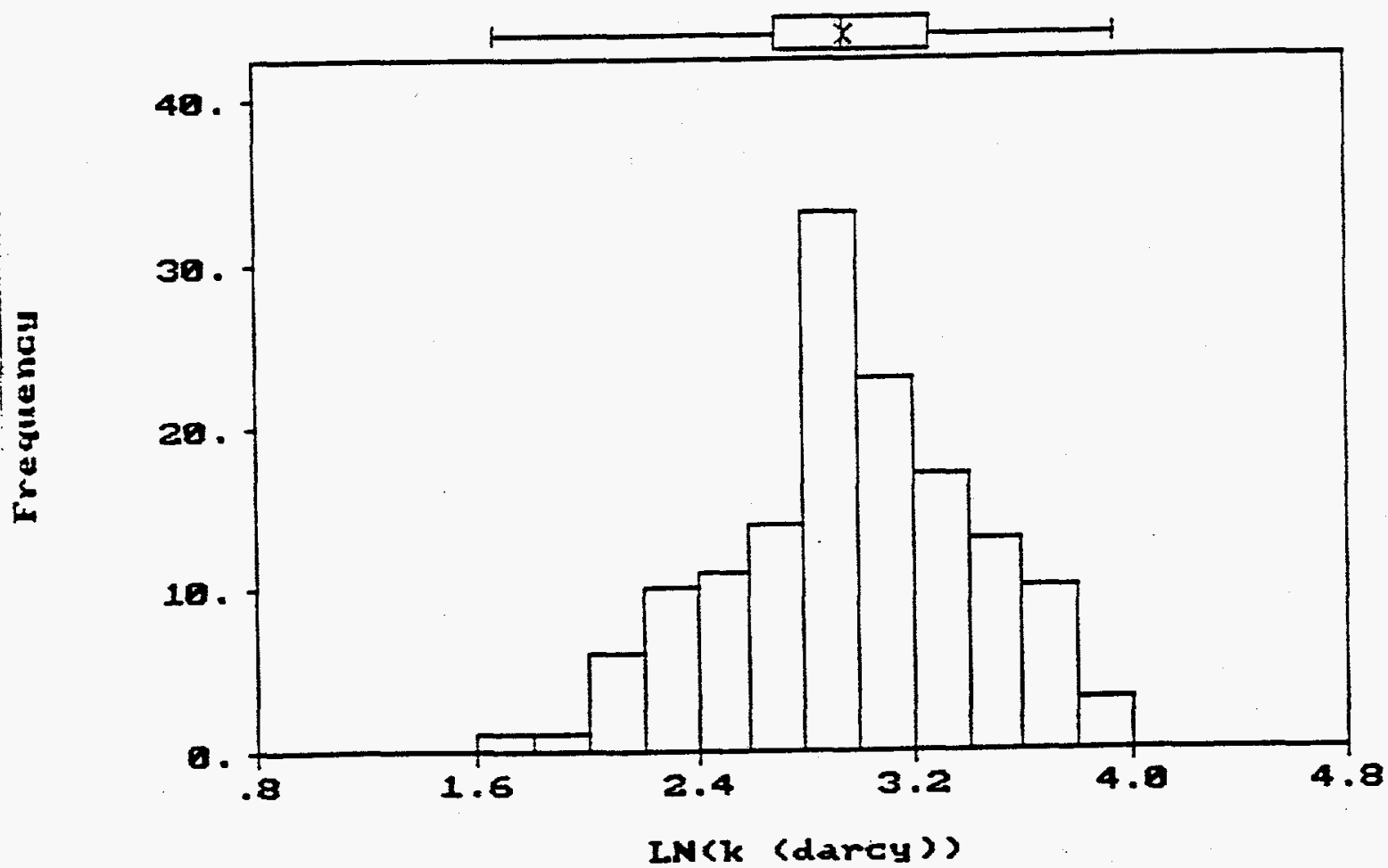

Figure 4-5. Histogram of natural logarithm transform of $S S-1$ air-permeability data. 
wide, as shown in Figure 4.7a. SS2 is within the same architectural element as SS1, CHII, and appears similar to SS1 in the predominance of medium and fine sands and low-angle to planar cross-bedding throughout the outcrop.

Six facies were identified within SS2, as shown in Figure 4.7b. F1 is approximately 0.4 meters high and consists of low angle, cross-laminated sand. The laminae are 2 to 4 millimeters thick, alternating between bands of lower-coarse and lower-fine sands.

F2 is approximately 0.1 meters high. Grain size is upper-medium, and the bedding is inclined to the east. F3 is approximately 0.4 meters high and is similar to F1. However, F3 contains volumetrically more of the finer sand than F1. F4 is about 0.3 meters high and is dominated by coarse sand interbedded with thinly laminated fine sand. F5 is a coarse sand scour fill, about 0.2 meters high. F6 consists of bedded coarse and medium sand about 0.15 meters high.

These facies were grouped into hydrofacies as follows: HD1 consists of F1 and F2; HD2 consists of F3; HD3 consists of F4; F5 and F6 together make up HD4.

One hundred and thirty sample locations were identified on this outcrop (Figure 4.8). Of these, 128 air-permeameter measurements were obtained. One non-measurements was due to a calcite nodule, the other to a hole in the outcrop.

A histogram of the SS2 data indicated a skewed right distribution. After performing a natural logarithm transform of the original data, the data appear to be normally distributed (Figure 4.9). Statistics of the transformed data are presented in Table 4.3.

Results of the Student's t-test for independent samples are shown in Table 4.4. There is no statistically significant difference between HD2 and HD3, but the hypothesis that the other possible combinations of facies have the same mean permeability is rejected.

Structural analysis via directional variogram estimation was performed on the logarithmic data set. Sample size of each hydrofacies was too small for variogram 


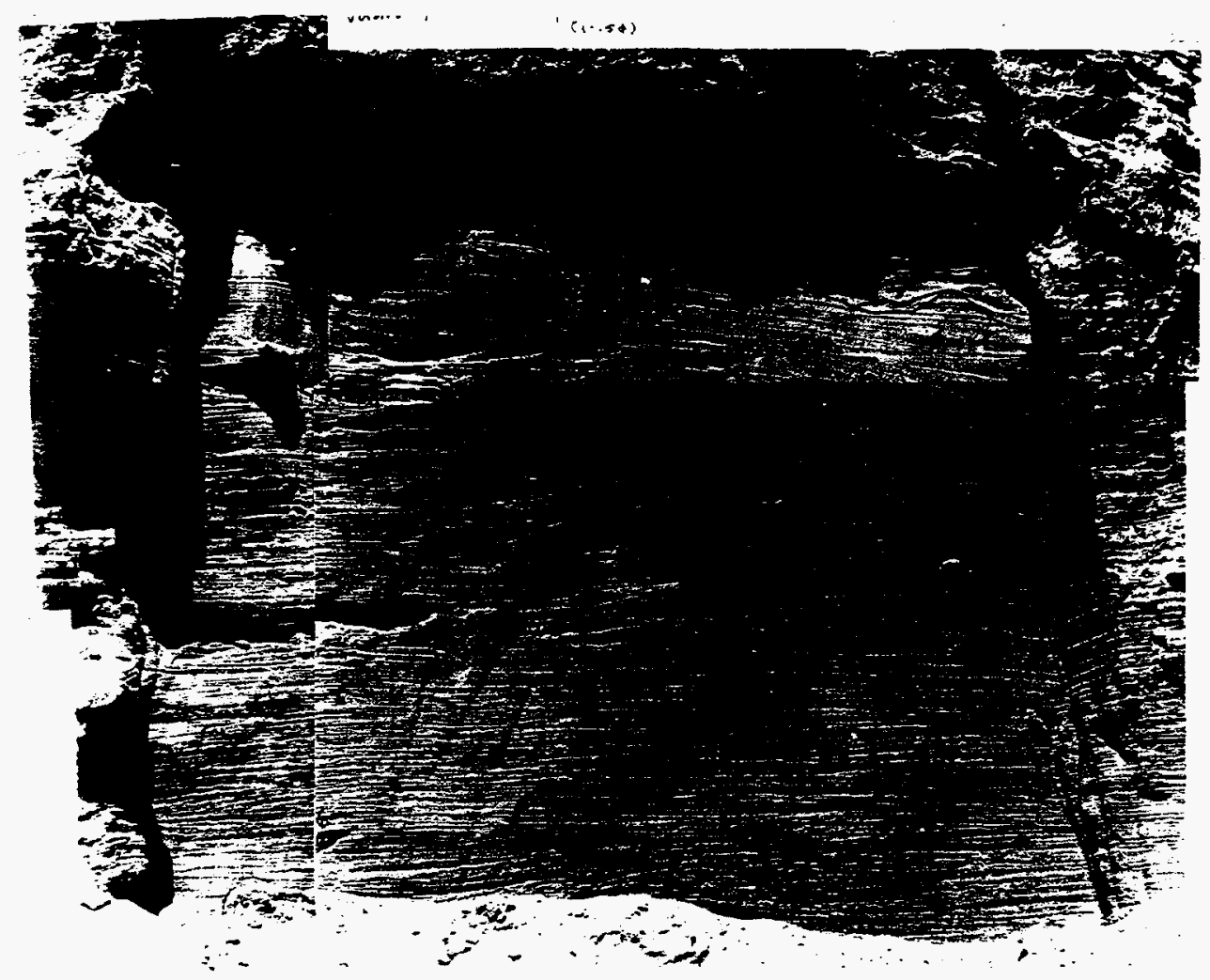

Figure 4-7a. Photograph of SS-2 study area.

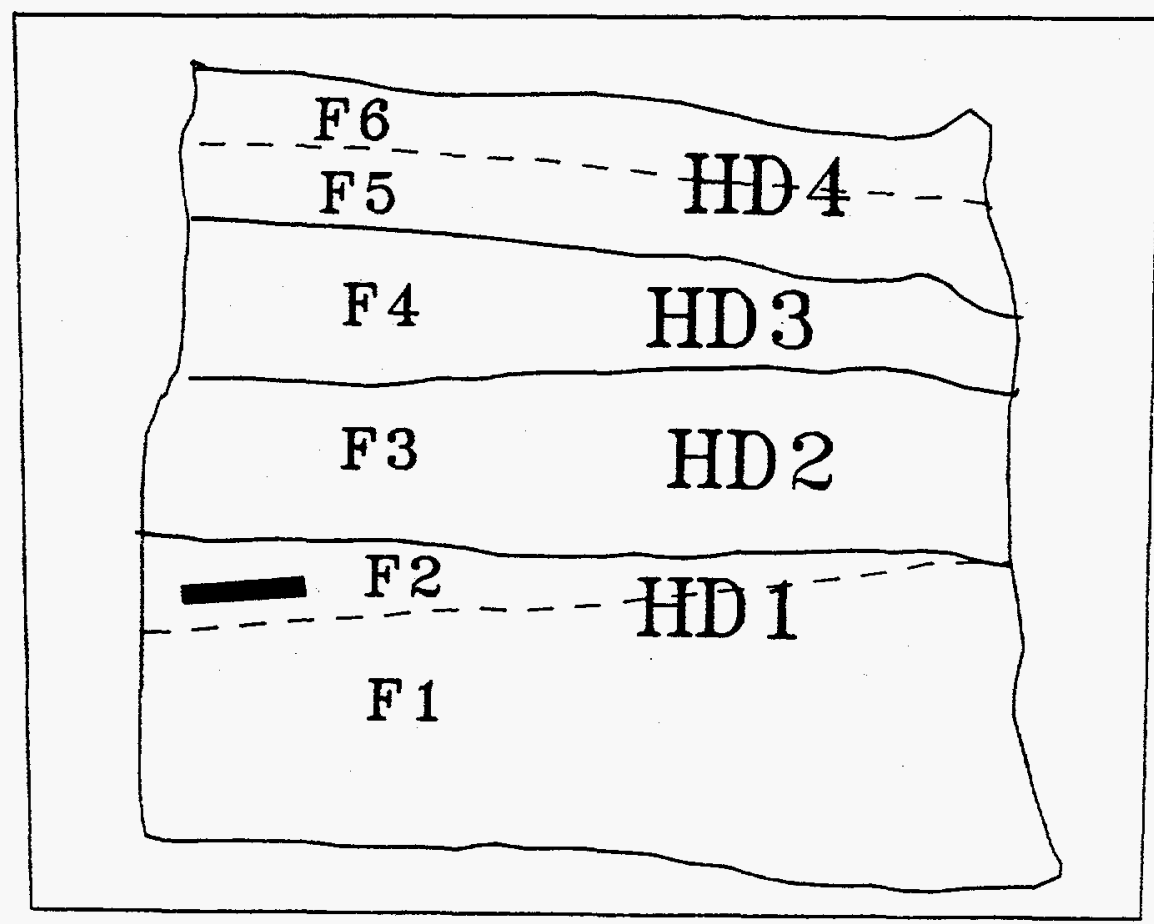

Figure 4-7b. Map of Ss-2 study area. Dashed lines show divisions of facies located within each hydrofacies.scale bar equals $30 \mathrm{~cm}$. 


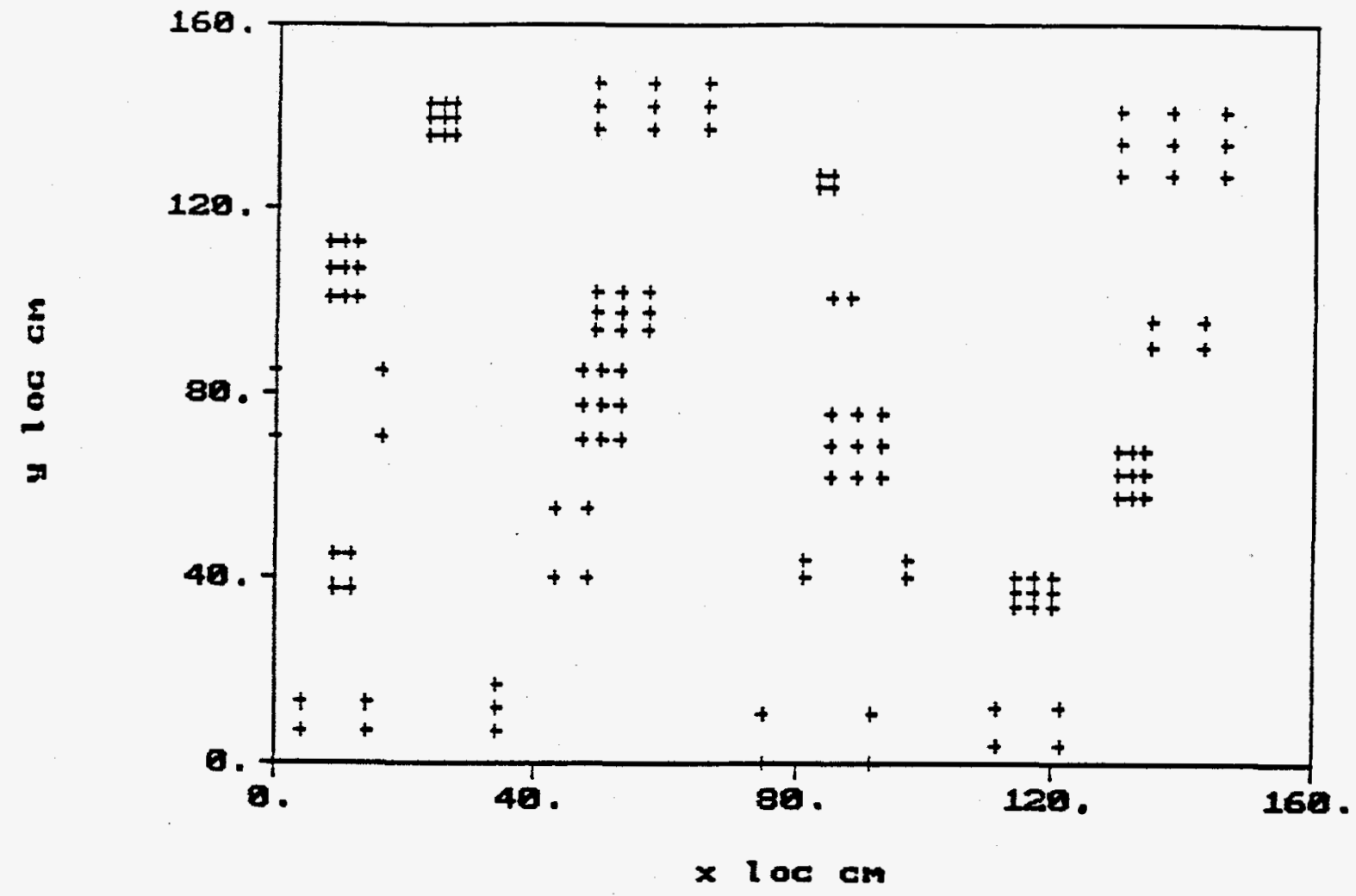

Figure 4-8. Distribution of 130 air-permeability sample locations in SS-2 study area.

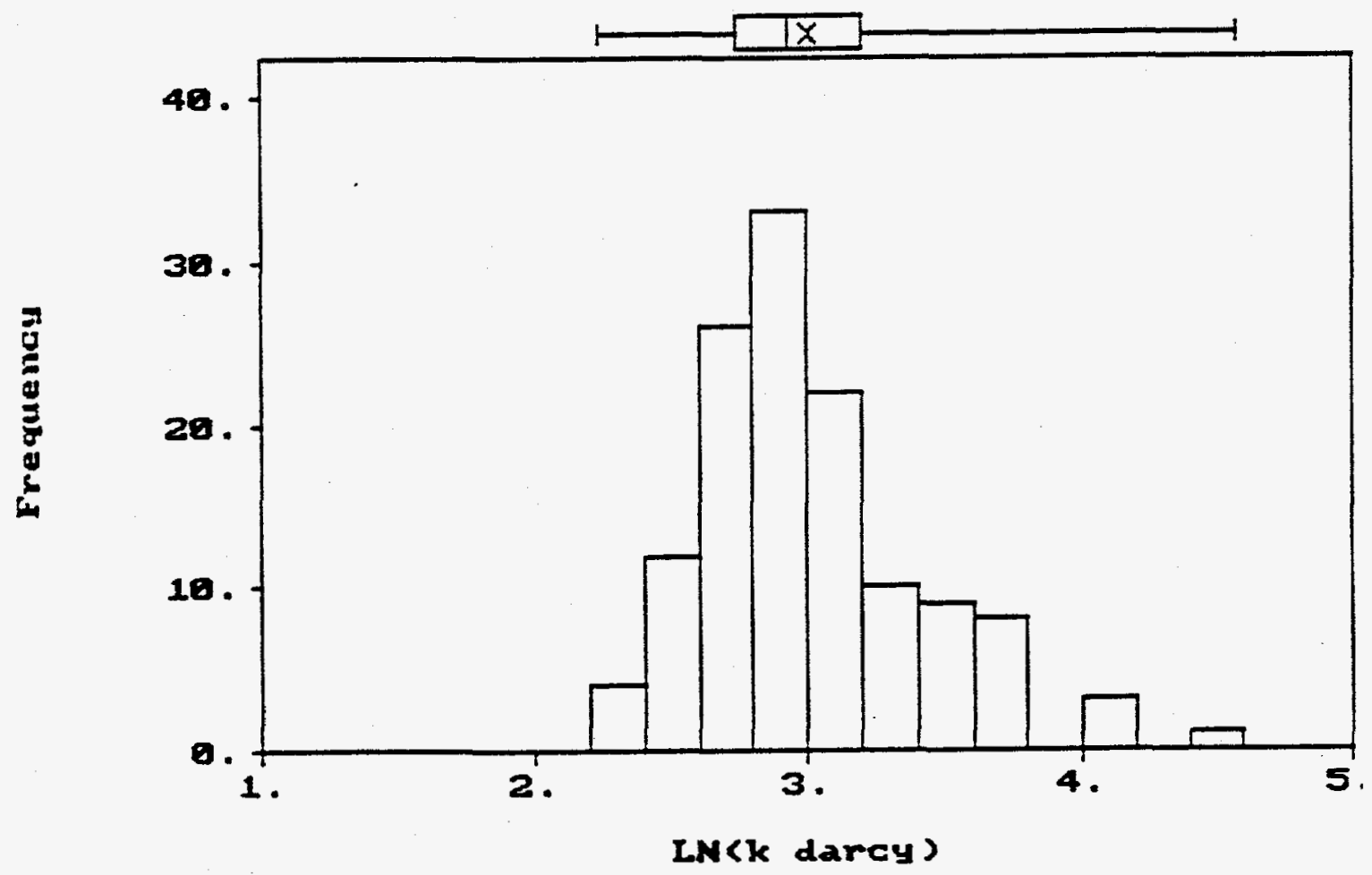

Figure 4-9. Histogram of natural logarithm transform of SS-2 air-permeability data. 
Table 4.3. Statistics of SS2 and SS2 Hydrofacies

\begin{tabular}{cccccc}
\hline \hline & SS2 & HD1 & HD2 & HD3 & HD4 \\
\hline $\mathrm{N}$ & 128 & 42 & 34 & 21 & 31 \\
\hline mean & 3.0 & 3.3 & 2.8 & 2.8 & 3.0 \\
\hline variance & 0.2 & 0.5 & 0.3 & 0.2 & 0.3 \\
\hline
\end{tabular}

Table 4.4. Results of Student's t-test for SS-2 hydrofacies.

\begin{tabular}{cccc}
\hline \hline $\mathrm{df} / \mathrm{t}_{\text {critical }} / \mathrm{t}_{\text {obained }}$ & HD2 & HD3 & HD4 \\
\hline HD1 & $74 / 2.00 / 5.05$ & $61 / 2.00 / 4.45$ & $71 / 2.00 / 2.33$ \\
\hline HD2 & -- & $53 / 2.01 / 0.32$ & $63 / 2.00 / 3.29$ \\
\hline HD3 & -- & -- & $50 / 2.00 / 3.35$ \\
\hline
\end{tabular}

estimation. The horizontal experimental variogram of the entire SS2 study area is shown in Figure 4.10a and is fitted with an exponential model:

$$
\gamma_{h}(\xi)=.04+.07[1-\exp (-\mid \xi V 15)]
$$

The vertical experimental variogram of the full SS2 study area is shown in Figure 4.10b. This is also fit with an exponential model:

$$
\gamma_{v}(\xi)=.04+.104[1-\exp (-1 \xi V 10)]
$$

The experimental vertical variogram departs from the fitted model at lag distances greater than 60 centimeters, and the experimental horizontal variogram departs from the fitted model at lag distances greater than 80 centimeters. However, in both cases the exponential model fits the observed permeability distribution up to about half the total distance over which measurements were taken. The range in the vertical direction, 30 centimeters, is close to the average vertical thickness of the observed hydrofacies, 40 centimeters (Figure $4.7 \mathrm{~b}$ ). 




Figure 4-10a. Fitted horizontal variogram of logarithmic Ss-2 air-permeability data. Model sill=.11, range=45, nugget=.04.

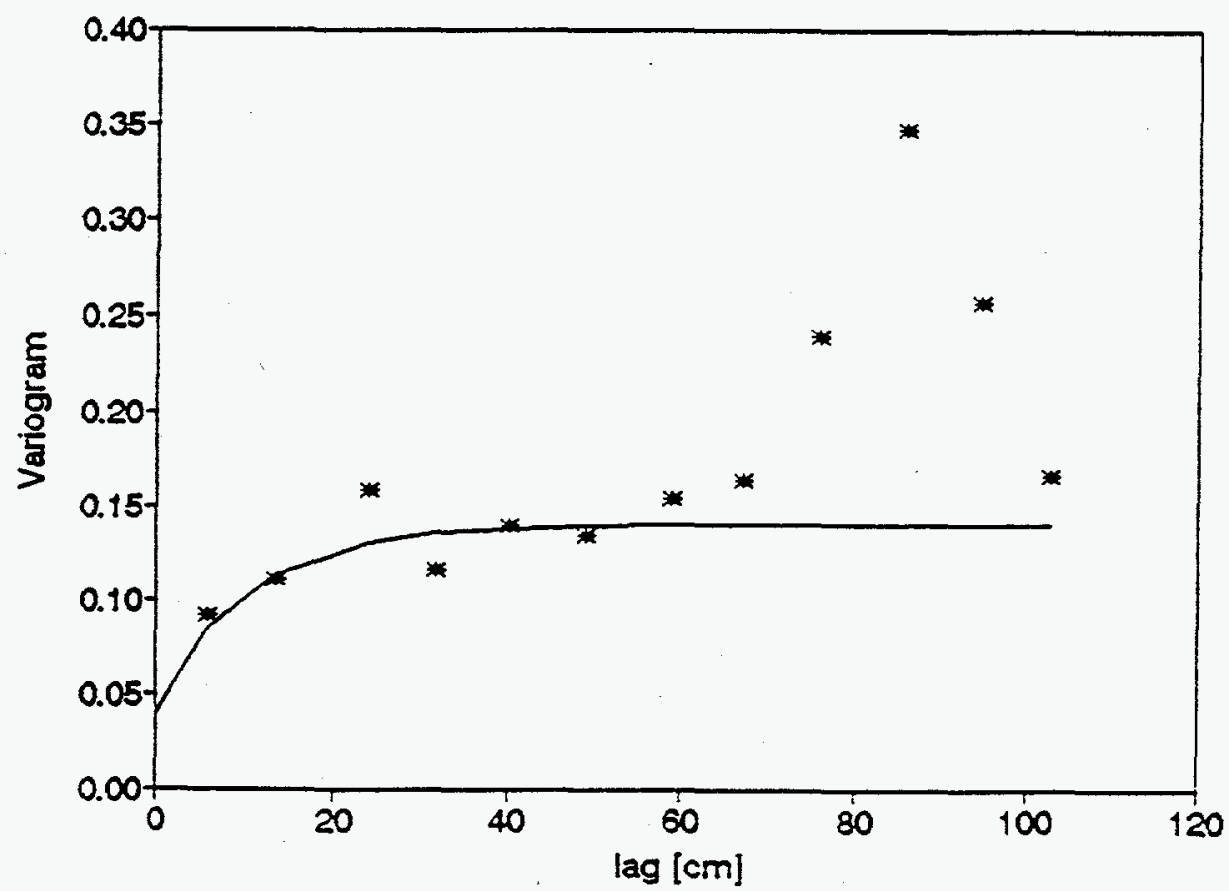

Figure 4-10b. Fitted vertical variogram of logarithmic ss-2 air-permeability data. Model sill=.14, range=30, nugget=.04. 
Small-Scale Study 3 (SS3)

The location referred to here as SS3 is situated across a small arroyo from SS1 and SS2. It is approximately one meter high and 2.5 meters wide (Figure 4.11a). This outcrop is within the CH-I element, but its appearance is very different than from SS1 and SS2. SS3 is characterized by three distinct layers. Grain size varies greatly between the layers, but within each layer both the grain size and style of cross-bedding are very homogenous. This deposit may represent some type of intermediate flow regime between a debris flow and a fluidized flow.

Three facies were identified on the outcrop, as shown in Figure 4.11b. The lower facies, F1, is approximately 0.25 meters high. It is a thickly laminated, planar bedding, lower-medium sand. The middle unit, F2, is approximately 0.2 meters high, with thickly laminated planar bedding. F2 is dominated by lower-very-coarse sand, but does include some poorly sorted lower-medium and upper-fine sands. Pebbles of about 5 millimeters in diameter are aiso present in the layer. The upper-most facies, F3, is very similar to F1. It is approximately 0.5 meter thick, and is made up of thickly laminated upper-fine sand, with some lower-coarse sand. One hundred and seventeen sample locations were identified on this outcrop (Figure 4.12). Of these, 112 air-permeameter measurements were obtained. All of the non-measurements were due to the presence of poorly consolidated, very coarse material.

A histogram of the SS3 data indicated a skewed right distribution (Figure 4.13). After performing a natural logarithm transform of the original data, the logarithmic data appear to be normally distributed (Figure 4.13). Statistics of the transformed data are presented in Table $\mathbf{4 . 5}$.

The Student's t-test showed that the hypothesis that F1 and F3 have the same mean permeability is rejected (Table 4.6). As such, further statistical analysis was carried out on the three facies, rather than combine $F 1$ and $F 3$ into a single hydrofacies. 


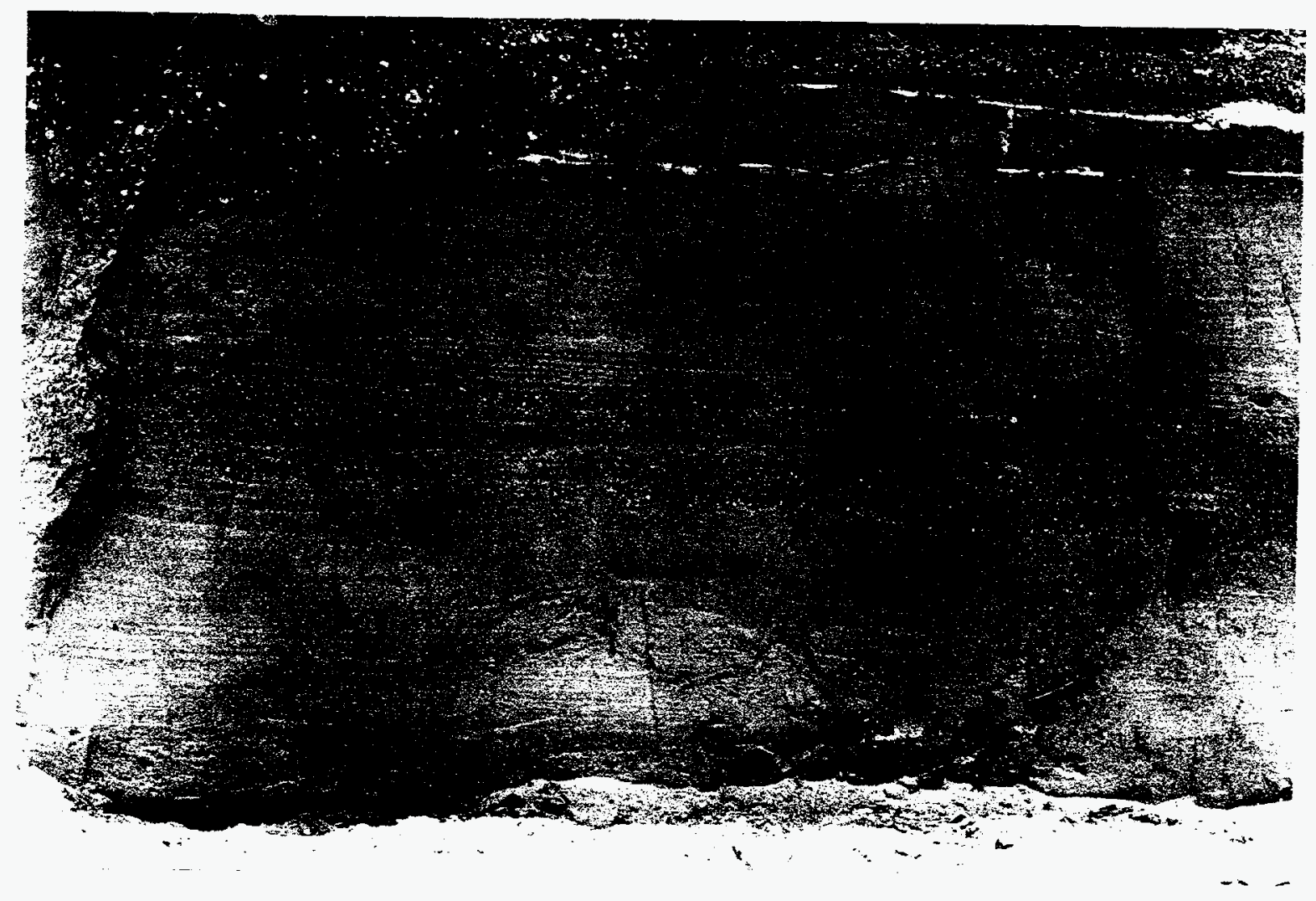

Figure 4-11a. Photograph of sS-3 study area.

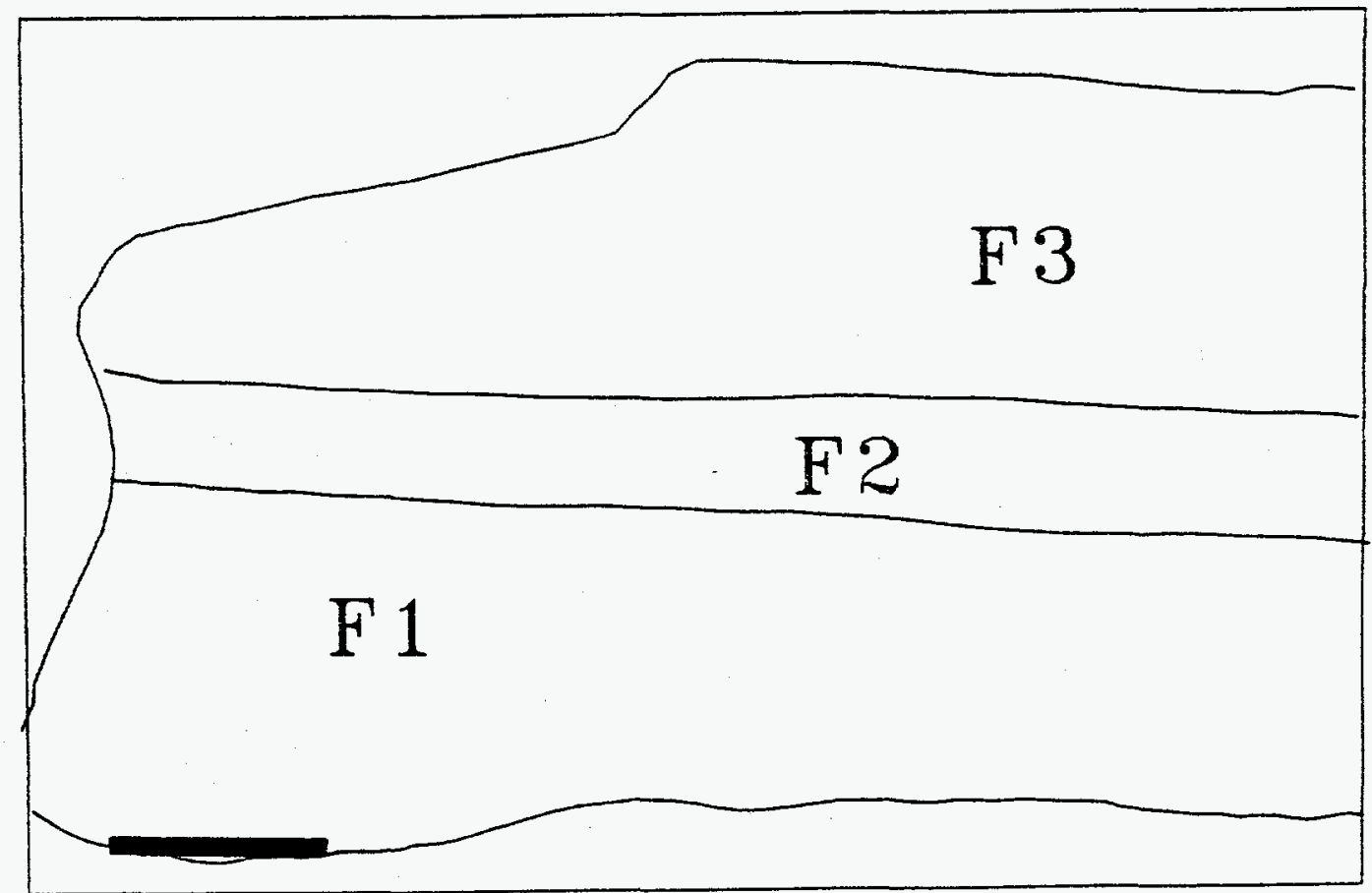

Figure 4-11b. Map of SS-3 study area. Facies identified in SS-3 were not grouped into larger hydrofacies. Scale bar equals $30 \mathrm{~cm}$. 


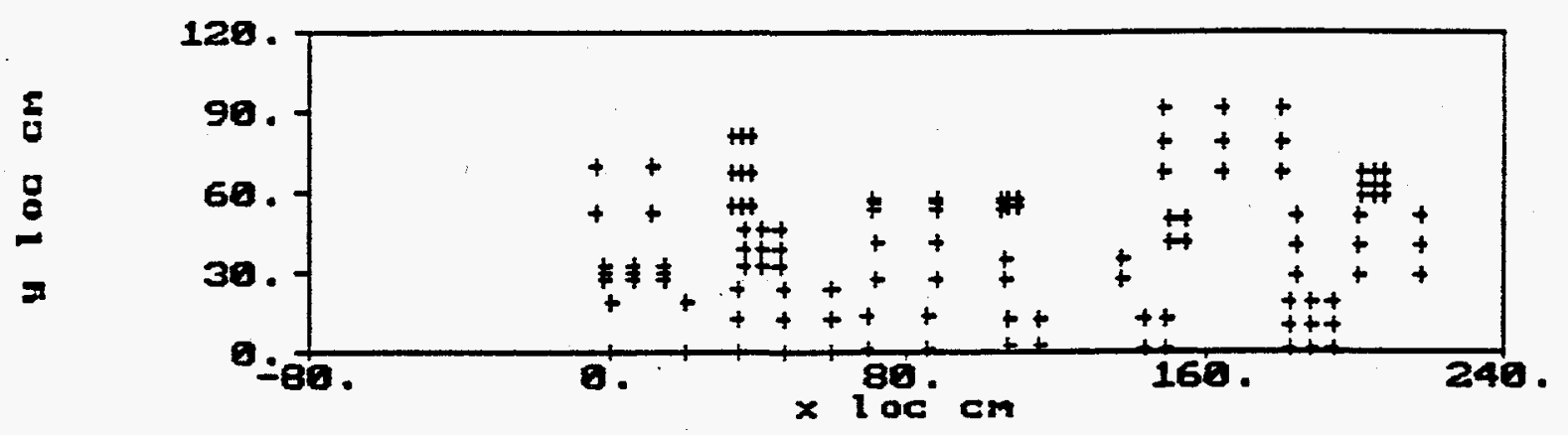

Figure 4-12. Distribution of 117 air-permeability sample locations in SS-3 study area.

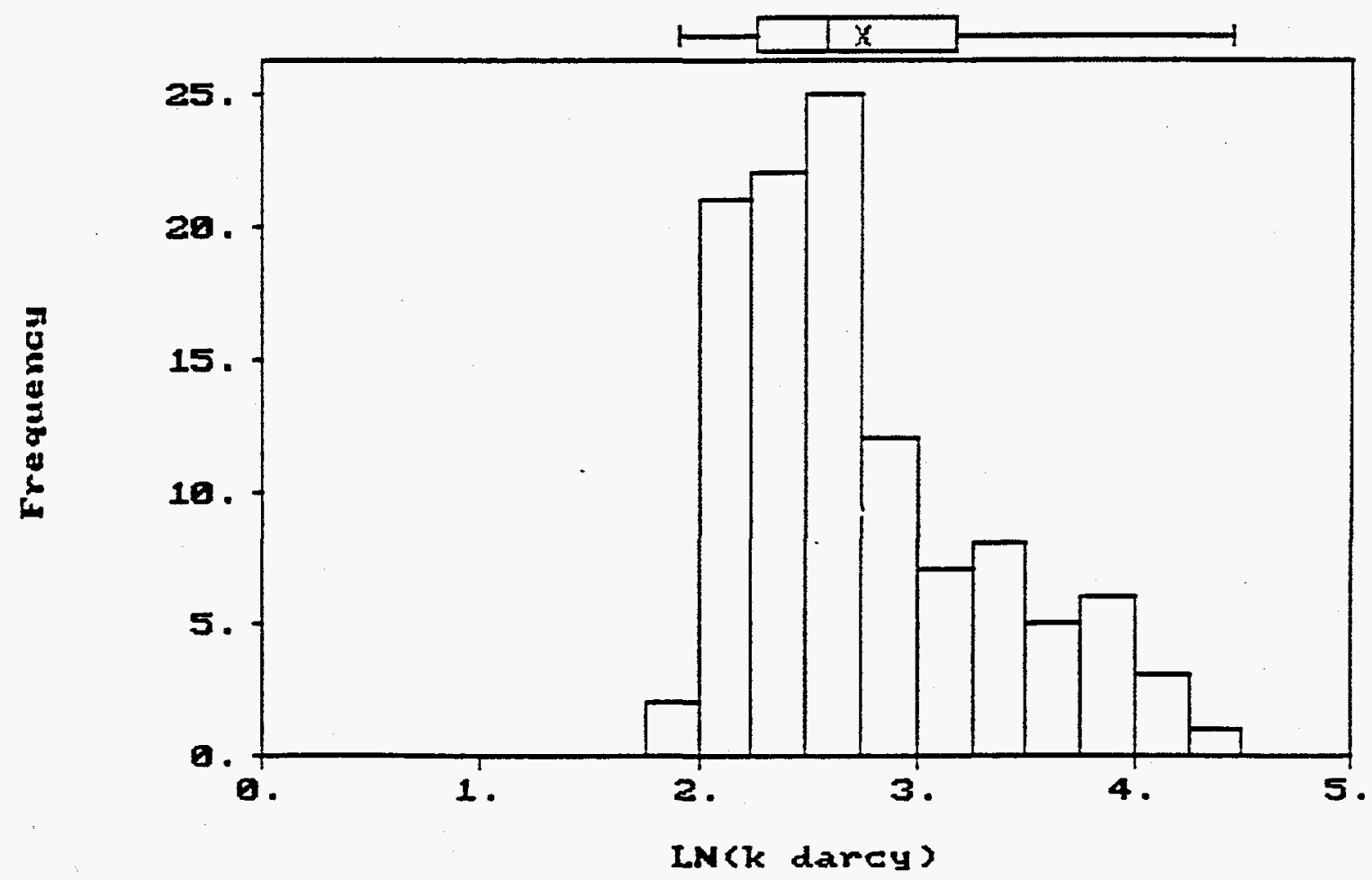

Figure 4-13. Histogram of natural logarithm transform of SS-3 air-permeability data. 
Table 4.5. Statistics of SS3 and SS3 facies.

\begin{tabular}{ccccc}
\hline & SS3 & F1 & $\overline{F 2}$ & F3 \\
\hline $\mathrm{N}$ & 109 & 27 & 32 & 50 \\
\hline mean & 2.8 & 2.5 & 3.5 & 2.4 \\
\hline variance & 0.4 & 0.1 & 0.2 & 0.1 \\
\hline
\end{tabular}

Table 4.6. Results of Student's t-test of SS3 facies.

\begin{tabular}{ccc}
\hline \hline $\mathrm{df} / \mathrm{t}_{\text {critical }} / \mathrm{t}_{\text {oximed }}$ & $\mathrm{F} 2$ & $\mathrm{~F} 3$ \\
\hline $\mathrm{F} 1$ & $57 / 2.00 / 9.27$ & $75 / 2.00 / 2.21$ \\
\hline $\mathrm{F} 2$ & --- & $80 / 2.00 / 15.27$ \\
\hline
\end{tabular}

Structural analysis via directional variogram estimation was also performed on the logarithmic data set. Omnidirectional variograms within each of the three facies were calculated and showed slight correlation, generally less than 20 centimeters. The horizontal experimental variogram of the entire SS3 data set is shown in Figure 4.14a, and is fit with an exponential model:

$$
\gamma_{h}(\xi)=.04+.12[1-\exp (-\mid \xi V 16.67)]
$$

The vertical experimental variogram of SS3 is shown in Figure 4.14b. This experimental variogram is of particular interest in that it reflects very clearly the vertical dimensions of the three facies. The variogram appears to reach a sill near lags of 30 to 40 centimeters, which is the distance where pairs of data from F1 and F2 and pairs from F2 and F3 would be considered most heavily. That is, it is the approximate thickness of the first layer. At a lag distance of about 45 centimeters, the experimental variogram decreases dramatically. This is the approximate thickness of F1 and F2 combined, and so reflects the decrease in variance found when data pairs from $F 1$ and $F 3$ are compared, and pairs from $F 1$ and $F 2$, and F2 and F3 are neglected. 


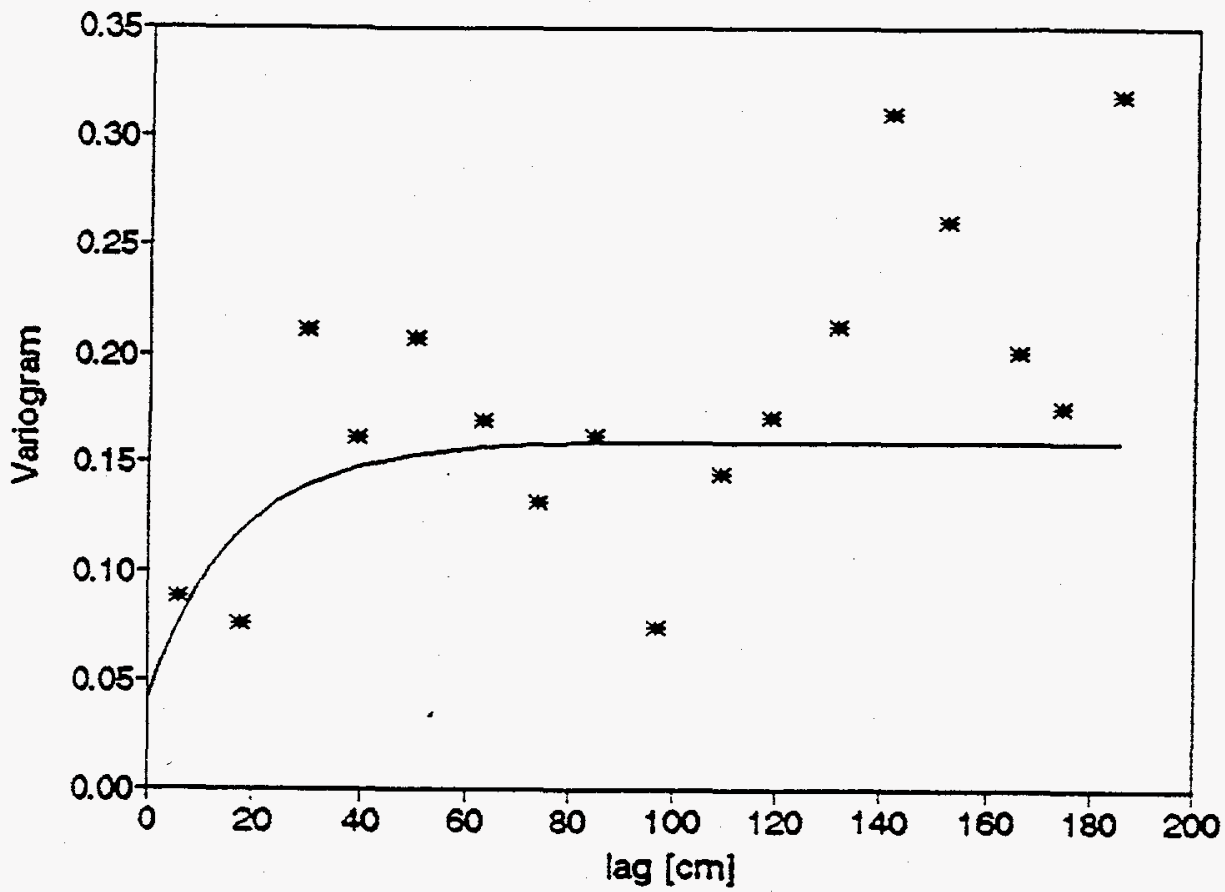

Figure 4-14a. Fitted horizontal variogram of logarithmic ss-3 air-permeability data. Model sill=.16, range=50, nugget=.04.

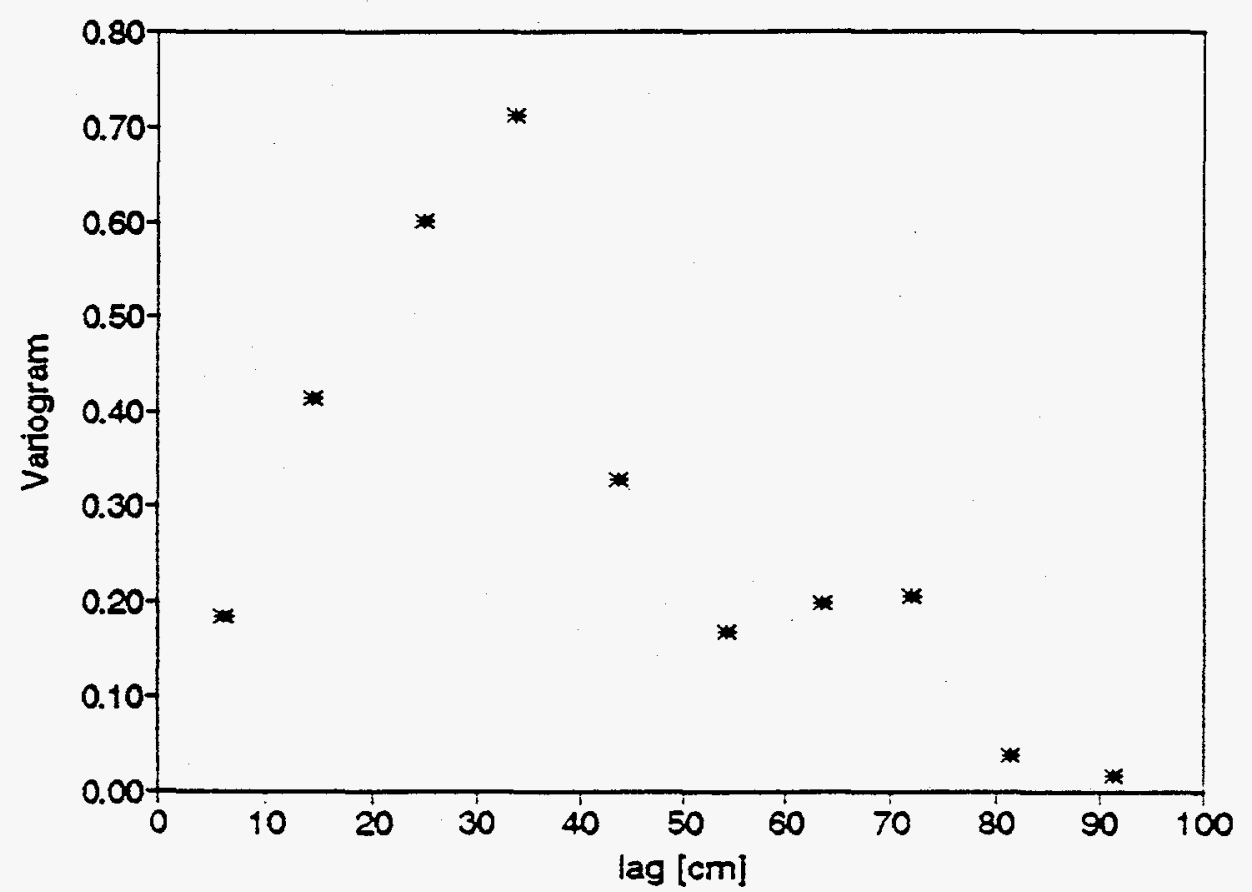

Figure 4-14b. Experimental vertical variogram of logarithmic SS-3 air-permeability data. 
Small-Scale Study 4 (SS4)

The location referred to here as SS4 is situated approximately 10 meters above SS2. The outcrop is 1.5 meters high and 2.4 meters wide (Figure 4.15). It consists of a homogeneous paleosol which appears to be structureless. There are calcite nodules ranging from three to ten centimeters in diameter scattered throughout a narrow band in the upper part of the outcrop. This outcrop occurs within architectural element $\mathbf{P}$, soils and stacked soils.

No facies were delineated within this outcrop. Grain size was very fine throughout the study area. Two hundred and sixteen sample locations were identified on this outcrop (Figure 4.16). Of these, 214 air-permeameter measurements were obtained.Two of the nonmeasurements were due to the presence of calcite nodules, the third fell on a fracture in the outcrop. The fracture is believed to be a result of surface exposure.

A histogram of the SS4 data indicated a skewed right distribution. After performing a natural logarithm transform of the original data, the logarithmic data appear to be normally distributed (Figure 4.17). Statistics of the transformed data appear in Table 4.7.

Table 4.7. Statistics of SS4

\begin{tabular}{cc}
\hline \hline $\mathrm{N}$ & 216 \\
\hline mean & 1.939 \\
\hline variance & 0.116 \\
\hline
\end{tabular}

The horizontal experimental variogram of the entire SS4 data set is shown in Figure 4.18a, and is fit with a linear model with a range of 15 centimeters:

$$
\begin{array}{ll}
\gamma(\xi)=.04+.0034|\xi| & \text { for } \xi<15 \mathrm{~cm} \\
\gamma(\xi)=.095 & \text { for } \xi>15 \mathrm{~cm}
\end{array}
$$




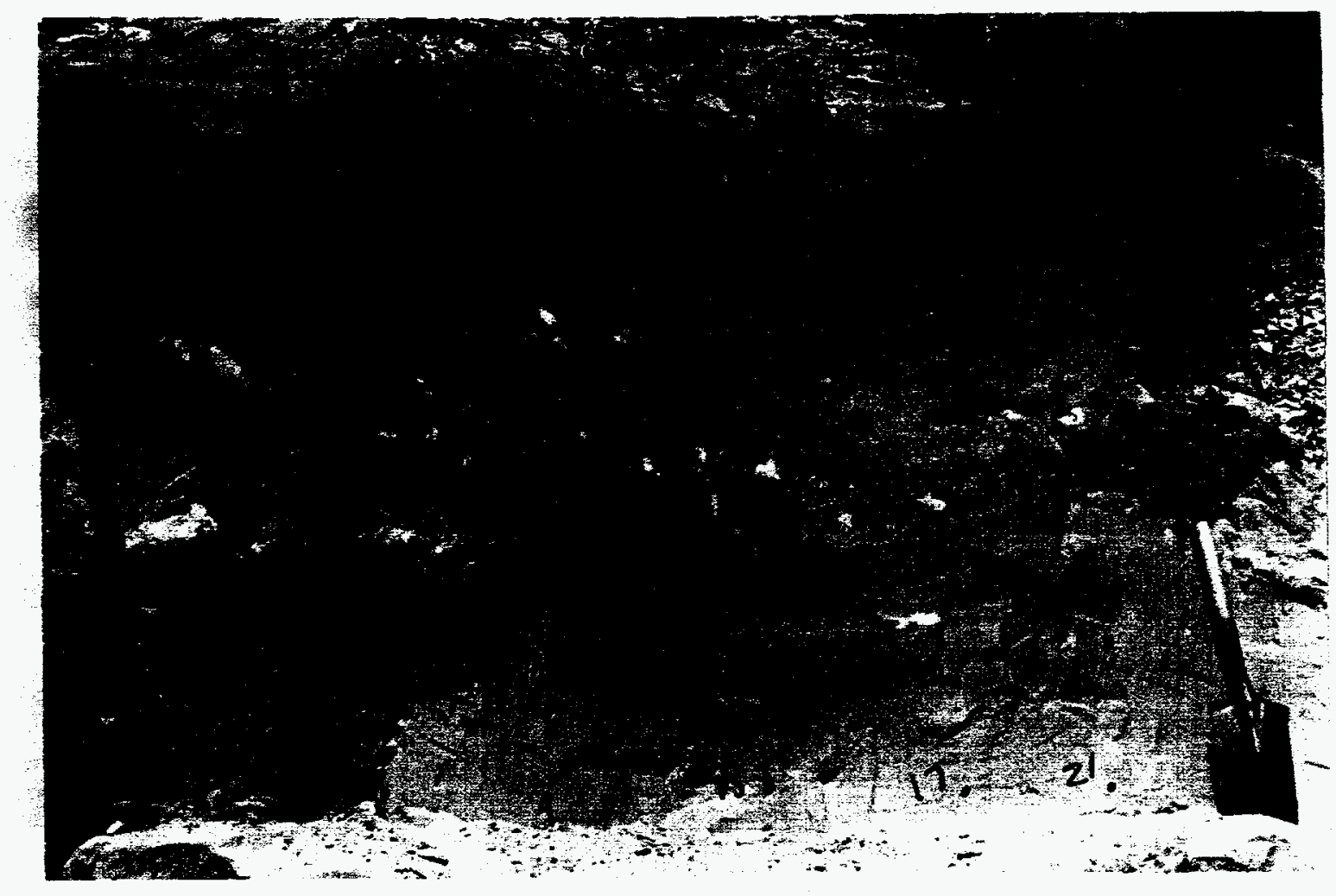

Figure 4-15. Photograph of ss-4 study area. As the soil appeared homogenous, no facies or hydrofacies were identified within ss-4. The shovel is 0.75 meters long. Numbers on the photograph represent control point locations. 


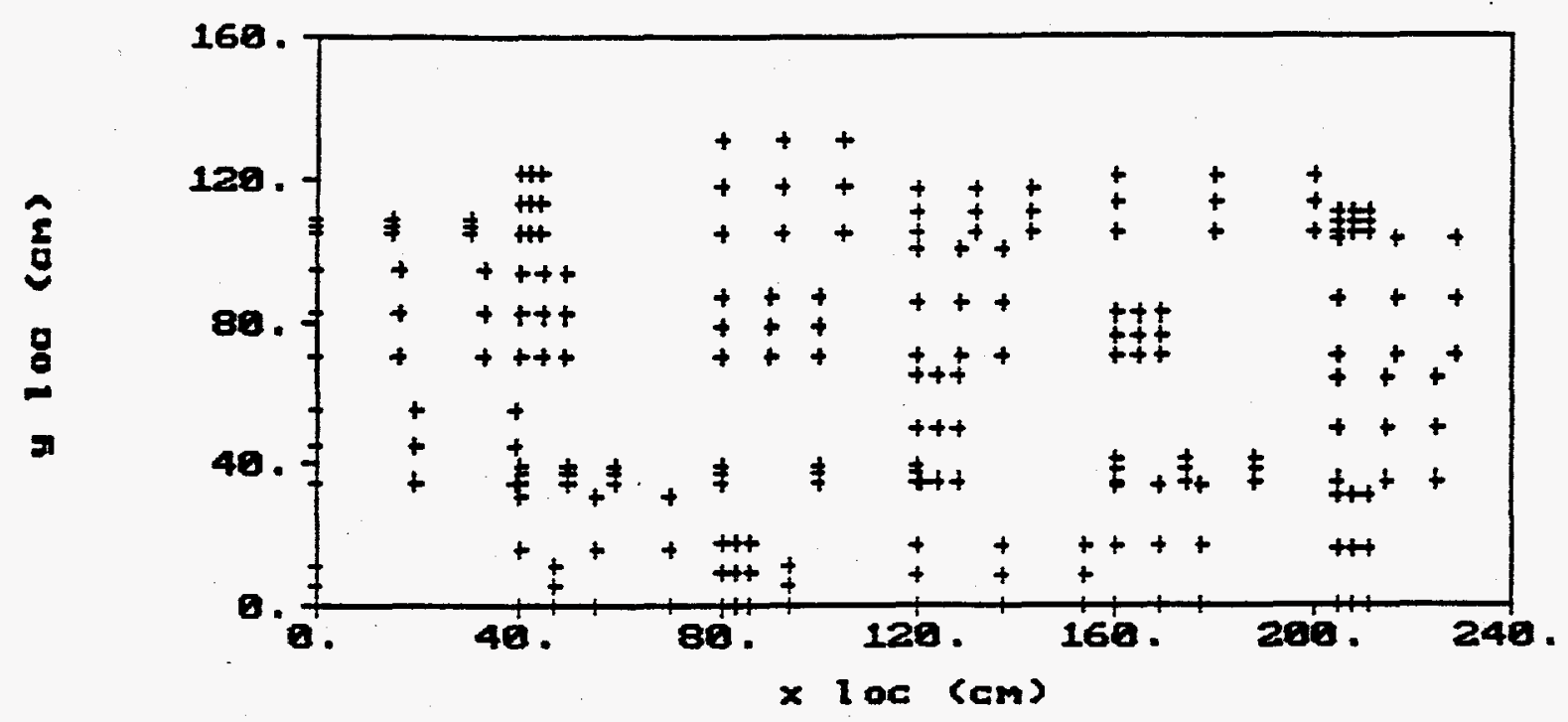

Figure 4-16. Distribution of 216 air-permeability sample locations in SS-4 study area.

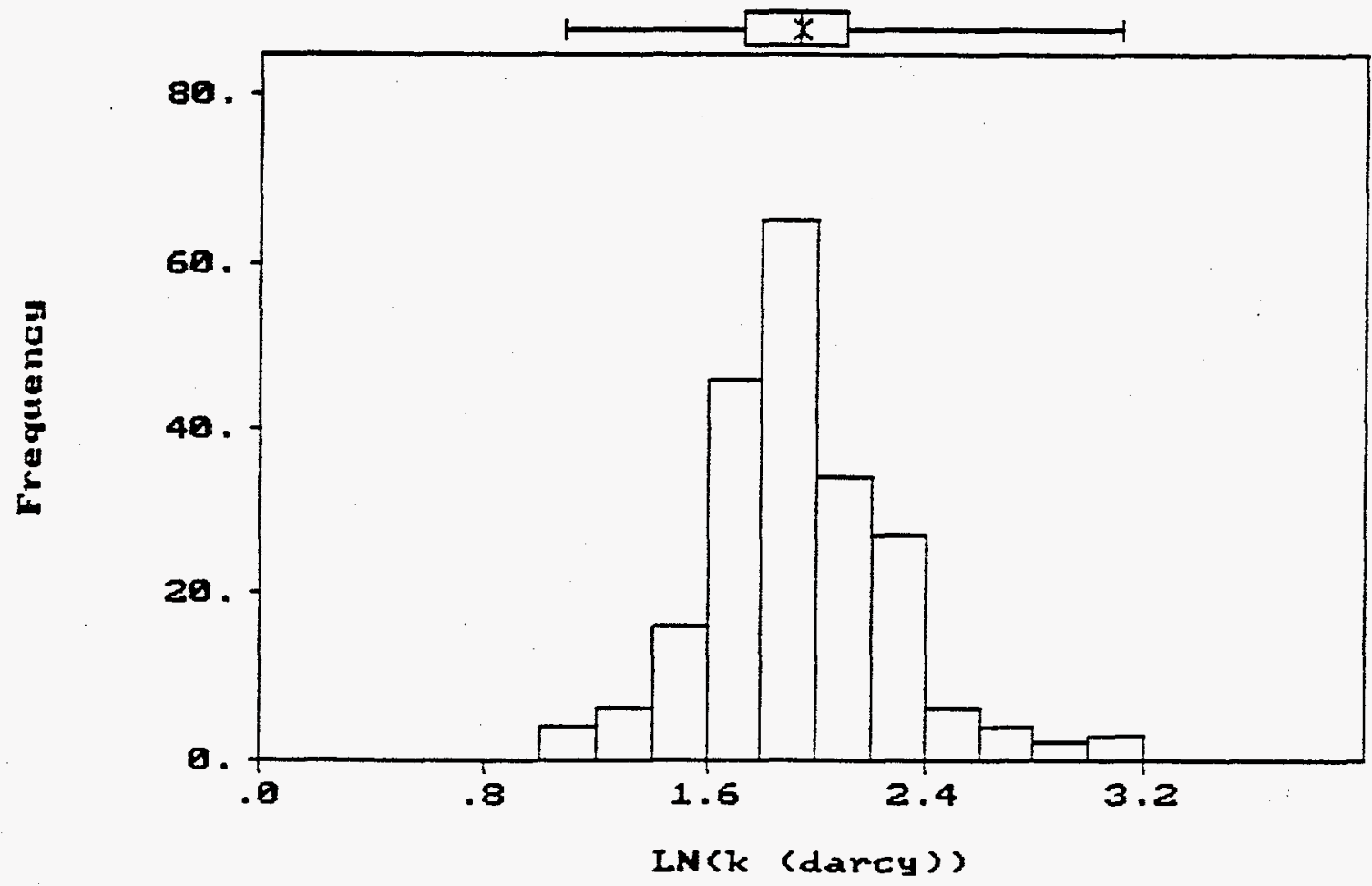

Pigure 4-17. Histogram of natural logarithm transforn of SS-4 air-permeability data. 


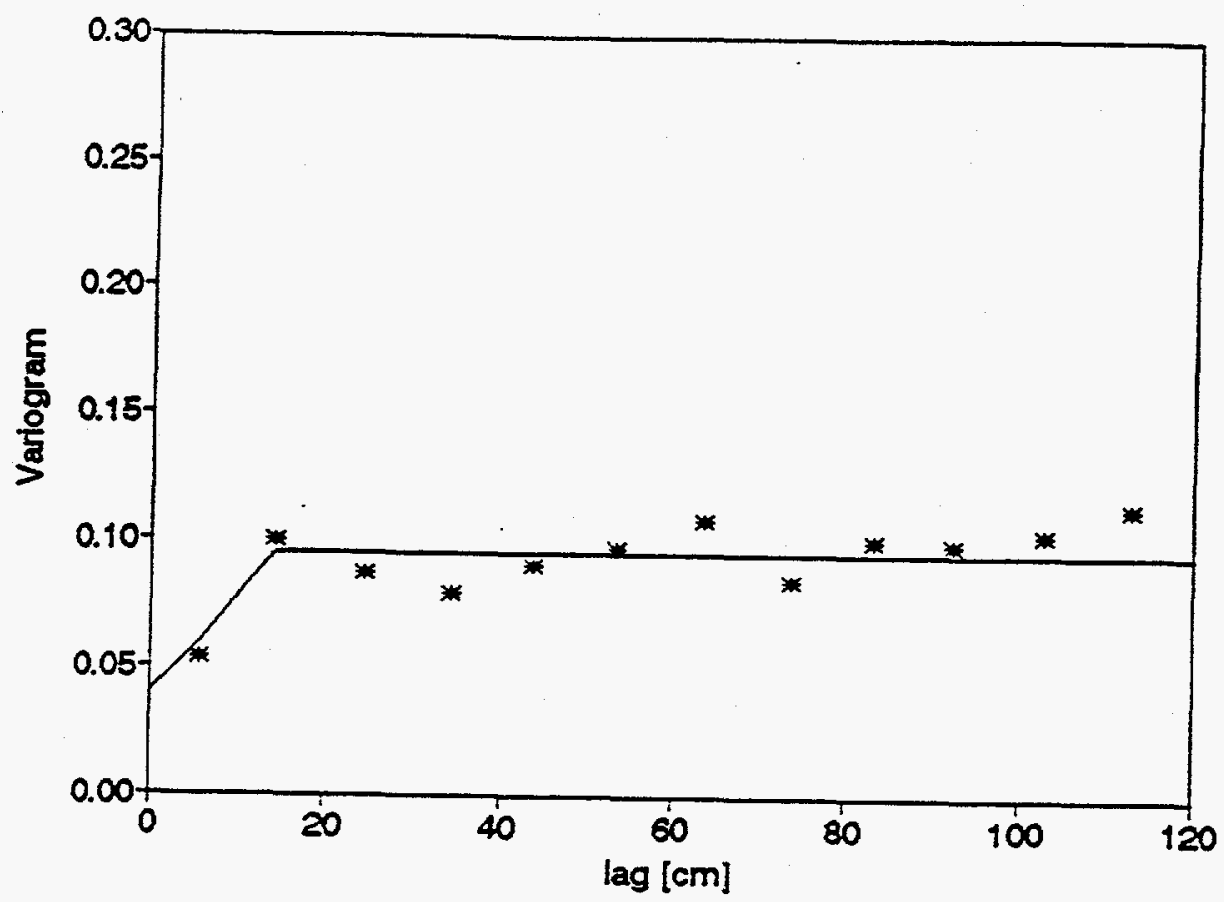

Figure 4-18a. Fitted horizontal variogram of logarithmic ss-4 air-permeability data. Model sill=.095, range=15, nugget $=.04$.

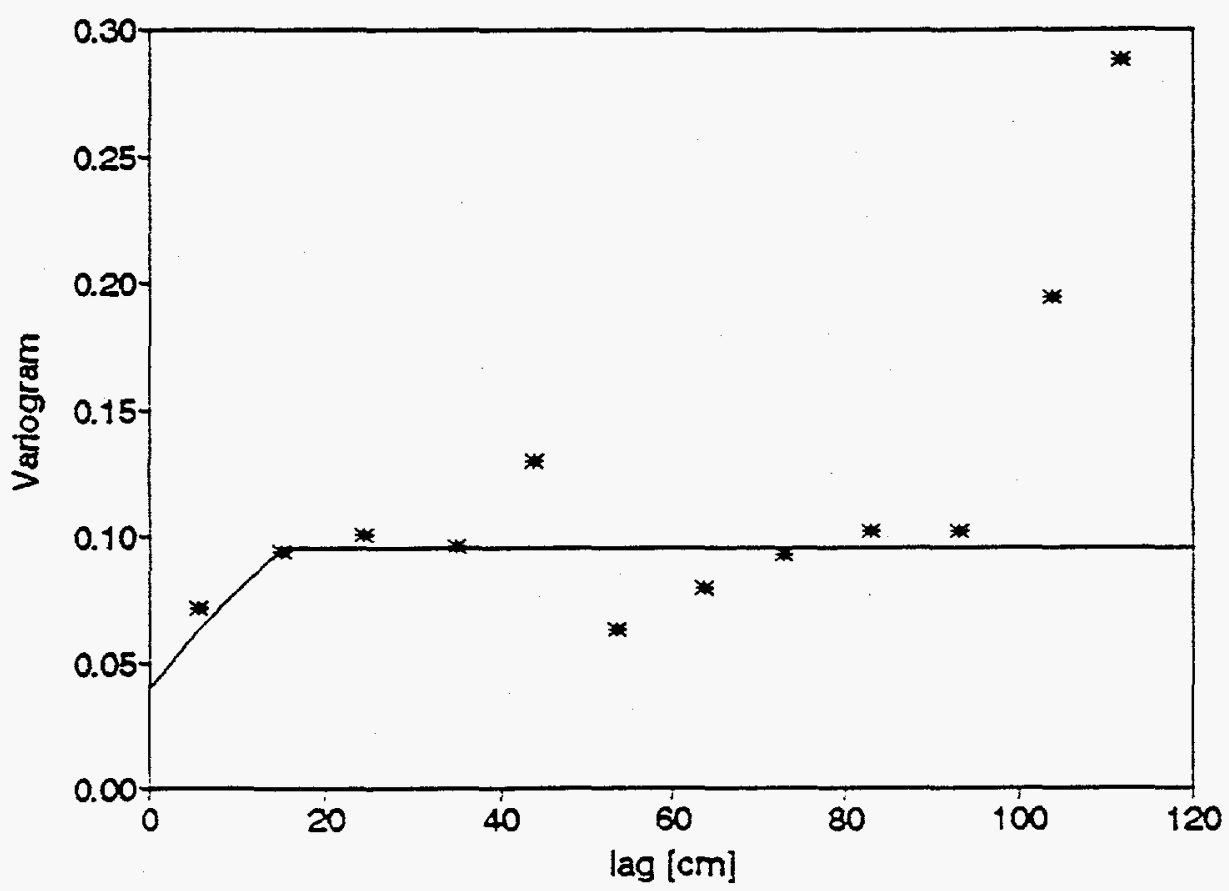

Figure 4-18b. Experimental vertical variogram of logarithmic SS-4 air-permeability data. Model sill=.095, range=15, nugget=.04. 
The experimental variogram appears largely uncorrelated, with a slight correlation apparent at lags less than 15 centimeters. The heterogeneity which does exist within this facies exists at a scale below the sampling interval. The pedogenesis has apparently destroyed all of the structure which was present in the unit before diagenetic alteration took place.

This observation is confirmed by examination of the vertical experimental variogram of the SS4 outcrop, which is presented in Figure $4.18 \mathrm{~b}$, modeled with a linear variogram model:

$$
\begin{array}{ll}
\gamma(\xi)=.04+.004|\xi| & \text { for } \xi<10 \mathrm{~cm} \\
\gamma(\xi)=.095 & \text { for } \xi>10 \mathrm{~cm}
\end{array}
$$

Again, the permeability distribution shows a slight correlation at very short lag distances; but the data is generally uncorrelated at the sampling scale. It seems then that variability within the $\mathbf{P}$ architectural element could be sufficiently described by the mean and the variance of the sample set. However, if small-scale structure is of interest, a linear variogram which reaches a sill at a very small range may be more representative.

\section{DISCUSSION}

While the value of a variogram for a lag distance of zero should theoretically fall at the origin, sampling error and variability at a scale smaller than the sampling scale can cause measurements taken at short distances to be very different (Isaaks,1989). In the experimental variograms presented here, a nugget, or jump at the origin, approaching 0.04 was

consistently observed. When calculated with the natural logarithmic transforms of the values obtained from testing of standards under field conditions, measurement error associated with the LSAMP was found to be approximately 0.01 (Chapter 2). It is hypothesized that the nugget of 0.04 found in most of these small-scale studies is due to both variability of the materials at a scale smaller than the sampling scale, and increased measurement error due to 
the weariness and irritability of workers subjected to adverse field conditions.

Another conclusion common to all of the studies presented here is that the permeability distribution data appear to be log-normally distributed with a variance less than one. Statistics of the four studies are summarized in Table 4.8.

Table 4.8. Statistics of the four study areas

\begin{tabular}{ccccc}
\hline & SS1 & SS2 & SS3 & SS4 \\
\hline $\mathrm{N}$ & 142 & 128 & 109 & 216 \\
\hline mean & 2.963 & 3.004 & 2.750 & 1.939 \\
\hline variance & 0.207 & 0.165 & 0.353 & 0.116 \\
\hline
\end{tabular}

A Student's t-test, Table 4.9, shows that the hypothesis that SS1 and SS2 have the same means cannot be rejected. The correlation lengths in the vertical direction in SS1 and SS2 might both correspond to the average vertical dimension of the hydrofacies, but there is no obvious geologic explanation for their correlation lengths in the horizontal direction.

Table 4.9. Results of Student's t-test of the four study areas

\begin{tabular}{cccc}
\hline \hline $\mathrm{df} / \mathrm{t}_{\text {crit }} / \mathrm{t}_{\text {obt }}$ & $\mathrm{SS} 2$ & $\mathrm{SS3}$ & $\mathrm{SS4}$ \\
\hline $\mathrm{SS} 1$ & $268 / 1.96 / 0.78$ & $249 / 1.96 / 3.22$ & $356 / 1.96 / 24.31$ \\
\hline $\mathrm{SS} 2$ & -- & $235 / 1.96 / 3.89$ & $342 / 1.96 / 26.10$ \\
\hline SS3 & -- & -- & $323 / 1.96 / 15.62$ \\
\hline
\end{tabular}

The findings from SS4 indicate that within the paleosol facies, permeability is correlated over an extremely short distance. This soil element is homogenous and appears structureless. The permeability distribution of SS4 might be adequately characterized by the mean and variance of the data set, depending on the scale of interest. At the scale of measurement in these studies, the statistical characterization of the more heterogeneous SS1 and SS2 deposits is furthered by the use of variogram estimation to describe the correlation structure. 
SS3 displays a strong connection between observable geologic features and the estimated variogram. The heterogenous layering within the study area leads to geographically distinct areas of differing mean permeabilities. The style of heterogeneity in SS3 is more clearly represented in the variogram than in the case of SS1 and SS2 due to the relative homogeneous nature of the SS1 and SS2 study areas. The permeability field in the horizontal direction in each of these three studies can be adequately characterized with an exponential variogram model. Where the vertical heterogeneity is not particularly extreme, this model also appears to describe the vertical permeability distribution. The vertical variogram in general reflects the dimensions of the geologic layering present in the outcrops.

\section{FUTURE WORK}

Future work planned for the Bosque field site includes further investigation of the $\mathbf{P}$ element to determine if the structureless feature found here characterizes a majority of the soils at the site. Further studies will also focus on the effects of lateral discontinuities in small-scale geologic features on the experimental variogram. Emphasis will also be placed on the statistical modeling of large variations in permeability over very small areas. This is of interest because of the laterally continuous, narrow clay drapes which are common to the fluvial deposits in the Bosque area. 


\section{CHAPTER V: MARKOV RANDOM FIELDS}

\section{INTRODUCTION}

All aquifers are heterogeneous with respect to properties that influence the flow of water and the movement of contaminants. It is widely recognized that one of the more important factors impacting the reliability of subsurface contaminant migration prediction is understanding how these aquifer properties are spatially distributed. While we recognize that the properties of a particular aquifer are fixed in space and thus deterministic, they are generally unknown to us except at a limited number of locations. This uncertainty can be cast in a geostatistical framework that allows us to treat the spatial distribution of aquifer properties as a random process with a correlation structure that can be inferred from the limited data set. Such an approach allows data requirements to be minimized while preserving the limited amount of information that is available within the financial constraints typically imposed on any aquifer characterization effort (Phillips and Wilson, 1989).

One of the goals of the DOE Field-Scale Subprogram is to establish viable methodologies for describing the behavior of contaminants released from surface and subsurface sources, especially in the context of natural heterogeneity (U.S Dept. of Energy, 1990). Conventional geostatistical approaches that have been presented in the hydrologic literature during the past several decades rely on the assumption of a single, representative scale of heterogeneity. They appear to be useful when the size of the contaminant problem is much larger or smaller than the size of the dominant structure of heterogeneity and when a single dominant scale of heterogeneity does, in fact, exist. However, when several scales of 
heterogeneity occur and when the flow or contamination problem spans more than one of these scales, traditional single-scale geostatistical constructs will generally fail to yield reliable contaminant transport predictions (Cushman, 1984).

\section{DISCRETE, NATURAL SCALES OF GEOLOGIC HETEROGENEITY}

Much of the focus of the DOE Field-Scale Subprogram aquifer characterization study at New Mexico Tech has been on mapping and air-permeability sampling of the Sierra Ladrones Formation alluvial deposits in the Albuquerque Basin. On the basis of the permeameter and mapping data, there appear to be two significant characteristics associated with the geologic structure of the alluvial deposits. These characteristics should be incorporated into our geostatistical model of alluvial aquifer heterogeneity. Probably the most visually apparent characteristic is the discrete nature of the deposits at many scales of observation. As illustrated in outcrop photographs, the deposits are characterized by distinctly discrete geologic structure for at least two different scales of observation. Such discrete structure is most likely due to abrupt changes in the depositional environment that typically occur as a result of sudden temporal fluctuations in climatic regime, tectonic conditions, or changes in the distribution of fluvial energy. Clearly, the geostatistical aquifer characterization model should be capable of reproducing such sharp lithologic interfaces. Not quite so apparent from the photographs is the fact that we also observe a hierarchy of scales of variation in which one or more scales of geologic structure are nested in larger scales of spatial variation. Since discrete structure and nested scales of variation are two features that are observed consistently throughout the deposits, they should be incorporated into the aquifer characterization model if it is to be a reliable predictor of aquifer heterogeneity. 


\section{CONTINUOUS VS. DISCRETE STOCHASTIC PROCESSES}

Both continuous and discrete modeis of random processes have been used to synthesize geologic phenomena. While continuous models can be quite useful in describing the structure of geologic phenomena at certain scales, discrete models are uniquely suited to the problem of describing aquifer characteristics in geologic materials that have been deposited, eroded, or altered under abruptly changing geologic conditions. Only discrete models can fully capture the sharp lithologic interfaces that have been observed in the Sierra Ladrones Formation alluvial deposits at certain scales of observation. Markov random field (MRF) models, in which the geologic properties of a depositional unit are correlated over a distinct neighborhood of a point, appear to offer the most promising methodology for describing abrupt variations in geologic structure because the correlation is imposed over a discrete spatial domain (Colarullo and Gutjahr, 1991).

Traditional geostatistical methods in general restrict control to the mean and second-order behavior of the geologic process. In fact, processes generated via traditional geostatistical methods are limited to gaussian processes due to the nature of the generating schemes, unless complicated integral equations are solved (Farmer, 1987). The failure of these traditional gaussian, or linear, stochastic models with respect to reproducing observed preferential migration pathways has been discussed in the literature, most notably by Journel and Alabert (1988). These inadequacies can be at least partially attributed to the occurrence of significant third- and higher-order joint moments that may occur in observed geologic structure. Since Gaussian models can only describe stochastic processes up to order two, they often need to be heavily conditioned on available data if a synthetic realization is to statistically reproduce an observed non-Gaussian random process with higher-order non-zero moments. Thus, in addition to accounting for multiple scales of embedded discrete and 
continuous structure, the geostatistical model should be capable of capturing the higher-order moments associated with the appropriate joint distribution (pdf) of the process $\mathbf{v}$ at certain scales without having to rely on excessive data conditioning. One means of simulating processes from multidimensional joint pdfs is via factorization of the joint $p d f p(v)$ into the product of one-dimensional conditional distributions (Hastings, 1970). The conditional approach makes the problem of generating observed joint structure tractable, particularly in large domains when the number of dimensions of the joint pdf is also large.

\section{LITHOLOGIC FACIES SEQUENCES AS ONE-DIMENSIONAL MARKOV CHAINS}

From the standpoint of incorporating discrete structure into the characterization model, we can resort to one of the classic discrete models that has traditionally been used to statistically characterize discrete geologic structure, the one-dimensional Markov chain model (Merriam, 1976). Markov chains are the simplest examples of dependent processes. They have historically been used to generate vertical sequences of lithologic facies, based on conditional probabilities estimated from the geologic record (see Figure 5.1).

In the terminology of Markov chain theory, the transition probability matrix $\mathbf{P}$ describes the conditional probability of moving from the present state at $n-1$ to any other future state at $\mathrm{n}$, given the present state. We condition the current estimate of the joint distribution $\pi_{\mathrm{n}}$ on $\mathbf{P}$, a state transition matrix that embodies what little we know from the geologic record:

$$
\overline{\pi_{n}}=\overline{\pi_{n-1}} P
$$

A Markov chain allows us to generate sequences with a prescribed joint distribution using the 


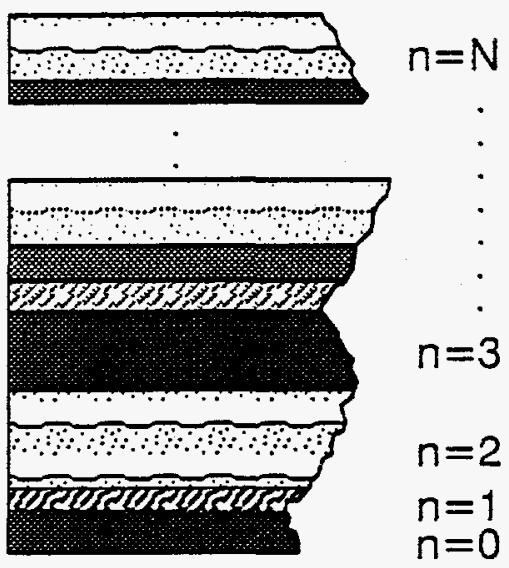

Figure 1. A Vertical Geologic Sequence as a One-Dimensional Markov Chain. 
conditional approach. In effect, the global joint distribution determined by an infinitely long chain is factored into conditional distributions defined by local inspection of the observed geologic record. This conditional approach to defining the joint behavior of the chain requires much less data than would be needed to directly estimate the joint distribution $\pi_{\mathrm{n}}$ because all that is needed are reliable estimates of the transition probabilities in matrix $\mathbf{P}$. In other words, transition probabilities can be obtained from a much shorter geologic record than would be required to establish the probability of any one given lithology occurring in the chain. We essentially use the conditional probability structure to 'build' the joint distribution.

Unlike the one-dimensional Markov chain, for which a single point partitions time into past and future, there is no such natural partitioning when we move into the spatial realm. We need to replace the concept of past and future with the concept of the neighborhood. The probability that a random variable take on a certain value at a site will then depend only on the variables at locations contained in some specified neighborhood of the site.

\section{THE JOINT DISTRIBUTION AS THE GIBBS DISTRIBUTION}

If one views the aquifer property process $\mathbf{v}$ at some scale as a discrete lattice process for which the mean of the process is known, statistical mechanics theory predicts that at maximum entropy, subject to the known mean, the probability of the entire process assuming state $\mathbf{v}$ follows the normalized Gibbs distribution:

$$
P(v)=\frac{e^{-U(\eta)}}{\int_{\eta} e^{-U(v)} d V}=\frac{e^{-U(v)}}{Z}
$$

where $U(\mathbf{v})$ represents the global energy contained in the lattice process $\mathbf{v}$. As shown in 
equation [5.2], the Gibbs distribution must be normalized by some measure of the total energy associated with the set of all possible states of the system $\mathbf{v}_{\mathbf{p}} . \quad \mathrm{Z}$ represents this scalar normalization factor, referred to as the partition function in the statistical mechanics literature.

The assumption of maximum entropy essentially amounts to a statement of maximum prior ignorance about the joint distribution. That is, we plead complete ignorance about the joint behavior. This state of maximum ignorance can be modified to reflect what little information we do have about the joint pdf, usually in the form of estimated statistical moments. When the maximization is made subject to the constraint of a known mean, we introduce only information related to the first-order moment. By not constraining the entropy maximization using assumptions related to second- or higher-order moments, the Gibbs distribution describes any arbitrary second- and higher-order moment behavior, depending on how $U(v)$ is defined. This very ambiguity in defining $U(v)$ is what allows us to make the conceptual leap from a system of gas molecules in Brownian motion, upon which the Gibbs derivation is based, to a correlated conductivity field. Whether we're dealing with the exchange of energy between colliding gas molecules or the exchange of information between adjacent conductivity sites, the Gibbs distribution describes a meaningful probabilistic structure under the conditions of the constrained maximum entropy.

It has been proven that Gibbs distributions and Markov random fields (MRFs) are equivalent (Spitzer, 1971). That is, if the joint probability law of a random process is the normalized Gibbs distribution [2], the associated random process is an MRF and vice versa. The Gibbs-Markov equivalence has also been proven for the case in which the field is conditioned on one or more pieces of data (Geman and Geman, 1984). If the Gibbs distribution is the probability statement for the MRF, it is clear that, unlike more traditional methods of synthesis that rely on weak or second-order stationarity, we have an explicitly defined joint pdf. In fact, besides permitting synthesis of discrete processes, MRFs allow us 
to characterize natural geologic structure that may exhibit significant third-, fourth-, and even higher-order moments that differ from the Gaussian case. We need not quantify these moments explicitly -- they are implicit to the Markov parameters that are used to define the energy function $U(v)$.

The normalized Gibbs distribution would thus appear to be a powerful tool for simulating MRFs. Unfortunately, it is not a simple matter to generate a sample realization from the joint Gibbs distribution given by equation [5.2]. Since the total mass of the joint pdf must be equal to one, the value of $\mathrm{Z}$ must be known if we wish to define a valid probability distribution. However, given that the number of possible states $\mathbf{v}_{\mathbf{p}}$ quite large, calculation of $\mathrm{Z}$ is generally prohibitively cumbersome. The fact that $\mathrm{Z}$ can not generally be calculated effectively precludes any kind of analytic treatment of the problem, and we are forced to turn to a conditional, Monte Carlo approach to generate the desired joint behavior.

\section{CONDITIONAL PDF AS THE JOINT PDF WITH Z RESTRICTED TO THE NEIGHBORHOOD}

To overcome the problem of estimating the partition function $Z$, we restrict it to account only for all possible states within a small region or neighborhood $C\left(\mathbf{x}_{0}\right)$, of a point $\mathbf{x}_{0}$ on the lattice. This 'restricted' form of the joint pdf is the conditional pdf:

$$
\begin{gathered}
P\left[v\left(x_{0}\right) \mid v(x) \text { at } x \in C\left(x_{0}\right)\right]=\frac{e^{-U^{\prime}\left[\left(x_{0}\right) \mid(x) \alpha x \in C\left(x_{0}\right)\right]}}{\int e^{-U^{\prime}\left[v(x) a t x \in C\left(x_{0}\right)\right]} d v^{\prime}} \\
v_{p}(x), \quad x \in C\left(x_{0}\right)
\end{gathered}
$$

analogous to the transition matrix $\mathbf{P}$ of conditional probabilities used to generate a one-dimensional Markov chain. We can then 'build' the correct joint behavior by locally and repeatedly applying the conditional operator in a manner similar to the case of the one-dimensional Markov 
chain when the joint distribution was indirectly derived on the basis of the transition probabilities. Geman and Geman (1984) refer to equation [5.3] as the Gibbs sampler because it is used to 'locally' sample off the Gibbs distribution.

Note that the denominator in [5.3] is the cumbersome normalizing factor $\mathrm{Z}$ restricted to the neighborhood. While it has been restricted to the neighborhood, it may still be intractable even for small simple processes, especially those that are continuous state processes. The problem of an intractable denominator in equation [5.3] is overcome using a Monte Cario importance sampling algorithm developed by Metropolis et al. (1953) to impose the correct joint behavior on an initially uncorrelated process. Since one uses the ratio of conditional probabilities at two lattice sites to make a decision about whether to update the process, the local normalizing factor in the denominator of equation [5.3] drops entirely from consideration.

It is the local nature of equation [5.3] that presents the fundamental problem with applying MRF theory to practical problems; one does not know a priori how these local energies, referred to as $U^{\prime}(v \mid$.$) for the remainder of this report, will become exhibited globally$ in the realization. When the joint pdf is bypassed to avoid the intractable problem of estimating the partition function $Z$, valuable information is lost that can not be regained until, in effect, we actually regenerate the joint pdf by virtue of its realizations. The inaccessibility of a relationship between local and global parameters is the inherent flaw of the MRF approach, but can be overcome through trial-and-error procedures or by empirically relating Markov parameters used to define $U^{\prime}(v \mid$.$) to more traditional geostatistical parameters such as correlation scale and$ variance. Farmer (1987) believes that it may not be possible to define global versions of local Markov parameters because it involves solution of an intractable inverse problem.

\section{INTERACTION ENERGY}

Although there are no analytic means of relating the Markov parameters to correlation 
scale, one does have control over the type of joint distribution produced by the conditional operator given by equation [5.3]. The operator may be defined by specifying the local energy function as:

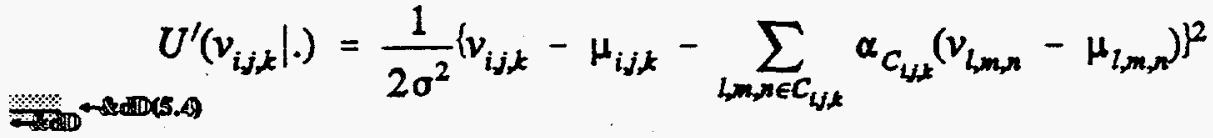

$$
\begin{aligned}
& =-\frac{1}{2 \sigma^{2}}\left\{\mu_{i, j \ell}+\sum_{(l, m, n) \in C_{i, j \ell}} \alpha_{c_{i, j}}\left(v_{l, m, n}-v_{i, j, k}-\mu_{l, m, n}\right)^{2}\right.
\end{aligned}
$$

where $\mu_{\mathrm{i}, \mathrm{j}, \mathrm{k}}$ and $\mu_{\mathrm{l}, \mathrm{m}, \mathrm{n}}$ represent the means of the random variable at sites $(\mathrm{i}, \mathrm{j}, \mathrm{k})$ and $(\mathrm{l}, \mathrm{m}, \mathrm{n})$, respectively, $\mathrm{C}_{\mathrm{i}, \mathrm{k}, \mathrm{k}}$ is the neighborhood or clique used to calculate the potential, and $\alpha_{\mathrm{C}_{\mathrm{i}, \mathrm{k}}}$ is the Markov parameter for the neighborhood or clique surrounding site $(i, j, k)$. When $U^{\prime}(v \mid$.$) is$ described by the quadratic given by equation [5.4], the resulting realization will be a sample from a multivariate gaussian joint distribution (Besag, 1974). Other types of joint distributions that can account for higher-order probabilistic behavior can be defined using various forms of $U^{\prime}(v \mid$.$) . Clearly, unlike conventional methods of stochastic process generation, one is not$ forced to assume a multivariate gaussian process because the replication of joint behavior involves the assumption of 'strong' stationarity (up to order $\infty$ ) instead of second-order, 'weak' stationarity. Note that the choice of a local energy potential function $U^{\prime}(v \mid$.$) tends to become$ less relevant to the structure of the realization as more data are available to condition the realization on.

\section{MARKOV PARAMETERS}

Together with the neighborhood system and properties of the initial uncorrelated process, Markov parameters used to define the local energy function $U(v \mid$.$) uniquely$ determine the discrete MRF. Markov parameters reflect the degree of local energy 
interaction, and are essentially equivalent to the Lagrange multipliers in the maximum entropy formulation used to derive the Gibbs distribution. While positive Markov parameters encourage growth of correlation structure through attraction, negative parameters inhibit it through repulsion. By extension, a zero-valued parameter implies lack of either positive or negative correlation. This can be seen by substituting $\alpha_{\mathrm{Ci}, \mathrm{j}, \mathrm{k}}=0$ into the potential $\mu_{\mathrm{i}, \mathrm{j}, \mathrm{k}}$ the conditional pdf [3] predicts equal likelihood of any value at a point regardless of the values at the surrounding neighbors, giving rise to an uncorrelated process.

Anisotropy can be incorporated into the field by specifying different parameters in different directions. Thus, by specifying positive parameters in one direction and negative parameters in another, one can generate distinctly layered types of structures. Use of second and higher even-valued orders allows the introduction of oblique structure that is not possible with the traditional continuum methods of random field synthesis. Such orders might be used to synthesize alternating directions of cross-bed deposition caused by a stream avulsing across a floodplain.

In order to statistically characterize the observed field in a Markovian sense, the true Markov parameters must be accurately estimated from the data. Because the optimal Markov parameters are those most likely to describe the observed MRF, maximum likelihood techniques can be used to estimate the true parameter set. Alternatively, a trial-and-error approach was used to estimate the Markov parameters. The MRF realization shown in Figure 5.2 appears to reproduce the overall characteristics of the geologic structure observed in section C-C'. It was generated using positive-valued parameters in the $\mathrm{x}$ - and diagonal directions and $y$-direction at low orders and negative parameters in the y-direction at high orders. 


\section{EVOLUTION OF 128-By-128 MRF REALIZATION}

Figure 5.3 is an example of how repeated application of the conditional operator [3] to an initially uncorrelated process produces a sample from a Gibbs distribution, or an MRF realization. It is clear that the Markov chain evolves in a highly nonlinear manner. Much more reordering occurs early in the chain because very little as known about the realization initially and so any information gained from sampling is very valuable and reduces uncertainty a great deal. As the conditional operator continues to be locally applied, the energy becomes more organized and we get more and more redundant information that is less useful to us in terms of increasing structure in the realization. Since the rate of convergence

for large $\mathrm{n}$ is of order $\sqrt{ } \mathrm{n}$, this slow down in convergence rate is to be expected (Geman and Geman, 1984). The convergence rate also depends on how close the initial uncorrelated process is to a bona fide MRF realization.

\section{8-by-128 BINARY HYDRAULIC CONDUCTIVITY REALIZATIONS}

Figure 5.4 shows an example of a binary hydraulic conductivity field generated using a fifth-order Markov random field model and a hydraulic conductivity contrast of 100-to-1. Also shown are pathlines generated using a multigrid flow solver and a particle tracking algorithm. It is clear that the discrete nature of the conductivity field is well-suited to its use in flow and transport simulators, which rely on spatial discretization of the conductivity field. In the context of numerical prediction, it obviously makes more sense to use a conductivity realization that is already discrete than to discretize a continuous realization. 

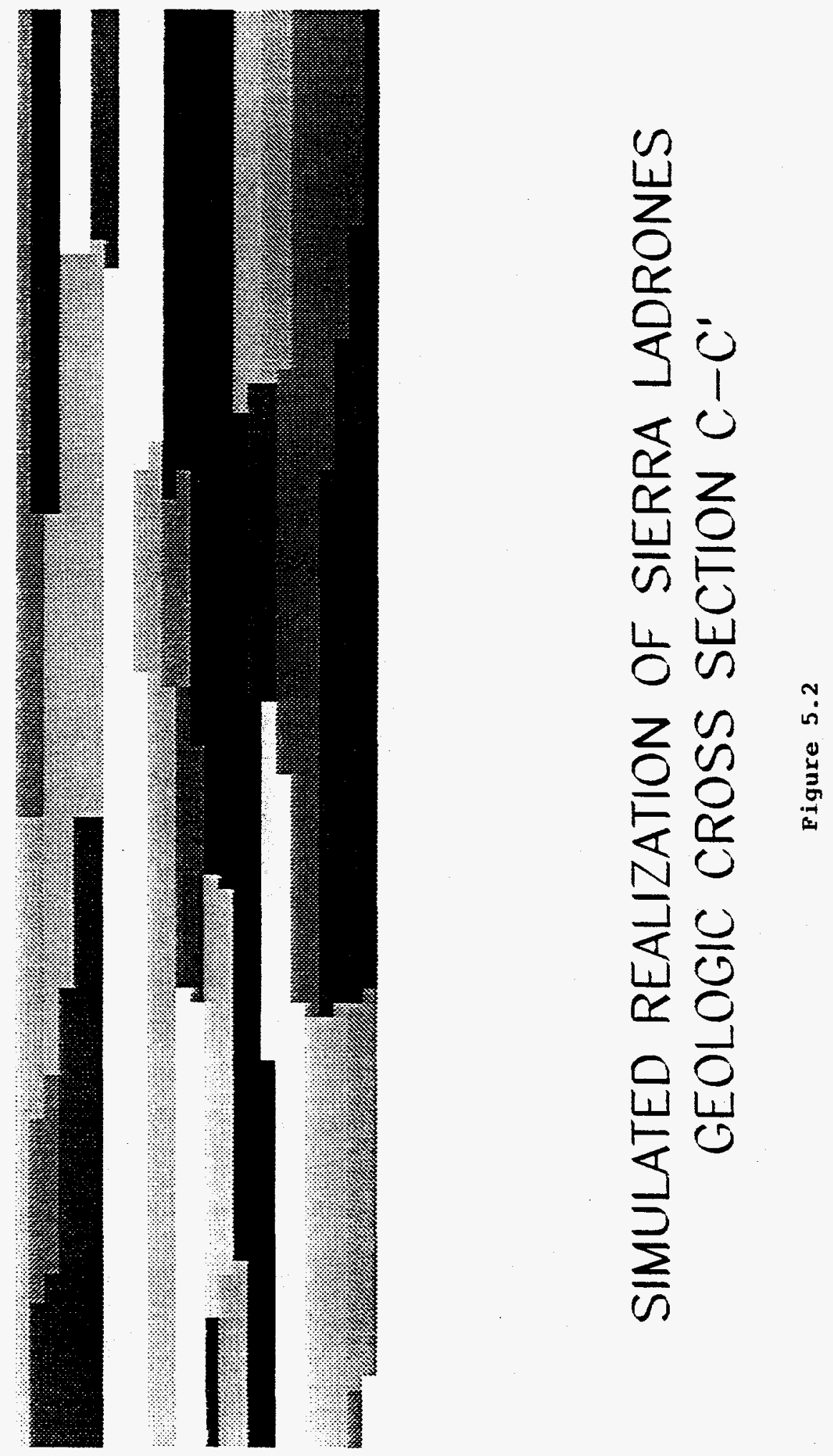


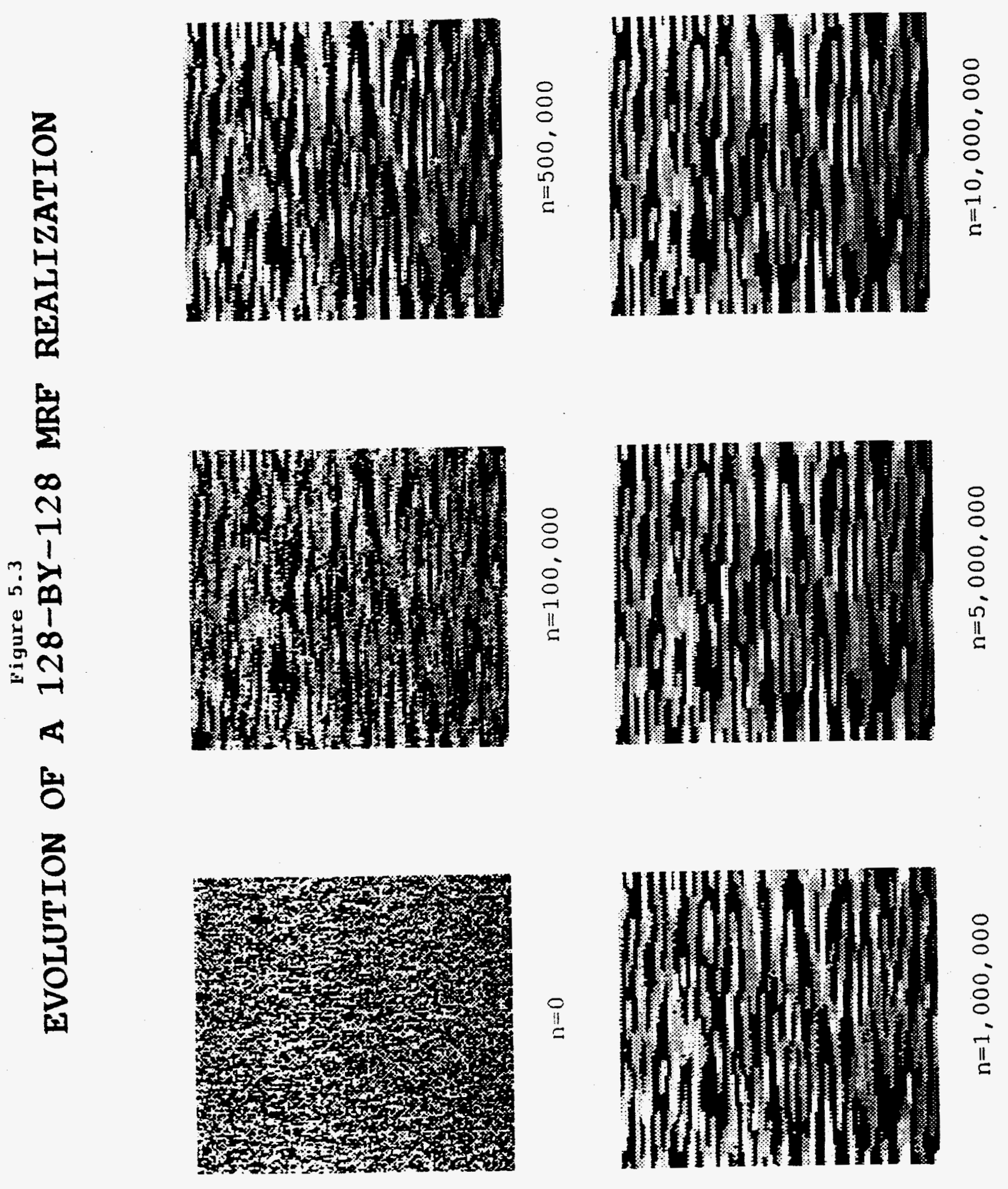




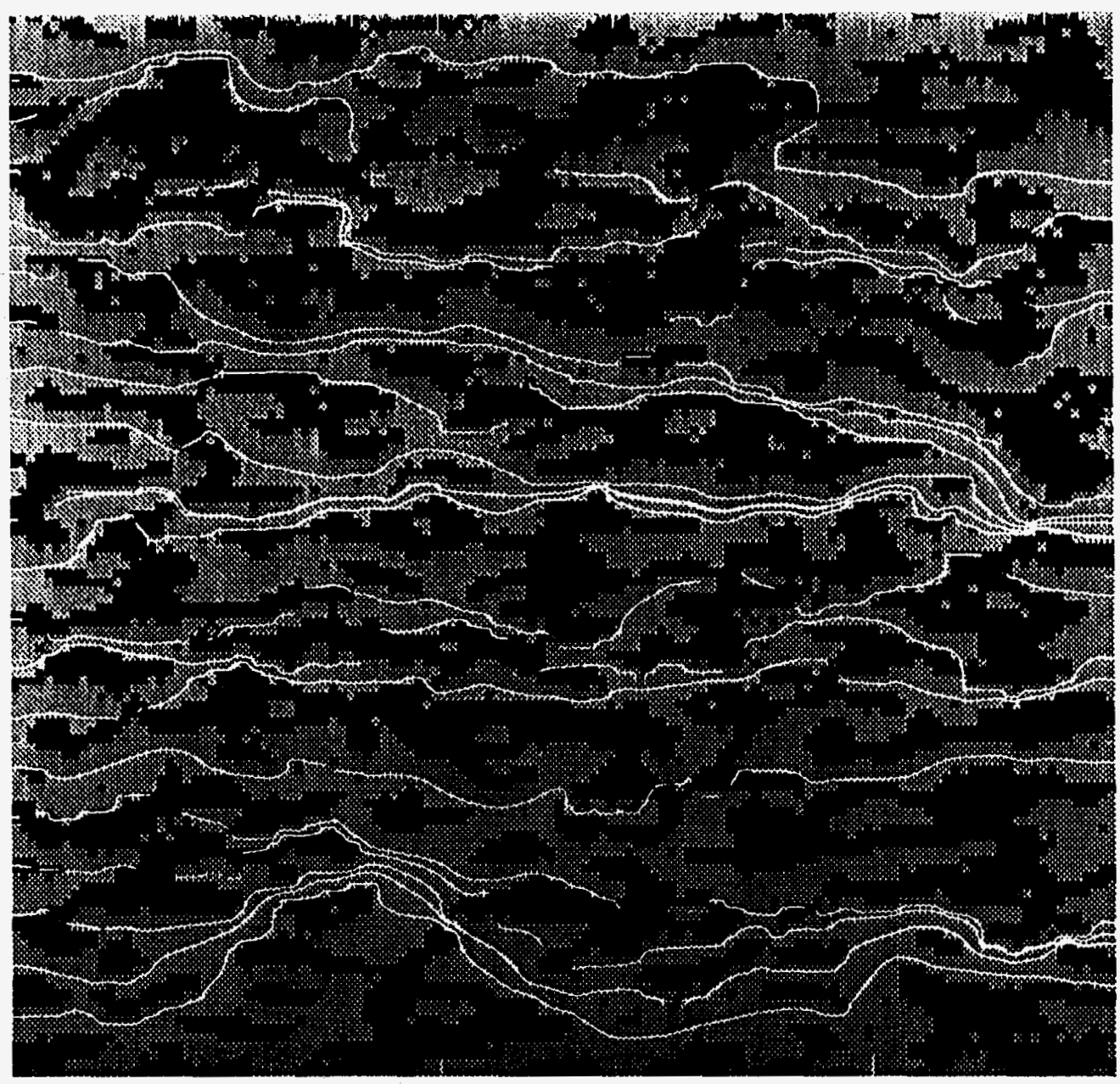

DISCRETE BINARY MARKOV RANDOM CONDUCTIVITY FIELD REALIZATION WITH PATHLINES FOR HORIZONTAL GRADIENT 


\section{8-by-128 MRF and FFT Realizations}

We might be interested in assessing how two-dimensional discrete and continuous conductivity realizations might yield different predictions of contaminant transport. Figure 5.5 shows the final MRF realization extracted from the end of the Markov chain presented earlier. Breakthrough curves were simulated for both the MRF realization and a statistically equivalent continuous realization generated using the FFT method, also shown in Figure 5.5 (Gutjahr, 1989). The continuous realization was generated using an exponential covariance function in order to produce the most 'discontinuous' continuous realization and make the two cases more comparable. The discrete nature of the Markov random field realization is readily apparent next to the continuous FFT field.

\section{Concentration Breakthrough Curves}

For this particular set of realizations, the initial and average breakthrough times were smaller for the continuous realization, but breakthrough time appears to have a larger variance for the discrete realization (see Figure 5.6). Thus, a remediation strategy designed on the basis of the continuous FFT conductivity field might not operate for a sufficient period of time to capture the entire plume. Since a single set of realizations such as those presented in Figure 5.5 can not be used to represent the range of possible stochastic behavior associated with either the discrete or continuous processes, many different conductivity realizations and their corresponding breakthrough curves are currently being generated in order to account for our uncertainty about the actual conductivity field. 
Figure 5.5

COMPARISON OF DISCRETE AND CONTINUOUS HYDRAULIC CONDUCTIVITY REALIZATIONS

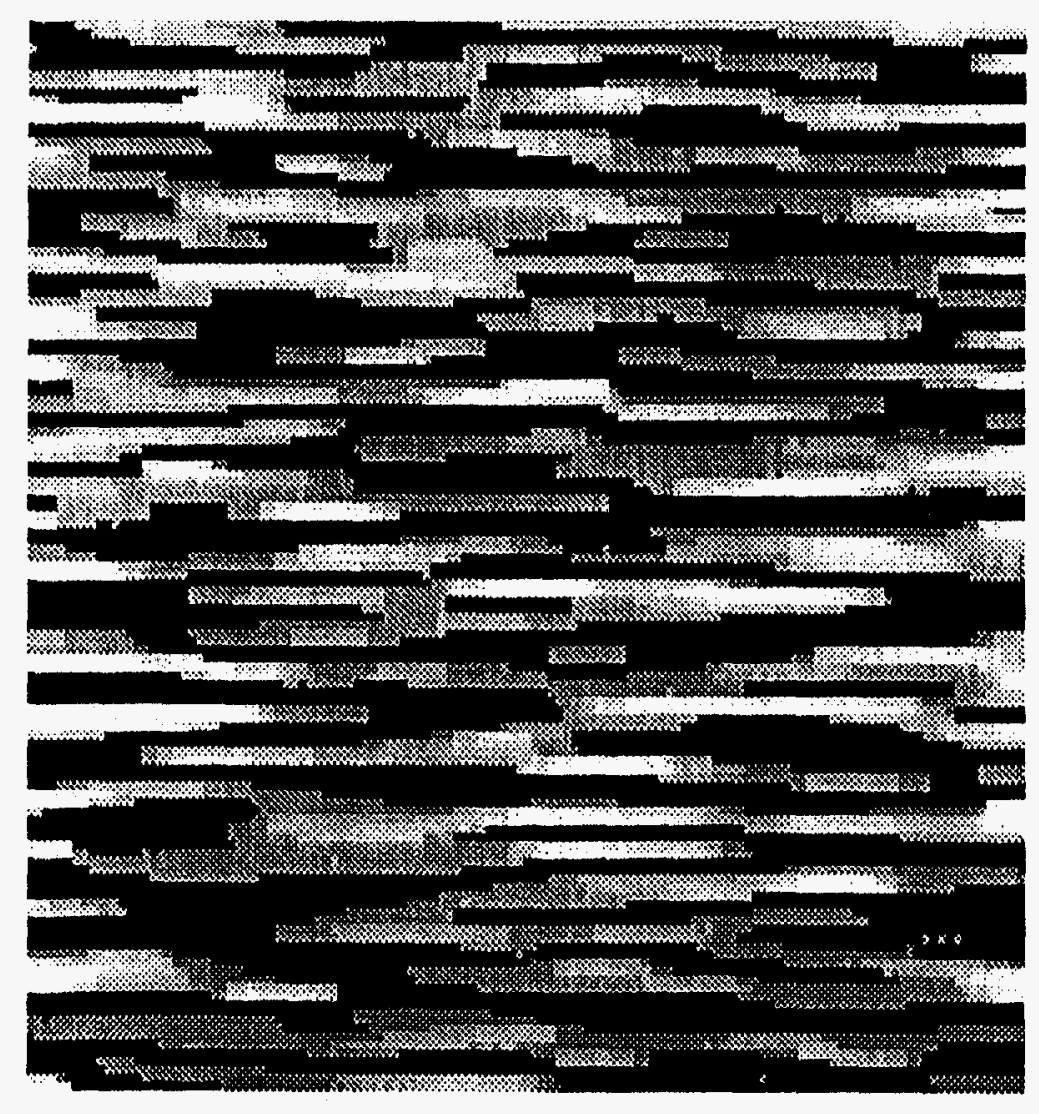

128-BY-128 DISCRETE MRE REALIZATION



128-BY-128 CONTINUOUS FFT REALIZATION 


\section{COMPARISON OF BREAKTHROUGH CURVES FOR}

\section{DISCRETE AND CONTINUOUS HYDRAULIC CONDUCTIVITY REALIZATIONS}

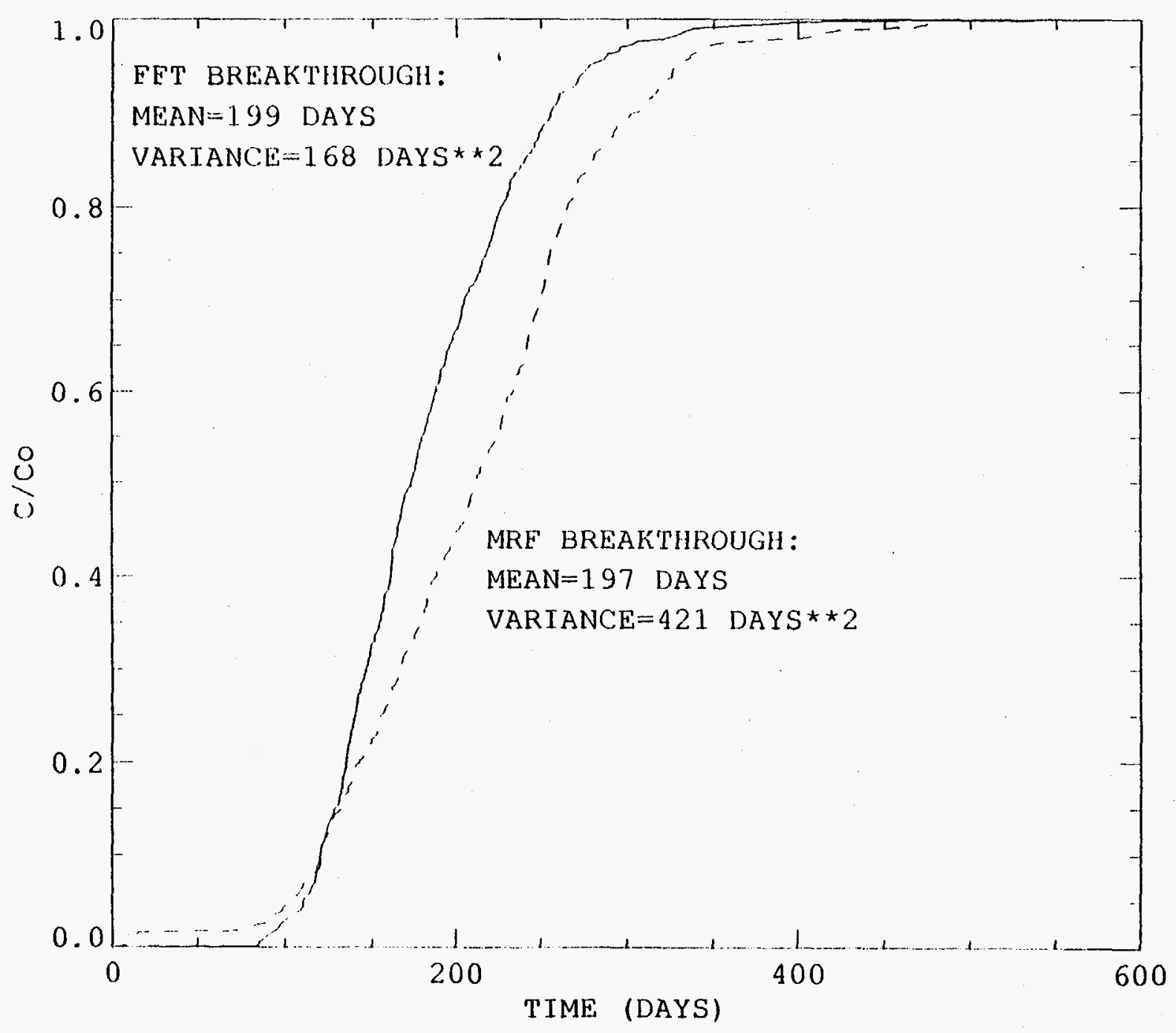

Figure 5.6 


\section{GENERATION OF MULTIPLE SCALE STRUCTURE}

The issue of discrete structure in the alluvial deposits has been addressed and incorporated into the geostatistical model using Markov random field theory. The second feature observed in the Sierra Ladrones Formation deposits, that related to embedded scales of heterogeneity, must also be incorporated. Hierarchical structures produced by natural geologic processes can be duplicated by embedding realizations generated separately at each scale. After realizations are generated at each scale where structure is evident, they are embedded to form a composite, multiple-scale realization, as demonstrated in Figure 5.7. For example, a large-scale discrete MRF could be used to describe allocyclic events such as sudden changes in climatic regime or tectonic uplift, while small-scale continuous realizations embedded within the large-scale discrete MRF realization could characterize more gradual autocyclic events such as stream avulsion. In this case, Miall's architectural element classification (Miall, 1985) might be used to delineate the large-scale features. Abrupt allocyclic events such as debris flows, or any event involving some type of nonconformal erosional or depositional process, would be best described by embedding a small-scale discrete MRF realization within the larger-scaled discrete MRF realization.

The fact that the embedding is not handled analytically, and in fact can not be handled analytically in the presence of MRF realizations generated using a Monte Carlo approach, is an advantage in that it allows explicit selection of only those scales of hydrogeologic interest. For example, if we know a plume is too large to be significantly impacted by heterogeneities below a certain scale, we can ignore variations occurring below that scale by simply not embedding them into the geologic structure. 
Figure 5.7. Embedding of multiple scales of heterogeneity.

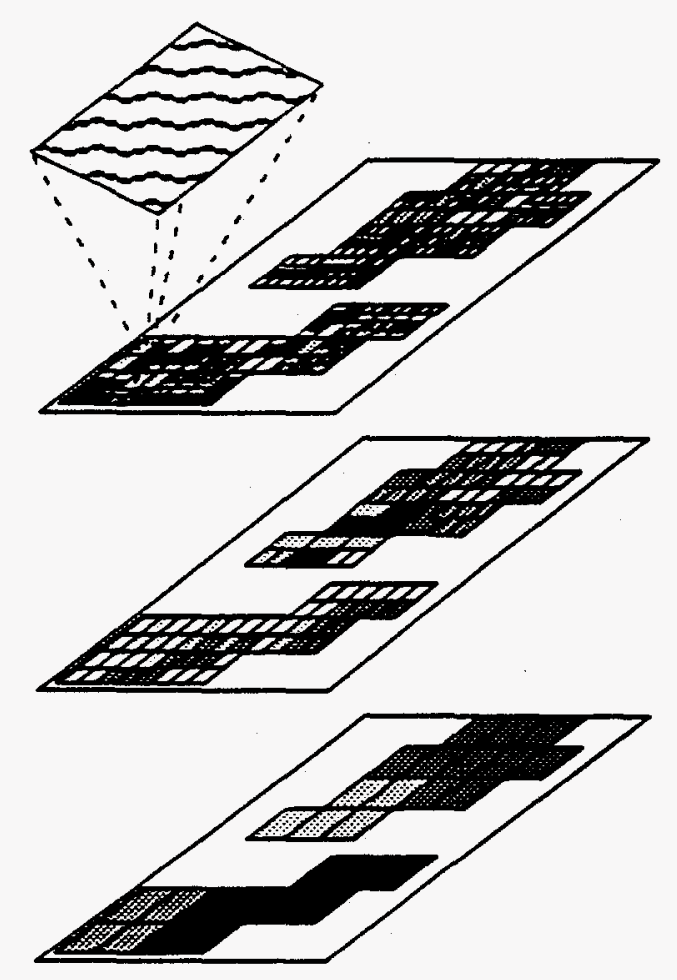

Continuous

Structure



Progressively

Finer-Grained

Discrete Structure

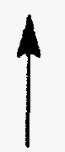

Coarsest-Grained Discrete Structure 


\section{TWO-SCALE MRF vs. SINGLE-SCALE CONTINUOUS REALIZATIONS}

Figure 5.8 and Figure 5.9 illustrate how two-scale realizations are constructed, where realizations at both scales are MRF realizations. These are intended only as examples of the field generation process and are not intended to be geologically realistic. In the first realization, the coarser-grained scale was generated as an 8-by-8 realization, and then the finer-grained structure was embedded as 16 -by-16 realizations to produce a 128 -by-128 composite. For the case of the second realization (Figure 5.9), the coarser-grained structure was generated on a 4-by-4 grid, then the 16-by-16 realizations embedded using the same Markov parameters to yield a 64-by-64 composite realization. It is clear that very a different geologic structure could be produced by simply changing the discretization at one of the scales.

The two composite realizations are presented in Figure 5.10 and Figure 5.11 alongside statistically-equivalent continuous FFT realizations, where statistical equivalence is again defined up to second order. As illustrated by the resulting breakthrough curves in Figure 5.12 and Figure 5.13, while the two-scale discrete and statistically equivalent single-scale continuous realizations produce different characteristic transport responses. More runs are needed to delineate whether the observed difference is significant.

\section{TWO-SCALE HYBRID MRF/CONTINUOUS VS. SINGLE -SCALE CONTINUOUS REALIZATIONS}

A two-scale hybrid realization constructed using a large-scale MRF realization and an embedded small-scale continuous FFT realization is presented in Figure 5.14, with it is corresponding statistically-equivalent single-scale continuous realization. The Markov parameters for the large-scale MRF realization were chosen to reflect discrete 


\section{EMBEDDING OF TWO DISCRETE SCALES}

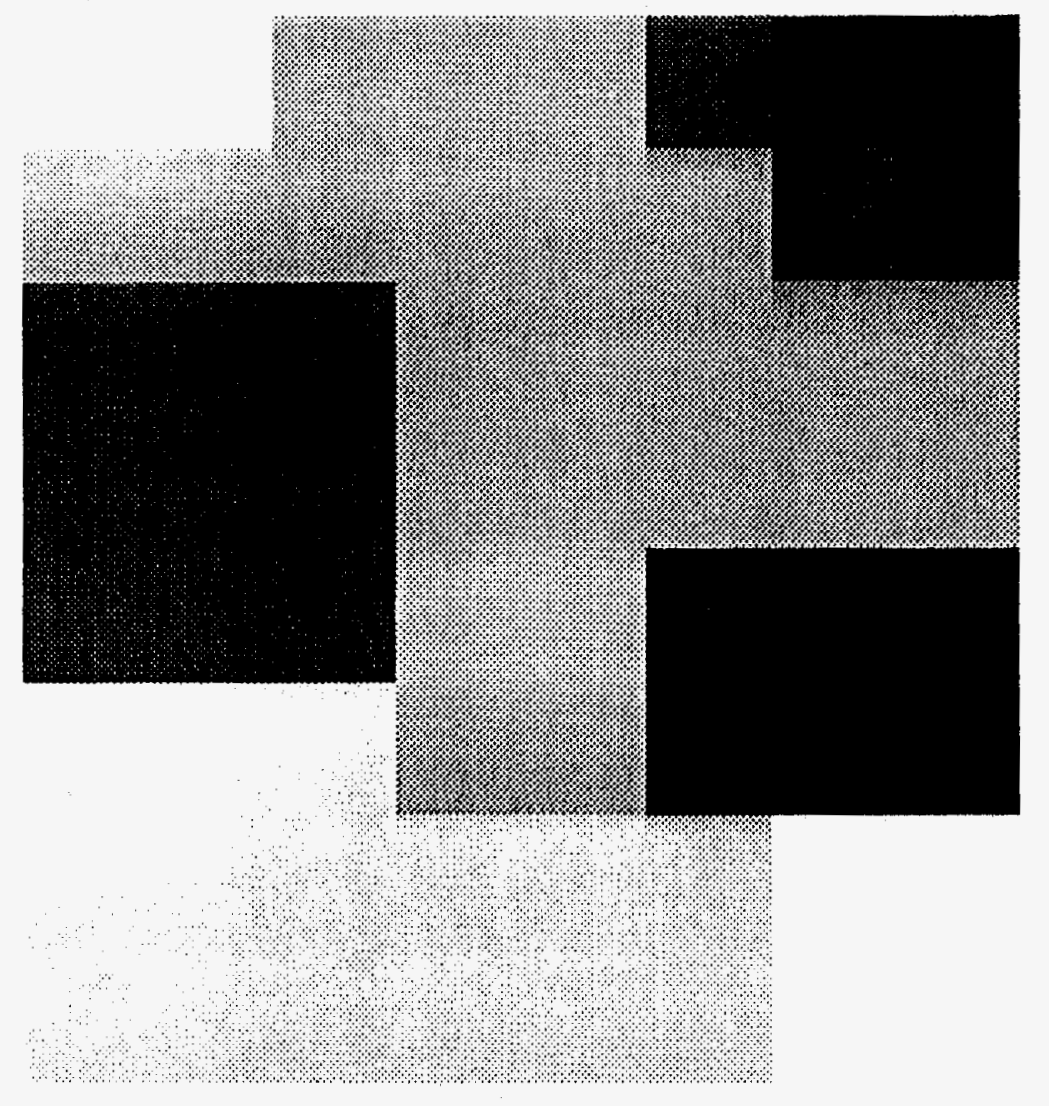

8-BY-8 LARGE-SCALE REALIZATION

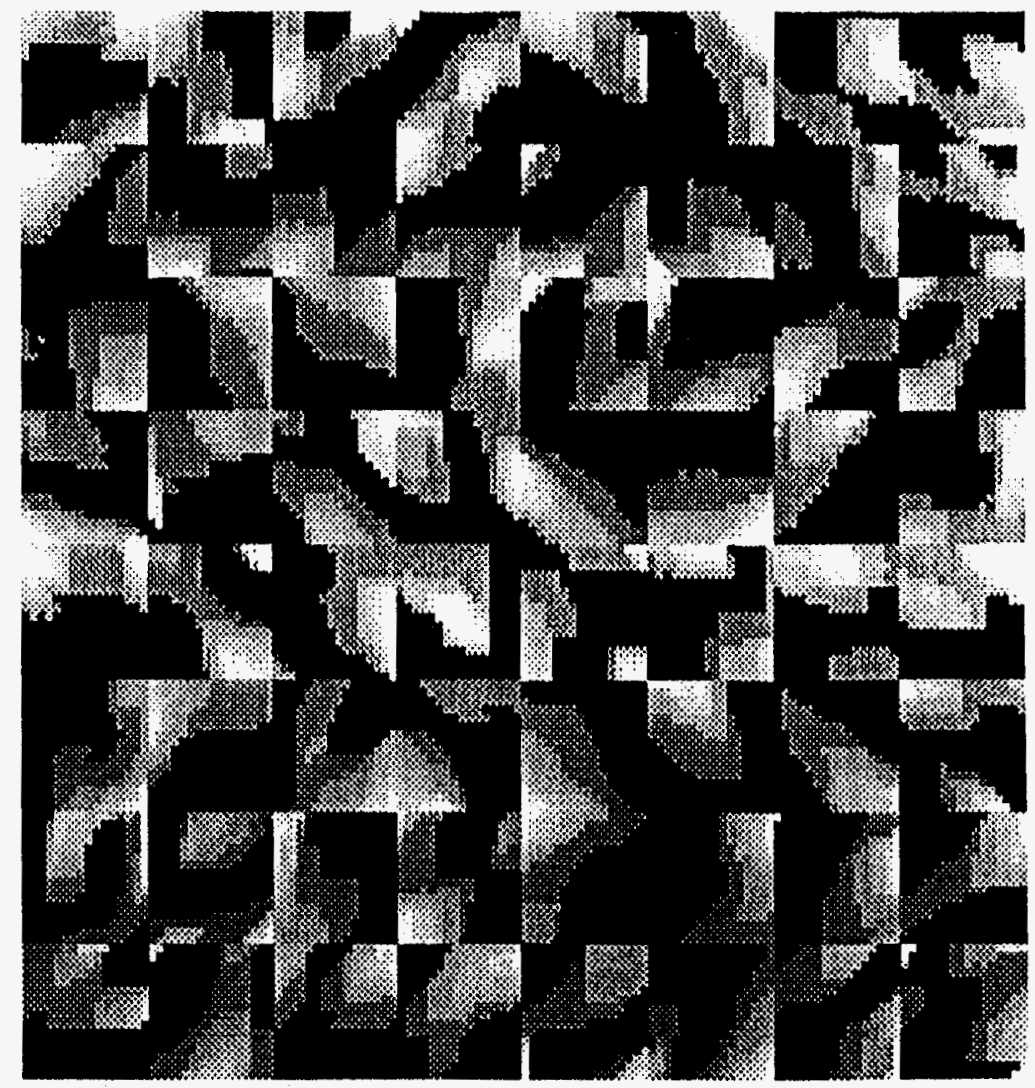

128-BY-128 SMALL-SCALE REALIZATION 


\section{EMBEDDING OF TWO DISCRETE SCALES}

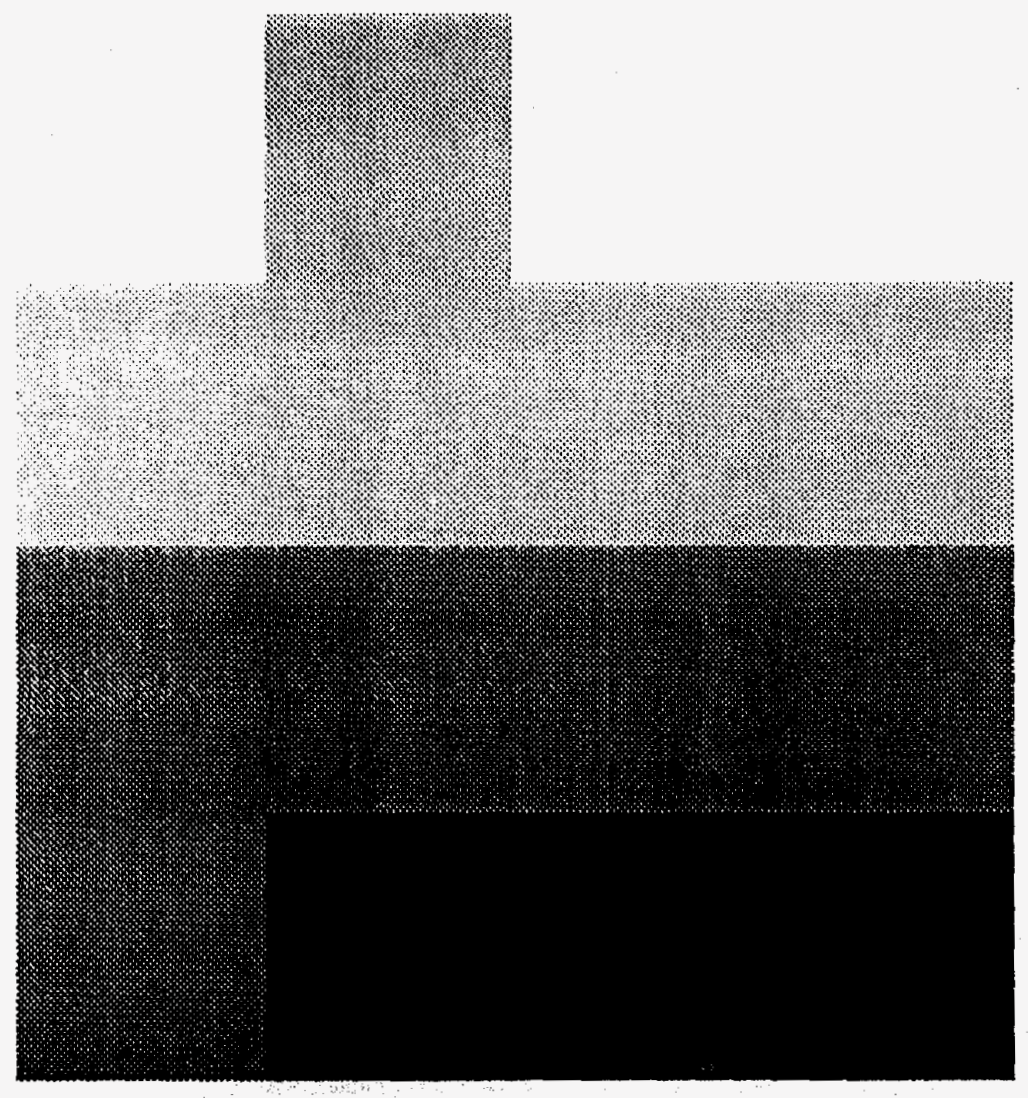

4-BY-4 LARGE-SCALE REALIZATION

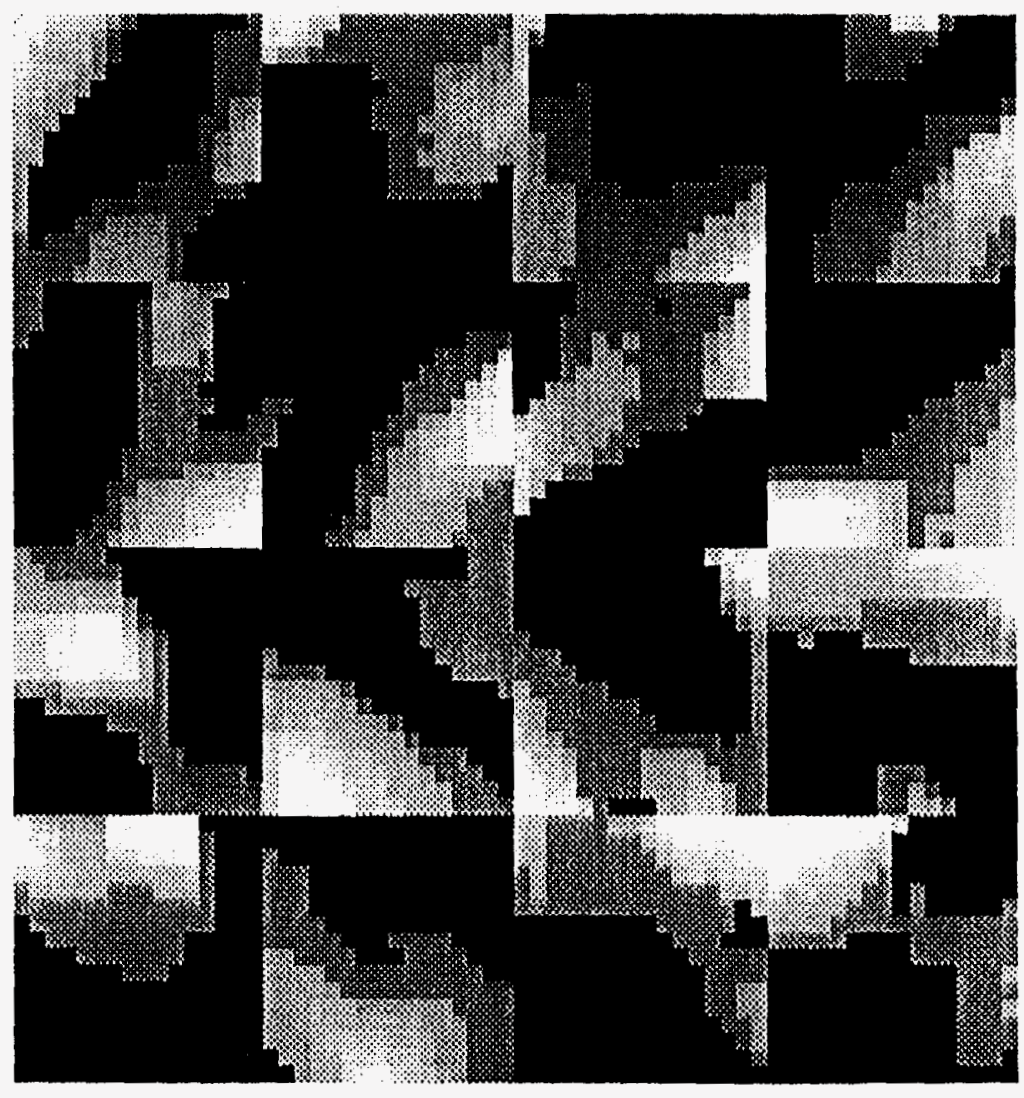

64-BY-64 SMALL-SCALE REALIZATION 



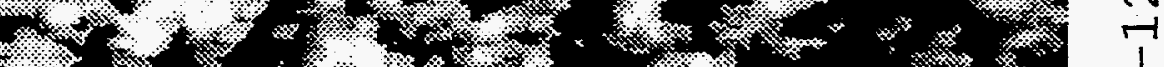

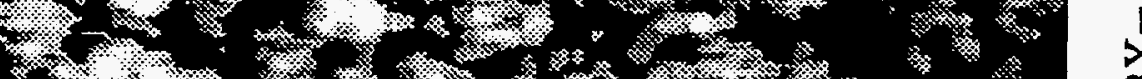

\%


N

节

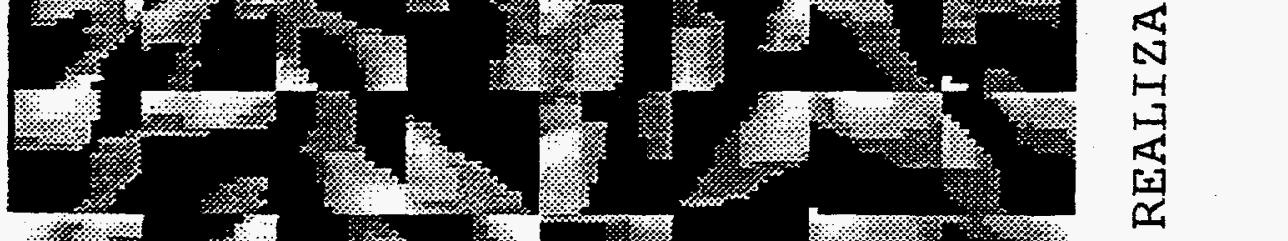




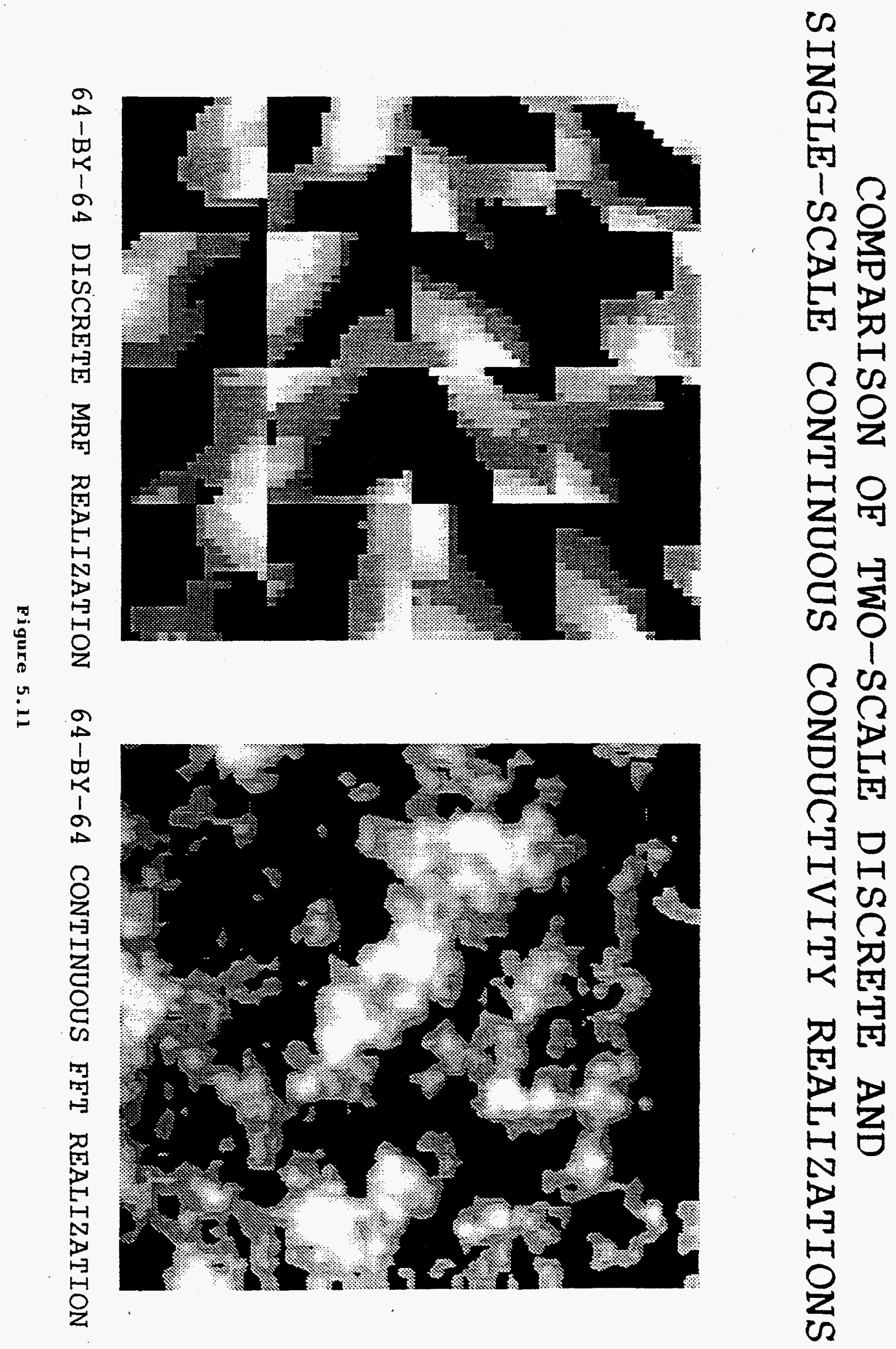


BREAKTHROUGH CURVES FOR STATISTICALLY EQUIVALENT MRF AND FET CONDUCTIVITY REALIZATIONS

(TWO-SCALE MRE REALIZATION)

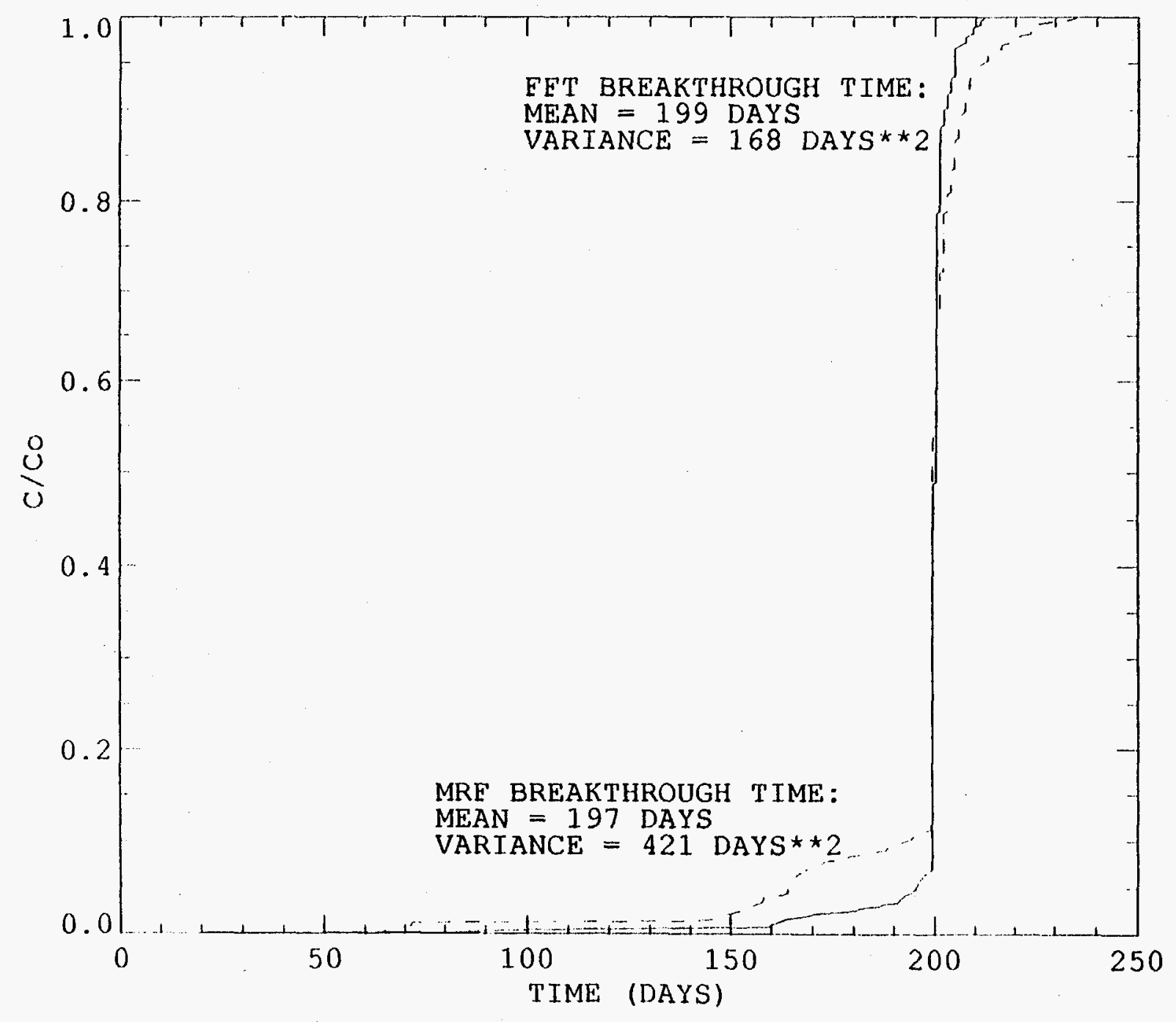

Figure 5.12 


\section{BREAKTHROUGH CURVES FOR STATISTICALLY EQUIVALENT MRE AND FFT CONDUCTIVITY REALIZATIONS (TWO-SCALE MRE REALIZATION)}

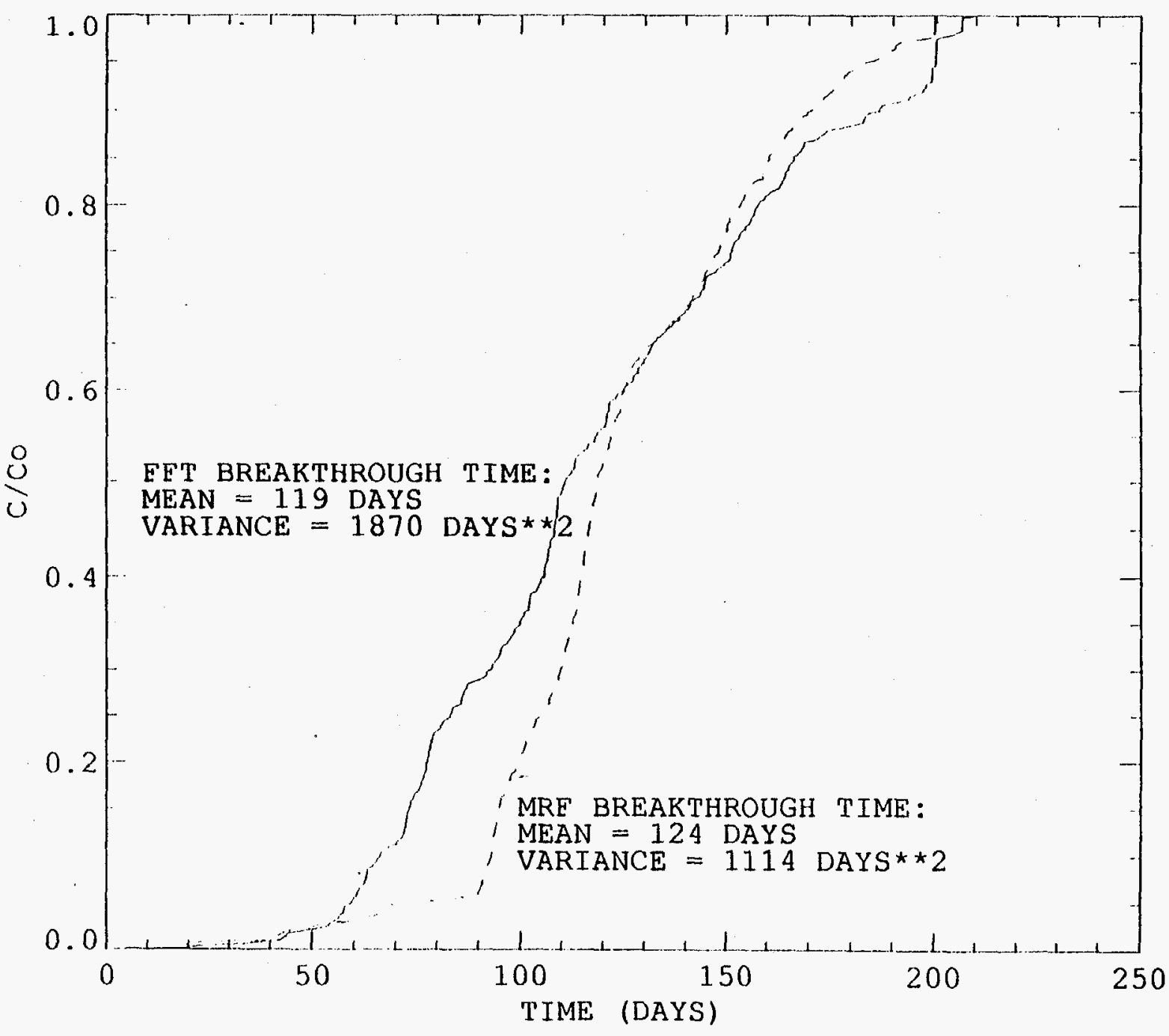

Pigure 5.13 


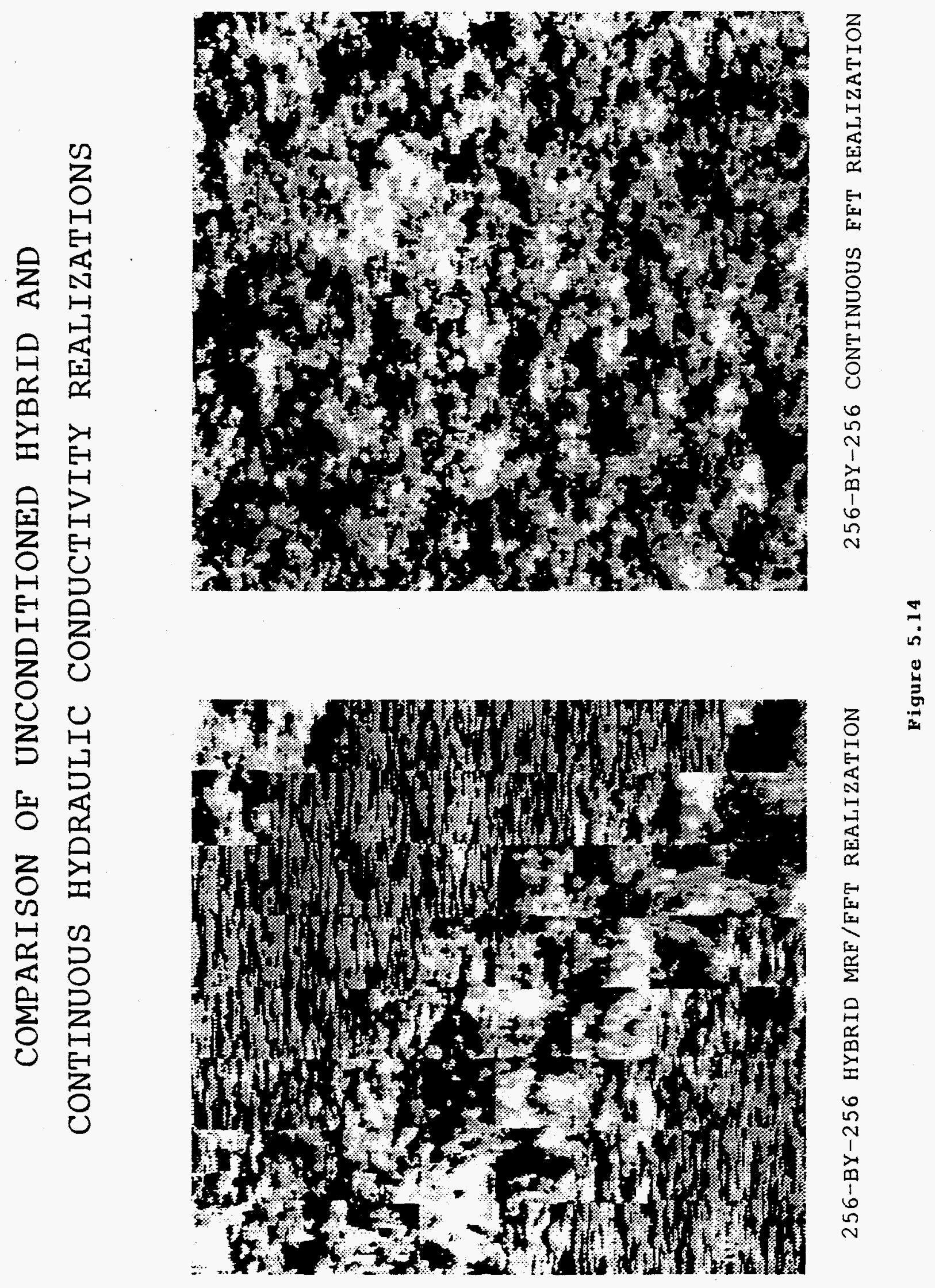


lithologies observed in the deposits at scales on the order of meters, while the moments of the small-scale FFT realizations were arbitrarily selected based on the random variable associated with the large-scale block in which it was embedded. Figures 5.15 again demonstrate that the use of a single-scaled, continuous geostatistical model could produce different travel time predictions compared to those of the more physically realistic two-scale hybrid discrete/continuous model. Again, more runs are needed to decide if the differences are significant.

Figure 5.16 are realizations similar to those presented in Figure 5.14, except that they have both been conditioned on a set of 192 synthetic point air-permeameter data. Conditioning was performed at the larger scale using point-to-block kriging similar to that used by Rubin and Gomez-Hernandez (1990) to define 'known' discrete random variables in certain large-scale blocks where point data was available. These large-scale conditioning blocks were placed in the initial uncorrelated MRF process and ignored during subsequent importance sampling so that they remained unchanged throughout the Markov chain and were honored in the final large-scale MRF realization. The small-scale embedded FFT realizations were conditioned on the point data by again performing point-to-block kriging, then by kriging the FFT realization at the locations nearest to the data points and adding the difference between the FFT realization and its kriged version to the original kriged realization. For the case of small-scale conditioning, the air-permeameter dataset was expanded to include boundary values of small-scale conditioned fields in adjacent large-scale blocks whenever those large-scaled blocks had the same lithology. This procedure imposed a certain degree of continuity between blocks with the same lithology, but the boundary values of adjacent blocks were not strictly honored because a non-zero search radius was used for the point-to-block kriging. Figures 5.17 demonstrate that, again, for this particular set of conditioned realizations, the characteristic transport behavior of the two-scale hybrid realization is different than that predicted by the statistically equivalent single-scale continuous realization. 


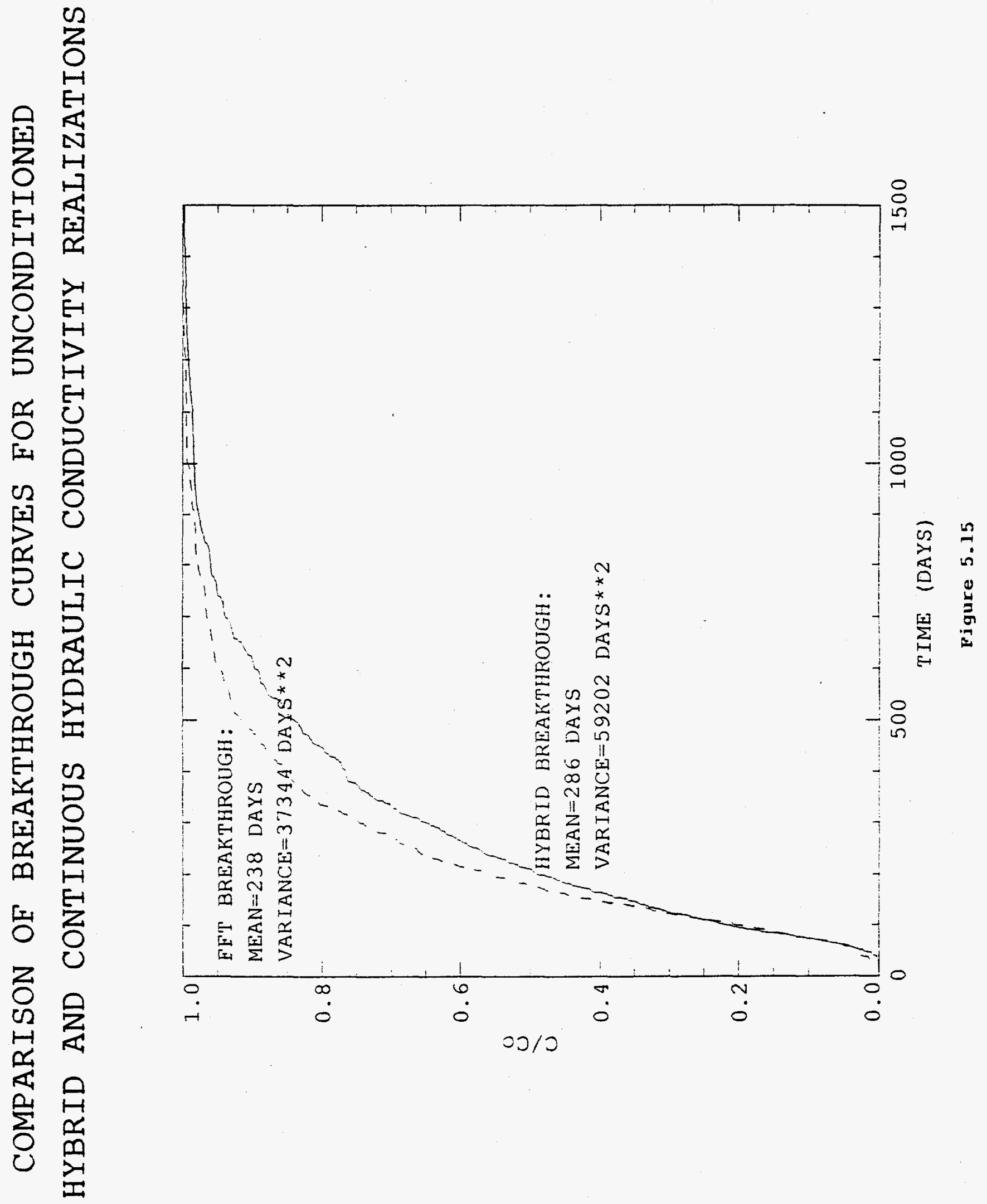




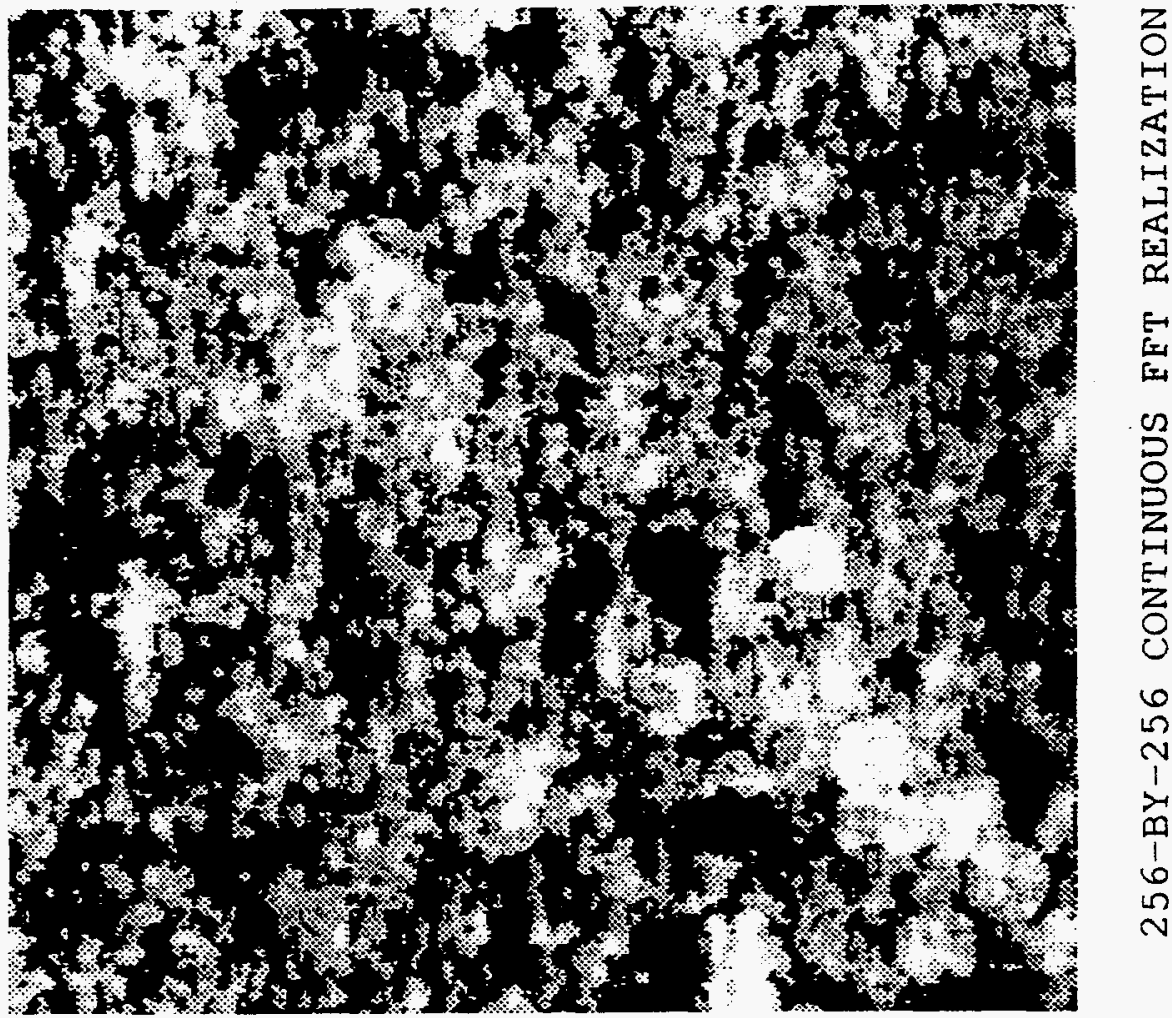

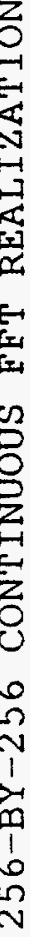

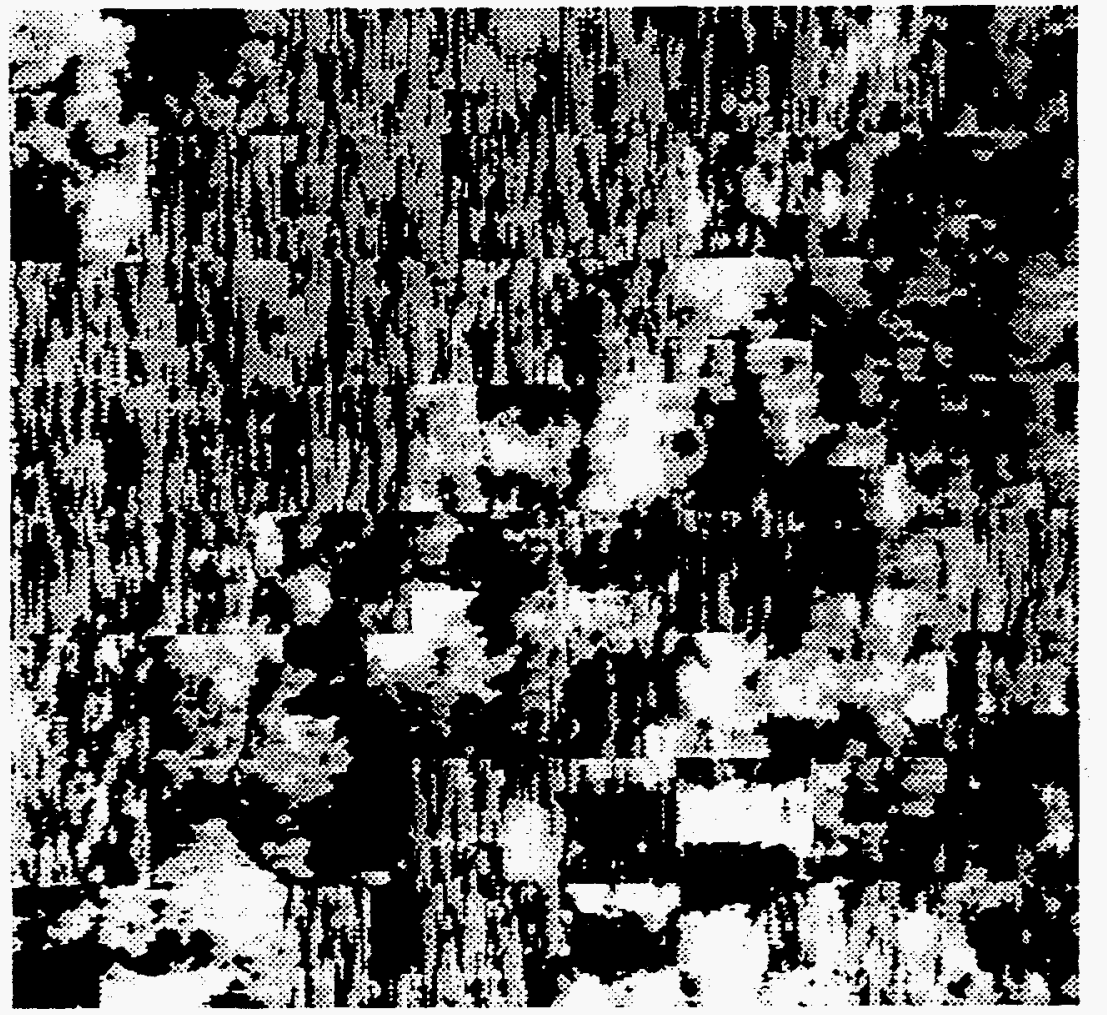




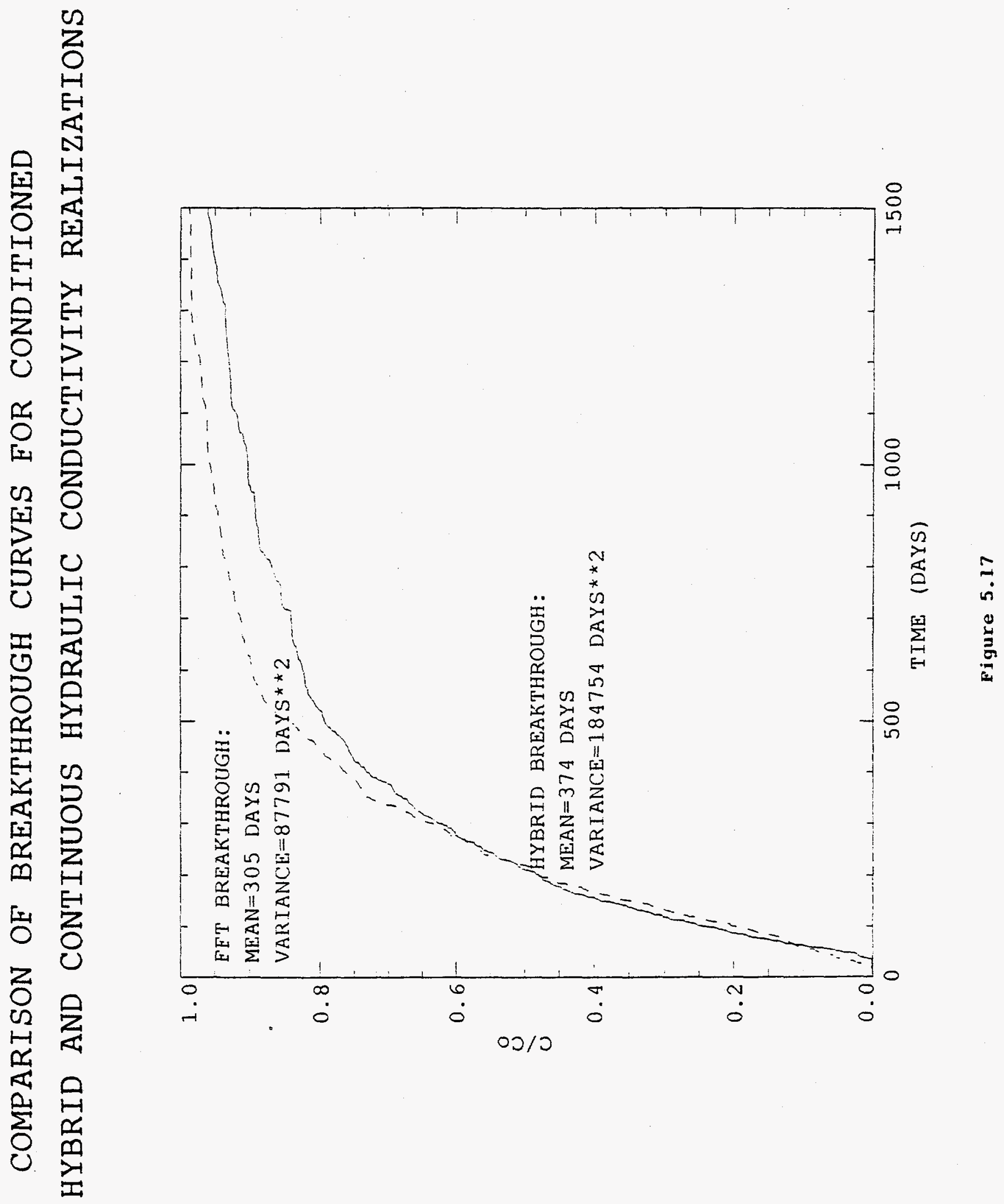




\section{DESIGN OF OPTIMAL SAMPLING NETWORKS}

A very important issue that needs to be addressed is the question of the scale at which additional conductivity sampling should be performed in order to gain the most information about the conductivity field (see Figure 5.18). Obviously, this question has meaning only when asked in the context of a particular flow or transport problem. For example, we might be interested in choosing a conductivity sampling location and scale that minimizes the concentration prediction variance at an EPA monitoring well. Depending on the nature of the transport problem and on the location of the well relative to the heterogeneities, more marginal information might be gained by geologic mapping than by air-permeameter sampling. We might gain even more information about monitor-well concentration by performing a pump test than by conducting a series of slug tests. A sampling network design algorithm can easily be developed using standard integer-programming techniques that essentially 'turn on' sampling at locations that yield the most additional information about the current estimate of the conductivity field (Cleveland and Yeh, 1990; 1991)

This algorithm can easily be extended to permit simultaneous optimization of conductivity information over both sampling location and scale.

\section{CONCLUSIONS}

It appears that Markov random fields are very well-suited to generating the kind of discrete structure that has been observed in alluvial deposits for at least one scale of observation. Using Markov random field theory, we are not forced to build artificial geologic structure lacking higher-order moments because we are no longer restricted to gaussian processes in which higher than second-order moments are neglected. Based on particle transport simulations performed to date, it is clear that discrete and continuoussingle-scale conductivity realizations, 
Figure 5.18. Schematic illustration of possible sampling strategy

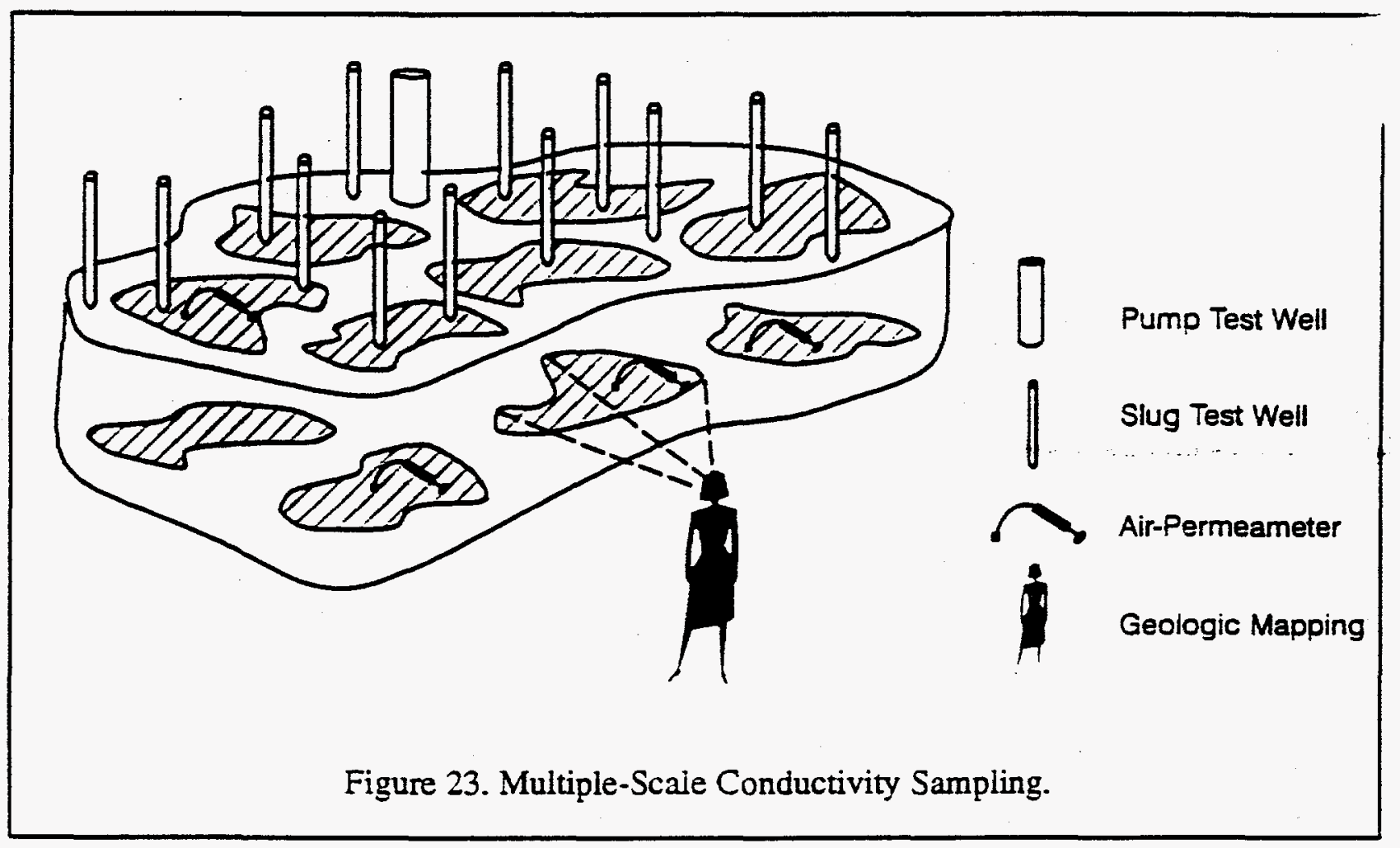


as well as multiple-scale and single-scale realizations, may exhibit very different flow and transport responses. Finally, it appears that it may be feasible to sequentially design sampling networks that simultaneously optimize both sampling location and scale, given a particular transport problem.

\section{FUTURE RESEARCH}

It is evident that we need to find a way to bridge the gap between local conditional Markov and global joint correlation parameters when building discrete portions of the geologic structure. Clearly, Markov parameters characterize the degree of interaction or correlation between neighboring values in a random field and are, in some manner, directly related to the correlation or integral scale. Correlation will certainly decrease with increasing distance between points, but will not do so geometrically (Isham, 1981). Methods of estimating the correlation properties of MRFs are notoriously difficult and only approximate results are available in most cases. The problem seems to be that Markov parameters describe higher-order properties than the covariance is capable of describing. As a result, the relationship between Markov parameters and correlation scale may be hopelessly corrupted by high-order effects unless such high-order effects are explicitly accounted for.

Preliminary numerical experiments reveal that the integral scale in binary, isotropic MRFs, estimated by fitting a series of cubic splines to discrete sample covariance functions estimated from the MRF realizations, increases as a logarithmic function of the isotropic Markov parameter. This logarithmic behavior is not surprising, given that the conditional probabilities associated with local structure change exponentially with respect to the Markov parameters.

In any event, the MRF, like the Gibbs distribution, is a manifestation of the 'smoothest' possible joint pdf, constrained only by the average energy in the field. It is expected that second- and higher-order behavior, and thus the dependence between Markov parameters and correlation scale, will depend on the choice of the neighborhood system, as well as on the local 
energy function $U^{\prime}(v \mid$.$) , the variance of the MRF, and the size of the field, all of which will$ dictate the variety of structures that the field can adopt. Using Monte Carlo simulation, it will be possible to infer how all of these variables impact the final joint probabilistic behavior of the geologic structure. For the case of Gaussian Markov random fields, the equivalence between MRF models and autoregressive models could be exploited in order to introduce some analytical capability to the research, but this would obviously be at the expense of ignoring what could be significant high-order moments in the observed geologic structure.

We also need to find methods of increasing the rate of convergence associated with Markov chains and judging convergence of the chains to MRF realizations. Convergence becomes especially slow late in the chain when low frequency components of the realization are being organized. This is because it takes a while for locally-defined characteristics to propagate through the domain. Using a renormalization group approach, we can define a fine- to coarse-grained cascade and renormalize the interaction energy functions, or Hamiltonians, as we move down the cascade (Gidas, 1989). In effect, the renormalization approach allows information to be transferred from small to large scales of variation. Structure is then generated by moving back up the cascade to simulate progressively finer-grained features.

Also of interest is the potential for reducing computational time by exploiting the parallel aspects of the Metropolis algorithm, maximum likelihood parameter estimation, and goodness-of-fit hypothesis testing. Since implementation of the Metropolis importance sampling algorithm requires that information at updated sites located in the neighborhood of other sites be serially communicated to the processors associated with those sites, a pseudo-parallel approach would be required (Geman and Geman, 1984). This could be effected by masking portions of the processor array that are associated with neighborhoods of sites currently being refreshed by the importance sampling algorithm (Dougherty, 1991). Alternatively, the domain could be subdivided into subdomains within which updating is performed independently of all other subdomains, again with information being communicated, this time between sets of 
processors. For fully parallel parameter estimation and goodness-of-fit testing, assignment of a single processor to each site would reduce the computational burden for a system of $M$ sites by roughly a factor of M. Clearly, parallel- and pseudo-parallel processing have the potential to speed up what are essentially very slow problems due to their nonlinear nature.

Finally, we need to develop objective criteria for determining the scales at which continuous conductivity realizations should be nested within discrete realizations, as well as scales at which discrete structure predominates. 


\section{CHAPTER VI: DISCUSSION AND CONCLUSIONS}

Stochastic hydrology was founded largely on the conceptualization of aquifer heterogeneity as a stochastic field. By representing the spatial variation of hydraulic conductivity as a multivariate Gaussian process and imposing certain assumptions allows for the analytical solution of the flow and transport governing equations (e.g. Bakr et al., 1979; Gelhar and Axness, 1983). Through the quantitative random field conceptualization, tremendous advances have been made in our ability to describe the evolution of a solute plume. Results of field tracer experiments show generally good comparison between the theoretical models and the observed plume behavior (e.g. Freyberg, 1986; Garabedian et al., 1991). Deviations from the dispersivity predicted by the model and those observed in the field have been attributed a variety of unmodeled physical processes (e.g. non-uniform flow field, spatial variability of porosity) and uncertainty associated with the estimation of the hydraulic conductivity correlation length and variance (Hess et al., 1992). These various factors could undoubtedly result in the observed difference. However, another possible reason for the discrepency between predicted and observed dispersivities is the appropriateness of the multivariate Gaussian conceptualization of heterogeneity.

Based on the stochastic conceptualization of heterogeneity, a physically based theory has been developed to quantify flow and transport through heterogeneous porous media. Since the multivariate Gaussian representation requires only the first two moments of the joint distribution, recent statistical characterizations of aquifer heterogeneity focus solely on the estimation of the first two moments and lack a physical conceptual basis (e.g. Woodbury and Sudicky, 1991; Hess et al., 1992). This approach falls short in improving our understanding of the heterogeneity itself.

The applicability of the multivariate Gaussian representation of heterogeneity has been 
questioned by some workers (e.g. Journel and Alabert, 1988). Alternative statistical models of heterogeneity which are believed to provide a better representation of certain aspects of heterogeneity have recently emerged. Journel and Alabert (1988) propose an indicator simulation algorithm which exhibits better spatial connectivity of extreme values. Wheatcraft and Tyler (1988) and Neumann (1990) speculate that heterogeneity is multi-scale and could be better represented as a fractal process. Based on our own field observations, Colarullo and Gutjahr (1992) have developed a multi-dimensional Markov random field algorithm for representing spatially discrete heterogeneity.

Future applications of stochastic hydrology theory will rely heavily on meaningful statistical characterizations of aquifer heterogeneity. Here, geostatistical characterization includes the selection of a random field model in addition to the subsequent parameterization of the model. In order to effectively characterize heterogeneity, a physically based conceptual framework is required.

This project has focused on investigating the relationship between observed geologic features and geostatistical characteristics. By studying the heterogeneity of actual geologic materials in the context of both sedimentology and stochastic fluid flow models, we can begin to develop a conceptual framework for the geostatistical characterization of aquifer heterogeneity.

\section{CONCEPTUAL MODEL OF HETEROGENEITY}

We begin by conceptualizing heterogeneity as a result of complex geologic processes which cannot be known in detail. While the details of the subsurface cannot be ascertained, there exists a relationship between the depositional processes and the general characteristics of the heterogeneity. Stochastic models are preferred over deterministic facies modeling (e.g. Anderson, 1990) since they acknowledge our uncertainty regarding the subsurface by representing the statistical characteristics of the spatial distribution of conductivity. 
Just as facies models of heterogeneity do not explicity account for our uncertainty of the specific spatial distribution of lithologies, stochastic models of heterogeneity do not explicity account for our understanding of the spatial distribution of lithologies based on depositional processes. These conceptualizations are not mutually exclusive by nature, they just have not been used together.

A framework is necessary so that we can relate the information regarding the geologic characterics to the stochastic models used to represent those characteristics. Since our information regarding the geologic characteristics is in the form of sedimentological models we must investigate the implications sedimentological information has on modeling the heterogeneity.

Sedimentological models are based on the premise that deposits of different sedimentary environments are different in 1) the type of lithofacies, 2) the spatial dimensions of the lithofacies, and 3) the spatial association of the lithofacies. Such information is very similar to the type of information the various stochastic models of heterogeneity attempt to characterize.

Similarly, stochastic models of heterogeneity differ in 1) the modality of the model, 2) the number of dominant scales of heterogeneity, and 3) degree of statistical anisotropy. From the outcrop study of the Sierra Ladrones Formation, we have seen a relationship between 1) the occurence of lithofacies and the modality of the permeability distribution, 2) the presence of at least two scales of heterogeneity governed by the scales of the lithofacies and the architectural elements, and 3) the orientation and dimensions of the lithofacies to the 




MVG = Multi-variate Gaussian

Figure 6.1. Conceptual Geostatistical-sedimentological model of heterogeneity. 
anisotropy of the correlation structure. Figure 6.1 illustrates how information of depositional processes can be used to infer the desired attributes of a random field model of heterogeneity.

\section{RESEARCH ACCOMPLISHMENTS}

The main research accomplishments include:

1) Development of a lightweight highly portable air mini-permeameter

2) Extensive field investigation of geologic heterogeneity at the two principal scales which show the relationship between depositional processes and correlation structure. At the element scale, the multi-dimensional variogram appears anisotropic with directions of maximum and minimum correlation lengths coinciding with the directions of the large scale depositional processes. The direction of maximum correlation corresponds to the orientation of the sand scours. The direction of weakest correlation (E-W) coincides with gradational an east-west transition from proximal to distal floodplain deposition.

3) Development of an algorithm for generating multi-dimensional Markov random fields.

4) A conceptual framework which will permit statistical models of hydraulic parameter distributions in alluvial sediments to be related to geoloically-based models of sediment deposition.

5) A methodology for conducting investigations that relate geological and geostatistical models that can be used in similar studies and generalized to geologic materials other than alluvial sediments.

\section{FUTURE WORK}

The methodology developed here has led to a more general conceptualization of aquifer heterogeneity. By recognizing that the random field representation of heterogeneity should be broadly based to include stochastic models which best represent the physical 
attributes of an aquifer, we have expanded the geostatistical characterization to include the choice of the most appropriate statistical model.

This conceptualization requires further refinement through testing at other outcrops. In addition, diagenetic effects have been neglected thus far but are expected to play a major role in the conceptualization and modeling of heterogeneity. Physical models of diagenesis will be useful in assessing the pervasiveness and distribution of diagenetic processes. Studies of early diagenesis in shallow aquifers are expected to enhance the ability to model the effects of diagenesis.

Based on the sedimentological conceptualization of heterogeneity, more sophisticated methods for estimating the statistical parameters of the different random field models (e.g. Phillips and Wilson, 1989) need to be pursued. This task however can only be successful if our conceptualization of heterogeneity is self-consistent in terms of geology and random field models. For example, the threshold crossing theory employed by Phillips and Wilson (1989) for the estimation of correlation lengths based on the mappable dimensions of hydrologic units was found to be difficult to apply to a system where the multivariate Gaussian representation was not meaningful. For deposits that can be conceptualized as a multivariate Gaussian field, the method is expected to be widely applicable.

\section{ACKNOWLEDGEMENTS}

This research was funded by the Subsurface Science Program, Office of Energy Research, U.S. Department of Energy under contract \#DE-FG04-89ER60843. Ruth Lohmann was the recipient of the Society Economic Paleontologists and Mineralogists 1991 E.D. McKee Grant. Susan Colarullo is a 1992 recipient of the American Geophysical Union Horton Research Grant; and Matt Davis is the recipient of the New Mexico Geological Society 1992 Wellnitz Fellowship. We would like to thank Dr. John Heller for early discussions regarding mechanical pressure sources used in air-permeametry and Mike 
Fort for his valuable assistance in developing the LSAMP curcuitry. 


\section{REFERENCES}

Adamson, A.W, 1979, A textbook of physical chemistry, Academic Press, New York.

Allen, J.R.L., 1974, Studies in fluviatile sedimentation: Implication of pedogenic carbonate units, Lower Old Red Sandstone, Anglo-Welsh Outcrop: Geological Journal, v. 9, p. 181-208.

Allen,J.R.L. 1983, Studies in fluviatile sedimentation: bars, bar-complexes and sandstone sheets (low sinuosity braided streams) in the Brownstones (L.Devonian), Welsh Borders. Sed.Geol. 33:237-293.

Armstrong,M. 1984, Common problems seen in variograms. Mathematical Geology 16:305313.

Bates, R.L., and J.A. Jackson, 1984, Dictionary of Geological Terms, 3rd ed.: The American Geological Institute, Doubleday, New York, $571 \mathrm{p}$.

Bear, J., 1972, Dynamics of fluids in porous media. American Elsevier, New York.

Besag, J., 1974, Spatial interaction and the statistical analysis of lattice systems (with discussion), J. Royal Statist. Soc., series B, v. 36, p. 192-326.

Birkeland, P.W., 1984, Soils and Geomorphology: Oxford University Press, London, 372 p.

Bryan, K., and F.T. McCann, 1937, The Ceja del Rio Puerco: A border feature of the Basin and Range province in New Mexcio, Part I, J. Geol., v. 45, 801-828.

Bryan, K., 1938, The Ceja del Rio Puerco: A border feature of the Basin and Range province in New Mexico, Part II, J. Geol., v.46, 1-16.

Burrough, P.A., 1983, Multiscale sources of spatial variation is soil. II. A non-Brownian fractal model and its applications in soil survey: Journal of Soil Science, v. 34, p. 599-620.

Chapin C.E. and W.R. Seager, 1975, Evolution of the Rio Grande rift in Socorro and Las Cruces areas, New Mexico Geological Society Guidebook 26, p. 297-321.

Cleveland, T.G. and W. W.-G. Yeh, 1990, Sampling Network Design for Transport Parameter Identification, J. Water Res. Plan. Manage., v. 116, n. 6, p. 764-783.

Cleveland, T.G. and W. W.-G. Yeh, 1991, Optimal Configuration and Scheduling of Ground-Water Tracer Tests, J. Water Res. Plan. Manage., v. 117, n. 1, p. 37-51. 
Colarullo, S.J., and A.L. Gutjahr, 1991, Characterization of aquifer heterogeneities using discrete Markov random fields: EOS (American Geophysical Union Transactions) v. 72(44), p. 227.

Cushman, J.H., 1984, On the unifying concepts of scale, instrumentation, and stochastics in the development of multiphase transport theory, Water Resour. Res., v. 20, p. 1668-1676.

Damsleth, E., C.B. Tjolsen, H. Omre, and H.H. Haldorsen, 1992, A two-stage stochastic model applied to a North Sea reservoir, Jour. Petr. Tech., April 1992, p. 402-409.

Davis, J.M., S.J. Colarullo, F.M. Phillips, and R.C. Lohmann, 1991, Alluvial aquifer heterogeneities in the Rio Grande valley: Implications for groundwater contamination: New Mexico Water Resources Research Institute Technical Completion Report No. 256, 111 p.

Davis, J.M., 1991, Technical Completion Report, Greater Confinement Disposal Heterogeneity Study, Nevada Test Site, Area 5, Radioactive Waste Management Site. Reynold's Electric \& Engineering Co.

Davis, J.M., J.L. Wilson, and F.M. Phillips, 1992a, An air-permeameter for the rapid and non-destructive sampling of moderately consolidated sediments: paper in preparation for to submission to Ground Water .

Davis, J.M., R.C. Lohmann, D.W. Love, and F.M. Phillips, 1992b, Architecture of the Sierra Ladrones Formation: Deposits of the ancestral Rio Grande system: paper in preparation for submission to New Mexico Geology.

Denny, G.S., 1940, Tertiary geology of the San Acacia area, New Mexico, J. Geol., v. 48, 73-106

Deutsch, C.V., and A.G. Journel, 1992, GSLIB: Geostatistical Software Library User's Guide, Oxford University Press, New York.

Dougherty, D.E., 1991, Hydrologic Application of the Connection Machine CM-2, Water Resources Research, v. 27, n. 12, p. 3137-3147.

Dreyer, T., A. Scheie, and O. Waldenhaug, 1990, Minipermeameter-based study of permeability trends in channel sand bodies: American Association of Petroleum Geologists Bulletin, v. 74(4), p. 359-374.

Eijpe, R., and K.J. Weber, 1971, Mini-permeameters for rock and unconsolidated sand, Am. Assoc. Petr. Geol. Bull., v.55, pp. 307-309. 
Englund,E., and A.Sparks. 1991, Geostatistical Environmental Assessment Software and Users Guide. EPA 600/8-91/008. Environmental Monitoring Systems Laboratory Office of Research and Development, U.S.E.P.A., Las Vegas, Nevada.

Farmer, C.L., 1987, The generation of stochastic fields of reservoir parameters with specified geostatistical distributions, paper presented at the IMA Conference on The Mathematics of Oil Production, Cambridge, July 6-7, 15 pp.

Freyberg, D.L., 1986, A natural gradient experiment on solute transport in a sand aquifer, 2, Spatial moments and the advection and dispersion of nonreactive tracers, Water Resour. Res., v. 22, 2031-2046.

Garabedian, S.P., D.R. LeBlanc, L.W. Gelhar, and M.A. Celia, 1991, Large-scale natural gradient tracer test in sand and gravel, 2, Analysis of spatial moments for a nonreactive tracer: Water Resour. Res. v. 27(5), p. 911-924.

Gelhar, L.W., and C.L. Axness, 1983, Three-dimensional stochastic analysis of macrodispersion in aquifers: Water Resour. Res. v. 19(1), p. 161-180.

Geman, S. and D. Geman, 1984, Stochastic Relaxation, Gibbs Distributions, and the Bayesian Restoration of Images, IEEE Trans. on Pattern Anal. Machine Intell., v. 6, n. 6,p. 721-741.

Gidas, B., 1989, A Renormalization Group Approach to Image Processing Problems, IEEE Trans. on Pattern Anal. Machine Intell., v. 11, n. 2, p. 164-180.

Gile, L.H., J.W. Hawley, and R.B. Grossman, 1981, Soils and geomorphology in the Basin and range area of southern New Mexico--Guidebook to the Desert Project, New Mexico Bureau of Mines \& Mineral Resources, Memoir 39., 222 p.

Goggin, D.J., M.A. Chandler, G. Kocurek, and L.W. Lake, 1988a, Patterns of permeability in eolian deposits: Page Sandstone (Jurassic) Northeastern Arizona: Society of Petroleum Engineers Formation Evaluation, v. 3, p. 297-306.

Goggin, D.J., R. Thrasher, and L.W. Lake, 1988b, A theoretical and experimental analysis of minipermeameter response including gas slippage and high velocity flow effects: In Situ, v. 12, p. 79-116.

Gotway, C.A., and N.A.C.Cressie, 1990, A spatial analysis of variance applied to soil-water infiltration. Water Resour. Res. 26: 2695-2703.

Gutjahr, A.L., 1989, Fast Fourier Transforms for Random Field Generation, Project Report for Los Alamos Grant to New Mexico Tech, Contract Number 4-R58-2690R, 106 p. 
Haldorsen, H.H., and E. Damsleth, 1990, Stochastic modeling: Journal of Petroleum Technology, v. p. 404-412.

Harris, J., 1991, Provenance analysis of upper Sierra Ladrones Formation near Bosque, New Mexico, unpublished data.

Hastings, W.K., 1970, Monte Carlo sampling methods using Markov chains and their applications, Biometrika, v. 57, n. 1, p. 97-109.

Hess, K.M., S.H. Wolf, and M.A. Celia, 1992, Large-scale natural gradient tracer test in sand and gravel, Cape Cod, Massachusetts, 3, Hydraulic conductivity variability and calculated macrodispersivities. Water Resour. Res., v. 28, 2011-2027.

Isaaks, E.H., and R.M. Srivastava, 1989, An Introduction to Applied Geostatistics: Oxford University Press, New York, 561 p.

Isham, V., 1981, An introduction to spatial point processes and Markov random fields, Int. Stat. Rev., v. 49 , p. $21-43$.

Journel, A.G. and C.J. Hujbreghts, 1978, Mining Geostatistics. New York: Academic Press.

Journel, A.G., and F.G. Alabert, 1988, Focusing on the spatial connectivity of extremevalued attributes: Stochastic indicator models of reservoir heterogeneity: Society of Petroleum Engineers paper 18324, presented at the 63rd Annual Technical Conference and Exhibition of the Society of Petroleum Engineers, Houston, Texas, Oct. 2-5.

Katz, D.L. and R.L. Lee, 1990, Natural gas engineering: production and storage, McGrawHiil Publishing Company, New York, 760 pp.

Kittridge, M.G., L.W. Lake, F.J. Lucia, and G.E. Fogg, 1989, Outcrop-subsurface comparisons of heterogeneity in the San Andres Formation. SPE paper 19596, presented at 64th Annual Technical Conference, October 8-11, San Antonio, Texas.

Lipman, P.W. and H.H. Mehnert, 1980, Potassium-argon ages from the Mount Taylor volcanic field, New Mexico: U.S. Geological Survey Professional Paper 1124-B, 8 p.

Lozinsky, R.P., 1988, Stratigraphy, sedimentology, and sand petrology of the Santa Fe Group and pre-Santa Fe Tertiary deposits in the Albuquerque Basin, Central New Mexico: PhD Dissertation, New Mexico Institute of Mining and Technology, Socorro, New Mexico, 298p.

Lozinsky, R.P., J.W. Hawley, and D.W. Love, 1991, Geologic overview and PlioceneQuaternary history of the Albuquerque Basin, Central New Mexico, in J.W. Hawley and D.W. Love eds., Quaternary and Neogene landscape evolution: A transect across 
the Colorado Plateau and Basin and Range provinces in West-Central and Central New Mexico: New Mexico Bureau of Mines and Mineral Resources Bulletin 137 , p. $157-162$.

Macedonio, G., and M.T. Pareschi, 1991, An algorithm for the triangulation of arbitrarily distributed points: Applications to volume estimate and terrain fitting: Computers and Geoscience, v. 17, p. 859-874.

Machette, M.N., 1978, Geologic map of the San Acacia quadrangle, Socorro County, New Mexico: United States Geological Survey Map GQ-1415, scale 1:24,000.

McGrath, D.G., and J.W. Hawley, 1987, Geomorphic evolution and soil-geomorphic relationships in the Socorro area, Central NM: in Mclemore, V.T., and Bowie M.R. eds., Guidebook to the Socorro Area, New Mexico: New Mexico Bureau of Mines and Mineral Resources, Socorro New Mexico, p. 55-67.

McKee, E.D., 1966, Significance of climbing-ripple structure, U.S. Geological Survey Professional Paper 550-D, p. D94-D103.

McKee, E.D., E.J. Crosby, and H.L. Berryhill Jr., 1967, Flood deposits, Bijou Creek, Colorado, June 1965, J. Sed. Petrology, v. 37, p. 829-851.

Merriam, D.F., 1976, Random Processes in Geology, Springer-Verlag, New York.

Metropolis, N., A.W. Rosenbluth, M.N. Rosenbluth, A.H. Teller, and E. Teller, 1953, Equations of State Calculations by Fast Computing Machines, Journal Chem. Phys.,v. 21, p. 1087-1091.

Miall, A.D., 1978, Lithofacies types and vertical profile models of braided river deposits: a summary: in Miall, A.D., ed., Fluvial Sedimentology: Canadian Society of Petroleum Geologists Memoir 5, p. 597-604.

Miall, A.D., 1985, Architectural element analysis: A new method of facies analysis applied to fluvial deposits: Earth Science Reviews, v. 22, p. 261-308.

Miall, A.D., 1988, Facies architecture in clastic sedimentary basins: in Kleinsphen, K.L., and Paola, C., eds., New perspectives in basin analysis: Springer-Verlag, New York, $452 \mathrm{p}$.

Munsell Color Charts, 1990, Edition Revised, Kollmorgen Instruments Corporation, Baltimore Maryland.

Neuman, S.P., 1990, Universal scaling of hydraulic conductivities and dispersivities in geologic media, Water Resour. Res., v. 26, 1749-1758. 
Phillips, F.M. and J.L. Wilson, 1989, An Approach to Estimating Hydraulic Conductivity Spatial Correlation Scales Using Geological Characteristics, Water Resour. Res., v. 25 , n. 1, p.141-143.

Rubin, Y. and J.J. Gomez-Hernandez, 1990, A Stochastic Approach to the Problem of Upscaling of Conductivity in Disordered Media: Theory and Unconditional Numerical Simulation, Water Resour. Res., v. 26, n. 4, p. 691-701.

Seager, W.R., M. Shafiqullah, J.W. Hawley, and R. Marvin, 1984, New K-Ar dates from basalts and the evolution of the southern Rio Grande rift, Geol. Soc. Amer. Bull., v. 95, p. 87-99.

Spiegel, Z., and B. Baldwin, 1963, Geology and water resources of the Santa Ana area, New Mexico, U.S. Geol. Surv. Water-Supply Paper 1525, 258pp.

Spitzer, F., 1971, Markov random fields and Gibbs ensembles, Amer. Math. Mon., v. 78,p. $142-154$.

Strearns, C.E., 1953, Tertiary geology of the Galesteo-Tongue area, New Mexico, Geol. Soc. Amer. Bull., v. 64, 459-508.

Symon, K.R., 1971, Mechanics. Addison-Wesley, Menlo Park, 639 pp.

U.S. Department of Energy, 1990, Subsurface Science Program, Program Overview and Research Abstracts, FY 1989- FY 1990, Office of Energy Research, DOE/ER-0432,150 pp.

Wheatcraft, S.W., and Tyler, S.W., 1988, An explanation of scale-dependent dispersivity in heterogeneous aquifers using concepts of fractal geometry: Water Resour. Res. v. 24(4), p. 566-578.

Woodbury, A.D., and E.A. Sudicky, 1991, The geostatistical characteristics of the Borden Aquifer, Water Resour. Res., v. 27, 533-546.

Young, J.D., 1982, Late Cenozoic geology of the lower Rio Puerco, Valencia and Socorro Counties, New Mexico: M.S. Thesis, New Mexico Institute of Mining and Technology, Socorro, 126 p. 
APPENDIX I

Graduate Students Trained and Degrees Granted

HYDROLOGY M.S. Ph.D.

J. Matthew Davis

1990

1993*

Susan J. Colarullo

$1993^{*}$

Ruth C. Lohmann

1992

Madeline B. Gotkowitz 1993*

Caroline Planert (part-time) 1993* 
APPENDIX II

Small-scale Permeability Study Data

SS-1 through SS-4 


\section{APPENDIX III \\ Publications Emanating from Project}

Colarullo, S.J., and A.L. Gutjahr, 1991, Characteriztion of aquifer heterogeneities using discrete Markov Random Fields (abstract), Eos Trans. AGU, 72, Fall Meeting Suppl., p. 227.

Davis, J.M. and F.M. Phillips, 1990, A Quantitative Geological Study of Heterogeneity: Sierra Ladrones Formation, Central New Mexico, in Transport and Mass Exchange Processes in Sand and Gravel Aquifers: Field and Modelling Studies, G. Moltyaner (ed.), Atomic Energy of Canada Limited, Chalk River, Ontario, Canada, p. 318-341.

Davis, J.M., S.J. Colarullo, R.C. Lohmann, and F.M. Phillips, 1991, Alluvial aquifer heterogeneities in the Rio Grande Valley: Implications for ground-water contamination, New Mexico Water Resources Research Institute Technical Completion Report No. 256, Las Cruces, New Mexico, 111 pp.

Davis, J.M., R.C. Lohmann, D.W. Love, and F.M. Phillips, 1992, Architectural Element Analysis for the Characterization of Aquifer Heterogeneity: Sierra Ladrones Formation, Albuquerque Basin (abstract), In Proceedings of the New Mexico Geological Society 1992 Annual Spring Meeting, New Mexico Geological Society, Socorro, New Mexico, p. 6.

Davis, J.M., Fred M. Phillips, J.L. Wilson, R.C. Lohmann, and D.W. Love, 1992, A Sedimentological-Geostastical Model of Aquifer Heterogeneity Based on Outcrop Studies (abstract), Eos Trans. AGU, 73(14), Spring Meeting Suppl., p. 112.

Gutjahr, A.L., 1991, Geostatistics for Sampling Designs and Analysis, in Groundwater Residue Sampling Design and Techniques, R. Nash and A. Leslie (eds.), American Chemical Society, Washington, D.C., p. 48-86.

Lohmann, R.C., J.M. Davis, D.W. Love and F.M. Phillips, 1991, Hydrogeologic investigations of Upper Sierra Ladrones Formation, in New Mexico Bureau of Mines and Mineral Resour. Bull. 137, 164-166.

Phillips, F.M., 1991, The History of Solute Transport Predictions for Groundwater: A Tale of Two Worlds (abstract), Eos Trans. 72, Fall Meeting Suppl., p. 171.

Phillips, F.M. and J.L. Wilson, 1989, An approach to estimating hydraulic conductivity spatial correlation scales using geological characteristics, Water Resour. Res., 25, 141-143. 
Phillips, F.M., J.L. Wilson, and J.M. Davis, 1989, Statistical analysis of hydraulic conductivity distributions: A quantitative geological approach, In Proceedings of the Conference on New Field Techniques for Quantifying the Physical and Chemical Properties of Heterogeneous Aquifers, F.J. Molz, J.G. Melville, and O. Guven (eds.), National Water Well Association, Dublin, Ohio, p. 19-32.

Phillips, F.M., J.M. Davis, A.L Gutjahr, and D.W. Love, 1990, A Quantitative Geological Study of Heterogeneity, Sierra Ladrones Formation, Central New Mexico (abstract), Eos Trans. AGU, 71(17), Spring Meeting Suppl., p. 509.

Wilson, J.L. and F.M. Phillips, 1990, The role of geology in parameter estimation (abstract), in Proceedings of the Fifth Canadian/American Conference on Hydrogeology, S. Bachu (ed.), National Water Well Association, Dublin, Ohio, p. 1.

Papers in preparation for submission to peer reviewed journals

Davis, J.M., F.M. Phillips, and J.L. Wilson, A portable field air-minipermeameter for rapid in-situ measurements, submitted to Groundwater.

Davis, J.M., R.C. Lohmann, F.M. Phillips, and J.L. Wilson, Alluvial architecture in the Sierra Ladrones Formation, Central New Mexico: Depositional controls on the permeability correlation structure, submitted to Geol. Soc. Amer. Bulletin.

Davis, J.M., Love, D.W., Phillips, F.M., and Lohmann, R.C., Architecture of the Sierra Ladrones Formation: Deposits of the ancestral Rio Grande, paper in preparation for submission to New Mexico Geology.

\section{Unpublished papers and presentations}

Davis, J.M., 1990, An approach for the characterization of spatial variability of permeability in the Sierra Ladrones Formation, Albuquerque Basin, central New Mexico, M.S. Thesis, New Mexico Institute of Mining and Technology, Socorro, New Mexico. 136 pp.

Lohmann, R.C., D.W. Love, and J.M. Davis, 1991, A sedimentological approach to hydrologic characterization: Sierra Ladrones Formation, presented at the Fourth Annual Conference of the AWRA New Mexico Section, September 18-19, Socorro, NM.

Lohmann, R.C., 1992, A sedimentological approach to hydrologic characterization: A detailed three-dimensional study of an outcrop of the Sierra Ladrones Formation, Albuquerque Basin, M.S. Independent Study, New Mexico Institute of Mining and Technology, Socorro, New Mexico, 130 pp. 
SS-1 data

July 29, 1992

mass of piston: $178.1 \mathrm{~g}$

length between sensors $5.15 \mathrm{~cm}$

tip seal i.d. $0.70 \mathrm{~cm}$

tip seal $0 . d .2 .80 \mathrm{~cm}$

\begin{tabular}{|c|c|c|c|c|c|c|c|}
\hline hydro unit & facies & $n$ & time (s) & $x(\mathrm{~cm})$ & $y(\mathrm{~cm})$ & $q[\mathrm{cc} / \mathrm{s}]$ & $k[$ da \\
\hline$I$ & 1 & 1 & 2.09 & 7 & 0 & 23.71 & 16.79 \\
\hline$I$ & 1 & 2 & 1.66 & 7 & 14 & 29.85 & 22.60 \\
\hline$I$ & 1 & 3 & 1.83 & 12 & 14 & 27.08 & 19.86 \\
\hline I & 1 & 4 & 5.85 & 12 & 0 & 8.47 & 5.31 \\
\hline I & 1 & 5 & $\mathrm{~nm}$ & 7 & 34 & \multicolumn{2}{|c|}{ mud ball } \\
\hline I & 1 & 6 & $\mathrm{~nm}$ & 7 & 41 & \multicolumn{2}{|l|}{ mud ball } \\
\hline I & 1 & 7 & 2.22 & 7 & 48 & 22.32 & 15.59 \\
\hline$I$ & 1 & 8 & 3.54 & 18.5 & 48 & 14.00 & 9.12 \\
\hline$I$ & 1 & 9 & 2.99 & 18.5 & 41 & 16.57 & 11.01 \\
\hline I & 1 & 10 & 3.19 & 18.5 & 34 & 15.53 & 10.23 \\
\hline I & 1 & 11 & 3.27 & 30 & 48 & 15.15 & 9.96 \\
\hline I & 1 & 12 & 3.43 & 30 & 41 & 14.45 & 9.44 \\
\hline I & 1 & 13 & 2.57 & 30 & 34 & 19.28 & 13.10 \\
\hline$I$ & 1 & 14 & $\mathrm{~nm}$ & 7 & 70 & \multicolumn{2}{|c|}{ mud clasts } \\
\hline II & 2 & 15 & 1.53 & 7 & 83 & 32.38 & 25.31 \\
\hline II & 2 & 16 & 2.1 & 7 & 96 & 23.59 & 16.69 \\
\hline II & 2 & 17 & 1.39 & 25 & 96 & 35.65 & 29.12 \\
\hline II & 2 & 18 & 1.38 & 25 & 83 & 35.90 & 29.44 \\
\hline I & 1 & 19 & 2.05 & 25 & 70 & 24.17 & 17.20 \\
\hline$I$ & 1 & 20 & 2.62 & 43 & 70 & 18.91 & 12.81 \\
\hline II & 2 & 21 & nm & 43 & 83 & \multicolumn{2}{|c|}{ mud ball } \\
\hline II & 2 & 22 & 1.88 & 43 & 96 & 26.36 & 19.18 \\
\hline II & 2 & 23 & 1.47 & 7 & 94 & 33.71 & 26.81 \\
\hline II & 2 & 24 & 1.83 & 7 & 96 & 27.08 & 19.86 \\
\hline II & 2 & 25 & 1.99 & 18.5 & 96 & 24.90 & 17.85 \\
\hline II & 2 & 26 & 1.73 & 18.5 & 94 & 28.64 & 21.38 \\
\hline III & 4 & 27 & 2.09 & 0 & 137 & 23.71 & 16.79 \\
\hline III & 4 & 28 & 2.24 & 4 & 137 & $22 \cdot 12$ & 15.42 \\
\hline III & 4 & 29 & 1.68 & 8 & 137 & 29.49 & 22.24 \\
\hline$I$ & 1 & 30 & 2.27 & 45 & 0 & 21.83 & 15.18 \\
\hline$I$ & 1 & 31 & 3.87 & 45 & 15 & 12.80 & 8.27 \\
\hline I & 1 & 32 & 2.15 & 55.5 & 15 & 23.05 & 16.21 \\
\hline$I$ & 1 & 33 & 2.29 & 55.5 & 0 & 21.64 & 15.02 \\
\hline I & 1 & 34 & 1.9 & 47 & 25 & 26.08 & 18.93 \\
\hline$I$ & 1 & 35 & 4.27 & 47 & 33 & 11.60 & 7.43 \\
\hline$I$ & 1 & 36 & 4.08 & 65 & 25 & 12.14 & 7.81 \\
\hline I & 1 & 37 & 5.1 & 65 & 33 & 9.72 & 6.14 \\
\hline I & 1 & 38 & 4.29 & 47 & 53 & 11.55 & 7.39 \\
\hline I & 1 & 39 & 3.66 & 52 & 53 & 13.54 & 8.79 \\
\hline $\bar{I}$ & 1 & 40 & 3.98 & 57 & 53 & 12.45 & 8.02 \\
\hline III & 3 & 41 & 1.97 & 55 & 94 & 25.15 & 18.08 \\
\hline III & 3 & 42 & 1.35 & 55 & 98 & 36.70 & 30.44 \\
\hline III & 3 & 43 & 1.77 & 75 & 98 & 27.99 & 20.75 \\
\hline III & 3 & 44 & 1.28 & 75 & 94 & 38.71 & 33.10 \\
\hline III & 4 & 45 & 1.89 & 57 & 133 & 26.22 & 19.05 \\
\hline III & 4 & 46 & 2.33 & 57 & 137 & 21.27 & 14.71 \\
\hline III & 5 & 47 & 1.77 & 57 & 141 & 27.99 & 20.75 \\
\hline III & 5 & 48 & 2.56 & 66 & 141 & 19.35 & 13.16 \\
\hline III & 4 & 49 & 2.66 & 66 & 137 & 18.63 & 12.59 \\
\hline III & 4 & 50 & 1.75 & 66 & 133 & 28.31 & 21.06 \\
\hline III & 4 & 51 & 2 & 75 & 133 & 24.77 & 17.73 \\
\hline III & 4 & 52 & 1.91 & 75 & 137 & 25.94 & 18.80 \\
\hline
\end{tabular}




\begin{tabular}{|c|c|c|c|c|c|c|c|}
\hline III & 5 & 53 & 1.81 & 75 & 141 & 27.37 & 20.15 \\
\hline$I$ & 1 & 54 & 1.25 & 88 & 0 & 39.64 & 34.4 \\
\hline$I$ & 1 & 55 & 1.97 & 88 & 2 & 25.15 & 18.08 \\
\hline I & 1 & 56 & 3.34 & 88 & 4 & 14.83 & 9.7 \\
\hline$I$ & 1 & 57 & $\mathrm{~nm}$ & 91 & 4 & mud ball & \\
\hline$I$ & 1 & 58 & $\mathrm{~nm}$ & 91 & 2 & mud bal1 & \\
\hline$I$ & 1 & 59 & 2.13 & 91 & 0 & 23.26 & 16.4 \\
\hline$I$ & 1 & 60 & 3.33 & 94 & 0 & 14.88 & 9.7 \\
\hline$I$ & 1 & 61 & $\mathrm{~nm}$ & 94 & 2 & mud ball & \\
\hline$I$ & 1 & 62 & $\mathrm{~nm}$ & 94 & 4 & mud ball & \\
\hline I & 1 & 63 & 1.5 & 89 & 30 & 33.03 & 26.0 \\
\hline$I$ & 1 & 64 & 1.55 & 89 & 35 & 31.97 & 24.8 \\
\hline$I$ & 1 & 65 & 3.01 & 89 & 40 & 16.46 & 10.9 \\
\hline$I$ & 1 & 66 & 2.67 & 101 & 40 & 18.56 & 12.5 \\
\hline$I$ & 1 & 67 & 2.69 & 101 & 35 & 18.42 & 12.4 \\
\hline$I$ & 1 & 68 & 3.09 & 101 & 30 & 16.04 & 10.6 \\
\hline$I$ & 1 & 69 & 2.06 & 113 & 30 & 24.05 & 17.0 \\
\hline$I$ & 1 & 70 & 1.74 & 113 & 35 & 28.48 & 21.2 \\
\hline I & 1 & 71 & 2.88 & 113 & 40 & 17.20 & 11.4 \\
\hline I & 1 & 72 & 1.79 & 92 & 54 & 27.68 & 20.4 \\
\hline$I$ & 1 & 73 & 1.46 & 92 & 56 & 33.94 & 27.0 \\
\hline$I$ & 1 & 74 & 1.21 & 94.5 & 56 & 40.95 & 36.3 \\
\hline I & 1 & 75 & 1.61 & 94.5 & 54 & 30.78 & 23.5 \\
\hline III & 3 & 76 & 1.8 & 92 & 88 & 27.53 & 20.3 \\
\hline III & 3 & 77 & 1.68 & 92 & 90 & 29.49 & 22.2 \\
\hline III & 3 & 78 & 1.53 & 92 & 92 & 32.38 & 25.3 \\
\hline III & 3 & 79 & 1 & 102 & 92 & 49.55 & 51.8 \\
\hline III & 3 & 80 & 1.48 & 102 & 90 & 33.48 & 26.5 \\
\hline III & 3 & 81 & 2.15 & 102 & 88 & 23.05 & 16.2 \\
\hline III & 3 & 82 & 1.64 & 112 & 88 & 30.21 & 22.9 \\
\hline III & 3 & 83 & 1.96 & 112 & 90 & 25.28 & 18.1 \\
\hline III & 3 & 84 & 1.98 & 112 & 92 & 25.02 & 17.9 \\
\hline III & 4 & 85 & 1.55 & 99 & 128 & 31.97 & 24.8 \\
\hline III & 4 & 86 & 1.94 & 99 & 133.5 & 25.54 & 18.4 \\
\hline III & 5 & 87 & 2.21 & 99 & 139 & 22.42 & 15.6 \\
\hline III & 5 & 88 & 2 & 109 & 139 & 24.77 & 17.7 \\
\hline III & 4 & 89 & 1.79 & 109 & 133.5 & 27.68 & 20.4 \\
\hline III & 4 & 90 & 1.57 & 109 & 128 & 31.56 & 24.4 \\
\hline III & 4 & 91 & 1.84 & 119 & 128 & 26.93 & 19.7 \\
\hline III & 4 & 92 & 1.69 & 119 & 133.5 & 29.32 & 22.0 \\
\hline III & 5 & 93 & 2.38 & 119 & 139 & 20.82 & 14.3 \\
\hline$I$ & 1 & 94 & 2.02 & 129 & 0 & 24.53 & 17.5 \\
\hline$I$ & 1 & 95 & 2.3 & 129 & 14 & 21.54 & 14.9 \\
\hline$I$ & 1 & 96 & 1.97 & 132 & 0 & 25.15 & 18.0 \\
\hline I & 1 & 97 & 2.99 & 132 & 14 & 16.57 & 11.0 \\
\hline$I$ & 1 & 98 & 1.68 & 133 & 28 & 29.49 & 22.2 \\
\hline$I$ & 1 & 99 & 1.05 & 133 & 38 & 47.19 & 46.9 \\
\hline I & 1 & 100 & 2.81 & 138 & 28 & 17.63 & 11.8 \\
\hline$I$ & 1 & 101 & 2.91 & 138 & 38 & 17.03 & 11.3 \\
\hline II & 2 & 102 & 1.19 & 139 & 60 & 41.64 & 37.3 \\
\hline II & 2 & 103 & 2.07 & 139 & 62 & 23.94 & 16.9 \\
\hline II & 2 & 104 & 1.17 & 161 & 60 & 42.35 & 38.4 \\
\hline II & 2 & 105 & 1.17 & 161 & 62 & 42.35 & 38.4 \\
\hline III & 3 & 106 & 1.37 & 146 & 96 & 36.17 & 29.7 \\
\hline III & 4 & 107 & 1.56 & 146 & 110 & 31.76 & 24.6 \\
\hline III & 3 & 108 & 1.31 & 152 & 96 & 37.82 & 31.9 \\
\hline III & 4 & 109 & 1.66 & 152 & 110 & 29.85 & 22.6 \\
\hline III & 4 & 110 & 1.46 & 146 & 126 & 33.94 & 27.0 \\
\hline III & 4 & 111 & 1.28 & 146 & 128 & 38.71 & 33.1 \\
\hline III & 4 & 112 & 1.13 & 157 & 128 & 43.85 & 40.9 \\
\hline
\end{tabular}




$\begin{array}{lrrrrrrr}\text { III } & 4 & 113 & 1.13 & 157 & 126 & 43.85 & 40.91 \\ \text { I } & 1 & 114 & 2.32 & 167 & 0 & 21.36 & 14.79 \\ \text { I } & 1 & 115 & 1.63 & 167 & 6 & 30.40 & 23.17 \\ \text { I } & 1 & 116 & 1.82 & 167 & 12 & 27.22 & 20.00 \\ \text { I } & 1 & 117 & 2.44 & 175 & 12 & 20.31 & 13.93 \\ \text { I } & 1 & 118 & 1.41 & 175 & 6 & 35.14 & 28.50 \\ \text { I } & 1 & 119 & 1.91 & 175 & 0 & 25.94 & 18.80 \\ \text { I } & 1 & 120 & 2.12 & 182 & 0 & 23.37 & 16.50 \\ \text { I } & 1 & 121 & 1.74 & 182 & 6 & 28.48 & 21.22 \\ \text { I } & 1 & 122 & 1.91 & 182 & 12 & 25.94 & 18.80 \\ \text { I } & 1 & 123 & 2.45 & 176 & 28 & 20.22 & 13.86 \\ \text { II } & 2 & 124 & 2.11 & 176 & 42 & 23.48 & 16.59 \\ \text { I } & 1 & 125 & 2.11 & 199 & 28 & 23.48 & 16.59 \\ \text { II } & 2 & 126 & 1.95 & 199 & 42 & 25.41 & 18.31 \\ \text { II } & 2 & 127 & 1.14 & 176 & 60 & 43.46 & 40.26 \\ \text { II } & 2 & 128 & 1.1 & 176 & 73 & 45.04 & 42.97 \\ \text { II } & 2 & 129 & 129 & 188 & 60 & \text { mud bal1 } \\ \text { II } & 2 & 130 & 1.15 & 188 & 73 & 43.09 & 39.64 \\ \text { III } & 3 & 131 & 2.11 & 197 & 92 & 23.48 & 16.59 \\ \text { III } & 3 & 132 & 1.23 & 197 & 97 & 40.28 & 35.32 \\ \text { III } & 3 & 133 & 1.27 & 197 & 102 & 39.01 & 33.52 \\ \text { III } & 3 & 134 & 1.14 & 202 & 102 & 43.46 & 40.26 \\ \text { II } & 3 & 135 & 1.56 & 202 & 97 & 31.76 & 24.63 \\ \text { III } & 3 & 136 & 1.95 & 202 & 92 & 25.41 & 18.31 \\ \text { III } & 3 & 137 & 1.77 & 207 & 92 & 27.99 & 20.75 \\ \text { III } & 3 & 138 & 1.06 & 207 & 97 & 46.74 & 46.11 \\ \text { III } & 3 & 139 & 1.3 & 207 & 102 & 38.11 & 32.29 \\ \text { III } & 4 & 140 & 1.29 & 207 & 120 & 38.41 & 32.69 \\ \text { III } & 4 & 141 & 1.61 & 207 & 130 & 30.78 & 23.57 \\ \text { III } & 5 & 142 & 2.76 & 207 & 140 & 17.95 & 12.06 \\ \text { IV } & 6 & 143 & 1.14 & 207 & 150 & 43.46 & 40.26 \\ \text { IV } & 6 & 144 & 1.31 & 217 & 150 & 37.82 & 31.90 \\ \text { III } & 5 & 145 & 2.09 & 217 & 140 & 23.71 & 16.79 \\ \text { III } & 4 & 146 & 1.48 & 217 & 130 & 33.48 & 26.54 \\ \text { III } & 4 & 147 & 1.28 & 217 & 120 & 38.71 & 33.10 \\ \text { III } & 4 & 148 & 1.24 & 227 & 120 & 39.96 & 34.85 \\ \text { III } & 4 & 149 & 1.75 & 227 & 130 & 28.31 & 21.06 \\ \text { III } & 5 & 150 & 2.67 & 227 & 140 & 18.56 & 12.53 \\ \text { IV } & 6 & 151 & 1.44 & 227 & 150 & 34.41 & 27.63\end{array}$


SS-2 data

August 11, 1992

mass of piston: $178.1 \mathrm{~g}$

length between sensors: $5.15 \mathrm{~cm}$

tip seal i.d.: $0.70 \mathrm{~cm}$

tip seal o.d.: $2.80 \mathrm{~cm}$

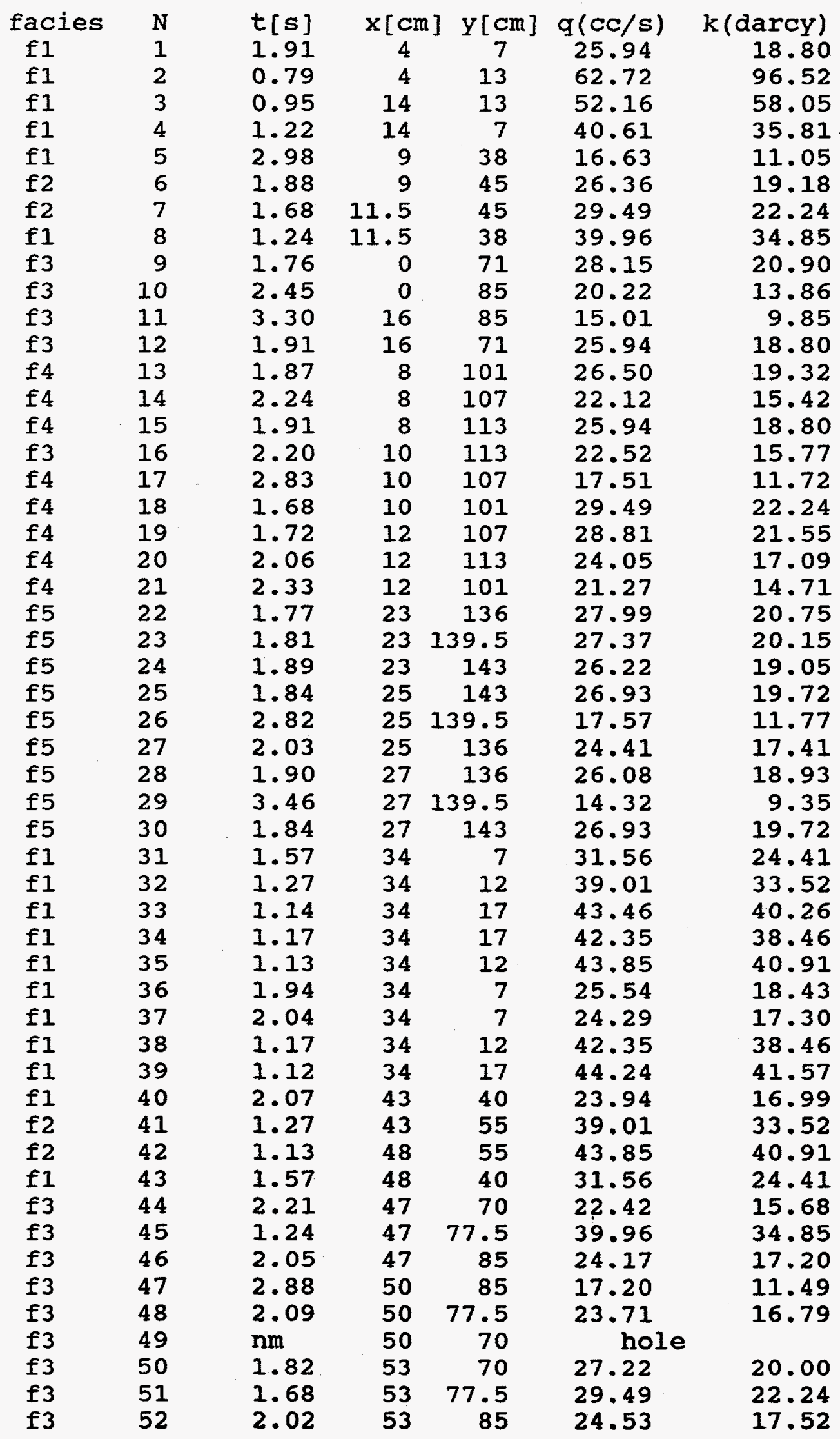




\begin{tabular}{|c|c|c|c|c|c|c|}
\hline$f 3$ & 53 & 2.55 & 49 & 94 & 19.43 & 13.22 \\
\hline$f 4$ & 54 & 2.14 & 49 & 98 & 23.15 & 16.31 \\
\hline$f 4$ & 55 & 2.09 & 49 & 102 & 23.71 & 16.79 \\
\hline$f 4$ & 56 & 1.91 & 53 & 102 & 25.94 & 18.80 \\
\hline $\mathrm{f} 4$ & 57 & 2.42 & 53 & 98 & 20.47 & 14.06 \\
\hline f3 & 58 & 2.77 & 53 & 94 & 17.89 & 12.01 \\
\hline f3 & 59 & 2.99 & 57 & 94 & 16.57 & 11.01 \\
\hline$f 4$ & 60 & 3.27 & 57 & 98 & 15.15 & 9.96 \\
\hline$f 4$ & 61 & 1.65 & 57 & 102 & 30.03 & 22.79 \\
\hline$f 5$ & 62 & 2.13 & 49 & 137 & 23.26 & 16.40 \\
\hline f5 & 63 & 1.52 & 49 & 142 & 32.60 & 25.55 \\
\hline f5 & 64 & 2.09 & 49 & 147 & 23.71 & 16.79 \\
\hline f5 & 65 & 2.67 & 57.5 & 147 & 18.56 & 12.53 \\
\hline f5 & 66 & 1.62 & 57.5 & 142 & 30.59 & 23.37 \\
\hline f5 & 67 & 1.36 & 57.5 & 137 & 36.43 & 30.10 \\
\hline f5 & 68 & 1.27 & 66 & 137 & 39.01 & 33.52 \\
\hline f5 & 69 & 2.02 & 66 & 142 & 24.53 & 17.52 \\
\hline$f 5$ & 70 & 2.46 & 66 & 147 & 20.14 & 13.79 \\
\hline$f 1$ & 71 & 1.73 & 75 & 0 & 28.64 & 21.38 \\
\hline$f 1$ & 72 & 0.97 & 75 & 11 & 51.08 & 55.40 \\
\hline$f 1$ & 73 & 1.16 & 91.5 & 11 & 42.71 & 39.04 \\
\hline 1 & 74 & 1.52 & 91.5 & 0 & 32.60 & 25.55 \\
\hline f1 & 75 & 1.82 & 81 & 40 & 27.22 & 20.00 \\
\hline$f 1$ & 76 & 1.63 & 81 & 44 & 30.40 & 23.17 \\
\hline$f 1$ & 77 & 2.05 & 97 & 44 & 24.17 & 17.20 \\
\hline 1 & 78 & 1.71 & 97 & 40 & 28.98 & 21.72 \\
\hline f3 & 79 & 1.77 & 85 & 62 & 27.99 & 20.75 \\
\hline f3 & 80 & 1.91 & 85 & 69 & 25.94 & 18.80 \\
\hline f3 & 81 & 2.28 & 85 & 76 & 21.73 & 15.10 \\
\hline f3 & 82 & 2.27 & 89 & 76 & 21.83 & 15.18 \\
\hline$f 3$ & 83 & 1.68 & 89 & 69 & 29.49 & 22.24 \\
\hline f3 & 84 & 1.46 & 89 & 62 & 33.94 & 27.07 \\
\hline f3 & 85 & 1.92 & 93 & 62 & 25.81 & 18.67 \\
\hline f5 & 86 & 1.52 & 49 & 142 & 32.60 & 25.55 \\
\hline$f 3$ & 87 & 2.10 & 93 & 76 & 23.59 & 16.69 \\
\hline$f 4$ & 88 & 2.20 & 85 & 101 & 22.52 & 15.77 \\
\hline$f 4$ & 89 & 2.39 & 85 & 102 & 20.73 & 14.27 \\
\hline f 4 & 90 & 2.27 & 88 & 101 & 21.83 & 15.18 \\
\hline$f 4$ & 91 & 2.15 & 88 & 102 & 23.05 & 16.21 \\
\hline f5 & 92 & 1.70 & 83 & 125 & 29.15 & 21.89 \\
\hline f5 & 93 & 1.58 & 83 & 127 & 31.36 & 24.19 \\
\hline f5 & 94 & 1.91 & 85 & 127 & 25.94 & 18.80 \\
\hline f5 & 95 & 1.38 & 85 & 125 & 35.90 & 29.44 \\
\hline$f 1$ & 96 & 1.41 & 111 & 4 & 35.14 & 28.50 \\
\hline fI & 97 & 1.20 & 111 & 12 & 41.29 & 36.82 \\
\hline$f 1$ & 98 & 0.92 & 121 & 12 & 53.86 & 62.59 \\
\hline f1 & 99 & 2.21 & 121 & 4 & 22.42 & 15.68 \\
\hline f1 & 100 & 1.41 & 114 & 34 & $35 \cdot 14$ & 28.50 \\
\hline$f 1$ & 101 & 1.95 & 114 & 37 & 25.41 & 18.31 \\
\hline$f 1$ & 102 & 2.88 & 114 & 40 & 17.20 & 11.49 \\
\hline f1 & 103 & 1.97 & 117 & 40 & 25.15 & 18.08 \\
\hline f1 & 104 & 1.94 & 117 & 37 & 25.54 & 18.43 \\
\hline f1 & 105 & 2.19 & 117 & 34 & 22.62 & 15.85 \\
\hline f1 & 106 & 1.60 & 120 & 34 & 30.97 & 23.77 \\
\hline f1 & 107 & 2.74 & 120 & 37 & 18.08 & 12.16 \\
\hline$f 1$ & 108 & 1.92 & 120 & 40 & 25.81 & 18.67 \\
\hline f3 & 109 & 2.24 & 130 & 58 & 22.12 & 15.42 \\
\hline f3 & 110 & $\mathrm{~nm}$ & 130 & 63 & nodule & \\
\hline f3 & 111 & 2.34 & 130 & 68 & 21.17 & 14.64 \\
\hline f3 & 112 & 2.37 & 132 & 68 & 20.91 & 14.41 \\
\hline
\end{tabular}




$\begin{array}{lllllll}\mathrm{f} 3 & 113 & 2.39 & 132 & 63 & 20.73 & 14.27 \\ \mathrm{f} 3 & 114 & 2.20 & 132 & 58 & 22.52 & 15.77 \\ \mathrm{f} 3 & 115 & 2.44 & 134 & 58 & 20.31 & 13.93 \\ \mathrm{f} 3 & 116 & 2.64 & 134 & 63 & 18.77 & 12.70 \\ \mathrm{f3} & 117 & 2.35 & 134 & 68 & 21.08 & 14.56 \\ \mathrm{f} 3 & 118 & 2.76 & 135 & 90 & 17.95 & 12.06 \\ \mathrm{f} 4 & 119 & 2.45 & 135 & 96 & 20.22 & 13.86 \\ \mathrm{f} 3 & 120 & 2.24 & 143 & 96 & 22.12 & 15.42 \\ \mathrm{f} 4 & 121 & 2.61 & 143 & 90 & 18.98 & 12.87 \\ \mathrm{f5} & 122 & 1.67 & 130 & 127 & 29.67 & 22.42 \\ \mathrm{f} 5 & 123 & 1.53 & 130 & 134 & 32.38 & 25.31 \\ \mathrm{f} 6 & 124 & 2.09 & 130 & 141 & 23.71 & 16.79 \\ \mathrm{f} 5 & 125 & 1.71 & 138 & 141 & 28.98 & 21.72 \\ \mathrm{f} 5 & 126 & 1.37 & 138 & 134 & 36.17 & 29.76 \\ \mathrm{f} 6 & 127 & 1.36 & 138 & 127 & 36.43 & 30.10 \\ \mathrm{f} 5 & 128 & 1.23 & 146 & 127 & 40.28 & 35.32 \\ \mathrm{f5} & 129 & 1.50 & 146 & 134 & 33.03 & 26.03 \\ \mathrm{f} 6 & 130 & 1.58 & 146 & 141 & 31.36 & 24.19\end{array}$


sS-3 data

September 4,1992

mass of piston: $178.1 \mathrm{~g}$

length between sensors: $5.15 \mathrm{~cm}$

tip seal i.d.: $0.70 \mathrm{~cm}$

tip seal o.d.: $2.80 \mathrm{~cm}$

length of tubing from filter to tip: $77 \mathrm{~cm}$

hydro

\begin{tabular}{|c|c|c|c|c|c|c|c|}
\hline it & facies & $n$ & $t[s]$ & $x[\mathrm{~cm}]$ & $Y[\mathrm{~cm}]$ & $q[\mathrm{Cc} /$ & $L-\infty$ \\
\hline 1 & 1 & 1 & 2.62 & 0 & 0 & 18.91 & 12.81 \\
\hline 1 & 1 & 2 & 2.94 & 20 & 0 & 16.85 & 11.22 \\
\hline 1 & 1 & 3 & 2.01 & 0 & 19 & 24.65 & 17.62 \\
\hline 1 & 1 & 4 & 2.2 & 20 & 19 & 22.52 & 15.77 \\
\hline 2 & 2 & 5 & 2.52 & -2 & 27 & 19.66 & 13.41 \\
\hline 2 & 2 & 6 & 2.01 & 6 & 27 & 24.65 & 17.62 \\
\hline 2 & 2 & 7 & 1.82 & 14 & 27 & 27.22 & 20.00 \\
\hline 2 & 2 & 8 & 1.53 & -2 & 30 & 32.38 & 25.31 \\
\hline 2 & 2 & 9 & 0.9 & -2 & 33 & 55.05 & 66.06 \\
\hline 2 & 2 & 10 & 1 & 6 & 30 & 49.55 & 51.88 \\
\hline 2 & 2 & 11 & 1.22 & 6 & 33 & 40.61 & 35.81 \\
\hline 2 & 2 & 12 & 1.38 & 14 & 30 & 35.90 & 29.44 \\
\hline 2 & 2 & 13 & 1.1 & 14 & 33 & 45.04 & 42.97 \\
\hline 1 & 3 & 14 & 2.02 & -4 & 53 & 24.53 & 17.52 \\
\hline 1 & 3 & 15 & 2.53 & 11 & 53 & 19.58 & 13.34 \\
\hline 1 & 3 & 16 & $\mathrm{~nm}$ & -4 & 70 & loose & gravel \\
\hline 1 & 3 & 17 & $\mathrm{~nm}$ & 11 & 70 & loose & gravel \\
\hline 1 & 1 & 18 & 3.6 & 34 & 0 & 13.76 & 8.95 \\
\hline 1 & 1 & 19 & 3.93 & 47 & 0 & 12.61 & 8.13 \\
\hline 1 & 1 & 20 & 1.91 & 60 & 0 & 25.94 & 18.80 \\
\hline 1 & 1 & 21 & 2.23 & 34 & 12 & 22.22 & 15.51 \\
\hline 2 & 2 & 22 & 1.56 & 34 & 24 & 31.76 & 24.63 \\
\hline 1 & 1 & 23 & 4.68 & 47 & 12 & 10.59 & 6.73 \\
\hline 2 & 2 & 24 & 1.42 & 47 & 24 & 34.89 & 28.20 \\
\hline 1 & 1 & 25 & 4.08 & 60 & 12 & 12.14 & 7.81 \\
\hline 2 & 2 & 26 & 1.05 & 60 & 24 & 47.19 & 46.98 \\
\hline 2 & 2 & 27 & 1.06 & 36 & 32 & 46.74 & 46.11 \\
\hline 2 & 2 & 28 & 0.88 & 41 & 32 & 56.30 & 69.98 \\
\hline 2 & 2 & 29 & 0.98 & 46 & 32 & 50.56 & 54.17 \\
\hline 2 & 2 & 30 & 2.04 & 36 & 39 & 24.29 & 17.30 \\
\hline 1 & 3 & 31 & 2.87 & 36 & 46 & 17.26 & 11.53 \\
\hline 2 & 2 & 32 & 1.42 & 41 & 39 & 34.89 & 28.20 \\
\hline 2 & 2 & 33 & 1.52 & 46 & 39 & 32.60 & 25.55 \\
\hline 1 & 3 & 34 & 3.53 & 41 & 46 & 14.04 & 9.14 \\
\hline 1 & 3 & 35 & 3.59 & 46 & 46 & 13.80 & 8.98 \\
\hline 1 & 3 & 36 & 2.51 & 33 & 55 & 19.74 & 13.47 \\
\hline 1 & 3 & 37 & 4.16 & 35.5 & 55 & 11.91 & 7.64 \\
\hline 1 & 3 & 38 & 4.45 & 38 & 55 & 11.13 & 7.11 \\
\hline 1 & 3 & 39 & 2.41 & 33 & 68 & 20.56 & 14.13 \\
\hline 3 & 4 & 40 & $\mathbf{n m}$ & 33 & 81 & loose & gravel \\
\hline 1 & 3 & 41 & 4.16 & 35.5 & 68 & 11.91 & 7.64 \\
\hline 1 & 3 & 42 & 3.78 & 38 & 68 & 13.11 & 8.48 \\
\hline 3 & 4 & 43 & $\mathrm{~nm}$ & 35.5 & 81 & loose & gravel \\
\hline 3 & 4 & 44 & $\mathrm{~nm}$ & 38 & 81 & loose & gravel \\
\hline 1 & 1 & 45 & 2.25 & 70 & 1 & 22.02 & 15.34 \\
\hline 1 & 1 & 46 & 2.38 & 86 & 1 & 20.82 & 14.34 \\
\hline 1 & 1 & 47 & 1.73 & 70 & 14 & 28.64 & 21.38 \\
\hline 1 & 1 & 48 & 1.57 & 86 & 14 & 31.56 & 24.41 \\
\hline 2 & 2 & 49 & 1.06 & 72 & 28 & 46.74 & 46.11 \\
\hline 2 & 2 & 50 & 1.51 & 88 & 28 & 32.81 & 25.79 \\
\hline
\end{tabular}




\begin{tabular}{|c|c|c|c|c|c|c|c|}
\hline 1 & 3 & 51 & 2.53 & 72 & 41 & 19.58 & 13.34 \\
\hline 1 & 3 & 52 & 2.51 & 88 & 41 & 19.74 & 13.47 \\
\hline 1 & 3 & 53 & 3.51 & 71 & 54 & 14.12 & 9.20 \\
\hline 1 & 3 & 54 & 3.41 & 88 & 54 & 14.53 & 9.50 \\
\hline 1 & 3 & 55 & 2.70 & 105 & 54 & 18.35 & 12.37 \\
\hline 1 & 3 & 56 & 3.44 & 71 & 56 & 14.40 & 9.41 \\
\hline 1 & 3 & 57 & 3.24 & 71 & 58 & 15.29 & 10.06 \\
\hline 1 & 3 & 58 & 3.38 & 88 & 56 & 14.66 & 9.60 \\
\hline 1 & 3 & 59 & 4.18 & 88 & 58 & 11.85 & 7.60 \\
\hline 1 & 3 & 60 & 2.52 & 105 & 56 & 19.66 & 13.41 \\
\hline 1 & 3 & 61 & 3.38 & 105 & 58 & 14.66 & 9.60 \\
\hline 1 & 1 & 62 & 3.16 & 107 & 3 & 15.68 & 10.34 \\
\hline 1 & 1 & 63 & 3.25 & 115 & 3 & 15.25 & 10.02 \\
\hline 1 & 1 & 64 & 1.60 & 107 & 12 & 30.97 & 23.77 \\
\hline 1 & 1 & 65 & 1.95 & 115 & 12 & 25.41 & 18.31 \\
\hline 2 & 2 & 66 & 1.20 & 106 & 28 & 41.29 & 36.82 \\
\hline 2 & 2 & 67 & 0.82 & 137 & 28 & 60.42 & 85.53 \\
\hline 2 & 2 & 68 & 1.30 & 106 & 35 & 38.11 & 32.29 \\
\hline 2 & 2 & 69 & 1.45 & 137 & 35 & 34.17 & 27.35 \\
\hline 1 & 3 & 70 & 3.43 & 107 & 55 & 14.45 & 9.44 \\
\hline 1 & 3 & 71 & 2.74 & 109 & 55 & 18.08 & 12.16 \\
\hline 1 & 3 & 72 & 3.39 & 107 & 58 & 14.62 & 9.56 \\
\hline 1 & 3 & 73 & 2.46 & 109 & 58 & 20.14 & 13.79 \\
\hline 1 & 1 & 74 & 3.35 & 143 & 1 & 14.79 & 9.69 \\
\hline 1 & 1 & 75 & 2.99 & 149 & 1 & 16.57 & 11.01 \\
\hline 1 & 1 & 76 & 3.26 & 143 & 12 & 15.20 & 9.99 \\
\hline 1 & 1 & 77 & 4.22 & 149 & 12 & 11.74 & 7.53 \\
\hline 2 & 2 & 78 & 1.88 & 150 & 41 & 26.36 & 19.18 \\
\hline 2 & 2 & 79 & 1.38 & 154 & 41 & 35.90 & 29.44 \\
\hline 12 & 5 & 80 & 2.33 & 150 & 50 & 21.27 & 14.71 \\
\hline 12 & 5 & 81 & 2.26 & 154 & 50 & 21.92 & 15.26 \\
\hline 1 & 3 & 82 & 3.07 & 148 & 67 & 16.14 & 10.69 \\
\hline 1 & 3 & 83 & 2.18 & 164 & 67 & 22.73 & 15.94 \\
\hline 1 & 3 & 84 & 1.93 & 180 & 67 & 25.67 & 18.55 \\
\hline 1 & 3 & 85 & 3.01 & 148 & 79 & 16.46 & 10.93 \\
\hline 1 & 3 & 86 & 2.66 & 148 & 91 & 18.63 & 12.59 \\
\hline 1 & 3 & 87 & 3.21 & 164 & 79 & 15.44 & 10.16 \\
\hline 1 & 3 & 88 & 2.58 & 180 & 79 & 19.20 & 13.04 \\
\hline 1 & 3 & 89 & 2.81 & 164 & 91 & 17.63 & 11.82 \\
\hline 1 & 3 & 90 & 2.61 & 180 & 91 & 18.98 & 12.87 \\
\hline 1 & 1 & 91 & 3.20 & 182 & 1 & 15.48 & 10.20 \\
\hline 1 & 1 & 92 & 2.78 & 188 & 1 & 17.82 & 11.96 \\
\hline 1 & 1 & 93 & 3.45 & 194 & 1 & 14.36 & 9.38 \\
\hline 1 & 1 & 94 & 2.64 & 182 & 10 & 18.77 & 12.70 \\
\hline 2 & 2 & 95 & 0.89 & 182 & 19 & 55.67 & 67.96 \\
\hline 1 & 1 & 96 & 3.04 & 188 & 10 & 16.30 & 10.80 \\
\hline 1 & 1 & 97 & 1.88 & 194 & 10 & 26.36 & 19.18 \\
\hline 2 & 2 & 98 & 1.33 & 188 & 19 & 37.25 & 31.15 \\
\hline 2 & 2 & 99 & 1.12 & 194 & 19 & 44.24 & 41.57 \\
\hline 2 & 2 & 100 & 1.41 & 184 & 29 & 35.14 & 28.50 \\
\hline 2 & 2 & 101 & 1.15 & 201 & 29 & 43.09 & 39.64 \\
\hline 2 & 2 & 102 & 1.25 & 218 & 29 & 39.64 & 34.40 \\
\hline 1 & 3 & 103 & 4.01 & 184 & 40 & 12.36 & 7.95 \\
\hline 1 & 3 & 104 & 3.64 & 201 & 40 & 13.61 & 8.84 \\
\hline 1 & 3 & 105 & 2.37 & 218 & 40 & 20.91 & 14.41 \\
\hline 1 & 3 & 106 & 3.97 & 184 & 51 & 12.48 & 8.04 \\
\hline 1 & 3 & 107 & 3.88 & 201 & 51 & 12.77 & 8.24 \\
\hline 1 & 3 & 108 & 3.97 & 218 & 51 & 12.48 & 8.04 \\
\hline 1 & 3 & 109 & 2.62 & 202 & 59 & 18.91 & 12.81 \\
\hline 1 & 3 & 110 & 3.22 & 205 & 59 & 15.39 & 10.13 \\
\hline
\end{tabular}




$\begin{array}{rrrrrrrr}1 & 3 & 111 & 2.71 & 208 & 59 & 18.28 & 12.32 \\ 1 & 3 & 112 & 2.66 & 202 & 63 & 18.63 & 12.59 \\ 1 & 3 & 113 & 2.65 & 205 & 63 & 18.70 & 12.64 \\ 1 & 3 & 114 & 3.20 & 208 & 63 & 15.48 & 10.20 \\ 1 & 3 & 115 & 2.50 & 202 & 67 & 19.82 & 13.53 \\ 1 & 3 & 116 & 3.44 & 205 & 67 & 14.40 & 9.41 \\ 1 & 3 & 117 & 3.49 & 208 & 67 & 14.20 & 9.26\end{array}$


SS-4 data

October 2, 1992

mass of piston: $178.2 \mathrm{~g}$

length between sensors: $5.15 \mathrm{~cm}$

tip seal i.d.: $0.70 \mathrm{~cm}$

tip seal 0.d.: $2.80 \mathrm{~cm}$

\begin{tabular}{|c|c|c|c|c|c|c|}
\hline facies & $\mathrm{n}$ & $t[s]$ & $x(\mathrm{~cm})$ & $y(\mathrm{~cm})$ & $q(c c / s)$ & $\mathrm{k}$ (darcy) \\
\hline 1 & 1 & 5.57 & 0 & 0 & 8.90 & 5.60 \\
\hline 1 & 2 & 6.37 & 47 & 0 & 7.78 & 4.86 \\
\hline 1 & 3 & 4.39 & 94 & 0 & 11.29 & 7.21 \\
\hline 1 & 4 & 5.57 & 0 & 5.5 & 8.90 & 5.60 \\
\hline 1 & 5 & 4.42 & 47 & 5.5 & 11.21 & 7.16 \\
\hline 1 & 6 & 5.16 & 94 & 5.5 & 9.60 & 6.07 \\
\hline 1 & 7 & 3.42 & 0 & 11 & 14.49 & 9.47 \\
\hline 1 & 8 & 5.41 & 47 & 11 & 9.16 & 5.77 \\
\hline 1 & 9 & 3.91 & 94 & 11 & 12.67 & 8.18 \\
\hline 1 & 10 & 3.43 & 0 & 35 & 14.45 & 9.44 \\
\hline 1 & 11 & 4.30 & 19.5 & 35 & 11.52 & 7.37 \\
\hline 1 & 12 & 3.35 & 39 & 35 & 14.79 & 9.69 \\
\hline 1 & 13 & 2.55 & 0 & 45 & 19.43 & 13.22 \\
\hline 1 & 14 & 4.10 & 19.5 & 45 & 12.08 & 7.76 \\
\hline 1 & 15 & 3.40 & 39 & 45 & 14.57 & 9.53 \\
\hline 1 & 16 & 3.98 & 0 & 55 & 12.45 & 8.02 \\
\hline 1 & 17 & 4.45 & 19.5 & 55 & 11.13 & 7.11 \\
\hline 1 & 18 & 4.09 & 39 & 55 & 12.11 & 7.78 \\
\hline 1 & 19 & 6.70 & 0 & 70 & 7.40 & 4.61 \\
\hline 1 & 20 & 5.63 & 16.5 & 70 & 8.80 & 5.53 \\
\hline 1 & 21 & 4.89 & 33 & 70 & 10.13 & 6.43 \\
\hline 1 & 22 & 6.05 & 0 & 82.5 & 8.19 & 5.13 \\
\hline 1 & 23 & 4.16 & 16.5 & 82.5 & 11.91 & 7.64 \\
\hline 1 & 24 & 4.13 & 33 & 82.5 & 12.00 & 7.70 \\
\hline 1 & 25 & 3.23 & 0 & 95 & 15.34 & 10.09 \\
\hline 1 & 26 & 4.37 & 16.5 & 95 & 11.34 & 7.25 \\
\hline 1 & 27 & 2.30 & 33 & 95 & 21.54 & 14.94 \\
\hline 1 & 28 & 5.50 & 0 & 105 & 9.01 & 5.67 \\
\hline 1 & 29 & 4.0 .7 & 15 & 105 & 12.17 & 7.83 \\
\hline 1 & 30 & 4.79 & 30 & 105 & 10.34 & 6.57 \\
\hline 1 & 31 & 4.59 & 0 & 107 & 10.79 & 6.87 \\
\hline 1 & 32 & 4.52 & 15 & 107 & 10.96 & 6.99 \\
\hline 1 & 33 & 5.95 & 30 & 107 & 8.33 & 5.22 \\
\hline 1 & 34 & 4.57 & 0 & 109 & 10.84 & 6.91 \\
\hline 1 & 35 & 4.13 & 15 & 109 & 12.00 & 7.70 \\
\hline 1 & 36 & 3.53 & 30 & 109 & 14.04 & 9.14 \\
\hline 1 & 37 & 3.42 & 40 & 0 & 14.49 & 9.47 \\
\hline 1 & 38 & 4.27 & 55 & 0 & 11.60 & 7.43 \\
\hline 1 & 39 & 3.44 & 70 & 0 & 14.40 & 9.41 \\
\hline 1 & 40 & 3.38 & 40 & 15.5 & 14.66 & 9.60 \\
\hline 1 & 41 & 4.71 & 55 & 15.5 & 10.52 & 6.69 \\
\hline 1 & 42 & 4.72 & 70 & 15.5 & 10.50 & 6.67 \\
\hline 1 & 43 & 4.06 & 40 & 31 & 12.20 & 7.85 \\
\hline 1 & 44 & 3.77 & 55 & 31 & 13.14 & 8.51 \\
\hline 1 & 45 & 4.74 & 70 & 31 & 10.45 & 6.64 \\
\hline 1 & 46 & 4.61 & 40 & 35 & 10.75 & 6.84 \\
\hline 1 & 47 & 4.20 & 49.5 & 35 & 11.80 & 7.56 \\
\hline 1 & 48 & 3.71 & 59 & 35 & 13.36 & 8.66 \\
\hline 1 & 49 & 2.91 & 40 & 37 & 17.03 & 11.35 \\
\hline 1 & 50 & 4.49 & 49.5 & 37 & 11.04 & 7.04 \\
\hline 1 & 51 & 3.73 & 59 & 37 & 13.28 & 8.61 \\
\hline 1 & 52 & 3.34 & 40 & 39 & 14.83 & 9.72 \\
\hline
\end{tabular}




\begin{tabular}{|c|c|c|c|c|c|c|}
\hline 1 & 53 & 4.50 & 49.5 & 39 & 11.01 & 7.02 \\
\hline 1 & 54 & 3.66 & 59 & 39 & 13.54 & 8.79 \\
\hline 1 & 55 & 3.66 & 40 & 70 & 13.54 & 8.79 \\
\hline 1 & 56 & 4.07 & 44.5 & 70 & 12.17 & 7.83 \\
\hline 1 & 57 & 5.29 & 49 & 70 & 9.37 & 5.91 \\
\hline 1 & 58 & 3.41 & 40 & 82 & 14.53 & 9.50 \\
\hline 1 & 59 & 4.34 & 44.5 & 82 & 11.42 & 7.30 \\
\hline 1 & 60 & 2.05 & 49 & 82 & 24.17 & 17.20 \\
\hline 1 & 61 & 3.05 & 40 & 94 & 16.25 & 10.76 \\
\hline 1 & $6 \overline{2}$ & 3.66 & 44.5 & 94 & 13.54 & 8.79 \\
\hline 1 & 63 & 4.66 & 49 & 94 & 10.63 & 6.76 \\
\hline 1 & 64 & 1.76 & 40 & 105 & 28.15 & 20.90 \\
\hline 1 & 65 & 5.00 & 42 & 105 & 9.91 & 6.27 \\
\hline 1 & 66 & 2.69 & 44 & 105 & 18.42 & 12.42 \\
\hline 1 & 67 & 2.17 & 40 & 113.5 & 22.83 & 16.03 \\
\hline 1 & 68 & 3.72 & 42 & 113.5 & 13.32 & 8.63 \\
\hline 1 & 69 & 2.27 & 44 & 113.5 & 21.83 & 15.18 \\
\hline 1 & 70 & 3.45 & 40 & 122 & 14.36 & 9.38 \\
\hline 1 & 71 & 5.12 & 42 & 122 & 9.68 & 6.12 \\
\hline 1 & 72 & 5.53 & 44 & 122 & 8.96 & 5.64 \\
\hline 1 & 73 & 6.47 & 80 & 0 & 7.66 & 4.78 \\
\hline 1 & 74 & 6.59 & 83 & 0 & 7.52 & 4.69 \\
\hline 1 & 75 & 5.59 & 86 & 0 & 8.86 & 5.58 \\
\hline 1 & 76 & 5.66 & 80 & 9 & 8.75 & 5.50 \\
\hline 1 & 77 & 4.99 & 83 & 9 & 9.93 & 6.29 \\
\hline 1 & 78 & 5.66 & 86 & 9 & 8.75 & 5.50 \\
\hline 1 & 79 & 4.42 & 80 & 18 & 11.21 & 7.16 \\
\hline 1 & 80 & 4.74 & 83 & 18 & 10.45 & 6.64 \\
\hline 1 & 81 & 5.20 & 86 & 18 & 9.53 & 6.02 \\
\hline 1 & 82 & 3.22 & 80 & 35 & 15.39 & 10.13 \\
\hline 1 & 83 & 4.42 & 100 & 35 & 11.21 & 7.16 \\
\hline 1 & 84 & 3.91 & 120 & 35 & 12.67 & 8.18 \\
\hline 1 & 85 & 3.31 & 80 & 37 & 14.97 & 9.82 \\
\hline 1 & 86 & 5.74 & 100 & 37 & 8.63 & 5.42 \\
\hline 1 & 87 & 4.55 & 120 & 37 & 10.89 & 6.94 \\
\hline 1 & 88 & 4.47 & 80 & 39 & 11.08 & 7.07 \\
\hline 1 & 89 & 5.39 & 100 & 39 & 9.19 & 5.79 \\
\hline 1 & 90 & 3.94 & 120 & 39 & 12.58 & 8.11 \\
\hline 1 & 91 & 4.30 & 80 & 70 & 11.52 & 7.37 \\
\hline 1 & 92 & 4.47 & 90 & 70 & 11.08 & 7.07 \\
\hline 1 & 93 & 5.40 & 100 & 70 & 9.18 & 5.78 \\
\hline 1 & 94 & 4.56 & 80 & 78.5 & 10.87 & 6.92 \\
\hline$\overline{1}$ & 95 & 6.08 & 90 & 78.5 & 8.15 & 5.10 \\
\hline 1 & 96 & 7.02 & 100 & 78.5 & 7.06 & 4.39 \\
\hline 1 & 97 & 3.31 & 80 & 87 & 14.97 & 9.82 \\
\hline 1 & 98 & 3.52 & 90 & 87 & 14.08 & 9.17 \\
\hline 1 & 99 & 4.51 & 100 & 87 & 10.99 & 7.01 \\
\hline 1 & 100 & 4.91 & 80 & 105 & 10.09 & 6.40 \\
\hline 1 & 101 & 3.20 & 92.5 & 105 & 15.48 & 10.20 \\
\hline 1 & 102 & 3.49 & 105 & 105 & 14.20 & 9.26 \\
\hline 1 & 103 & 1.81 & 80 & 118 & 27.37 & 20.15 \\
\hline 1 & 104 & 2.42 & 92.5 & 118 & 20.47 & 14.06 \\
\hline 1 & 105 & 5.36 & 105 & 118 & 9.24 & 5.83 \\
\hline 1 & 106 & 5.95 & 80 & 131 & 8.33 & 5.22 \\
\hline 1 & 107 & 3.34 & 92.5 & 131 & 14.83 & 9.72 \\
\hline 1 & 108 & 4.31 & 105 & 131 & 11.50 & 7.36 \\
\hline 1 & 109 & 5.96 & 120 & 0 & 8.31 & 5.21 \\
\hline 1 & 110 & 8.95 & 137 & 0 & 5.54 & 3.41 \\
\hline 1 & 111 & 9.24 & 154 & 0 & 5.36 & 3.30 \\
\hline 1 & 112 & 6.36 & 120 & 8.5 & 7.79 & 4.87 \\
\hline
\end{tabular}




\begin{tabular}{|c|c|c|c|c|c|c|}
\hline 1 & 113 & 6.44 & 137 & 8.5 & 7.69 & 4.81 \\
\hline 1 & 114 & 5.07 & 154 & 8.5 & 9.77 & 6.18 \\
\hline 1 & 115 & 4.68 & 120 & 17 & 10.59 & 6.73 \\
\hline 1 & 116 & 3.99 & 137 & 17 & 12.42 & 8.00 \\
\hline 1 & 117 & 4.48 & 154 & 17 & 11.06 & 7.06 \\
\hline 1 & 118 & 5.08 & 120 & 35 & 9.75 & 6.17 \\
\hline 1 & 119 & 4.81 & 124 & 35 & 10.30 & 6.54 \\
\hline 1 & 120 & 4.41 & 128 & 35 & 11.24 & 7.18 \\
\hline 1 & 121 & 5.02 & 120 & 50 & 9.87 & 6.25 \\
\hline 1 & 122 & 5.57 & 124 & 50 & 8.90 & 5.60 \\
\hline 1 & 123 & 3.35 & 128 & 50 & 14.79 & 9.69 \\
\hline 1 & 124 & 4.74 & 120 & 65 & 10.45 & 6.64 \\
\hline 1 & 125 & 3.02 & 124 & 65 & 16.41 & 10.89 \\
\hline 1 & 126 & 5.66 & 128 & 65 & 8.75 & 5.50 \\
\hline 1 & 127 & 3.35 & 120 & 70 & 14.79 & 9.69 \\
\hline 1 & 128 & 6.31 & 128.5 & 70 & 7.85 & 4.91 \\
\hline 1 & 129 & 6.09 & 137 & 70 & 8.14 & 5.09 \\
\hline 1 & 130 & 3.71 & 120 & 85 & $13 \cdot 36$ & 8.66 \\
\hline 1 & 131 & 6.58 & 128.5 & 85 & 7.53 & 4.70 \\
\hline 1 & 132 & 5.10 & 137 & 85 & 9.72 & 6.14 \\
\hline 1 & 133 & 6.13 & 120 & 100 & 8.08 & 5.06 \\
\hline 1 & 134 & 3.94 & 128.5 & 100 & 12.58 & 8.11 \\
\hline 1 & 135 & 4.53 & 137 & 100 & 10.94 & 6.97 \\
\hline 1 & 136 & 7.94 & 120 & 105 & 6.24 & 3.86 \\
\hline 1 & 137 & 4.41 & 131.5 & 105 & 11.24 & 7.18 \\
\hline 1 & 138 & 4.11 & 143 & 105 & 12.06 & 7.74 \\
\hline 1 & 139 & 3.74 & 120 & 111 & 13.25 & 8.58 \\
\hline 1 & 140 & 4.09 & 131.5 & 111 & 12.11 & 7.78 \\
\hline 1 & 141 & 1.67 & 143 & 111 & 29.67 & 22.42 \\
\hline 1 & 142 & 4.72 & 120 & 117 & 10.50 & 6.67 \\
\hline 1 & 143 & $\mathrm{~nm}$ & 131.5 & 117 & fracture & \\
\hline 1 & 144 & 3.93 & 143 & 117 & 12.61 & 8.13 \\
\hline 1 & 145 & 10.11 & 160 & 0 & 4.90 & 3.01 \\
\hline 1 & 146 & 10.36 & 168.5 & 0 & 4.78 & 2.94 \\
\hline 1 & 147 & 7.23 & 177 & 0 & 6.85 & 4.26 \\
\hline 1 & 148 & 6.21 & 160 & 17 & 7.98 & 4.99 \\
\hline 1 & 149 & 7.88 & 168.5 & 17 & 6.29 & 3.89 \\
\hline 1 & 150 & 8.12 & 177 & 17 & 6.10 & 3.78 \\
\hline 1 & 151 & 5.09 & 160 & 34 & 9.73 & 6.16 \\
\hline 1 & 152 & 5.64 & 168.5 & 34 & 8.79 & 5.52 \\
\hline 1 & 153 & 5.56 & 177 & 34 & 8.91 & 5.61 \\
\hline 1 & 154 & 4.75 & 160 & 35 & 10.43 & 6.63 \\
\hline 1 & 155 & 3.02 & 174 & 35 & 16.41 & 10.89 \\
\hline 1 & 156 & 3.44 & 188 & 35 & 14.40 & 9.41 \\
\hline 1 & 157 & 5.09 & 160 & 38 & 9.73 & 6.16 \\
\hline 1 & 158 & 4.34 & 174 & 38 & 11.42 & 7.30 \\
\hline 1 & 159 & 4.67 & 188 & 38 & 10.61 & 6.75 \\
\hline 1 & 160 & 5.85 & 160 & 41 & 8.47 & 5.31 \\
\hline 1 & 161 & 2.06 & 174 & 41 & 24.05 & 17.09 \\
\hline 1 & 162 & 4.52 & 188 & 41 & 10.96 & 6.99 \\
\hline 1 & 163 & 5.18 & 160 & 70 & 9.57 & 6.04 \\
\hline 1 & 164 & 4.72 & 164.5 & 70 & 10.50 & 6.67 \\
\hline 1 & 165 & 4.79 & 169 & 70 & 10.34 & 6.57 \\
\hline 1 & 166 & $\mathrm{~nm}$ & 160 & 76 & calcite & nodule \\
\hline 1 & 167 & 5.81 & 164.5 & 76 & 8.53 & 5.35 \\
\hline 1 & 168 & 5.31 & 169 & 76 & 9.33 & 5.89 \\
\hline 1 & 169 & 6.46 & 160 & 82 & 7.67 & 4.79 \\
\hline 1 & 170 & 6.12 & 164.5 & 82 & 8.10 & 5.07 \\
\hline 1 & 171 & 5.66 & 169 & 82 & 8.75 & 5.50 \\
\hline 1 & 172 & 7.57 & 160 & 105 & 6.55 & 4.06 \\
\hline
\end{tabular}




\begin{tabular}{|c|c|c|c|c|c|c|}
\hline 1 & 173 & 4.99 & 180 & 105 & 9.93 & 6.29 \\
\hline 1 & 174 & 4.34 & 200 & 105 & 11.42 & 7.30 \\
\hline 1 & 175 & 4.10 & 160 & 113 & 12.08 & 7.76 \\
\hline 1 & 176 & 2.95 & 180 & 113 & 16.80 & 11.18 \\
\hline 1 & 177 & 4.33 & 200 & 113 & 11.44 & 7.32 \\
\hline 1 & 178 & 3.13 & 160 & 121 & 15.83 & 10.46 \\
\hline 1 & 179 & 2.66 & 180 & 121 & 18.63 & 12.59 \\
\hline 1 & 180 & 3.84 & 200 & 121 & 12.90 & 8.34 \\
\hline 1 & 181 & 9.06 & 20.5 & 0 & 5.47 & 3.37 \\
\hline 1 & 182 & 8.30 & 208 & 0 & 5.97 & 3.69 \\
\hline 1 & 183 & 9.45 & 211 & 0 & 5.24 & 3.23 \\
\hline 1 & 184 & 6.85 & 205 & 15.5 & 7.23 & 4.51 \\
\hline 1 & 185 & 5.74 & 208 & 15.5 & 8.63 & 5.42 \\
\hline 1 & 186 & 6.15 & 211 & 15.5 & 8.06 & 5.04 \\
\hline 1 & 187 & 3.96 & 205 & 31 & 12.51 & 8.06 \\
\hline 1 & 188 & 5.34 & 208 & 31 & 9.28 & 5.85 \\
\hline 1 & 189 & 5.31 & 211 & 31 & 9.33 & 5.89 \\
\hline 1 & 190 & 3.02 & 205 & 35 & 16.41 & 10.89 \\
\hline 1 & 191 & 5.90 & 215 & 35 & 8.40 & 5.27 \\
\hline 1 & 192 & 5.36 & 225 & 35 & 9.24 & 5.83 \\
\hline 1 & 193 & 4.77 & 205 & 49.5 & 10.39 & 6.60 \\
\hline 1 & 194 & 7.17 & 215 & 49.5 & 6.91 & 4.30 \\
\hline 1 & 195 & 6.52 & 225 & 49.5 & 7.60 & 4.74 \\
\hline 1 & 196 & 5.97 & 205 & 64 & 8.30 & 5.20 \\
\hline 1 & 197 & 6.98 & 215 & 64 & 7.10 & 4.42 \\
\hline 1 & 198 & 6.02 & 225 & 64 & 8.23 & 5.16 \\
\hline 1 & 199 & 4.45 & 205 & 70 & 11.13 & 7.11 \\
\hline 1 & 200 & 4.37 & 217 & 70 & 11.34 & 7.25 \\
\hline 1 & 201 & 2.88 & 229 & 70 & 17.20 & 11.49 \\
\hline 1 & 202 & 3.64 & 205 & 86.5 & 13.61 & 8.84 \\
\hline 1 & 203 & 4.77 & 217 & 86.5 & 10.39 & 6.60 \\
\hline 1 & 204 & 6.17 & 229 & 86.5 & 8.03 & 5.03 \\
\hline 1 & 205 & 5.10 & 205 & 103 & 9.72 & 6.14 \\
\hline 1 & 206 & $\mathrm{~nm}$ & 217 & 103 & calcite & nodule \\
\hline 1 & 207 & 4.60 & 229 & 103 & 10.77 & 6.86 \\
\hline 1 & 208 & 4.40 & 205 & 105 & 11.26 & 7.19 \\
\hline 1 & 209 & 5.23 & 208 & 105 & 9.47 & 5.98 \\
\hline 1 & 210 & 5.55 & 211 & 105 & 8.93 & 5.62 \\
\hline 1 & 211 & 5.13 & 205 & 108 & 9.66 & 6.11 \\
\hline 1 & 212 & 5.23 & 208 & 108 & 9.47 & 5.98 \\
\hline 1 & 213 & 5.85 & 211 & 108 & 8.47 & 5.31 \\
\hline 1 & 214 & 4.70 & 205 & 111 & 10.54 & 6.70 \\
\hline 1 & 215 & 4.05 & 208 & 111 & 12.23 & 7.87 \\
\hline 1 & 216 & 3.90 & 211 & 111 & 12.70 & 8.20 \\
\hline
\end{tabular}

